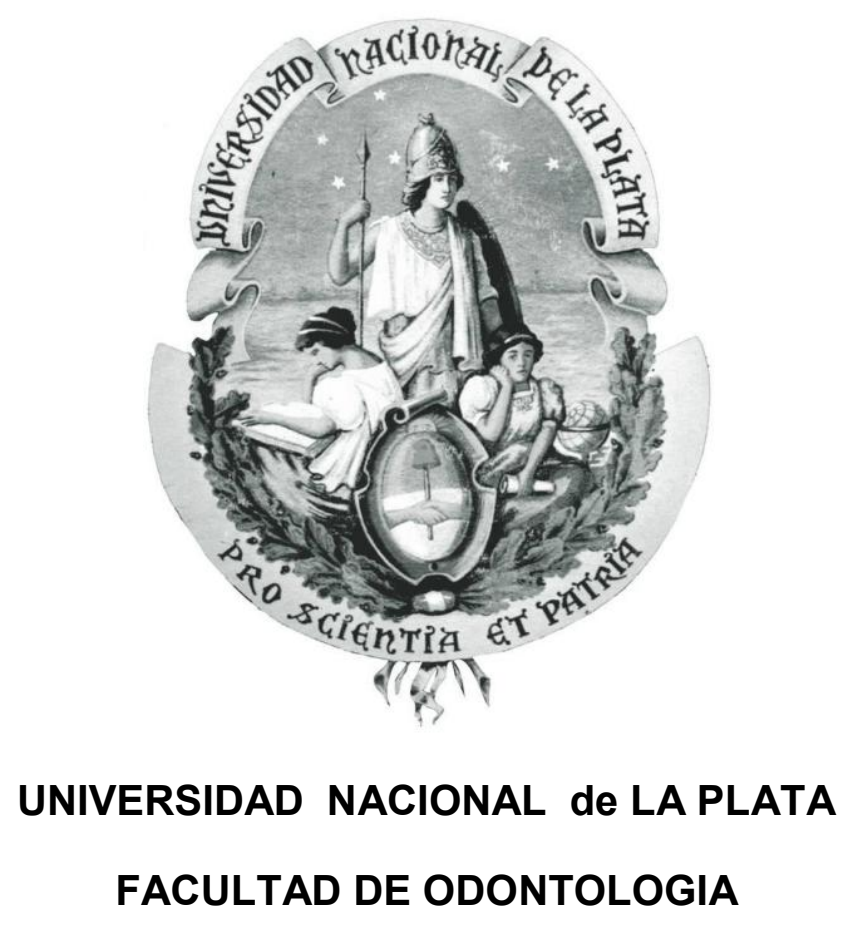

TESIS DE DOCTORADO

\title{
FACTORES QUE INFLUYEN EN LA RETENCIÓN DE LOS PERNOS PREFORMADOS DE RESINA REFORZADOS CON FIBRAS
}

\author{
Od: PABLO FERNANDO BIANCHI \\ Director: Dr. PEDRO SALAZAR \\ Codirector: Dra MONICA FERNANADEZ LORENZO
}


UNIVERSIDAD NACIONAL de LA PLATA

FACULTAD DE ODONTOLOGIA

TESIS DE DOCTORADO

FACTORES QUE INFLUYEN EN LA

RETENCIÓN DE LOS PERNOS

PREFORMADOS DE RESINA REFORZADOS

CON FIBRAS

Od: PABLO FERNANDO BIANCHI

Director: Dr. PEDRO SALAZAR

Codirector: Dra MONICA FERNANADEZ LORENZO

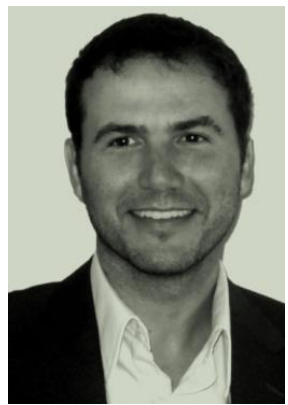

2014 


\section{AGRADECIMIENTOS}

Al Dr. Pedro Salazar, por haber confiado en mí desde el primer momento y por todo su apoyo desde entonces.

A la Dra. Monica Fernandez Lorenzo, por estar siempre disponible y dispuesta a ayudarme. Por ser un ejemplo de esfuerzo, trabajo y dedicación. Muchas gracias.

Al Dr. Alejandro Paz por su ayuda y consejos en la realización de este trabajo.

A la Licenciada en Biología Mariela Theiller por su importante colaboración en los estudios realizados con microscopio electrónico de barrido. 


\section{DEDICATORIA}

A MIS HIJAS MICAELA Y LOURDES 


\section{INDICE GENERAL}

\section{INTRODUCCION}

1.1 El tratamiento endodóntico y sus consecuencias.

1.1.1 Cambios estructurales.

1.1.2 Cambios histo-químicos.

1.1.3 Perdida de la resistencia del diente durante el tratamiento endodóntico.

1.1.4 Perdida de la función mecano-receptora de la pulpa dentaria.

1.1.5 Generación de microfracturas.

1.1.6 Efecto de la presión hidráulica del cemento.

1.2 Historia de los pernos endodónticos.

1.3 Clasificación de los pernos endodónticos.

1.3.1 Pernos muñón pasivo.

1.3.2 Pernos preformados metálicos pasivos.

1.3.3 Pernos preformados cerámicos pasivos.

1.3.4 Pernos preformados de resina reforzados con fibra (PRRF). 
1.4.2 Matriz de los PRRF.

1.4.3 Radiopacidad de los PRRF.

1.4.4 Fibras de refuerzo.

1.4.5 Conducción de luz.

1.4.6 superficie del PRRF.

1.5 Técnica clínica para remodelar el canal radicular a las medidas y formas de los PRRF.

1.8 Colocación del medio cementante en el lecho del PRRF.

1.9.1 Clasificación de los adhesivos.

1.9.2 Generaciones de los adhesivos dentales.

1.9.3 Consideraciones ideales para un adhesivo.

1.10 Cementos utilizados para la fijación de PRRF.

1.10.1 Cementación convencional. 
1.10.1.1 Cemento de ionómero vítreo como medio Cementante.

1.10.2 Cementación adhesiva.

1.10.2.1 Cementos a base de resina.

2. OBJETIVOS.

2.1 Objetivos generales.

2.1.1 Objetivos específicos.

2.2 Hipótesis más relevantes.

3.1 Materiales.

3.2 Métodos.

3.2.1 Evaluación del acondicionamiento de la dentina en el canal radicular para recibir un PRRF.

3.2.1.1 Tratamiento quirúrgico de los conductos radiculares.

3.2.1.2 Remodelación del canal radicular para la cementación del PRRF.

3.2.1.3 Acondicionamiento de la dentina en cada grupo.

3.2.1.4 Corte de las muestras para su observación en

el microscopio electrónico de barrido (MEB). 
3.2.2 Evaluación de los espacios vacios de cemento entre el PRRF y dentina según la técnica clínica de cementación utilizada.

3.2.2.1 Grupos de muestra según la técnica de cementación.

3.2.3 Estudio de la filtración marginal. (Penetración de un colorante).

3.2.4 Interfases PRRF, medio cementante y dentina mediante análisis en MEB.

3.2.5 Formación de tags en la adhesión de PRRF. Análisis mediante MEB.

4.1 Resultados de la evaluación del acondicionamiento de la dentina en el canal radicular para recibir un PRRF.

4.2 Resultados de la evaluación de los espacios vacios de cemento entre PRRF y dentina según la técnica clínica de cementación utilizada.

4.3 Resultados del estudio de la filtración marginal (Penetración de un colorante).

4.4 Análisis de las interfases PRRF, medio cementante y dentina con MEB.

4.5 Evaluación con MEB de la formación de tags utilizando los 
protocolos de los experimentos anteriores para cementar un PRRF.

5. DISCUSION.

6. CONCLUSION.

6.1 Recomendaciones.

7. BIBLIOGRAFIA. 


\section{INTRODUCCION}




\subsection{El tratamiento endodóntico y sus consecuencias.}

La restauración del diente desvitalizado ha representado desde siempre un capitulo controvertido dentro de la odontología restauradora. El empirismo y la tradición clínica dictaron por mucho tiempo las pautas de su tratamiento y los fracasos han sido y son corrientes. Estos fracasos, que corresponden a la práctica odontológica diaria, se hayan documentados en trabajos de seguimientos longitudinales ${ }^{8-96}$.

El perfeccionamiento y masificación de las técnicas endodónticas ha posibilitado que cada vez más piezas regresen a la función masticatoria y pasen a ocupar un lugar entre las restauraciones de media y baja complejidad con demandas funcionales mayores.

El tratamiento endodóntico tiene consecuencias relevantes sobre la pieza dentaria ${ }^{7}$. Se observan cambios estructurales, histo-químicos, pérdida de tejido dentinario, una sensibilidad deprimida y secuelas del tratamiento restaurador.

Se sabe que, en general, cualquier preparación cavitaria destruye el estado pretensado, libera las tensiones y, como consecuencia, las cúspides dentarias se separan produciéndose una real deflexión ${ }^{64}$.

Por otra parte, la apertura del techo de la cámara pulpar provoca la destrucción de la estructura en cúpula, a lo que se le puede agregar la ruptura del anillo circunferencial de apoyo formado por los rebordes marginales. Debe considerarse además que hay una relación directa entre la 
deformación de la estructura dentinaria removida y la deformación que ocurre durante la función.

\subsubsection{Cambios estructurales.}

En cuanto a los cambios estructurales la cavidad de acceso a los conductos disminuye la rigidez de un diente en un $5 \%$, si se realiza una cavidad oclusal el déficit será de un $20 \%$ más, llegando al $63 \%$ si se agrega el tallado de los rebordes marginales ${ }^{103}$. También se debe contemplar el efecto del factor profundidad. Se ha reportado que duplicando la profundidad de una cavidad, la deflexión se incrementa, en una proporción semejante a la profundidad cavitaria por ocho. Así por ejemplo, un diente posterior endodónticamente tratado tiene una profundidad cavitaria tres o cuatro veces mayor que uno vital, por lo que, frente a una misma carga será muy superior la deflexión ${ }^{58-60}$.

Es necesario considerar también que los desgastes de ensanchamiento producidos como consecuencia del tratamiento endodóntico van a conducir a una disminución de la resistencia. Por ese motivo los tallados para los pernos deberán tener muy en cuenta la morfología y volumen radicular, manteniéndose en el tercio medio y evitando provocar socavados o debilitamiento y riesgos de perforaciones.

\subsubsection{Cambios histo - químicos.}

Debe analizarse asimismo la combinación de los factores histoquímicos que producen una dentina más frágil que la vital. Estos cambios aumentan a lo largo del tiempo en el que el diente endodonciado permanece en boca. 
En 1972 Helfer y colaboradores demostraron que el diente con endodoncia posee un porcentaje de agua un $9 \%$ menor que una pieza vital. El agua no se recupera una vez perdida, ni siquiera en una atmosfera saturada de humedad ${ }^{55}$. Esta disminución, junto con la variación de la disposición de las fibras de colágeno $^{105}$, serian responsables de un debilitamiento de un $14 \%$ más pronunciado en el maxilar inferior y llegando a un máximo en los incisivos.

Es necesario considerar también que la edad de los dientes afecta la elasticidad de los mismos ya que, a medida que envejecen, más dentina peritubular se deposita dentro del túbulo, quitando espacio a la materia orgánica y a los fluidos tisulares quienes son los que le dan la flexibilidad a los tejidos vivos.

\subsubsection{Perdida de la resistencia del diente durante el tratamiento endodóntico.}

Estudios múltiples han demostrado que la causa principal de la pérdida de resistencia del órgano dentario es la pérdida del tejido que puede sufrir el diente sea por caries, fracturas, abrasiones, tanto de la corona como de la raíz, junto con tallados indiscriminados de tejido remanente sano y útil $^{69}$. Se ha reportado que las menores concentraciones de esfuerzos fueron evidentes cuando se deja dentina residual a nivel del hombro ${ }^{56}$. Por esos motivos es aconsejable que se extremen los esfuerzos para conservar la máxima estructura coronaria que sea posible ya que una excesiva remoción de estructura incrementa la pérdida de fortaleza y resistencia a la fractura del diente ${ }^{79}$ 
Hace varias décadas que se ha postulado que, para obtener buenos resultados es, crítica la existencia de resina residual coronal al hombro ${ }^{117}$. Por otra parte Milot y Stein ${ }^{85}$ concluyeron que si la mayor parte de la estructura dentaria se mantiene, el perno tiene poco efecto en la resistencia. En concordancia Sorensen y Martinoff $^{118}$ afirmaron que lograr que permanezca la máxima estructura dentaria luego de la terapia endodóntica y la preparación para el perno es fundamental para el éxito del tratamiento endodóntico y restaurador.

\subsubsection{Perdida de la función mecano-receptora de la pulpa dentaria.}

Loweistein et. al. ${ }^{70}$ analizaron las diferencias entre la sensibilidad a las presiones de dientes vitales y no vitales durante el proceso masticatorio y notaron marcadas diferencias. Debe considerarse que las piezas dentarias y los tejidos periodontales son sometidos a cargas de distintas magnitudes. Las presiones que sufren las membranas periodontales son controladas por mecano-receptores que, en forma refleja, controlan la actividad muscular, constituyendo un mecanismo protector. Sin embargo, estos autores demostraron que, frente a cargas mínimas, el umbral de los dientes no vitales resulta ser un $57 \%$ mayor que el de los vitales, este hallazgo le permitió relacionar a la pulpa con la sensibilidad a la presión.

Esta presunta función mecano-receptora de la pulpa dentaria también fue encontrada en una experiencia in vivo, en la que dientes vitales y no vitales vecinos o contra laterales fueron sometidos a fuerzas de palancas y los no vitales revelaron umbrales al dolor dos veces mayores que los vitales. 
Debe tenerse en cuenta que estos resultados fueron obtenidos previa anestesia de ambos grupos de dientes. Los autores concluyeron que algún tipo de mecano-receptor estaría presente en la pulpa vital. Para los dientes con soporte óseo óptimo, estos mecano-receptores son eficientes frente a estímulos menores comparados con aquéllos que hacen entrar en acción a los receptores periodontales de los dientes no vitales ${ }^{101}$. Podría sugerirse entonces que existiría a nivel pulpar un mecanismo protector frente a las fuerzas oclusales, de un umbral más bajo que el periodontal que, al ser extirpado junto con la pulpa, dejaría al diente con menor capacidad de reacción para activar su mecanismo de defensa.

Cabe destacar que la dentina tiene una naturaleza y una función hidrodinámica. Presenta entre 19000 y 45000 túbulos por mm² llenos de líquido, encerrados por capas de esmalte o cemento bastante impermeables, que transfieren hidráulicamente las cargas masticatorias ${ }^{102}$. Puede pensarse que las diferencias de elasticidad entre esa fase liquida y la calcificada activarían esos receptores, como respuesta, por ejemplo a la flexión de la raíz ${ }^{101}$

El diente despulpado responde a cargas dos veces mayores que el vital, lo que habla de una distorsión de su mecanismo propioceptor que lo deja en inferioridad de condiciones frente a las cargas derivadas de la función y para-función. 


\subsubsection{Generación de microfracturas.}

Entre otras secuelas es importante mencionar que se pueden formar microfracturas como consecuencia de los procedimientos restauradores. Estas microfracturas también pueden ser factores que inicien el proceso de corrosión de metales no nobles ${ }^{30-43}$.

Otra secuela se puede producir durante la obturación, es debida a la acción de cuña por condensación lateral, causante de la mayoría de fracturas verticales ${ }^{84}$

Por otra parte, durante la colocación de los pernos, la deformación de la raíz es mayor que durante la condensación lateral y podría iniciarse una fractura en el futuro ${ }^{97}$. Debe notarse que, en la preparación del conducto, el exceso de presión o de diámetro de los instrumentos utilizados para el tallado del canal puede inducir la formación de fracturas ${ }^{22}$, así como también la utilización de pernos activos o autorroscantes y el torque ejercido sobre esos elementos ${ }^{66}$.

Es importante mencionar que al utilizar instrumental rotatorio durante la desobturación y preparación del perno se puede generar un aumento de

la temperatura. Se ha reportado que a los $6 \mathrm{~mm}$ del ápice se genera un aumento de temperatura de $31^{\circ} \mathrm{C}$ y se sabe que el daño en los tejidos periodontales surge a partir de una elevación de $10^{\circ} \mathrm{C}$. Por este motivo Eriksson y Sundstrom ${ }^{30}$ han recomendado realizar el fresado a baja velocidad y con intermitencia, dada la imposibilidad de irrigar el interior del canal. También sugirieron que este recalentamiento podría traducirse en una mayor incidencia de microfracturas. 


\subsubsection{Efecto de la presión hidráulica del cemento.}

La presión hidráulica del cemento es la ejercida contra las paredes dentinarias del canal en el momento del cementado ${ }^{6}$. Esta presión aumenta cuando se llena el canal con la ayuda de un léntulo ${ }^{53}$, siendo especialmente intenso en paredes paralelas. En la actualidad muchos pernos preformados traen en su superficie canales que disipan esta presión. También se puede aliviar la presión cuidando la forma de introducir el perno en el canal.

Si la fractura de un diente aislado representa un problema, este adquiere mayor dramatismo cuando integra una estructura compleja. Una fractura de la raíz lleva por lo general a un pronóstico desfavorable indicando su extracción. En muchos casos dicha fractura se diagnostica tardíamente lo que conlleva una importante pérdida ósea, inflamación y supuración de los tejidos gingivales próximos. Esto se acompaña frecuentemente con sintomatología o desprendimiento de la prótesis.

\subsection{Historia de los pernos endodónticos.}

Desde hace mucho tiempo, los clínicos que desean mejorar la rehabilitación de los dientes tratados endodónticamente enfrentan el desafío de crear restauraciones seguras con pronóstico previsible y confiable.

En 1724 Pierre Fauchard ${ }^{32}$ describía los pasos para construir coronas a perno de oro o plata, estriados. Para logar mayor retención eran introducidos calientes en la cavidad realizada en la raíz para llegar a fundir el medio cementante. Black en el siglo XIX llenaba el canal radicular de oro 
cohesivo, colocando luego un tornillo. Esto demuestra que, ya en sus orígenes, el perno era un elemento de fijación o retención.

En los últimos tiempos, el interés en los pernos ha venido creciendo, viéndose reflejado en la gran cantidad de trabajos de investigación, impulsados en muchos casos por la diversidad de pernos preformados que aparecieron en el mercado odontológico.

La rehabilitación de las piezas endodonciadas se clasifican en dos grupos, un primer grupo de restauraciones indirectas, cuando se utilizan pernos-muñón colados metálicos o de cerámica, que se realizan en laboratorios de prótesis dentales, que luego son cementados. Un segundo grupo está constituido por restauraciones directas donde se utilizan materiales de restauración como la amalgama, ionómeros vítreos de restauración o resinas que pueden ser soportadas o no por pernos preformados cementados en el conducto dental previamente preparado.

En base a la modalidad de rehabilitación Dallari propuso la siguiente clasificación ${ }^{21}$ :

1-pernos metálicos con retención activa

2-pernos metálicos con retención pasiva

3-pernos no metálicos pasivos

El grupo (1) se conforma por todos los pernos metálicos colados que generan una fricción sobre las paredes del conducto a lo que se les agrega 
un medio cementante como los oxifosfatos. Incluye a todos los sistemas de pernos preformados que generan fricción o presentan en su superficie espiras que cortan la dentina, generando una intima relación que, en la mayoría de los casos, provoca microfisuras tal como lo muestra la microscopia electrónica de barrido (MEB) de la Fig. 1.

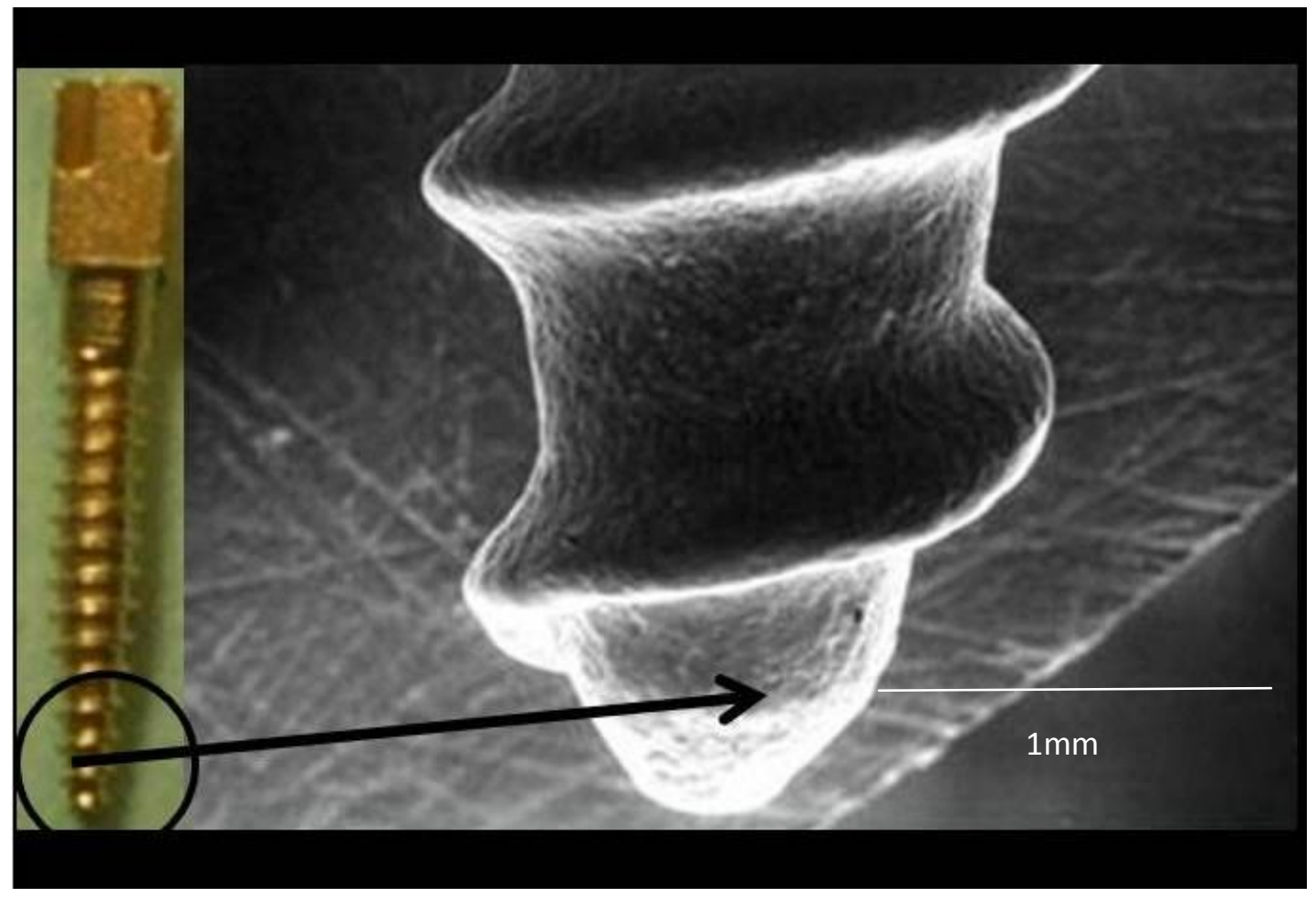

Fig.1 La fotografía muestra Perno Dentatus ${ }^{\mathrm{MR}}$ tipo tornillo cuyas espiras friccionan la dentina y generan una retención activa (izquierda). En la MEB se aprecia el filo de la rosca generadora de la retención activa.

Entre los pernos con retención pasiva grupo (2), encontramos los pernos preformados (Fig.2) y los pernos colados colocados en el canal radicular sin que originen fricción y cementados con técnicas adhesivas. 


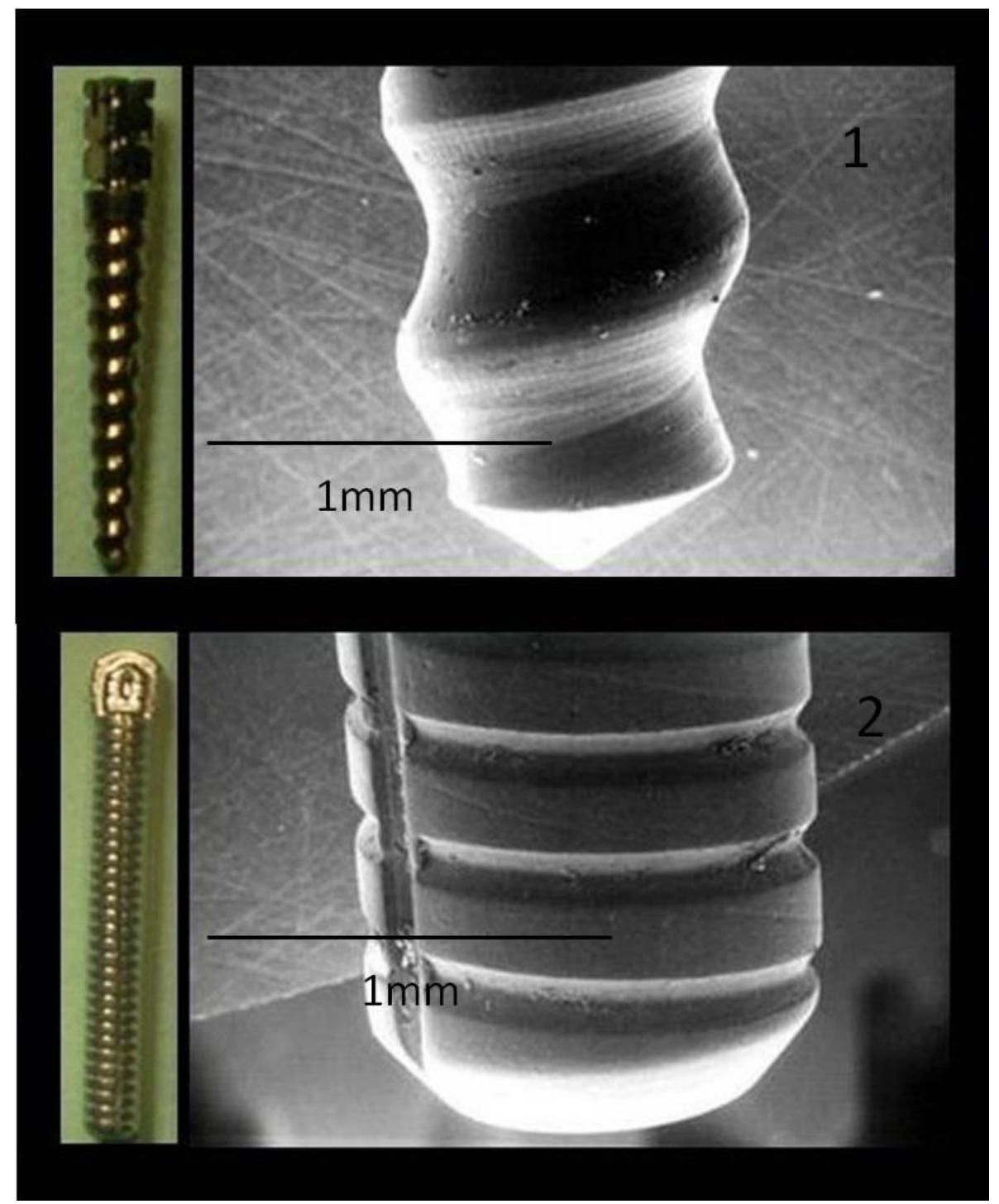

Fig.2 Microfotografía 1 perno preformado Unimetric ${ }^{\mathrm{MR}}$, denominado Cerrado, presenta ondulaciones en su superficie que se comportan pasivamente, constituyendo una traba micromecánica. Microfotografía 2 perno $\operatorname{Parapos}^{\mathrm{MR}}$, presenta gran cantidad de espiras inactivas muy juntas y se puede observar con un canal de escape longitudinal para disipar la presión hidráulica del medio cementante.

En la Fig. 3 se observan los parámetros a tener en cuenta en el caso de un perno metálico colado activo según lo indicado por shillingburrg y 
$\operatorname{kessler}^{115}$.La longitud del perno debe ser 2/3 de la longitud del conducto, dejando $3 \mathrm{~mm}$ de sellado apical.

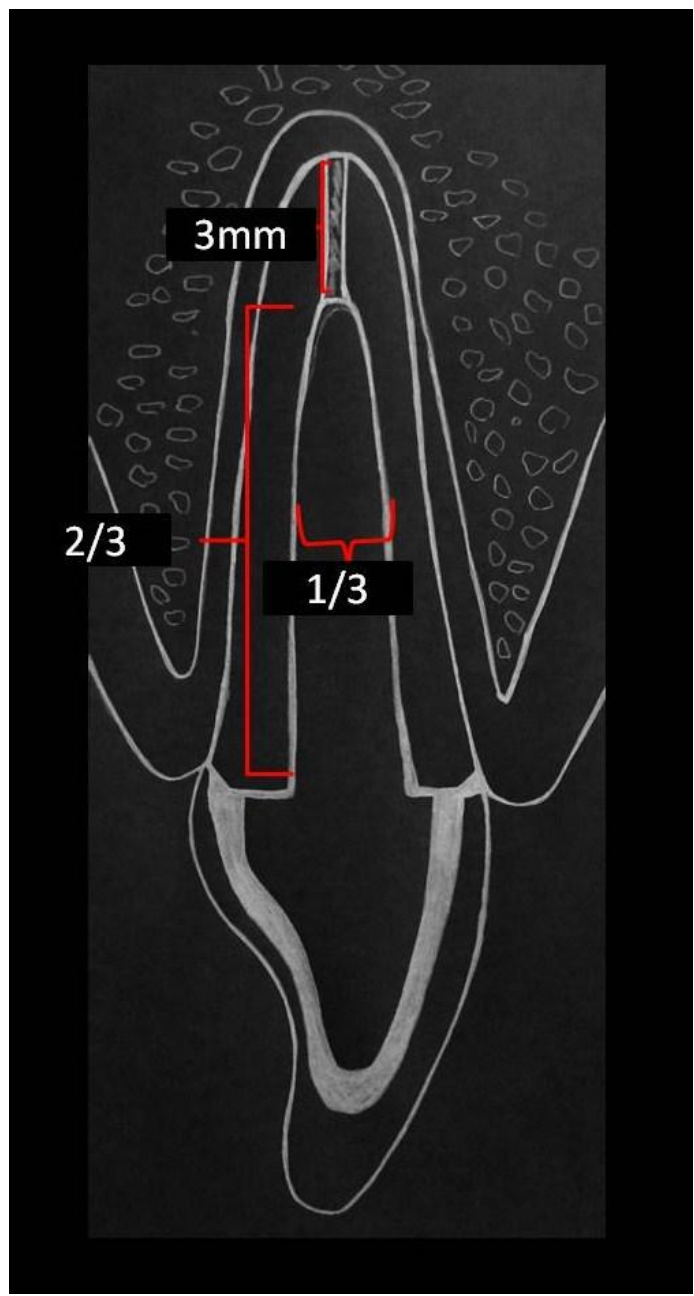

Fig.3 La Figura muestra los parámetros de un perno metálico colado activo según Shillingburg y kessler ${ }^{29}$. La longitud del perno debe ser $2 / 3$ de la longitud del conducto dejando $3 \mathrm{~mm}$ de sellado apical como mínimo.

En la Fig.4 se muestra la acción del perno activo sobre las paredes el origen de una fractura longitudinal que lleva a la extracción de la pieza dentaria, acompañada en la mayoría de los casos de pérdida de tejido óseo, inflamación y dolor. 


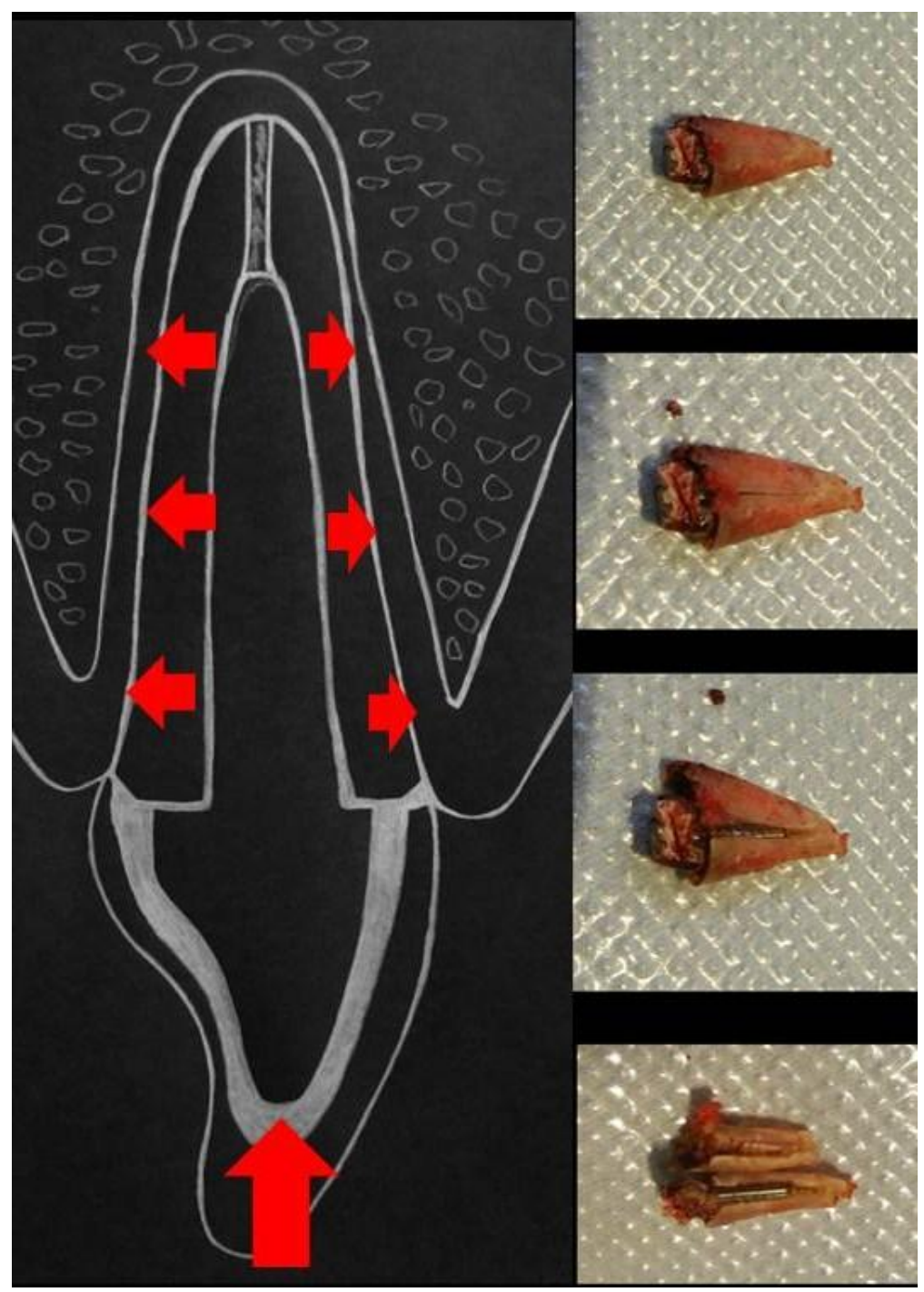

Fig.4 llustración de la acción del perno sobre las paredes coronarias. El efecto cuña provoca una fisura que desemboca en fractura.

El grupo (3) reúne a todos los sistemas de pernos intraconducto no metálicos como los cerámicos y los pernos de resina reforzados con fibra (PRRF), tal como el mostrado en la Fig.5. 


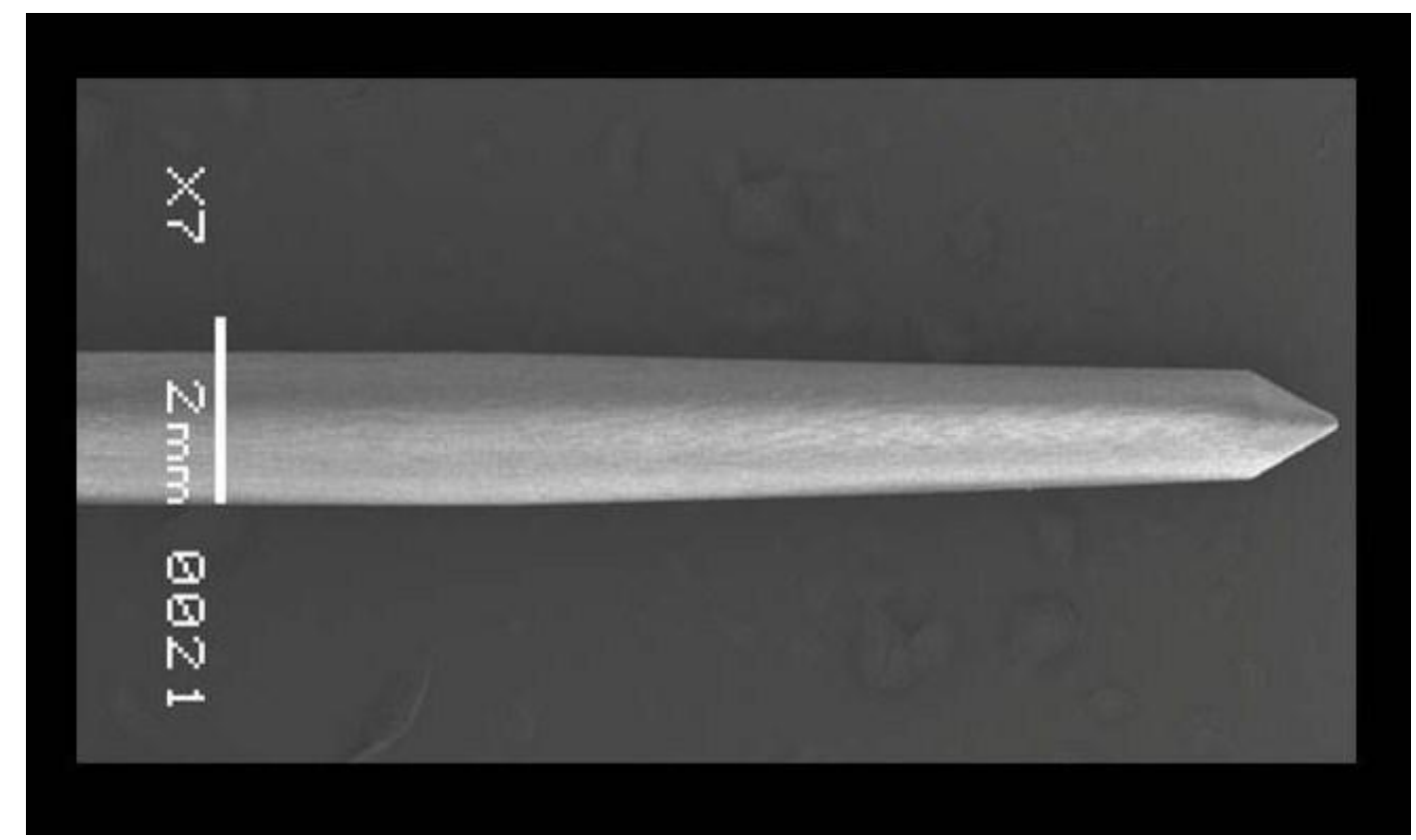

Fig.5 La microfotografía muestra un perno de resina reforzado con fibras x7 (MEB)

\subsection{Clasificación de los pernos endodónticos.}

Los conocimientos que hoy se tienen sobre materiales y los estudios clínicos longitudinales llevan a pensar que los pernos colados y preformados con retención activa pueden considerarse obsoletos.

Una clasificación que parte de la anterior pero que está enriquecida por los diferentes métodos de cementado pasivo es la que divide a los pernos en pernos muñón cementados pasivamente y pernos preformados cementados pasivamente asociados a la reconstrucción de la parte coronaria.

\subsubsection{Pernos muñón pasivo.}

Shilimburg y Kessler $^{115}$ describieron las características del perno muñón clásico: el perno debería tener $2 / 3$ de la longitud radicular y $1 / 3$ de su 
diámetro, quedando a $4 \mathrm{~mm}$ del ápice. Asimismo debe tener una retención a fricción contra las paredes del conducto apoyándose en una superficie coronaria plana. Sin embargo, en la práctica clínica los fracasos por fractura son frecuentes. Con el fin de reducir estos fracasos, Sorensen y Martinof ${ }^{119}$ proponen utilizar el efecto férula para evitar el efecto cuña, sugiriendo que se deje tejido coronal remanente para que las cargas se distribuyan más uniformemente a lo largo de la superficie radicular. (Fig. 6)

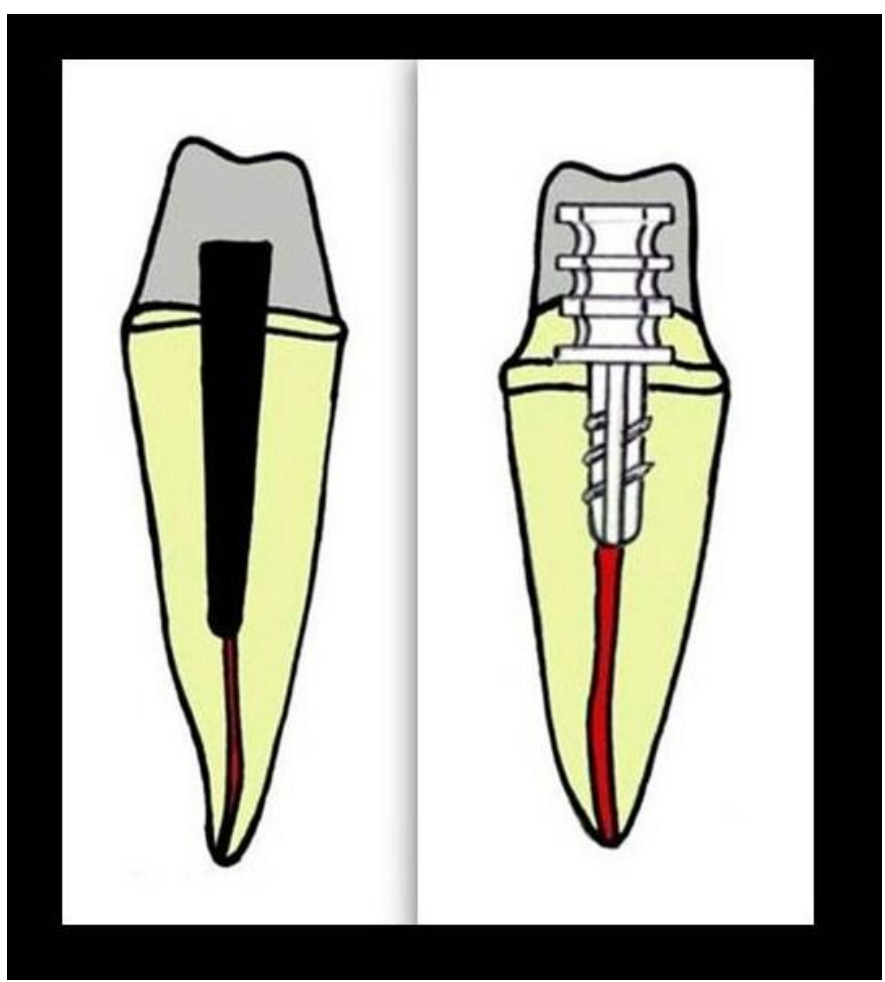

Fig.6 La figura muestra la comparación de dos reconstrucciones: en el lado izquierdo no presenta remanente de tejido coronario. La figura del lado derecho si lo presenta y es allí donde se produce el efecto férula que distribuye mejor las cargas.

Debe tenerse en cuenta que el papel del perno, cualquiera sea el material que lo compone, es permitir la reconstrucción del muñón, sin pretender reforzar la estructura radicular ${ }^{20}$. Las investigaciones en el campo de la adhesión dentinaria, iniciadas por $\mathrm{Mc} \mathrm{Comb}^{80}$ y continuadas por 
Nacabayashi ${ }^{90}$, han propuesto la utilización de la dentina endodónciada acondicionada para recibir cementos adhesivos. Los estudios de Natanson ${ }^{92}$ - 93 sobre el cementado pasivo sugieren la utilización de EDTA e hipoclorito sódico y la utilización de pernos colados o prefabricados. Este método permite la presencia de un diafragma elástico entre el perno y la dentina, representado por el cemento, que permite una retención de acción pasiva.

Gracias a los sistemas adhesivos los pernos muñón se han hecho menos invasivos que en las técnicas clásicas, de hecho la longitud se puede reducir a la corona clínica que se debe rehabilitar y su diámetro al de la instrumentación endodóntica.

\subsubsection{Pernos preformados metálicos pasivos.}

El mismo principio de pasividad se ha extendido a los PPF que consiguieron una amplia difusión por ser económicos y acelerar los procedimientos clínicos, pues evitan la participación de los laboratorios protéticos.

Los PPF metálicos son realizados con diferentes aleaciones metálicas entre ellas pueden mencionarse latón, acero, aleaciones de oro y titanio. Se los clasifica según su superficie en lisos o con espiras retentivas para el cemento. Sin embargo, estos pernos no tendrán un contacto íntimo con la dentina radicular. (Fig.7) 


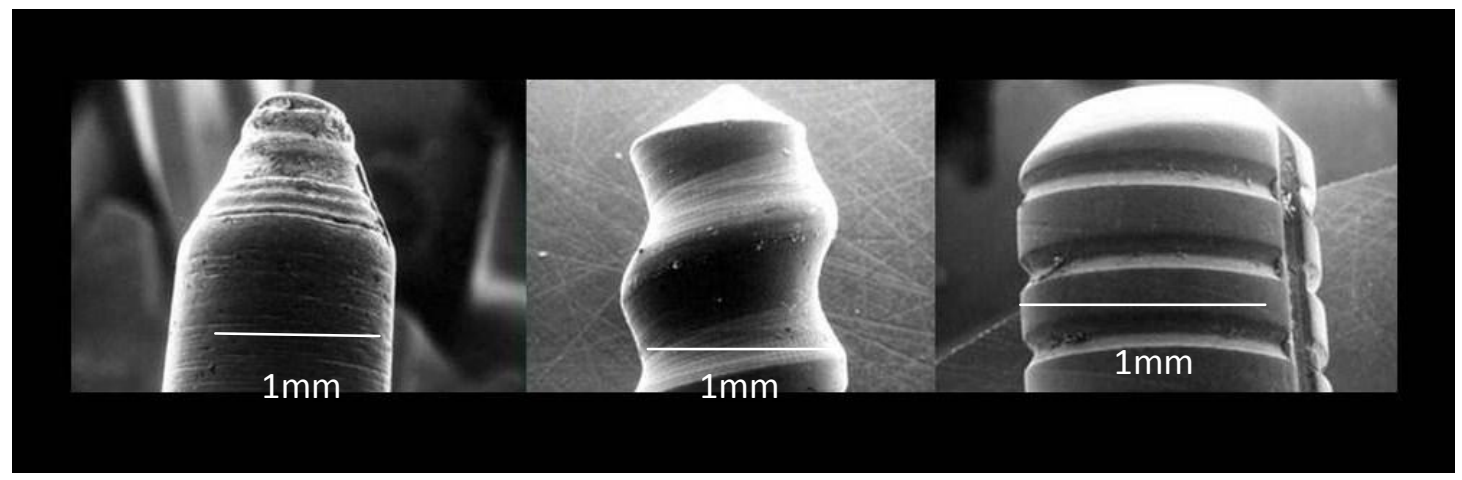

Fig.7 Microfotografía MEB que muestra diferentes PPF. La Figura de la izquierda muestra la superficie de un PPF liso, al centro y a la derecha PPF con espiras.

Otra forma de clasificar los pernos preformados metálicos es por la forma geométrica de su superficie y por tener o no cabeza retentiva para ayudar mecánicamente a la retención del mațerial restaurador que conforma el muñón tal como lo muestra la Fig.8.

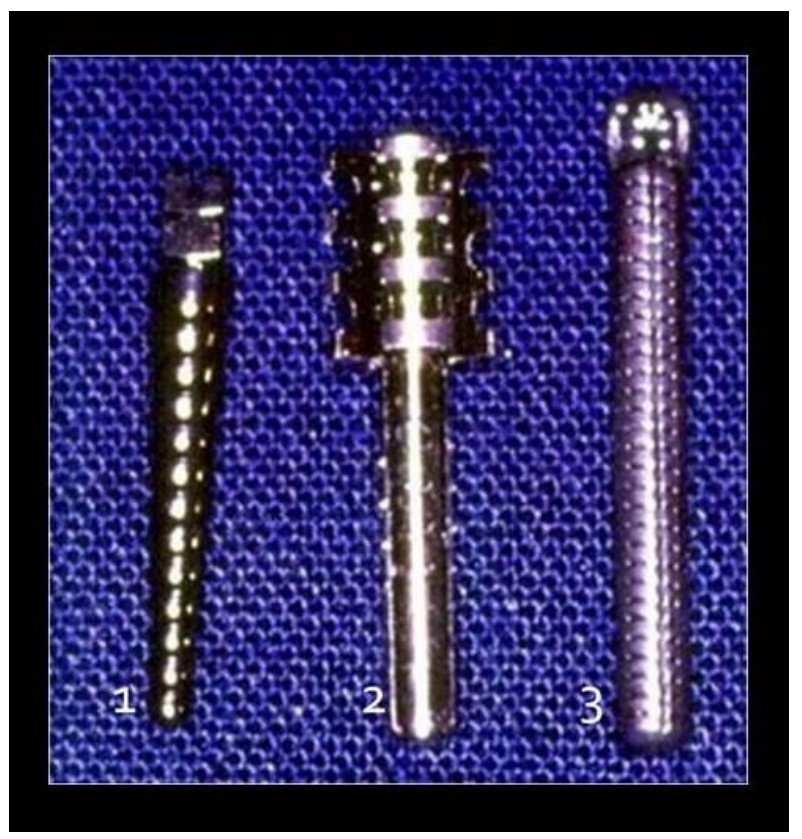

Fig.8 La fotografía muestra distintos tipos de PPF: 1 cónico sin cabeza retentiva. 2 cilíndrico con cabeza retentiva. 3 cilíndrico sin cabeza retentiva. 
Sin embargo, problemas debidos a la corrosión de los metales ${ }^{104}-133$, bimetalismo y alergia a algunos de los componentes de las aleaciones ${ }^{61}$ además de las alteraciones de color en las restauraciones llevaron a tratar de eliminar los metales en la rehabilitación del diente endodonciado.

\subsubsection{Pernos preformados cerámicos pasivos.}

Estos pernos al aparecer en el mercado odontológico gozaron de una buena difusión por sus cualidades estéticas y su biocompatibilidad ${ }^{89-137-130}$.

En este grupo se encuentran los de bióxido de circonio, que permiten eliminar el problema estético y biológico pero no resuelven los problemas estructurales. Por el contrario, su rigidez crea una concentración de tensión elevada y no uniforme que se descarga sobre la raíz ${ }^{25}$. Estos pernos, incluso silinizados, presentan una baja adhesión a la dentina radicular ${ }^{24}$.

\subsubsection{Pernos preformados de resina reforzados con fibra (PRRF).}

Los PRRF propusieron un nuevo concepto restaurador ya que los diferentes elementos utilizados en la restauración, perno, cemento, material restaurador y dentina forman un complejo estructural y homogéneo y pueden absorber las cargas funcionales igual que un diente integro ${ }^{27}$. (Fig. 9) 


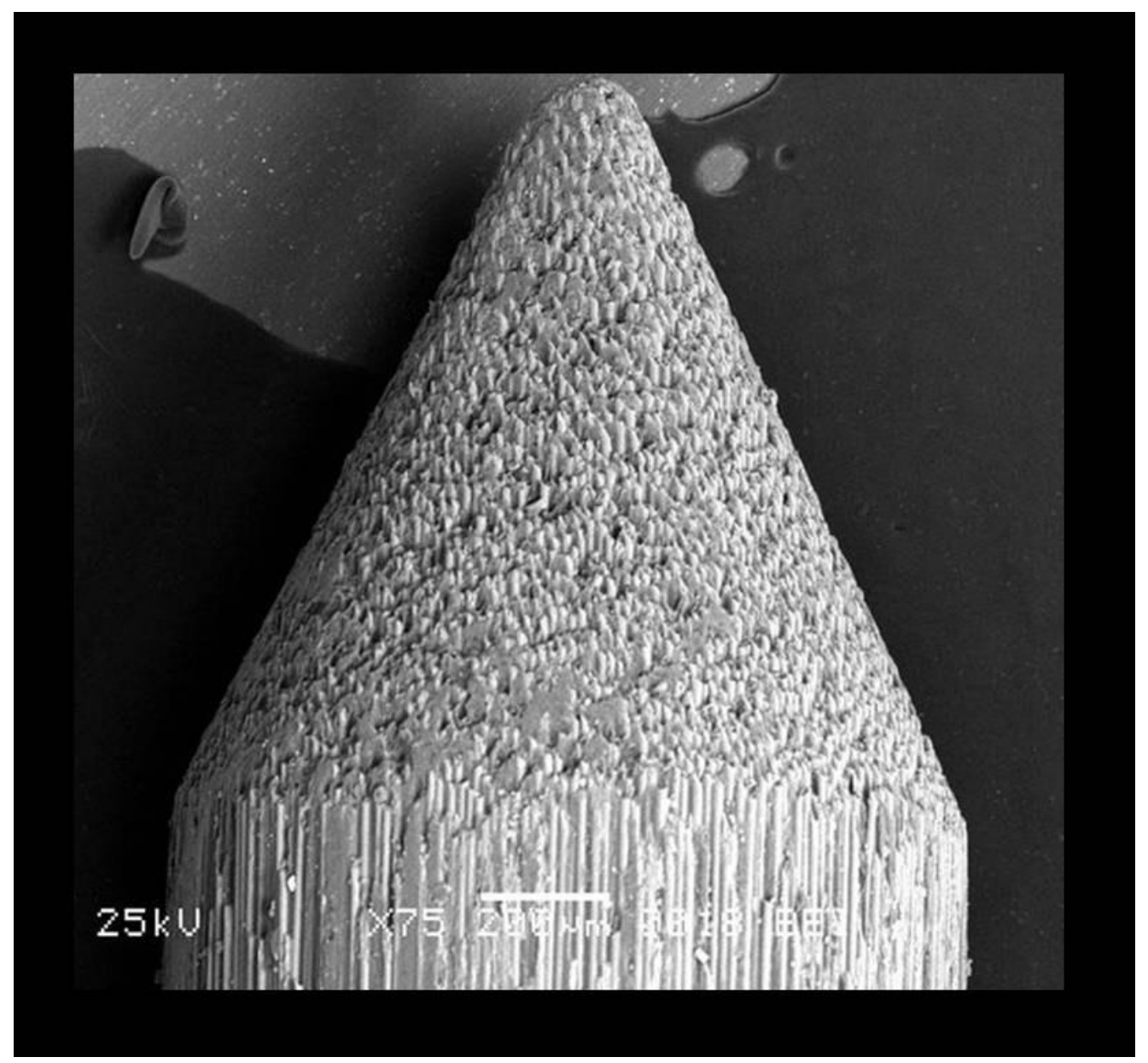

Fig. 9 Microfotografía (MEB) que muestra un PRRF en su parte apical.

Es importante destacar que las ventajas de estos pernos son la ausencia de fracturas y el bajo número de fracasos. Los fracasos reportados se han dado únicamente en dientes con escaso tejido coronal residual, altamente comprometidos ${ }^{40}$.

Las fotografías de la Fig.10 muestran que, si no hay tejido coronal residual, tratar de conformar un muñón en estas circunstancias lleva a un fracaso en la rehabilitación. 


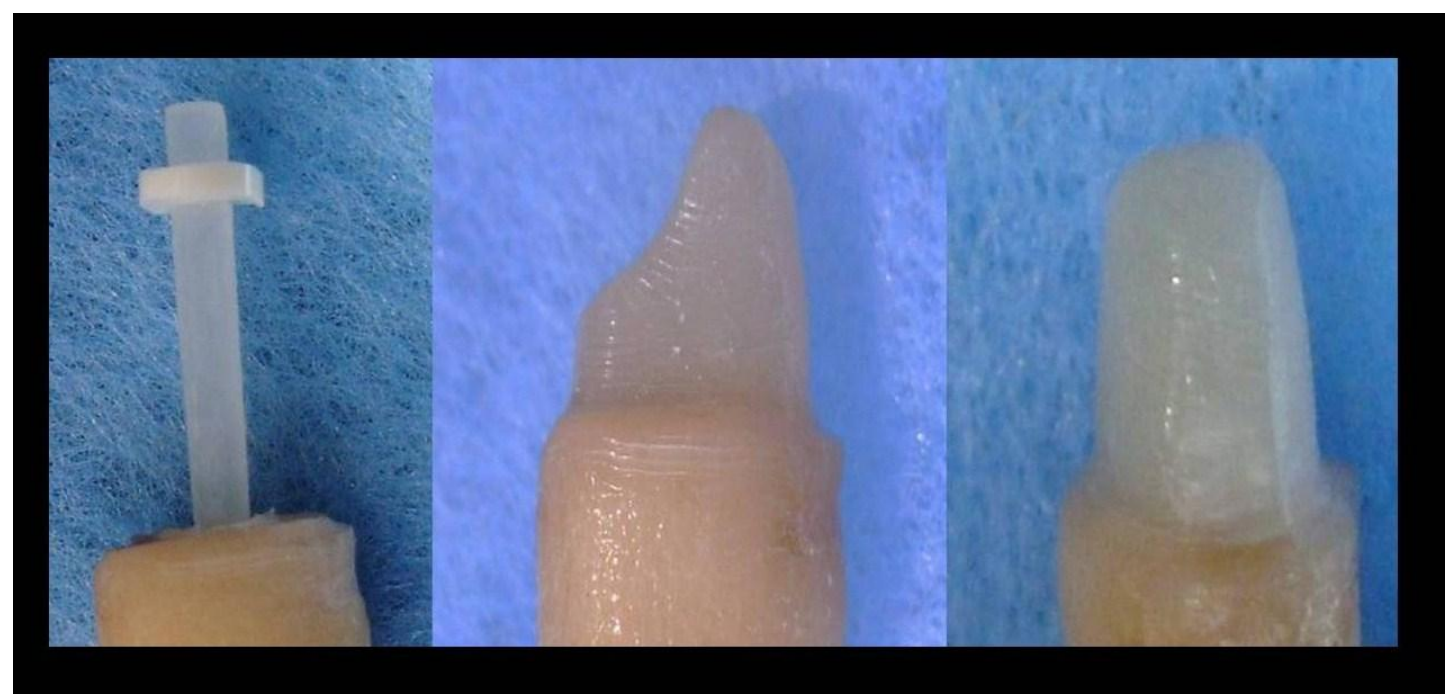

Fig.10 La imagen de la izquierda muestra un diente sin remanente coronario con un PRRF cementado. La imagen del centro y derecha la reconstrucción del muñón con resina.

Por ese motivo una de sus principales indicaciones para su utilización es la necesidad de contar con tejido residual coronal sano para generar el efecto férula ya descripto. En la Fig. 11 muestra que un adecuado tejido coronal residual permite que se produzca el efecto férula antes mencionado.

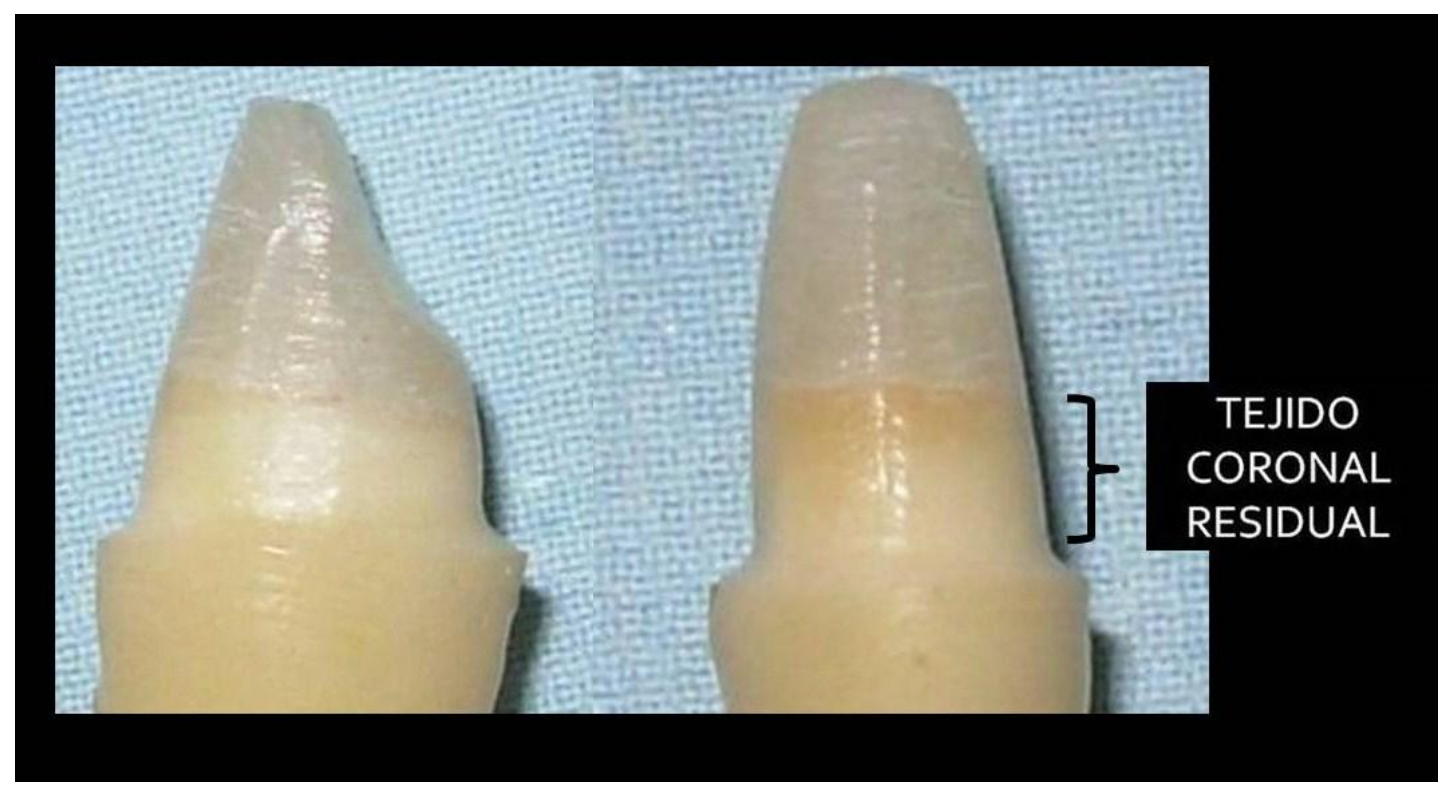

Fig.11 La fotografía muestra el adecuado tejido residual que formara parte del muñón. 
Por lo antes expuesto, es posible considerar a los PRRF como un refuerzo para la estructura del diente endodonciado y preferibles a los pernos colados.

\subsection{Desarrollo de los PRRF.}

En el año 1983 Lovell propone por primera vez la utilización de fibras de carbono sumergidas en una matriz de naturaleza orgánica para desarrollar pernos. Sin embargo el desarrollo más importante de los pernos se debe principalmente a Duret ${ }^{25}$ que introdujo en 1988 los pernos de resina reforzados con carbono y una técnica innovadora que cambiaría la rehabilitación del diente con tratamiento endodóntico.

El modulo de elasticidad del PRRF, si bien puede variar en relación a cómo recibe una carga, es a lo largo de su eje de 90GPa, mientras que para una incidencia de $30^{\circ}$ con el eje longitudinal de las fibras es aproximadamente unos $34 \mathrm{GPa}$ y cuando las cargas son perpendiculares a las fibras, es de $8 \mathrm{Gpa}$. Estas situaciones de carga en estos pernos se asemejan a fuerzas funcionales y parafuncionales y presentan valores similares a las de un diente integro ${ }^{26}$.

Los primeros pernos reforzados con fibra de carbono de color oscuro tenían una forma cilíndrica de doble sección y se los denominaba como unidad protésica.

Con el objeto de mejorar la calidad del cementado, reduciendo los poros por englobamiento de aire durante el proceso, aparecen pernos con 
estrías laterales paralelas al eje longitudinal del perno. Luego se desarrollaron y salieron al mercado pernos con morfología denominada endodóncica con una conicidad fija de 0,02 y diámetros de acuerdo a las normas ISO para poder tener semejanza con los instrumentos endodónticos y con los conductos preparados.

Una modificación que aparece posteriormente es en lo estético: se cubre a la matriz de carbono con fibras blancas de cuarzo. Posteriormente, aparecieron los pernos blancos constituidos en su totalidad por fibras de cuarzo o de vidrio y luego los pernos translucidos, que permiten una modificación en la utilización de cementos, como es el caso de los de curado dual $^{47}$. Sin embargo, hoy se sabe que no pueden utilizarse cementos de fotopolimerización en estos casos ya que no se puede garantizar un endurecimiento correcto y una polimerización completa ${ }^{1}$.

\subsubsection{Macroestructura y microestructura de los PRRF.}

Tal como se describió previamente los PRRF se forman a partir de una matriz de resina que puede contener diferentes tipos de fibras de refuerzo. Las características de su microestructura dependen del diámetro de las fibras, su densidad, de la unión fibra matriz y de la extensión de la superficie externa.

Estos parámetros se pueden evaluar en forma cualitativa y cuantitativa con la utilización del MEB, (Fig.12 y 13). 


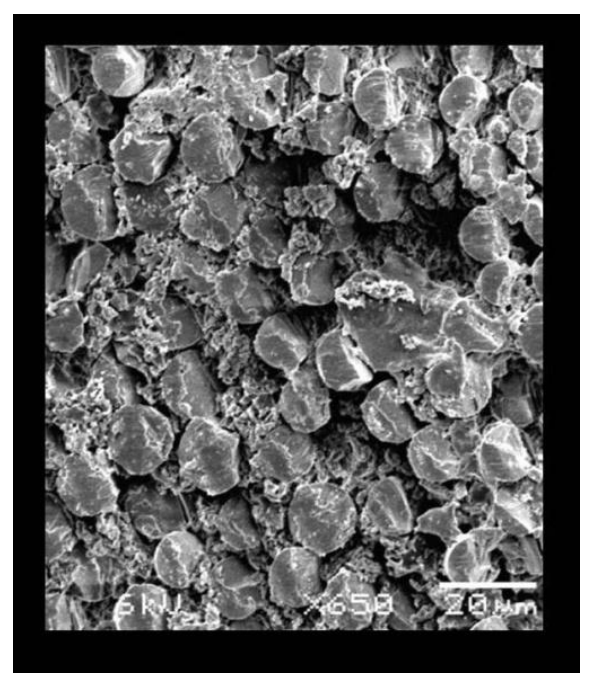

Fig.12 Microfotografía donde se pueden observan, en un corte transversal de un PRRF, la cantidad de fibras y la calidad de su unión con la matriz.

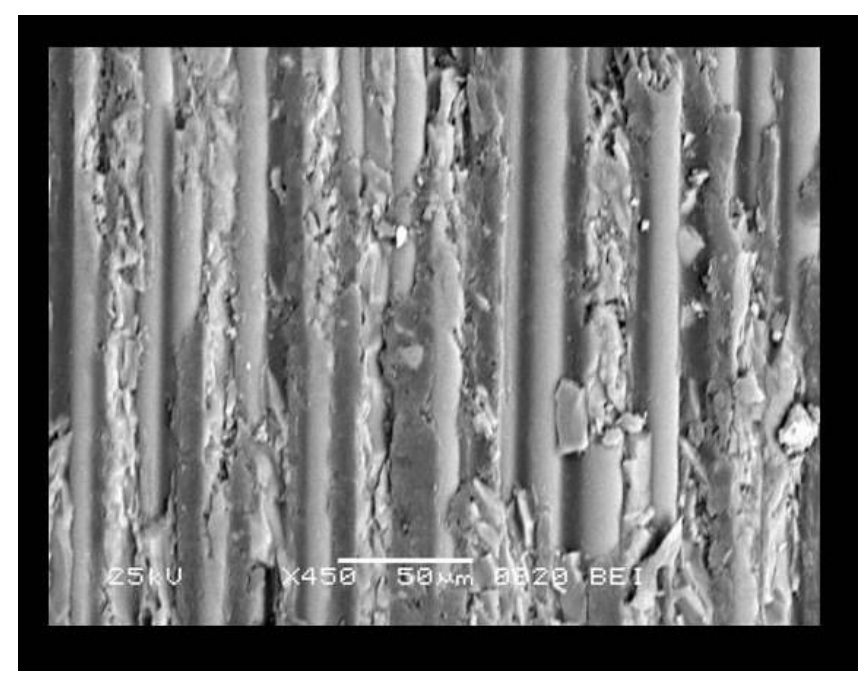

Fig. 13 Microfotografía que muestra una vista longitudinal de un PRRF con la matriz de resina entre las fibras de vidrio.

Se los puede fabricar utilizando moldes preformados en los cuales las fibras son pretensionadas y la matriz se inyecta a presión para que la resina ocupe un lugar entre las fibras. Otro método que genera pernos de menor calidad es el de sumergir las fibras en una matriz de resina ${ }^{16}$. 


\subsubsection{Matriz de los PRRF.}

La matriz de resina engloba las fibras y en sus principios constituía aproximadamente el $36 \%$ del peso de la estructura. En la actualidad varía de acuerdo a la marca comercial. Está compuesta por resina epoxi o sus derivados y en algunos casos adicionalmente pueden contener radiopacadores.

La resina epoxi se une mediante radicales libres comunes a la resina BIS-GMA, componente que predomina en todos los cementos adhesivos. Los pernos con mayores imperfecciones en su matriz son más débiles y menos resistentes a la tensión de las cargas. (Fig.14)

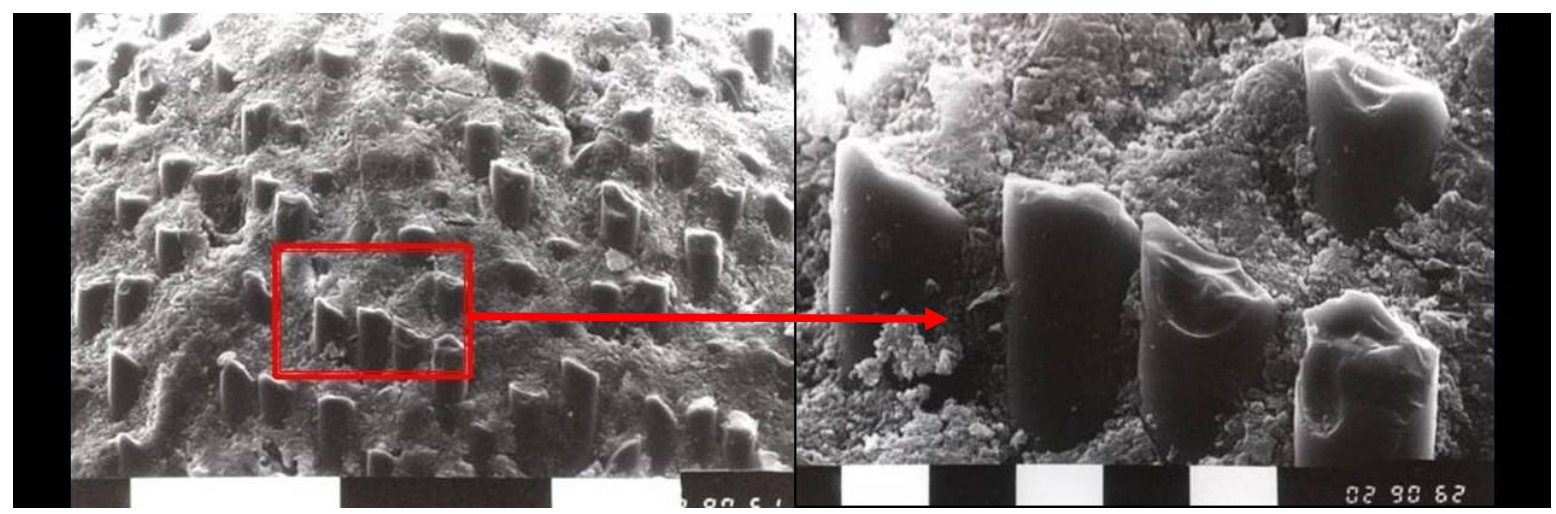

Fig.14 A la izquierda microfotografía de la matriz del perno englobando las fibras de refuerzo y el detalle a su derecha

\subsubsection{Radiopacidad de los PRRF.}

Desde el punto de vista clínico y legal la radiopacidad de los pernos es importante, para cumplir con estas exigencias se han introducidos pernos translúcidos radiopacos. Sin embargo no debe olvidarse que los aditivos radiopacos podrían influir en la resistencia a la flexión del perno ${ }^{77}$. Si la radiopacidad del PRRF es elevada se puede diferenciar claramente de los 
tejidos dentarios y de otros elementos con los que comparte el espacio dentro de la raíz tales como la gutapercha, medios cementantes y los que conforman el muñón. Si no contamos con estos tipos de PRRF es preferible utilizar cementos radiopacos que contrasten con el perno. (Fig.15).

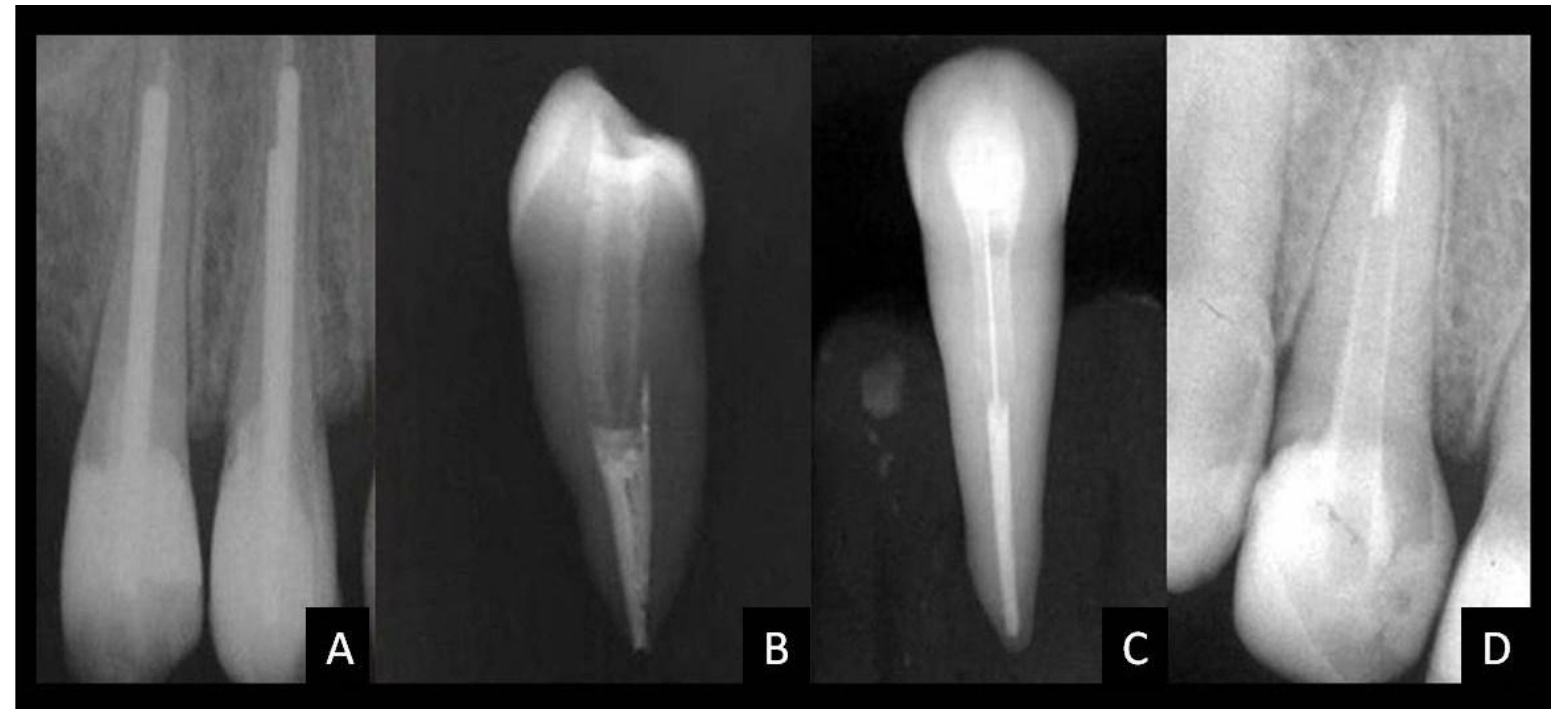

Fig.15 En las radiografías se muestran pernos radiopacos (A), cementos radiopacos, que generan contraste, (B y D) y pernos que contienen en su centro un hilo de titanio (c).

\subsubsection{Fibras de refuerzo.}

Las fibras más eficientes probadas en este campo son las fibras de vidrio, las fibras de carbono y las de cuarzo.

Las fibras de vidrio más comunes son las compuestas de sílice en aproximadamente un $60 \%$ pudiendo contener calcio, aluminio, boro y hierro. Estas son las más estéticas. Un aspecto crítico para las fibras de vidrio es que son las más afectadas por el debilitamiento hidrolitico que ocurre en casos de filtración marginal ${ }^{112}$. 
Las fibras de carbono tienen las mejores propiedades mecánicas ${ }^{135}$ pero debido a que son antiestéticas se las utiliza en el sector posterior.

Las fibras de cuarzo tienen propiedades mecánicamente similares a las de carbono, y son más resistentes a la fractura que las de vidrio y carbono $^{75}$.Se presentan como translúcidas y son eficaces conductores de luz.

\subsubsection{Conducción de luz.}

El perno de resina reforzado con fibras debe permitir el pasaje de luz, este dará a la restauración más naturalidad y permitirá la activación de cementos a base de resina. Estudios como los de Texeira ${ }^{122}$ nos advierten que no todos los pernos conducen efectivamente la luz y algunos no llegan al mínimo requerido para una fotoactivación. En la Fig.16 se comparan la capacidad de transmitir la luz entre distintas marcas comerciales de PRRF.

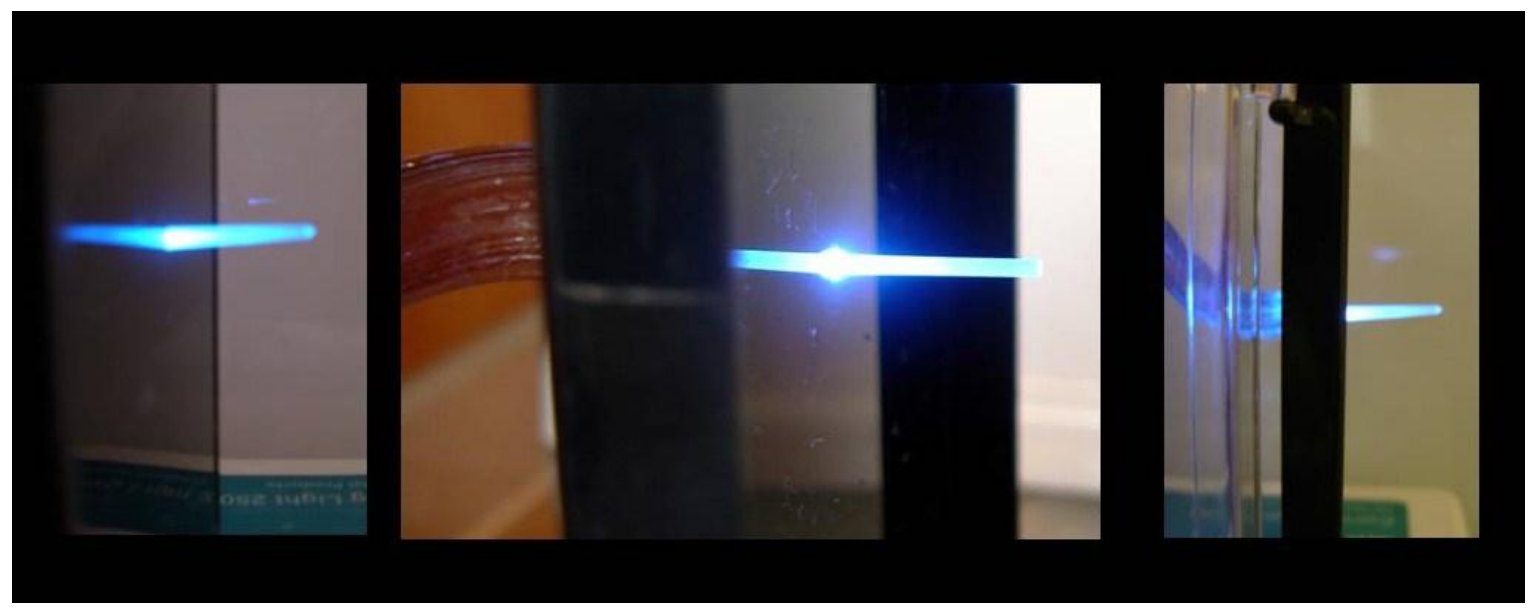

Fig. 16 En las fotos se muestran diferentes marcas de PRRF de vidrio y su capacidad para transmitir la luz. 


\subsubsection{Superficie del PRRF.}

La superficie de los pernos se muestra liza al ojo desnudo tal como se visualiza en la Fig. 17.

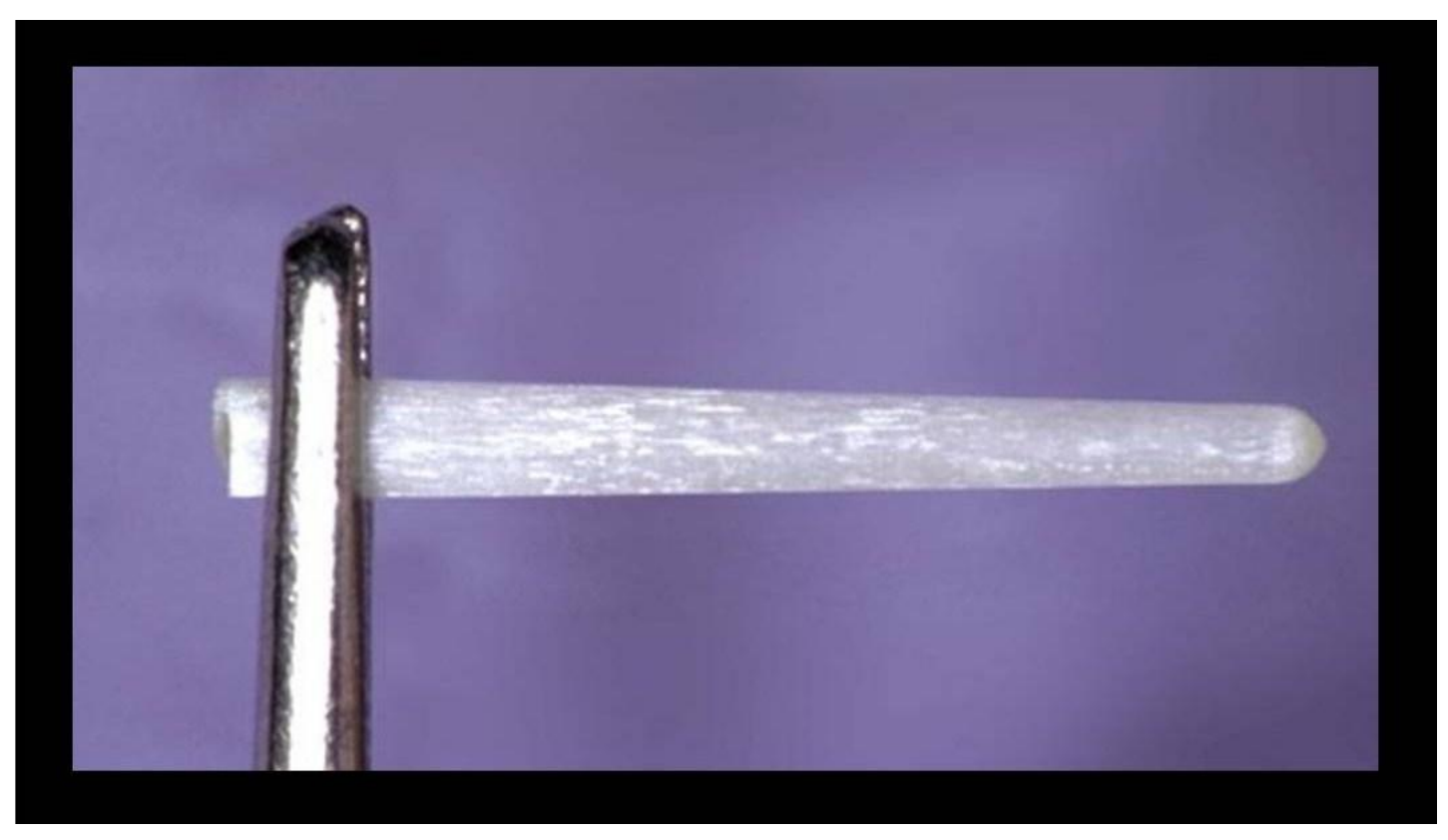

Fig. 17 Macrofotografía del perno de resina reforzado con fibras.

Sin embargo la observación con el MEB nos muestra irregularidades que conferirán una ayuda en la retención micromecánica. (Fig.18)

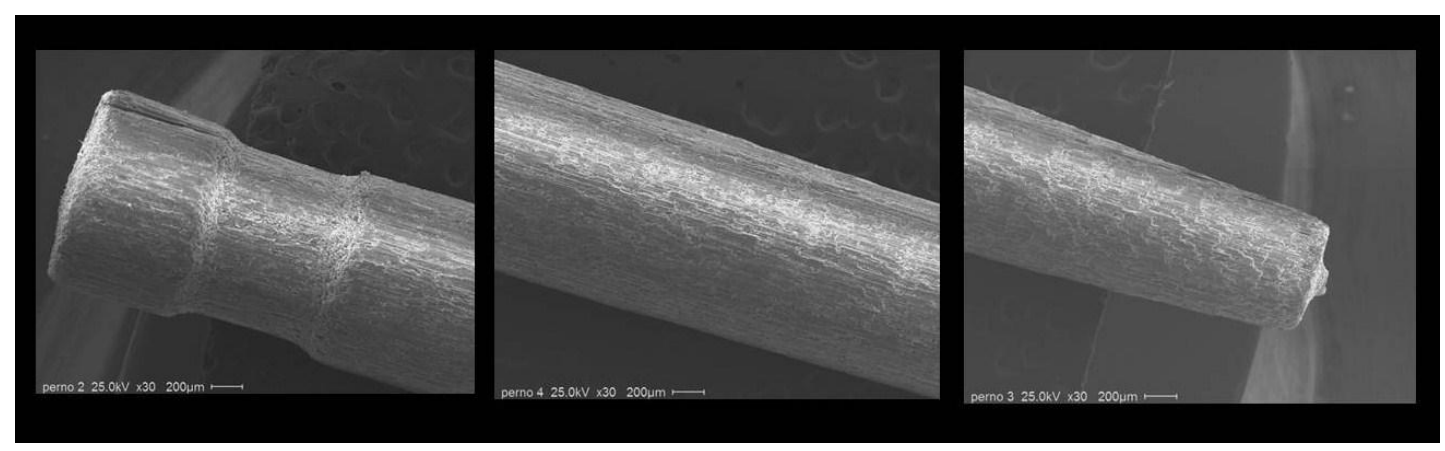

Fig.18 Microfotografía del PRRF. Se muestran su parte coronal (izquierda), media (centro) y apical (derecha). 


\subsection{Técnica clínica para remodelar el canal radicular a las medidas y forma del PRRF.}

Tener conocimiento de la anatomía radicular es crucial en la endodoncia, y siempre se debe considerar que la radiografía tiene sus limitaciones en cuanto a la definición y planos que se pueden observar.

La conformación del lecho para el perno se puede realizar posterior a la endodoncia, como lo es en la mayoría de los casos. Sin embargo, diversos estudios muestran que la calidad del cierre es mejor cuando se realiza inmediatamente después de colocar la gutapercha en el canal radicular $^{99}$

La técnica más utilizada para desobturar los conductos es a través de instrumental rotatorio, esta técnica es rápida pero es peligrosa ya que puede provocar perforaciones, alterar el cierre apical y ensancharlo en forma exagerada.

Para remover la gutapercha, las fresas de Gate-Glidden se consideran las más adecuadas, también con éstas se busca inferir la profundidad y de esa forma ajustar el largo del poste. Sin embargo, Goldberg y $\operatorname{cols}^{45}$ demostraron que no hay una técnica clínica que asegure la total remoción del material de obturación endodóntica.

Con respecto al ajuste del largo del perno se recomienda que el perno debe ser igual al largo de la corona clínica o por lo menos igual a la mitad de la distancia entre la cresta ósea alveolar y el ápice radicular o, como mínimo, 
extenderse hacia la dirección apical $4 \mathrm{~mm}$. Cuanto más largo sea el poste mayor será la retención.

Hasta hace algunos años se creía que la adhesión dentro del conducto podía suplir la traba mecánica, sin embargo Goracci ${ }^{52}$ demostró que la traba mecánica es fundamental para retener el PRRF.

El ancho del perno influye poco en la retención pero es importante en relación a sus propiedades físicas. Se debe respetar la conicidad de los conductos, por esto no se deberían utilizar pernos cilíndricos.

Se aconseja que luego de determinada la longitud del conducto y su diámetro y realizada la correspondiente desobturación con fresas GatesGlidden a una velocidad de rotación entre 1000 y 2000 rpm se lave con clorhexidina entre cambios de fresa; utilizando fresas de peso (largo) número 1 y luego la 2 diámetro de $0,9 \mathrm{~mm}$. Por último se deberá pasar la fresa específica proporcionada por el fabricante acorde a la forma del perno que se coloque.

Finalizada la remodelación del canal radicular se procede a la limpieza de la dentina del conducto radicular para recibir al PRRF.

\subsection{Adhesión a la dentina radicular.}

La adhesión dentro del canal radicular es un tema controversial. Se sabe que es primordial la penetración y polimerización de los adhesivos dentro de los túbulos dentinarios y poder llegar a la formación de resin tags (resina endurecida en el interior de los conductillos dentinarios). La dentina 
presenta los canalículos totalmente obturados por material orgánico y por sustancias utilizadas para sellar el conducto como cementos y conos de gutapercha.

Uno de los objetivos de este trabajo fue poder llegar a definir cuál es la técnica clínica y los materiales más apropiados para dejar a la dentina libre de contaminación y poder lograr la mejor adhesión.

\subsection{Acondicionamiento del PRRF.}

El objetivo del acondicionamiento del perno es lograr modificaciones en su superficie para mejorar la unión micromecánica o adhesiva con el medio cementante.

La superficie, tal como se describió en el punto 1.4.6, es originalmente microrrugosa, por lo que una limpieza con alcohol es suficiente para aumentar su energía superficial y quedar formadas microretenciones con el cemento.

Se ha demostrado que el grabado con ácido fluorhídrico al $10 \%$ genera daño en las fibras de vidrio ${ }^{34}$. La realización de arenados que deterioran la superficie es también perjudicial ${ }^{9}$. Sin embargo, Radovic ${ }^{100}$ demostró que postes con alta densidad de fibras de cuarzo se pueden arenar para llegar a la matriz ${ }^{3}$.

Se ha demostrado que la silanizacíon de la superficie del perno da un aumento efectivo en la resistencia adhesiva ${ }^{107}$. Otros estudios no mostraron diferencias significativas al realizar la silanizacíon ${ }^{98}$. 


\subsection{Colocación del medio cementante en el lecho del PRRF.}

La forma de cómo llevar el cemento al conducto remodelado es un acto complejo que puede influir en la formación de espacios vacios (burbujas de aire) que generan inconvenientes en la retención del mismo y la posibilidad de que dichos espacios den lugar a futuras filtraciones.

Uno de los objetivos trazados en el presente trabajo es poder comparar distintas técnicas y llegar a demostrar cuál es la que más conviene utilizar en la labor diaria y cuáles evitar por generar mayor riesgo de formación de espacios.

\subsection{Sistemas adhesivos.}

Para que las resinas compuestas se adhieran de manera eficaz y duradera a la estructura dental es fundamental que se emplee previamente una resina de baja viscosidad o un adhesivo y que sea capaz de penetrar en lo íntimo de la dentina y ahí polimerizarse.

Estos son los llamados adhesivos dentinarios, que buscan un mejor sellado marginal, así como también la disminución de la sensibilidad postoperatoria y las microfiltraciones. Un sistema adhesivo es el conjunto de materiales que sirven para realizar todos los pasos de la adhesión del material restaurador, tales como la preparación de la superficie del esmalte y dentina, la adhesión química y/o micromecánica al esmalte y dentina y la adhesión química al material restaurador. 


\subsubsection{Clasificación de los adhesivos.}

En los últimos años se han desarrollado distintos tipos de adhesivos así como también han aparecido múltiples clasificaciones de éstos. Como una manera de simplificar sus aplicaciones clínicas han sido clasificados de diferentes formas:

\section{SEGÚN CÓMO INTERACTÚAN CON EL BARRILLO DENTINARIO}

Los sistemas adhesivos con grabado ácido total

Los sistemas adhesivos autograbantes

2 SEGÚN EL MECANISMO DE ACCIÓN Y EL NÚMERO DE PASOS EMPLEADOS

Adhesivos de tres pasos

Adhesivos que eliminan el barrillo dentinario

Adhesivos de dos pasos

Adhesivos de dos pasos.

Adhesivos que disuelven el barrillo

dentinario

Adhesivos de un paso 


\section{POR EL ACONDICIONAMIENTO ÁCIDO}

Los que emplean un acondicionamiento ácido previo. Ácido y adhesivo se aplican en etapas diferentes.

Los que no emplean un acondicionamiento ácido previo. Ácido y adhesivo se aplican en etapas diferentes.

\section{POR LOS SISTEMÁS DE ACTIVACIÓN}

Fotoactivados. No ocasionan cambios de color y producen menor estrés de contracción cuando se aplican una sola capa.

De doble activación (dual). Puede utilizarse una resina con cualquier activación.

Activados químicamente. (Están en desuso). 


\section{SEGÚN LA TÉCNICA DE UTILIZACIÓN}

Fotoactivados que usan acondicionamiento ácido.

Fotoactivados que son autocondicinantes.

Activación dual que utiliza acondicionamiento ácido.

Activación dual que son autocondicionadores.

\section{ADHESIVOS CON AGREGADOS}

Adhesivos con flúor: disminuye la solubilidad de la dentina, menor recurrencia de caries.

Adhesivos con relleno que aumenta su viscosidad, disminuye su escurrimiento y aumenta la capa elástica. 


\section{SEGÚN GENERACIONES}

Desde la época de Buonocore, 7 distintas generaciones de agentes adhesivos han aparecido.

\subsubsection{Generaciones de los adhesivos dentales.}

Primera generación: Buonocore ${ }^{14}$, al principio de la década de los sesenta, propone el uso de un compómero, que teóricamente podía unirse al calcio de la dentina. Sin embargo, al contacto con el agua ésta adhesión disminuía considerablemente, demostrando resultados clínicos muy pobres.

Segunda generación: Una segunda generación de adhesivos fueron desarrollados para el uso clínico a principios de la década de los ochenta. La mayoría de estos materiales eran esteres halofosfóricos de resinas sin relleno, tales como el bisfenol A-glicidylmetacrilato (BISGMA) o el hidroxietil metacrilato (HEMA). Su mecanismo de unión a la dentina se basaba en la unión del calcio, presente en el barro dentinario, por grupos fosfatos del adhesivo. Por lo tanto, estos adhesivos modifican el barro destinario. Sin embargo, este sistema adhesivo presentaba una fuerza de adhesión bastante débil, que no contrarrestaba la fuerza producida por la contracción de polimerización, produciéndose la filtración marginal de las restauraciones. 
Tercera generación: Una tercera generación de adhesivos fue introducida en Estados Unidos al final de la década de los ochenta. Este nuevo sistema adhesivo, se basaba principalmente en la remoción parcial o modificación del barro dentinario, que permitía la penetración de la resina adhesiva a la dentina subyacente. Clínicamente estos adhesivos mejoraron la retención y la integridad marginal, en comparación con los anteriores. Sus resultados clínicos aún no fueron los óptimos, pero en comparación con sus predecesores, estos últimos adhesivos, disminuyeron la filtración marginal, pero no la eliminaron.

Cuarta generación: Este sistema adhesivo aparece a principios de la década de los noventa, son llamados "three step" o "tres-pasos" o también sistemas adhesivos con grabado ácido total. Su mecanismo de acción consta de tres pasos: acondicionamiento, aplicación de un Primer, y luego de la del adhesivo. El acondicionamiento de la dentina se basa en la técnica de grabado ácido total propuesta por Fusayama y colaboradores ${ }^{41}$, en el año 1979, que consiste en el grabado ácido simultáneo de la dentina y el esmalte, que desmineraliza el componente inorgánico, y expone las fibras de colágeno.

La malla de colágeno desmineralizada es tratada con un Primer, que consiste en una resina de tipo hidrofílica, que actúa como un agente de enlace entre la resina adhesiva, que es hidrofóbica, y la dentina húmeda, que es hidrofílica. El primer es capaz de penetrar la dentina húmeda, para luego unirse a través de enlaces químicos a la resina adhesiva.

Finalizada la aplicación del adhesivo, éste es polimerizado, para terminar con la colocación de la resina compuesta restauradora. 
Quinta generación: Ésta nueva generación fue desarrollada para simplificar los tratamientos en una única botella, por esto fueron llamados "one-bottle" o "monobotella", y también corresponden a sistemas adhesivos con grabado ácido total. El procedimiento se basa en el mismo de la generación anterior, ahorrándose un paso. Se realiza el grabado ácido total y luego la aplicación del adhesivo que en su interior contiene el Primer. Finalmente se polimeriza y se procede a realizar la restauración con la resina compuesta. Este sistema adhesivo, al igual que el anterior, ha demostrado un buen comportamiento en cuanto a fuerza adhesiva y sellado marginal. Al igual que en los sistemas adhesivos de cuarta generación, se reportaron reacciones de sensibilidad postoperatoria asociadas al grabado ácido, que remueve el barro dentinario y aumenta la permeabilidad de los túbulos.

Sexta generación: En la actualidad el desarrollo de los adhesivos dentinarios está orientado a simplificar los pasos operatorios, disminuyendo etapas en la técnica y asimismo solucionar problemas como la sensibilidad postoperatoria de los sistemas adhesivos con grabado ácido total (cuarta y quinta generación de adhesivos dentinarios). Fue así como aparecieron los sistemas autograbantes, que no requieren un grabado ácido previo a su aplicación, encontrándose los primers autograbantes (two-step o dos pasos) y los adhesivos autograbantes (all-in-one-materials o materiales todo en uno). Los primers autograbantes, consisten en dos botellas. La primera combina el grabado ácido y la aplicación del primer y la segunda contiene el adhesivo de resina. Este material puede grabar el esmalte y la dentina simultáneamente, es decir, desmineraliza el componente inorgánico de la 
dentina infiltrando con el primer las fibras de colágeno expuestas, con un segundo paso operatorio que es la aplicación del adhesivo.

Los adhesivos autograbantes, al igual que los primers autograbantes corresponden a dos botellas, la primera que contiene el ácido y el primers y la segunda que contiene el adhesivo. La diferencia radica en que en los adhesivos autograbantes se mezclan ambos componentes para ser aplicados en un sólo paso clínico, a diferencia de los primers autograbantes en que ambos componentes deben ser aplicados por separado, en dos pasos operatorios. En teoría los adhesivos autograbantes, desmineralizan el componente inorgánico de la dentina y del esmalte, promoviendo la difusión de monómeros de resina adhesiva dentro de la malla de colágeno desmineralizada.

Séptima generación: A fines del 2002 se introdujeron en el mercado los adhesivos pertenecientes a una nueva generación, que a pesar de ser muy semejantes a los de sexta generación, presentan todos los ingredientes en un solo frasco y no necesitan el mezclado.

\subsubsection{Condiciones ideales para un adhesivo.}

Es necesario que el adhesivo sea capaz de:

1. Adherirse a la dentina con una fuerza igual o mayor que la de un composite al esmalte grabado.

2. Alcanzar rápidamente la máxima fuerza de adhesión para permitir manipulaciones de acabado y pulido, así como el restablecimiento funcional post-operatorio del paciente en un lapso de tiempo rápido.

3. Ser biocompatible y no irritar el tejido pulpar. 
4. Prevenir las microfiltraciones.

5. Demostrar una estabilidad prolongada en el medio oral.

6. Ser de fácil de aplicación y clínicamente indulgente.

7. Tener baja tensión superficial.

8. Tener baja viscosidad.

9. Tener propiedades mecánicas adecuadas: para resistir las fuerzas de masticación.

10. Ser Hidroresistentes.

\subsection{Cementos utilizados para la fijación de PRRF.}

Existen dos tipos de cementación que se pueden realizar estas son: Cementación convencional y cementación adhesiva.

\subsubsection{Cementación convencional.}

Podemos llamar fijación convencional a las técnicas que buscan un mecanismo mejorado de la traba mecánica, entre el perno y la dentina. Estas técnicas no realizan preparaciones especificas sobre el sustrato (no utilizan sistemas adhesivos resinosos).

Una técnica de tipo convencional para fijar los pernos a los lechos realizados en el canal radicular es la utilización de cementos que tengan menos variables y que sean más predecibles, como por ejemplo la utilización de ionómeros vítreos. La cementación con este tipo de cemento permite una técnica más rápida, económica, una manipulación más conocida por el odontólogo. 


\subsubsection{Cemento de ionómero vítreo como medio cementante.}

Estos cementos se desarrollaron en 1974 por Wilson y Kent ${ }^{129}$ basándose en materiales ya existentes tomando características similares a las del cemento de silicato y del policarboxilato de cinc. Presenta usos múltiples como lo son la protección dentino pulpar, reconstrucción de muñones y como medio cementante. En este trabajo solo se lo describe como medio cementante.

Existen ionómeros vítreos denominados convencionales y otros con resinas dentro de su composición. Pueden presentarse comercialmente como un polvo y un líquido o en dos pastas para ser mezcladas en forma manual o mecánica. Los que vienen envasados en capsulas favorecen su dispensación y el mezclado del material, su proporción es establecida por balanzas de extrema exactitud.

Estos materiales son cementos, por lo tanto existe una reacción entre un ácido (líquido) y una base (polvo). La base está compuesta por fluoraluminosilicato que hace reaccionar al polvo con un ácido. El líquido contiene ácido poliacrílico, ácido tartárico, ácido itacónico y agua. El ácido poliacrílico aporta los grupos carboxilos para unirse químicamente al calcio de la estructura dentaria. El agua, como en otros cementos, es la encargada de disociar. Los ácidos restantes, a los cuales se le puede agregar el ácido maléico, tienen la función de aumentar la reactividad del líquido, reducir la gelificación y disminuir la viscosidad.

Una opción que se puede presentar es que el líquido sólo tenga agua destilada, ácido tartárico o ticónico y el ácido poliacrílico es provisto disecado 
en el polvo. Cuando el polvo se mezcla con el agua, los componentes se hidratan. Este tipo de ionómero se denomina al agua y simplifica la manipulación y proporción del material. En este trabajo se utilizó este tipo de presentación del ionómero vítreo.

La cuantificación es fácil de lograr ya que es posible valerse de cucharas que proporcionan la justa cantidad de polvo para cierto número de gotas. El mezclado se realiza sobre papel satinado que impide la absorción del material, la espátula es plástica. Si la espátula es metálica el componente silícico del material la rayaría y restos de la misma se incorporarían al material. La proporción de los componentes puede variar de acuerdo a la marca comercial. El polvo no debe separarse en partes ya que el tiempo cumple un rol muy importante.

El protocolo establece que la manipulación se debe realizar en forma suave para no romper la estructura del gel y el tiempo de mezcla no debe exceder los 45 segundos para evitar la unión total de polvo al líquido. La consistencia para cementar debe ser similar a la del fosfato de cinc, formar un hilo de $2 \mathrm{~cm}$ de longitud y tener un brillo en su superficie que indica la presencia de carboxilos libres necesarios para obtener una buena adhesión.

Comprender la reacción del material permite realizar una correcta manipulación para lograr una adhesión aceptable y buenas propiedades mecánicas.

El ácido poliacrílico una vez disociado por el agua, reacciona con el polvo produciendo la formación de un gel de ácido silícico, mientras que el calcio, aluminio, y flúor ionizan. 
La presencia silícica en la composición y la propiedad de ionizar son los que establecen el nombre de ionómero vítreo.

Los grupos carboxilos derivados del ácido poliacrílico son los encargados de atrapar a los elementos ionizados que toman en primer lugar al calcio y luego al aluminio. En el caso de contener flúor los iones fluoruro se liberan al medio produciendo un efecto antibacteriano.

Una vez concluida dicha reacción, que puede llevar horas, la estructura formada es un gel de ácido silícico en una matriz de poliacrilato de calcio y aluminio.

El grado de translucidez se asemeja al de la estructura dentaria y es capaz de mimetizarse con la estructura protética. La resistencia del material a la compresión es elevada en comparación a otros agentes de unión. La solubilidad que presenta es relativamente baja en medios acuosos y ácidos gracias a componentes como el aluminio en su estructura final.

Es importante mencionar la necesidad de proteger al ionómero vítreo hasta el momento de su fraguado final con el objetivo de impedir la salida o entrada de componentes líquidos durante su endurecimiento total. ${ }^{78-83-82}$.

La estética de los polímeros definitivamente mejoró las condiciones ópticas de los nuevos ionómeros vítreos cuya denominación paso a ser la de "ionómeros vítreos con resina". La nueva resina incorporada no solo disminuye la fragilidad si no que aumentó la resistencia abrasiva y la translucidez del material. La manipulación se realiza en forma similar a los convencionales con la posibilidad de utilizar espátulas metálicas puesto que la resina impide el contacto del acero con las partículas de sílice. 


\subsubsection{Cementación adhesiva.}

La aparición de medios cementantes resinosos con propiedades físicas y estéticas superiores a los convencionales y con capacidad de generar una adhesión muy superior a los diferentes sustratos dentarios como no dentarios logró mejorar el contacto entre las partes y al mismo tiempo aportar otra ventajas clínicas.

Por lo tanto, serán llamadas fijaciones adhesivas a las que cumplen los siguientes requisitos:

A) Establecen adhesión entre el diente y la restauración a través de los cementos a base de resina y de los acondicionamientos superficiales.

B) Emplean un cemento a base de resina como medio cementante.

C) Acondicionan las superficies de la restauración y las correspondientes a las preparaciones dentarias.

D) Emplean sistemas de adhesión sobre las superficies a unir.

Con estos cementos se ha podido lograr menor desgaste de tejidos sanos y una mejor adhesión - integración de algunos materiales a la superficie sobre la cual se colocan, y se logra un mejor sellado marginal ya que son virtualmente insolubles.

Tienen la posibilidad de sellar a la dentina y de mejorar la estética en las técnicas de rehabilitación coronaria. 


\subsubsection{Cementos a base de resina.}

Los cementos a base de resina nacen de las resinas compuestas o composites.

Los composites son materiales combinados con diferentes aplicaciones en la odontología, una de ellas el cementado.

Para que se considere un material combinado debe presentar una matriz orgánica, un refuerzo cerámico y un agente de enlace encargado de mantener unidos a los dos anteriores.

La matriz es el componente con excelentes propiedades ópticas y de bajas propiedades mecánicas.

Los polímeros utilizados generalmente son de alto peso molecular, con cadenas cruzadas e hidrofobicos, por ejemplo se pueden citar: Bis Fenol A más metacrilato de glicidilo (BisGma), dimetacrilato de uretano (Udma) etc. Sus altos pesos moleculares aumentan la viscosidad del material. Para solucionar dicho inconveniente se incorporan polímeros de bajo peso molecular como Metacrilato de metilo (MMA) o el trietilenglicol dimetacrilato (Tegdma). Puede suceder que en una determinada composición presente una matriz de BisGma con otra como la Udma, en este caso la última resina, de menor peso molecular, actúa como diluyente.

Los rellenos o agentes de refuerzo son a base de vidrios, los que le dan al material altas propiedades mecánicas. Es evidente que existe una relación entre éstas y el porcentaje de la sustancia inorgánica como así también una relación indirecta entre el relleno y las propiedades ópticas. 
En la utilización de resinas como medio cementante se reduce en grados variables el contenido cerámico para disminuir la viscosidad. Presentan características particulares en su manipulación, endurecimiento, propiedades físicas y comportamiento óptico.

Entre las características de los cemento a base de resina se pueden citar las siguientes, son prácticamente insolubles, su biocompatibilidad depende del grado de permeabilidad dentinaria. Se presentan translucidos en diferentes grados y no presentan fase elástica prolongada. En cuanto a las resistencias compresivas, de tracción, de flexión, desgaste y fatiga superan a todos los otros medios cementantes. Se polimerizan más rápido en anaerobiosis y forman una capa inhibida en presencia de oxigeno. Se contraen al polimerizar. Puede formar tensiones internas que provocaran fallas en la adhesión-integración y perdida del sellado marginal. Estos problemas se minimizan cuando el espesor del cemento es reducido (no debe tener más de 100micrones de espesor).

Se los suele clasificar según el modo en que activan su polimerización ${ }^{19}$.

- Autoactivables: se presentan dos pastas, la polimerización se activa al reaccionar un peróxido con una amina terciaria aromática y forman las primeras valencias con radicales libres. Se los indica donde la activación de luz no puede llegar. Suelen sufrir decoloraciones con el tiempo. Los autuactivados tienen menor grado de conversión que los fotoactivados duales. 
- Foto activados duales: se presentan es dos pastas una base y la otra catalizadora. Sus componentes son iguales a las del anterior pero se les agrega un componente, la (canforquinona), capaz de iniciar la polimerización cuando se lo expone a una luz azul.

- Opcionales: similares a los duales pero el fotoactivador se incorpora solamente en la pasta base por lo que, si se quiere, se puede utilizar sólo. Se tiene además la utilidad de un fotoactivable, evitando los problemas del dual, tales como decoloraciones a distancia o atrapamiento de aire en la mezcla.

- Fotoactivables: sólo se activan con la aplicación de la luz azul. Se pueden utilizar resinas tipo flow para cumplir dicha función.

También se los puede clasificar de acuerdo con su adhesividad en adhesivos por si mismos o como agentes de fijación ${ }^{51}$ :

- Adhesivos por si mismos: pueden adherirse específicamente a estructura dentaria o no dentaria por la presencia de monómeros adhesivos como los ésteres fosfatados $u$ otras moléculas polifuncionales como 4-META. Otros cementos a base de resina más recientes presentan monómeros ácidos que permiten generar adhesión a superficies dentarias. A semejanza de los adhesivos autograbantes, producen un acondicionamiento ácido en la superficie del diente con la que generan un contacto y establecen adhesión. 
- Como agente de fijación: su presentación comercial puede ser en una única pasta (activación física) envasada en jeringas y en dos pastas (activación química o dual), envasadas en jeringas. Es importante aclarar que la presentación de una única pasta debe ser utilizada cuando el sustrato a cementar permita el pasaje de la fuente de activación lumínica.

Para seleccionar el mejor método adhesivo es importante analizar qué tipo de interfaces se producen entre el tejido dentario y el PRRF. Con ese propósito se seleccionaron tres técnicas de análisis que son reportadas en la literatura como las más adecuadas ${ }^{128}$ : a) estudio de la filtración marginal (penetración de un colorante); b) análisis de las interfases medio cementante con el PRRF y la dentina con MEB c) evaluación con MEB de la formación de tags. Cabe destacar que un aporte importante del presente trabajo lo constituye haber utilizado las tres técnicas en forma comparativa, esto no es habitual encontrarlo en la literatura reciente. 
2. OBJETIVOS 


\subsection{Objetivos generales:}

El objetivo general de este trabajo fue determinar si existen diferencias significativas entre los diferentes materiales de cementación para pernos de resina reforzados con fibras y establecer la técnica adecuada para preparar el tejido dentinario que recibirá un sistema adhesivo.

\subsubsection{Objetivos específicos:}

- Analizar y valorar microscópicamente cuáles son las técnicas, que mejor cumplen la función de descontaminar la superficie dentinaria, para recibir un sistema adhesivo.

- Determinar microscópicamente cuál es la técnica que genera menor cantidad de espacios vacíos en el momento de introducir el cemento para fijar el perno de resina reforzado con fibras (PRRF).

- Determinar microscópicamente si existe penetración de un colorante en cada una de las interfases producidas entre los cementos y el perno que podrían causar posibles infiltrados bacterianos.

- Cuantificar la penetración del colorante antes mencionado.

- Analizar y valorar microscópicamente las interfases producidas entre los materiales de cementación y la dentina como así también entre los cementos y el PRRF.

- Evaluar y medir microscópicamente la formación de tags en los conductillos dentinarios del lecho modificado para recibir un PRRF.

- Relacionar los resultados de la microfiltraciones con los obtenidos en la penetración de un colorante, y formación de tags. 


\subsection{Hipótesis más relevantes:}

- Existen técnicas de limpieza de dentina que producen mejores resultados en la descontaminación y liberación de los tapones de barro que obstruyen los conductillos dentinarios.

- Existen técnicas para llevar el cemento al lecho preparado para el perno que disminuyen la generación de espacios vacíos, mejorando el campo de adhesión.

- Algunos medios cementantes causan un cierre defectuoso durante la fijación del poste de resina reforzado con fibras.

- Es posible identificar una combinación de técnicas y materiales que conduzca a un resultado clínico óptimo. 
3. MATERIALES Y

MÉTODOS 


\subsection{Materiales.}

Las marcas comerciales de los materiales e instrumentos en el presente trabajo fueron elegidos por ser los más utilizados durante más de 9 años en la cátedra de Operatoria Dental B de la Universidad Nacional de La Plata.
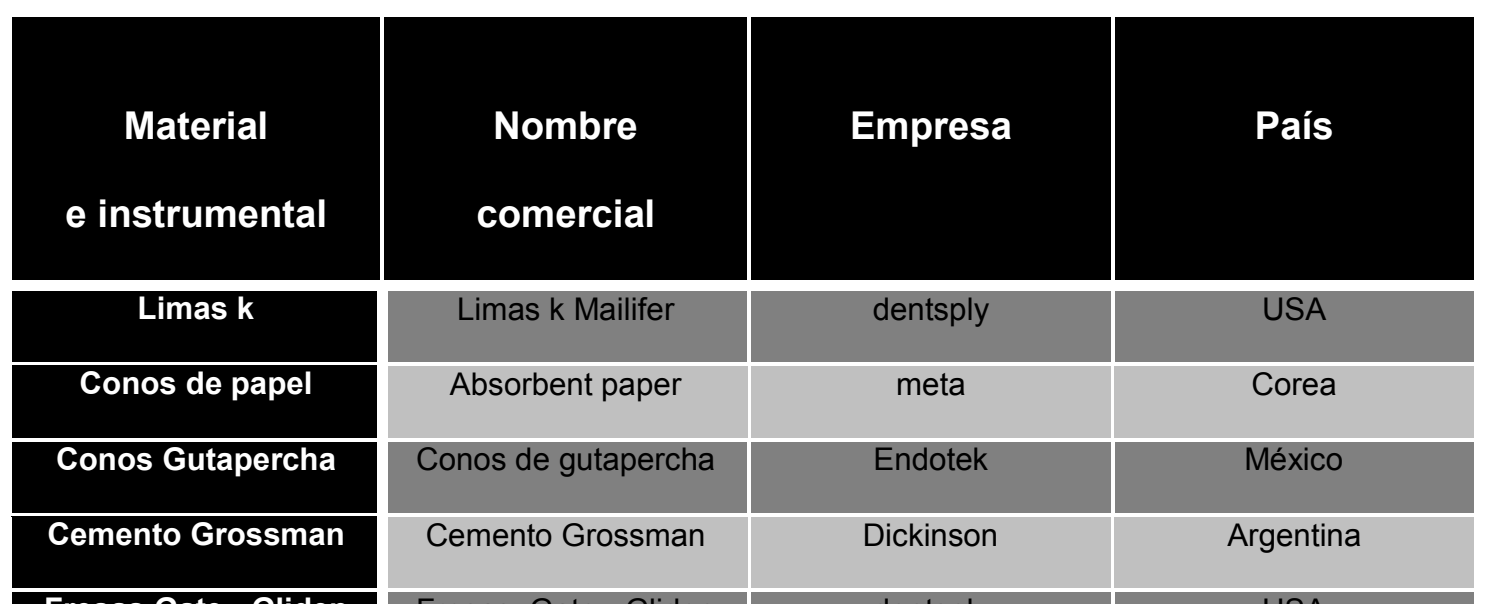

\begin{tabular}{|l|l|l|l}
\hline Limas $\mathrm{k}$ Mailifer & \\
\hline Absorbent paper
\end{tabular}

dentsply

USA

\begin{tabular}{|c|}
\hline Fresas Gate - Gliden \\
\hline EDTA 19\% \\
\hline Puntas NaviTip \\
\hline
\end{tabular}

Conos de gutapercha

meta

Corea

\begin{tabular}{|c|c|c|}
\hline Cemento Grossman & Dickinson & Argentina \\
\hline Fresas Gate - Gliden & dentsply & USA \\
\hline File- Eze & Ultradent & USA \\
\hline Puntas NaviTip & Ultradent & USA \\
\hline
\end{tabular}

Alcohol Yodado 2\%

\begin{tabular}{|c|c|c|}
\hline \multicolumn{3}{|c|}{ Preparado en droguería } \\
\hline Ketac Cem & 3 M Espe & USA \\
\hline C\&B & BISCO & USA \\
\hline Single Bon & $3 M$ & \\
\hline Enforce & USA \\
\hline EXACTO & Angelus & USA \\
\hline Lentulo & Dentsply & Brasil \\
\hline Z250 & USA & USA \\
\hline
\end{tabular}

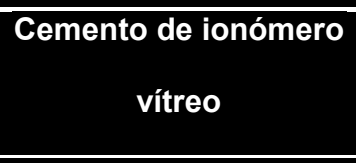

Cemento a base de resina de autocurado

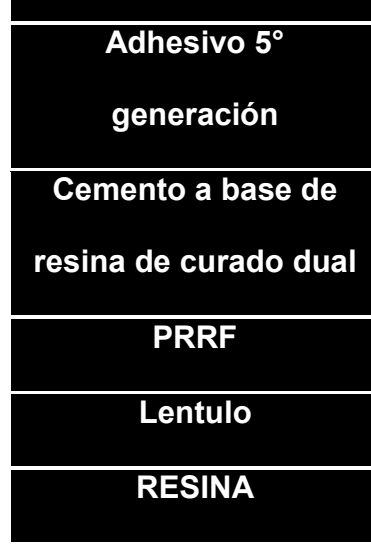




\subsection{Métodos.}

\subsubsection{Evaluación del acondicionamiento de la dentina en el canal radicular para recibir un PRRF.}

En este estudio se utilizaron 21 piezas dentarias humanas; incisivos, caninos y premolares unirradiculares, extraídas por enfermedad periodontal o por indicación ortodóntica. Dichas piezas se muestran en la Fig.19.

Las piezas fueron descontaminadas y se distribuyeron aleatoriamente en tres grupos de 7 piezas cada uno y se almacenaron en solución NAF (Fluoruro de sodio $0,2 \mathrm{mg}$, hidroxipropilmetilcelulosa $1 \mathrm{gr}$, cloruro de sodio $0,1 \mathrm{gr}$, cloruro de potasio $0,1 \mathrm{gr}$, cloruro de magnesio $5 \mathrm{mg}$, cloruro de calcio $15 \mathrm{mg}$, sulfato de potasio $40 \mathrm{mg}$, solución xilitol al $70 \%=4,3 \mathrm{~g} \cdot \mathrm{pH}$ neutro 7 ) que se renovaba cada 72 horas hasta el momento de ser utilizadas en los ensayos

\subsubsection{Tratamiento quirúrgico de los conductos radiculares.}

A las piezas dentarias se les realizó la cavidad de acceso a la cámara pulpar con una piedra redonda de diamante de $2 \mathrm{~mm}$ de diámetro y se rectificaron las paredes con una fresa endoZ a alta velocidad e irrigación con agua.

La preparación quirúrgica de los conductos se realizó con limas de endodoncia "K" de la número 15 a la 40 (limas Maillefer Dentsply USA). Se realizó irrigación entre el pasaje de cada lima con hipoclorito sódico al $5 \%$ utilizando jeringas de insulina. La secuencia de instrumentación quirúrgica de los conductos se muestra en la Fig.19 


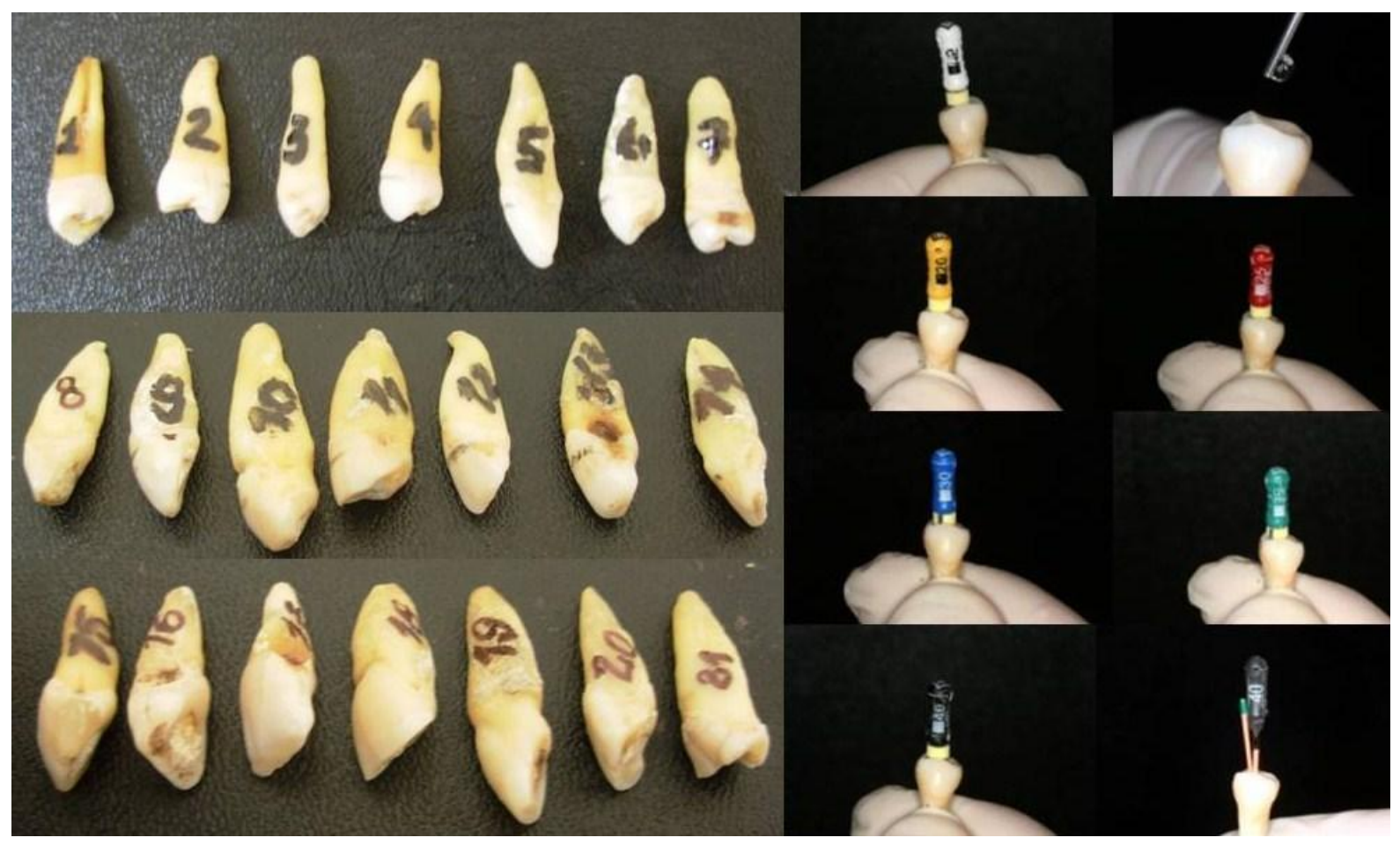

Fig.19 Piezas dentarias para realizar el experimento (izquierda)y secuencia de la instrumentación quirúrgica de los conductos(derecha).

Terminada la instrumentación de los conductos se secaron con conos de papel (Absorbent paper Meta Corea). Acto seguido se procedió a la obturación de los conductos con la técnica de condensación lateral en frio con conos de gutapercha (Endoteck. México) y cemento Grossman (Dickinson. Argentina) preparado según las normas indicadas por el fabricante.

Las piezas se guardaron a la espera del fraguado del cemento por el término de 7 días y seguidamente se procedió a cortar las coronas con una piedra troncocónica de grano grueso $2 \mathrm{~mm}$ por encima del límite corona radicular tal como se muestra en la Fig.20 


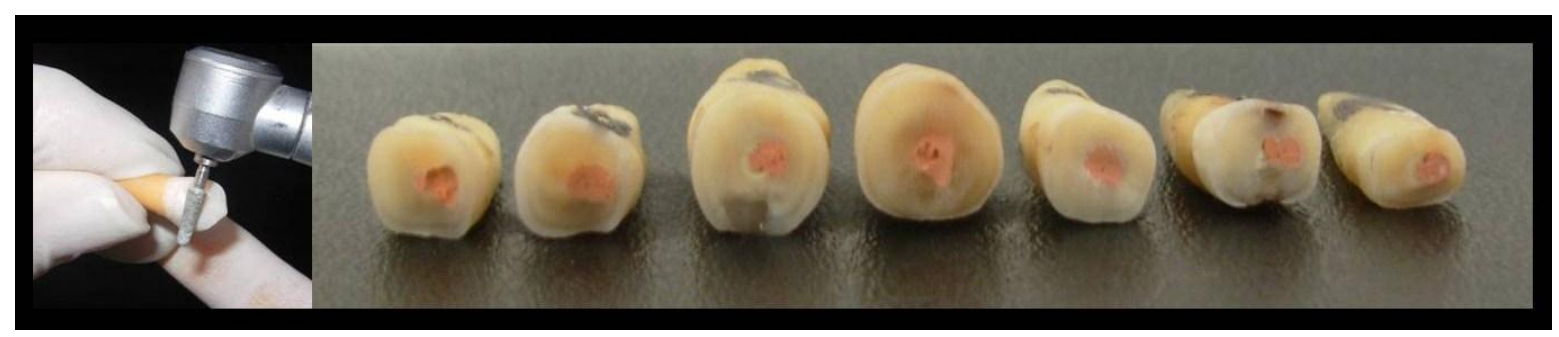

Fig. 20 Cortes de las coronas a $2 \mathrm{~mm}$ por encima del límite corono - radicular.

Posteriormente se procedió a tomar radiografías (Fig. 21) para poder comprobar, que el estado final de cada obturación era el correcto

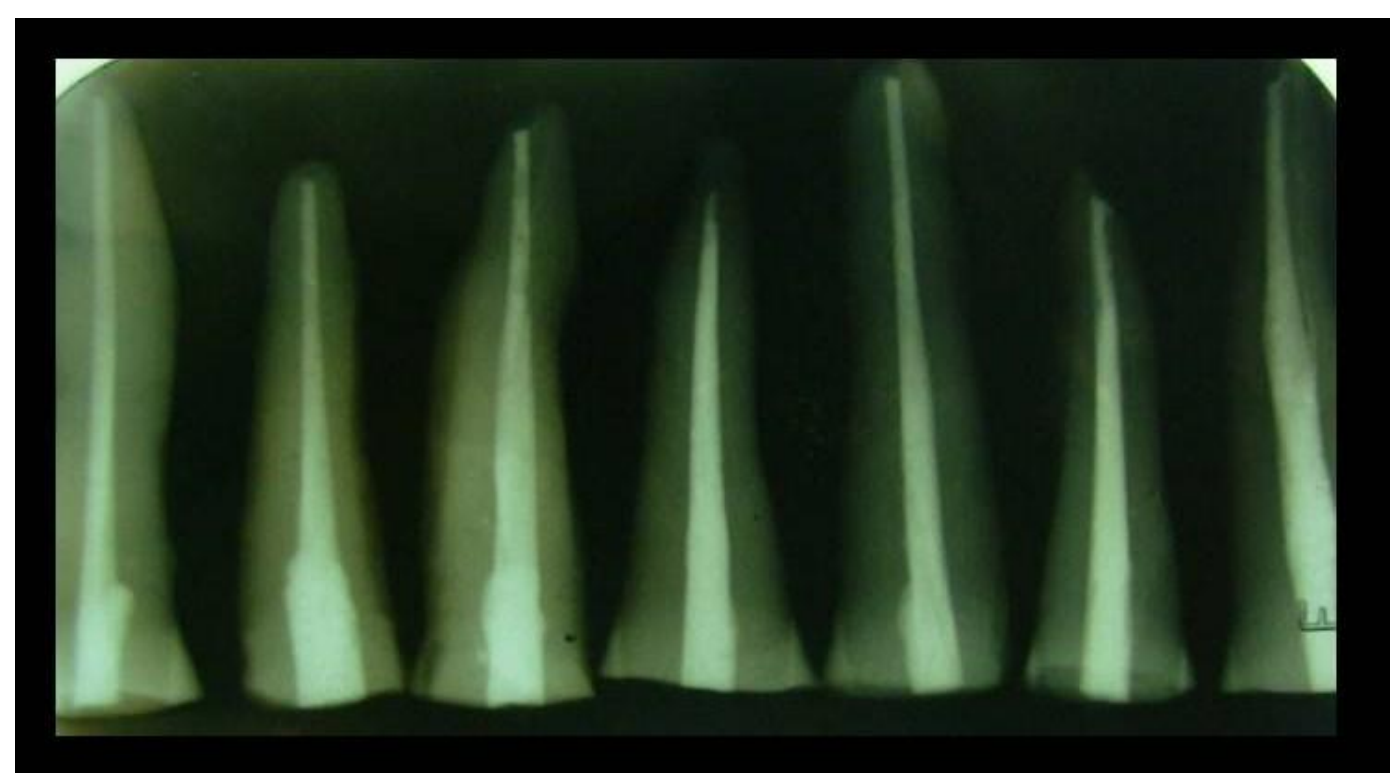

Fig. 21 Radiografías donde se evalúa el resultado de los tratamientos endodónticos.

\subsubsection{Remodelación del canal radicular para la cementación del PRRF.}

Se procedió a la desobturación parcial de los conductos con fresas de Gate-Gliden $\mathrm{N}^{\circ} 1$ (Fig. $22 \mathrm{~A}$ ) y $\mathrm{N}^{\circ} 2$ en una profundidad de $9 \mathrm{~mm}$ dentro del conducto y luego se pasó la fresa de largo $\mathrm{N}^{\circ} 2$ (Fig. 22 B) para continuar con las fresas indicadas por el fabricante para la colocación del PRRF. (Fig. 22C). Entre el paso de cada fresa se irrigó el lecho con clorhexidina al $2 \%$. 


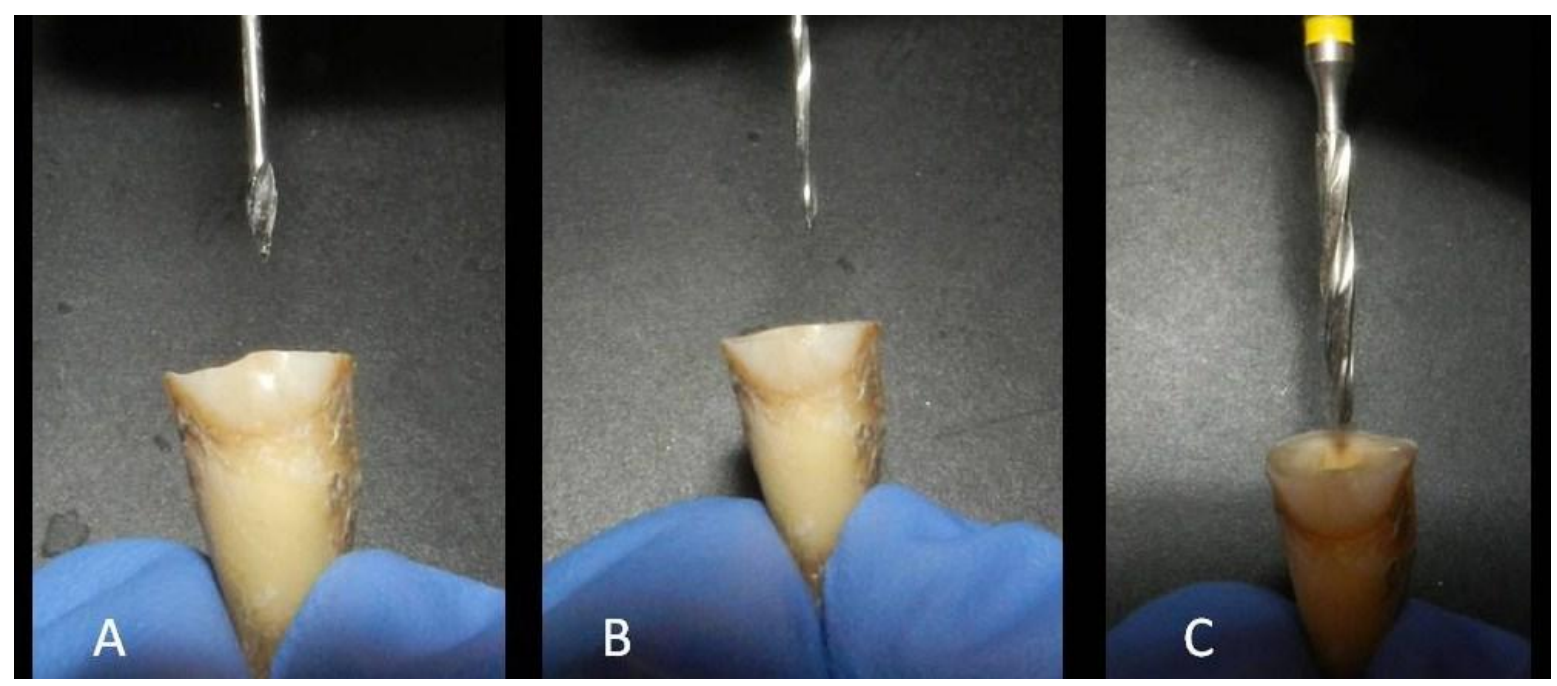

Fig.22 Desobturación de los conductos. A con fresa de Gate-Gliden $N^{\circ} 1$ Y N²; B fresa de largo C; fresa provista por el fabricante para adaptar el PRRF al conducto.

Terminada la desobturación se procedió a tomar unas nuevas radiografías y verificar la correcta realización de los procedimientos. En los casos en que se observaron restos de material se procedió a limpiar mecánicamente esa zona en particular. (Fig. 23)

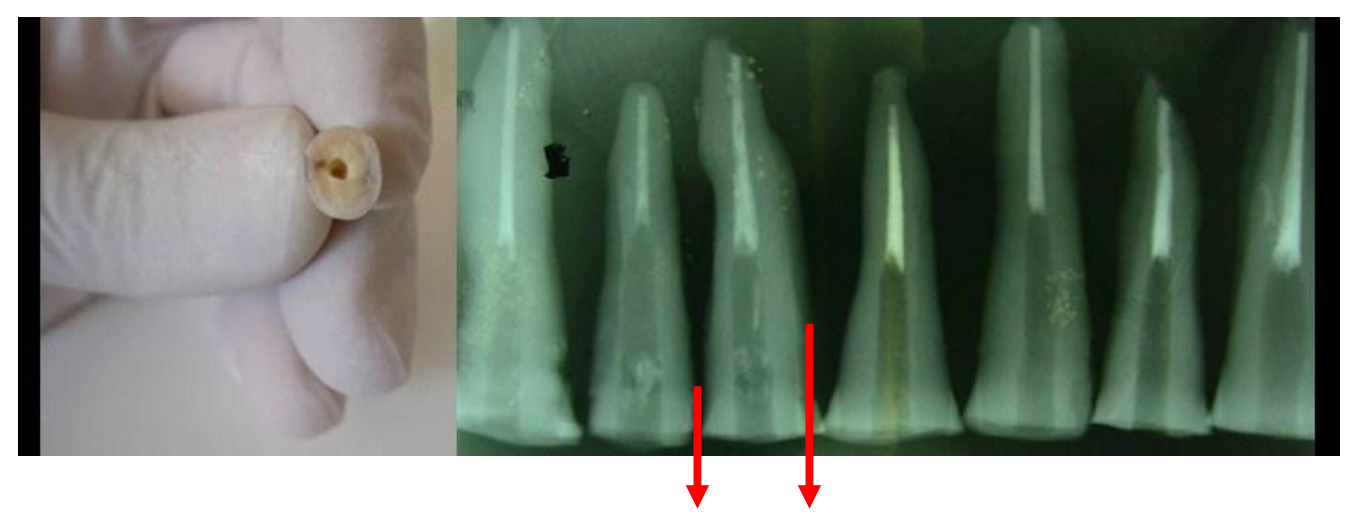

Restos de gutapercha y cemento

Fig.23 Pieza desobturada (izquierda). Radiografías que muestran que en algunas de las piezas permanecían residuos de cemento y gutapercha (derecha).

\subsubsection{Acondicionamiento de la dentina en cada grupo.}

A los grupos se los denominó A, B, C: 
Grupo A: Este grupo se tomó como control y no se le realizó ningún tipo de acondicionamiento en la dentina.

Grupo B: Este grupo recibió un acondicionamiento de la dentina utilizando Ácido etillendiaminotetraacético (EDTA) al $19 \%$ (File-Eze. Ultradent. USA). Que fue colocado en el interior del conducto, frotándolo contra sus paredes con puntas NaviTip (Ultradent. Usa) durante 30 segundos. (Fig. 24)

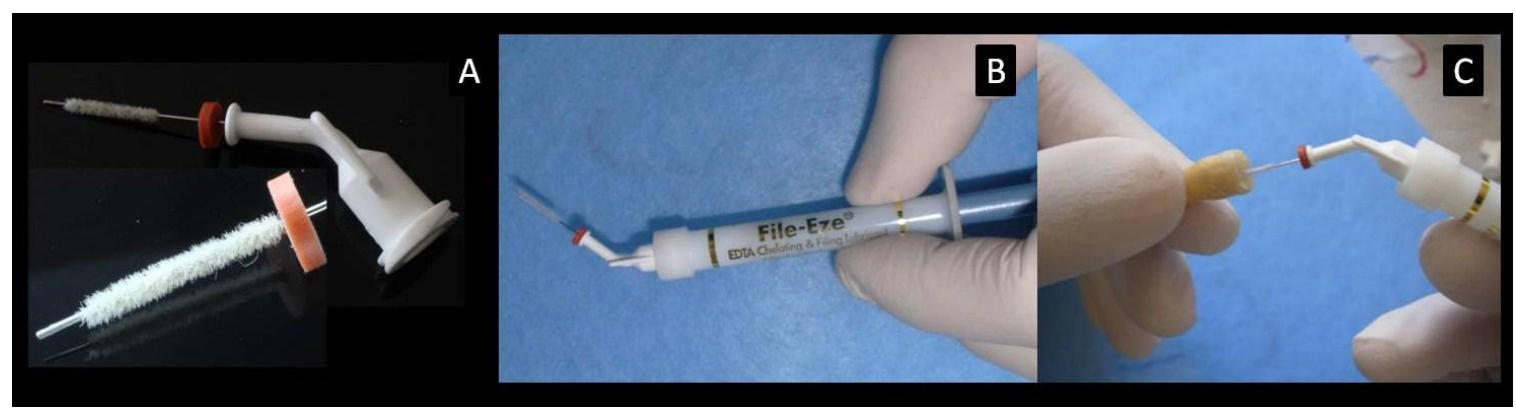

Fig. 24 Acondicionamiento del grupo B. A: puntas NaviTip B: EDTA al 19\%File-Eze C: Colocación y fricción del EDTA en la muestra

Luego fueron lavados con agua a presión utilizando una jeringa tipo Luer de $20 \mathrm{ml}$ y se terminó secándolos con conos de papel.

Grupo C: este grupo recibió un acondicionamiento de la dentina realizado con alcohol yodado $2 \%$ colocado en el conducto y frotándolo contra sus paredes con puntas NaviTip (Ultradent. Usa) durante 30 segundos. (Fig. 25). Luego fueron lavados con agua a presión utilizando una jeringa tipo Luer de $20 \mathrm{ml}$ y se terminó secándolos con conos de papel. 


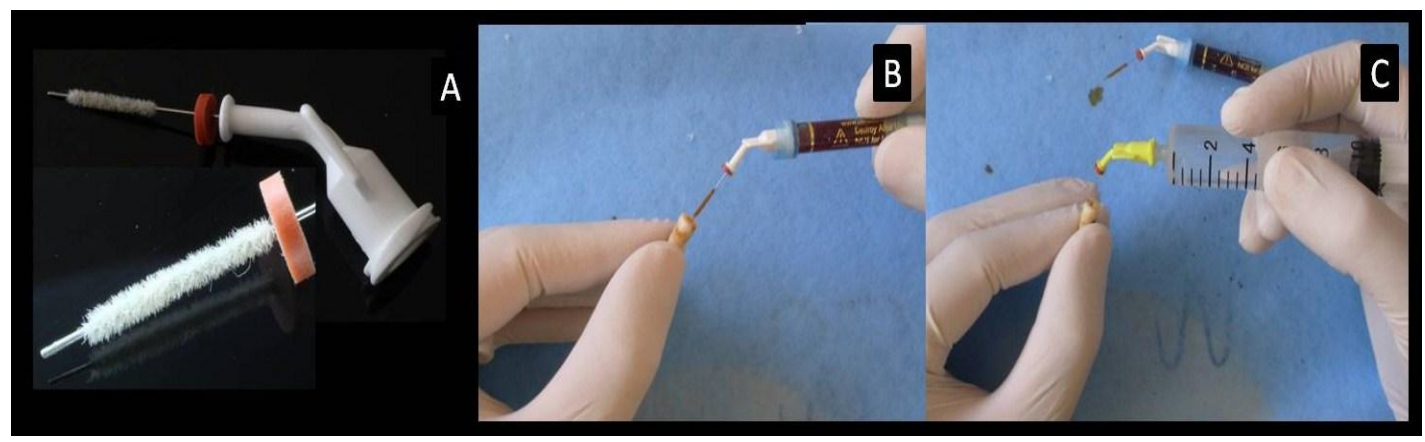

Fig.25 Acondicionamiento del grupo C. A: Puntas NaviTip utilizadas para aplicar y frotar el alcohol yodado sobre la dentina. B: Colocación y fricción dentro del conducto. C: lavajes con agua.

\subsubsection{Corte de las muestra para su observación en el microscopio electrónico de barrido (MEB).}

Para la observación de las muestras en el MEB fue necesario cortarlas. Para la realización del corte se colocó en el interior del conducto cinta de teflón, para evitar contaminar la superficie que luego se observó en el MEB. (Fig. 26)

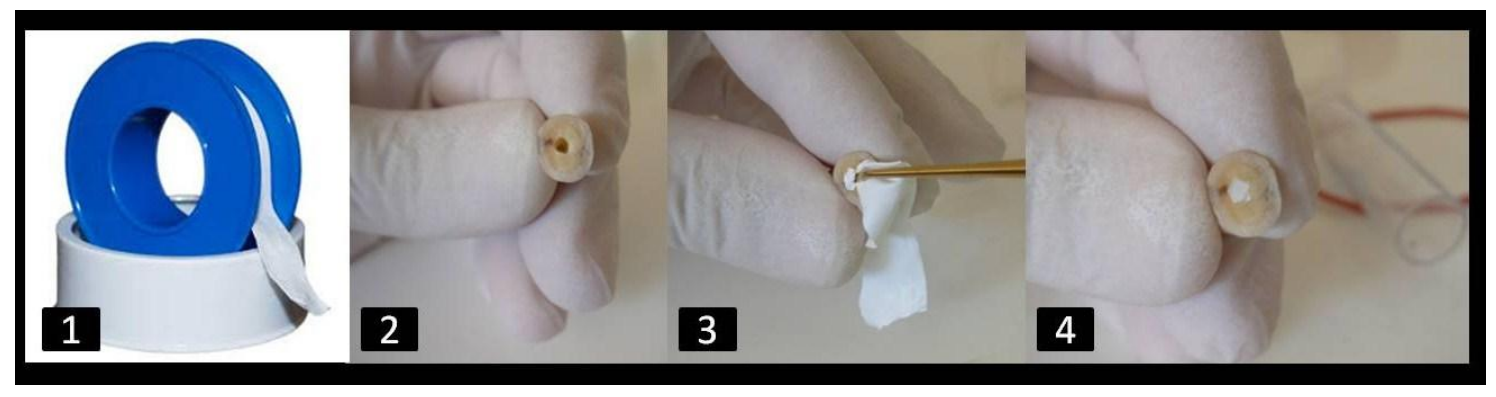

Fig.26 Preparación antes del corte de la muestra para su observación en MEB. 1 cinta de teflón, 2 conducto terminado de instrumentar y tratado, 3 empaquetamiento de la cinta de teflón, 4 teflón dentro del conducto y listo para el corte de la muestra.

Con fresa redonda $1 / 2$ se realizo una demarcación longitudinal de $9 \mathrm{~mm}$ de largo por vestibular y lingual o palatino en sentido corono-apical y una transversal sentido vestíbulo-lingual o palatino. Seguidamente, con escoplo y martillo, la muestra seccionada en dos partes iguales. (Fig. 27) 


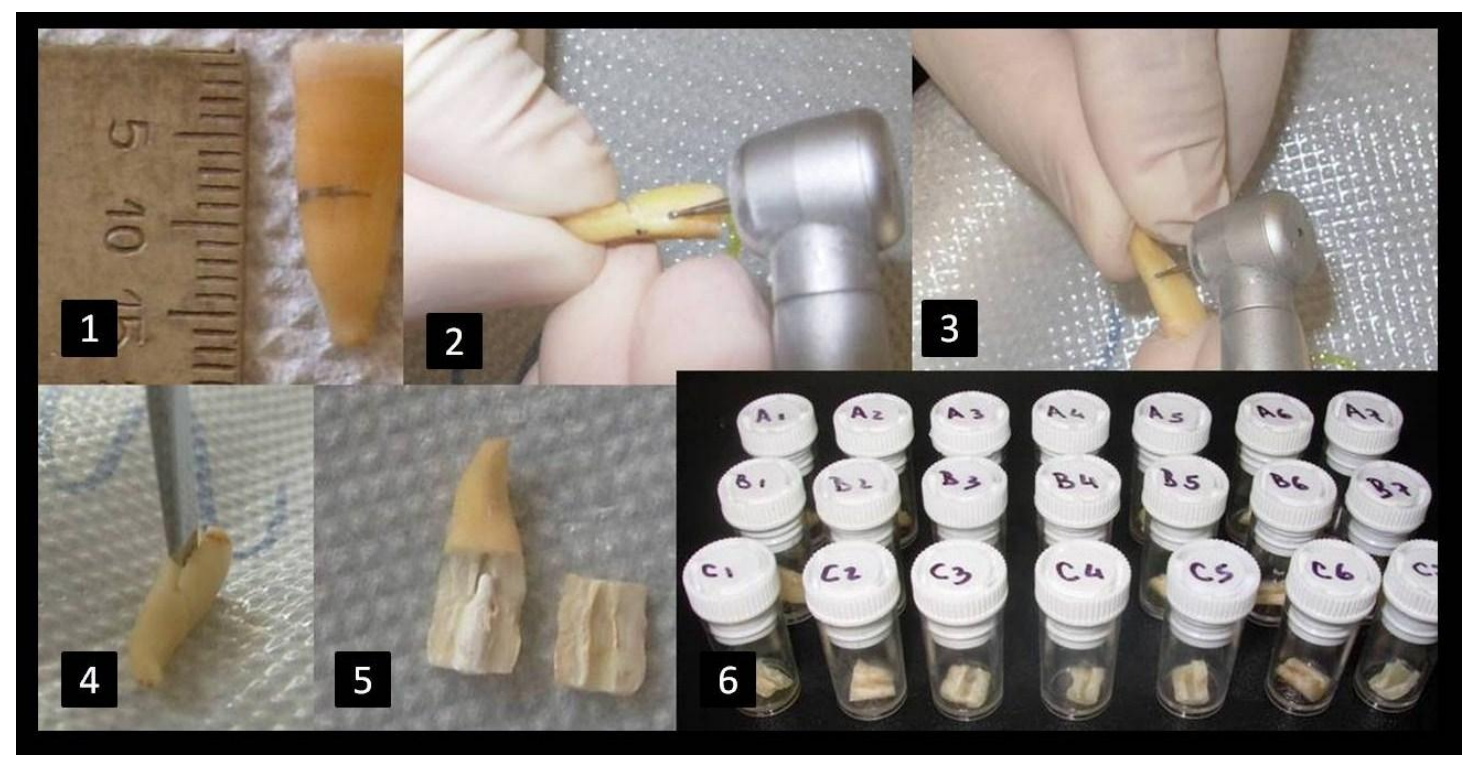

Fig.27 Corte de la muestra: 1 Se marco la raíz a los $9 \mathrm{~mm}$ en sentido corono apical para efectuar el corte. 2 Marcación del corte en sentido longitudinal con fresa redonda 1/2. 3 Marcado transversal con la misma fresa. 4 Corte con cincel y martillo. 5 La muestra queda dividida en dos partes iguales. 6 Muestras divididas según su tratamiento y almacenadas.

Como resultado quedaron 7 piezas de cada grupo divididas en mitades que se denominaron con la letra del grupo al que pertenecían asignándoles un número a cada muestra:

\section{A1 A2 A 3 A4 A5 A6 A7}

\section{B1 B2 B3 B4 B5 B6 B7}

\section{C1 C2 C3 C4 C5 C6 C7}

Una mitad de cada una de estas dos muestras fue metalizada mediante el método de sputtering dejando una capa de oro en sus superficies de 200 Ä. Posteriormente se observaron en el MEB (Phillips modelo 505). La Fig. 28 muestra el conducto preparado para el PRRF en la zona coronal, media y apical. Posteriormente se procedió a contar mediante 
una grilla milimetrada la cantidad de conductos dentinarios libres de residuos de cemento, gutapercha y barro dentinario.

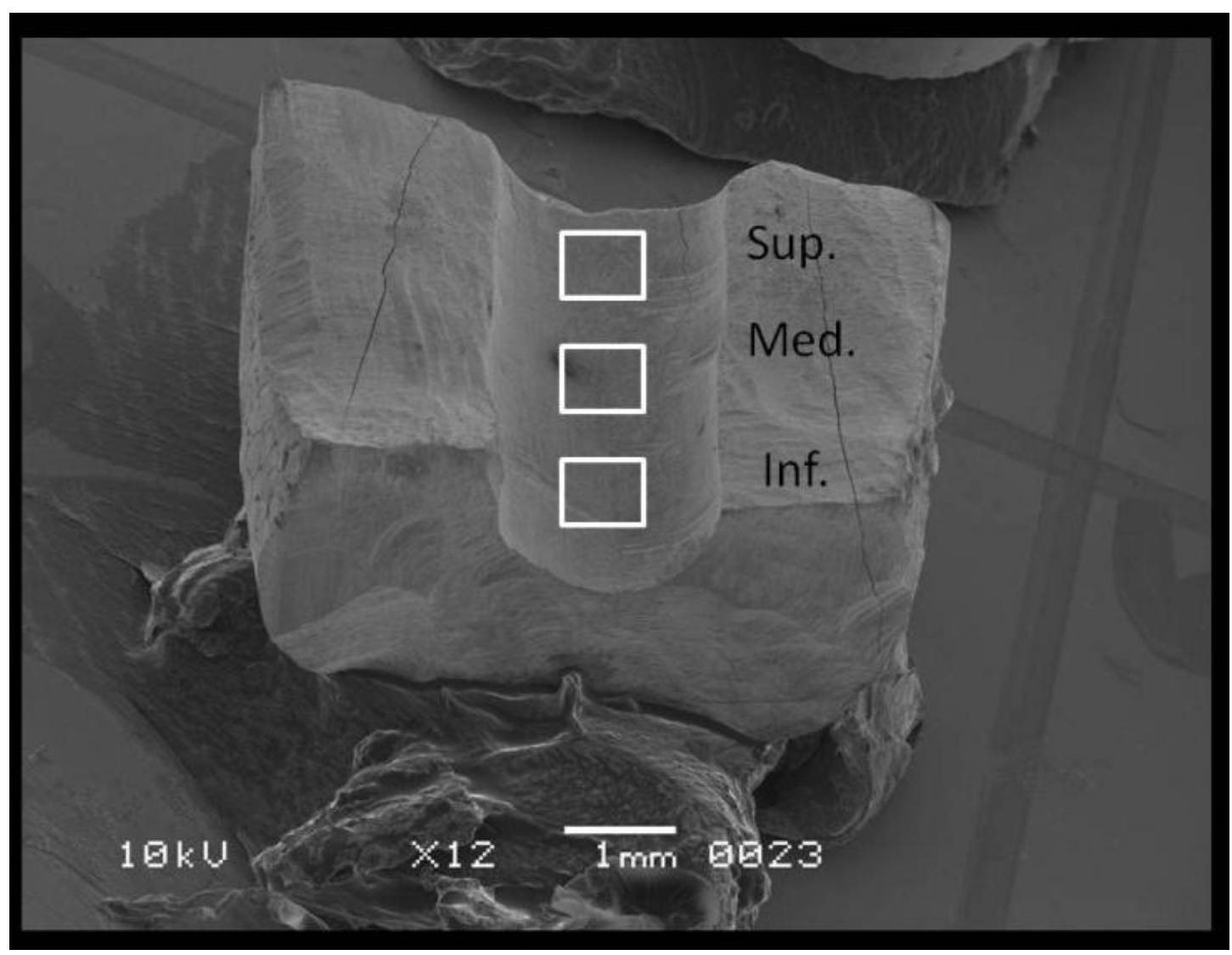

Fig.28 Microscopia panorámica donde se observan la zona superior, media e inferior que se observaran para el análisis correspondiente.

A las otras 21 mitades restantes de las muestras se les realizó un grabado con acido fosfórico al 37\% (Ultra Etch Ultradent USA) durante 10 segundos colocándolo y friccionándolo con puntas NaviTip. Luego se las lavó con agua con jeringa Luer $20 \mathrm{ml}$ y se las secó con torundas de papel absorbente. (Fig.29 y 30) 


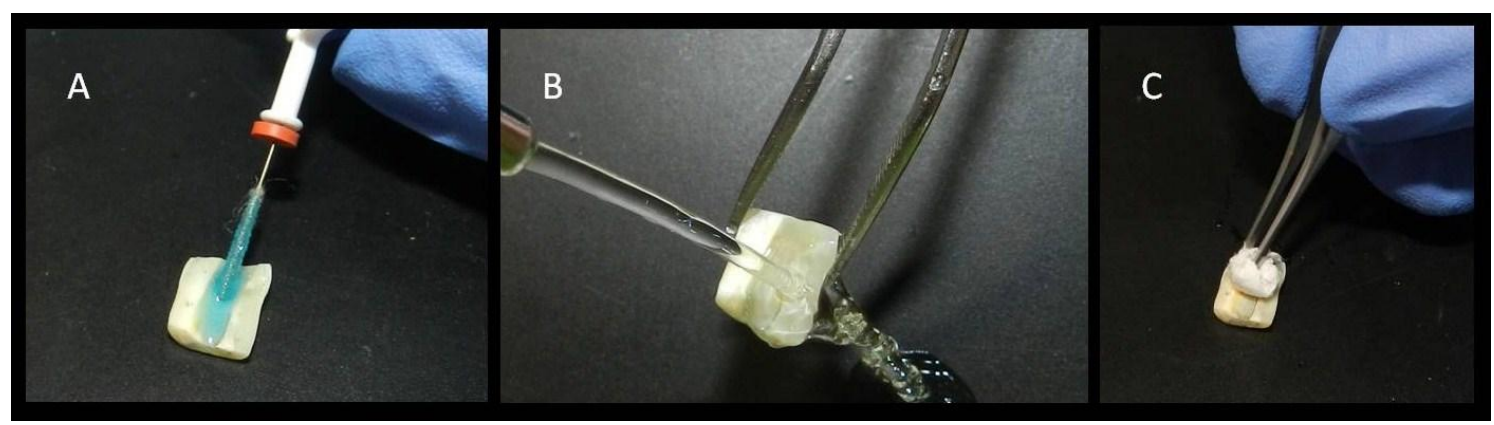

Fig. 29 A. Tratamiento con ácido fosfórico al 37\% y frotado sobre la dentina con puntas NaviTip durante 10 segundos. B. Lavado con $20 \mathrm{ml}$ de agua. C. Secado con papel absorbente.

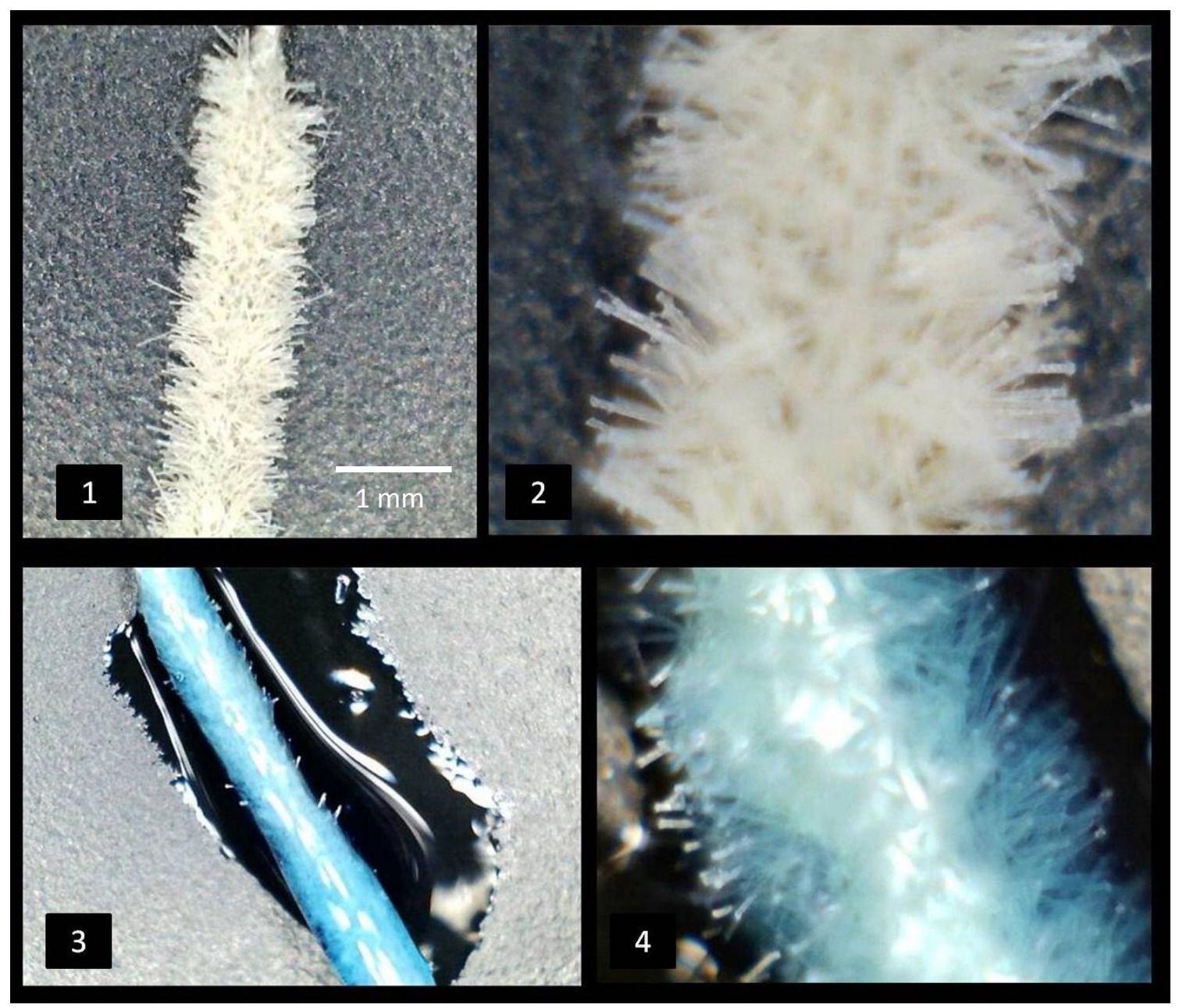

Fig.30 1 Punta NaviTip vista en una magnificación de 200\%. 2 Detalle a 600\%. Foto 3 Punta NaviTip embebida en ácido fosfórico al 37\% en una ampliación de 150\%. 4 Detalle de la foto anterior en $600 \%$.

\section{Luego de los tratamientos respectivos las piezas fueron nombradas}

como: 
D1 D2 D3 D4 D5 D6 D7 (Sin acondicionamiento de la dentina + 10 segundos de ácido fosfórico 37\% colocados con puntas NaviTip).

E1 E2 E3 E4 E5 E6 E7 (Acondicionamiento de la dentina con EDTA + 10 segundos de ácido fosfórico $37 \%$ colocados con puntas NaviTip).

F1 F2 F3 F4 F5 F6 F7 (Acondicionamiento de la dentina con alcohol yodado

+ 10 segundos de ácido fosfórico $37 \%$ colocados con puntas NaviTip).

Estas muestras fueron preparadas y visualizadas con MEB.

\subsubsection{Evaluación de los espacios vacios de cemento entre PRRF y dentina según la técnica clínica de cementación utilizada.}

Para esta evaluación se utilizaron 63 piezas humanas, con los mismos parámetros de inclusión y exclusión del punto anterior.

A las piezas se les cortó la corona $2 \mathrm{~mm}$ por encima del límite corono radicular. Se les realizó el tratamiento de conducto y su desobturación parcial en $9 \mathrm{~mm}$ con las mismas técnicas e instrumentos que en el estudio del acondicionamiento dentinario.

A 42 piezas que recibieron como medios cementantes cementos a base de resina se les limpió la superficie dentinaria utilizando la técnica de grabado con ácido fosfórico al $37 \%$ colocado y frotado contra las paredes con puntas NaviTip durante 10 segundos. Posteriormente se lavaron las muestras con agua utilizando jeringa Luer de $20 \mathrm{ml}$ y se secaron con conos de papel. 
Las 21 piezas restantes recibieron como medio cementante al ionómero vítreo, este material se une a la dentina a través de una adhesión especifica que puede verse aumentada tratando la superficie dentinaria con ácido poliacrílico al 10\% (Denton Conditioner. GC MR Japón). El mismo se aplicó con un micropincel y se dejo actuar durante 1 minuto. A continuación se lavó y se secó. Preparada la dentina se utilizó el medio cementante ketac Cem (3M Espe USA) (Fig. 31), cuya composición se detalla en la tabla siguiente.

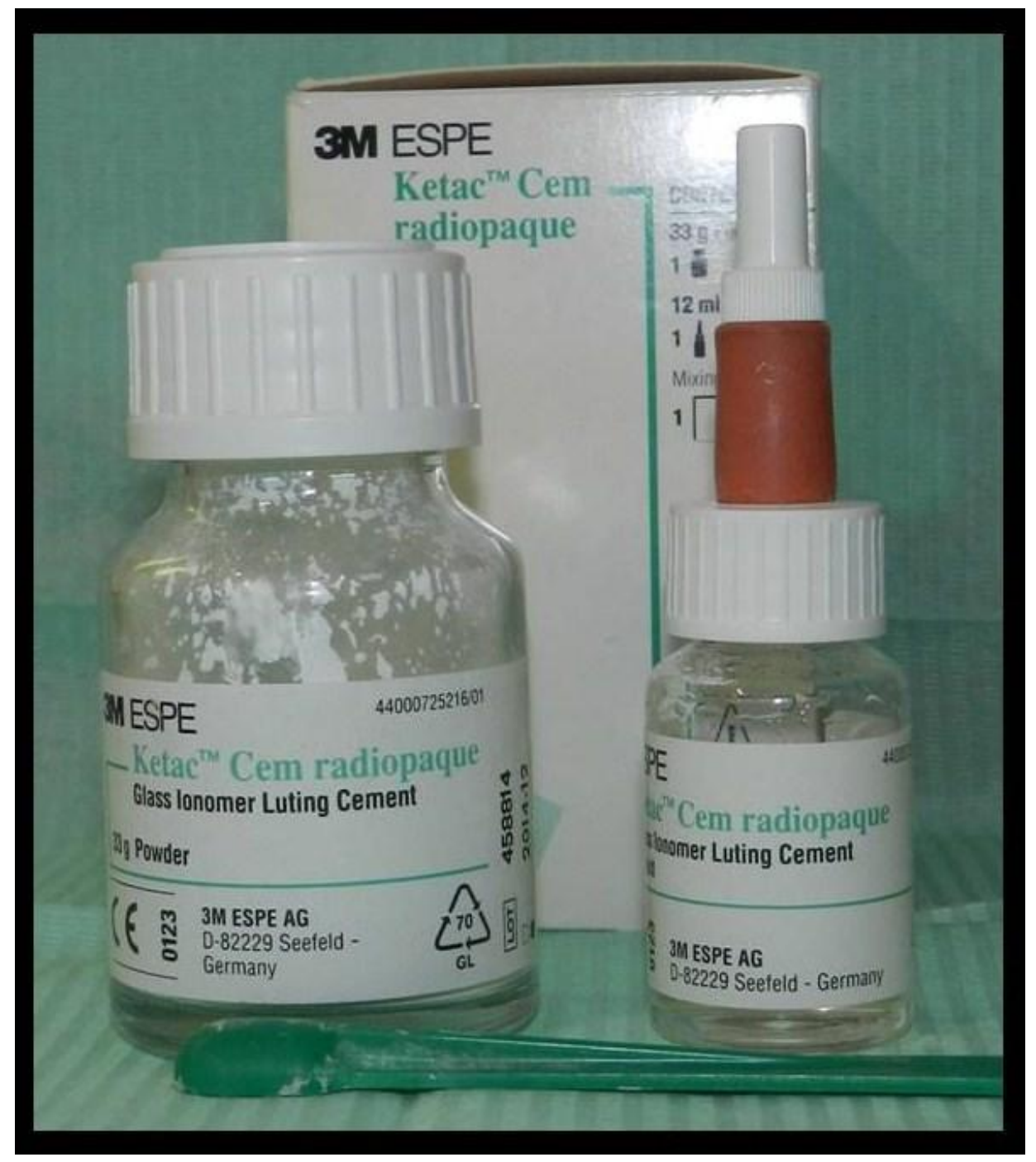

Fig. 31 Cemento ionómero vítreo KETAC CEM 3M ESPE MR 


\begin{tabular}{|c|}
\hline COMPOSICIÓN DEL IONÓMERO VITREO KETAC CEM 3M ESPE \\
\hline POLVO \\
\hline ÓXIDO DE SILICIO \\
\hline ÓXIDO DE ALUMINIO \\
\hline FLUORURO DE ALUMINIO \\
\hline FLUORURO POLIACRILICO \\
\hline \\
\hline
\end{tabular}

Para la mezcla del material se proporcionó como indica el fabricante, una medida de polvo por dos gotas de líquido. El polvo se llevó sobre el liquido todo de una vez. Se utilizó un papel satinado y una espátula de plástico. La mezcla se realizo en forma suave y abarcando la menor superficie de papel posible. El tiempo de mezcla fue de 30 segundos y el resultado final fue un material brilloso y de consistencia semi masillosa.

\subsubsection{Grupos de muestras según la técnica de cementación:}

- Grupo A: Se utilizó cemento de ionómero vítreo.

- Grupo B: Se utilizó cemento a base de resina de autocurado.

- Grupo C: Se utilizó cemento a base de resina de curado dual. 
Grupo A: Se utilizó como medio cementante al ionómero vítreo de cementado que se dividió en tres grupos de 7 piezas según cómo se colocó el cemento en el lecho para el perno.

Grupo A I: Se llevó el ionómero vítreo embadurnado en el perno.

Grupo A II: Se llevó el cemento con léntulo a baja velocidad.

Grupo A III. Se llevó el cemento con léntulo a baja velocidad y en el perno.

Grupo B: Se utilizó como medio cementante cemento a base de resina de autocurado. (C\&B BISCO MR). (Fig. 32)

Este cemento se presenta en dos pastas la base y la catalizadora que se proporcionan en una misma cantidad, se mezclan hasta obtener una pasta homogénea de color uniforme que luego lleva al conducto.

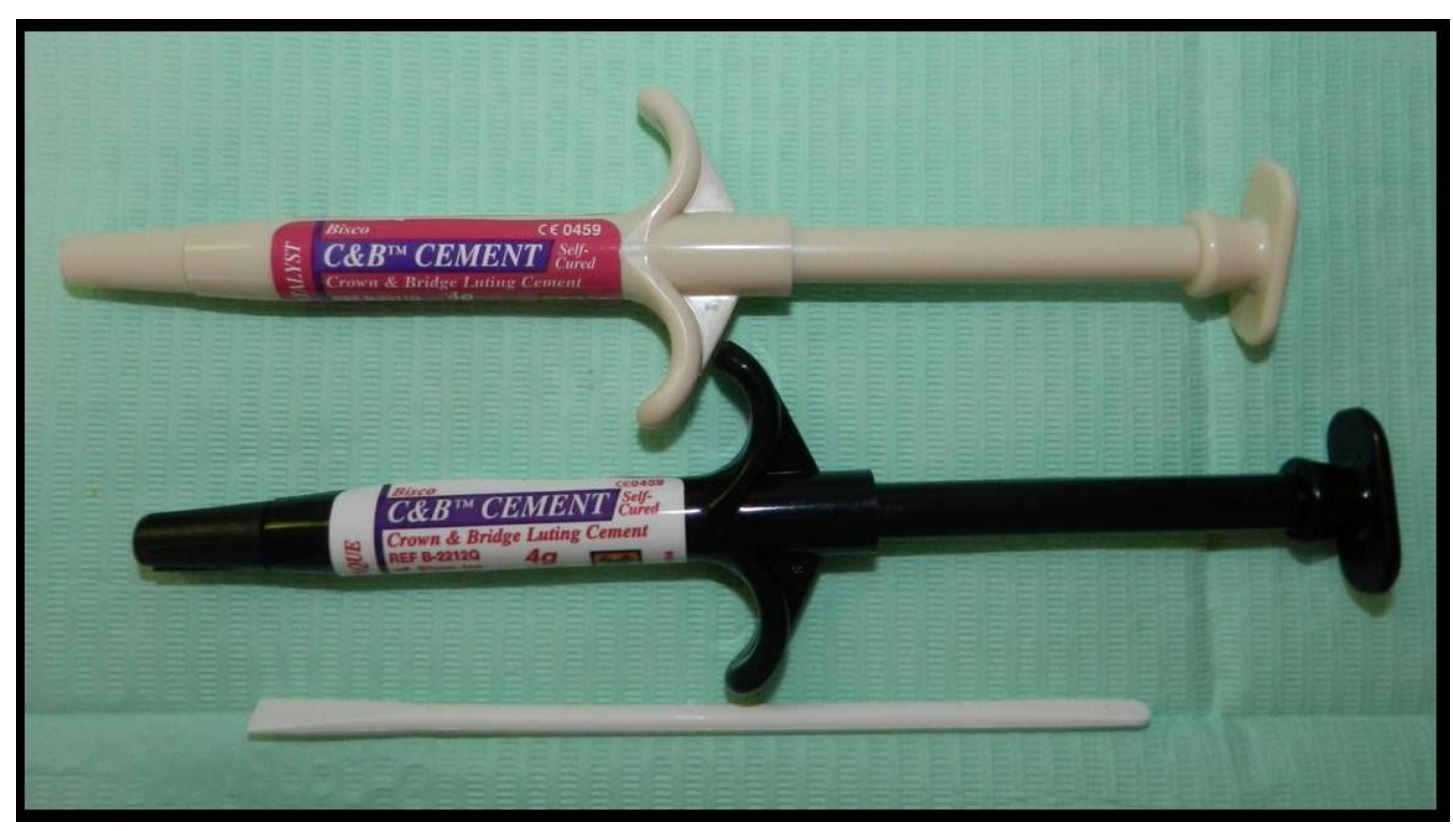

Fig.32 Cemento a base de resina de autocurado C\&B CEMENT ${ }^{\text {MR }}$ 
Antes de colocar el cemento se impregnó a la dentina con adhesivo dentinario de $5^{\circ}$ generación, el Single bond (3M USA) con un micropincel, este debe ser lo suficientemente pequeño para llegar al fondo del conducto radicular remodelado luego se fotopolimerizó por 20 segundos (Fig.33).

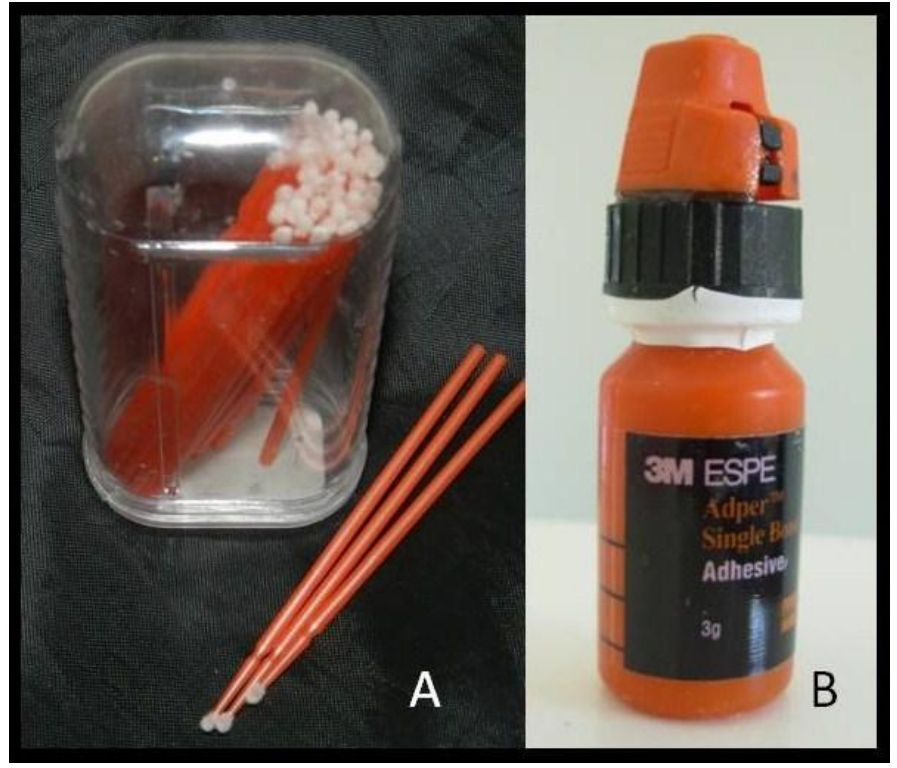

Fig. 33 Foto A Micropinceles utilizados para la colocación del adhesivo. Foto B Adhesivo monocomponente single bond $3 M \mathrm{MSA}^{\mathrm{MR}}$

Las muestras del grupo B se subdividieron en tres grupos según cómo se llevó el cemento al lecho.

Grupo Bl: Se llevó el cemento a base de resina de autocurado embadurnando el perno.

Grupo BII: Se llevó el cemento a base de resina de autocurado con lentulo a baja velocidad.

Grupo BIII: Se llevó el cemento a base de resina de autocurado con lentulo a baja velocidad y en el perno. 
Una vez colocado el PRRF se le ejerció cierta presión durante 10 segundos, con un pincel se retiró el exceso y se esperó el endurecimiento del cemento.

Grupo C: Se utilizó como medio cementante cemento a base de resina de curado dual Enforce DENTSPLY ${ }^{\text {MR }}$ Fig. 34

Este cemento se presenta en pasta base y catalizadora que se dispensó en igual cantidad y se mezcló hasta obtener una pasta homogénea.

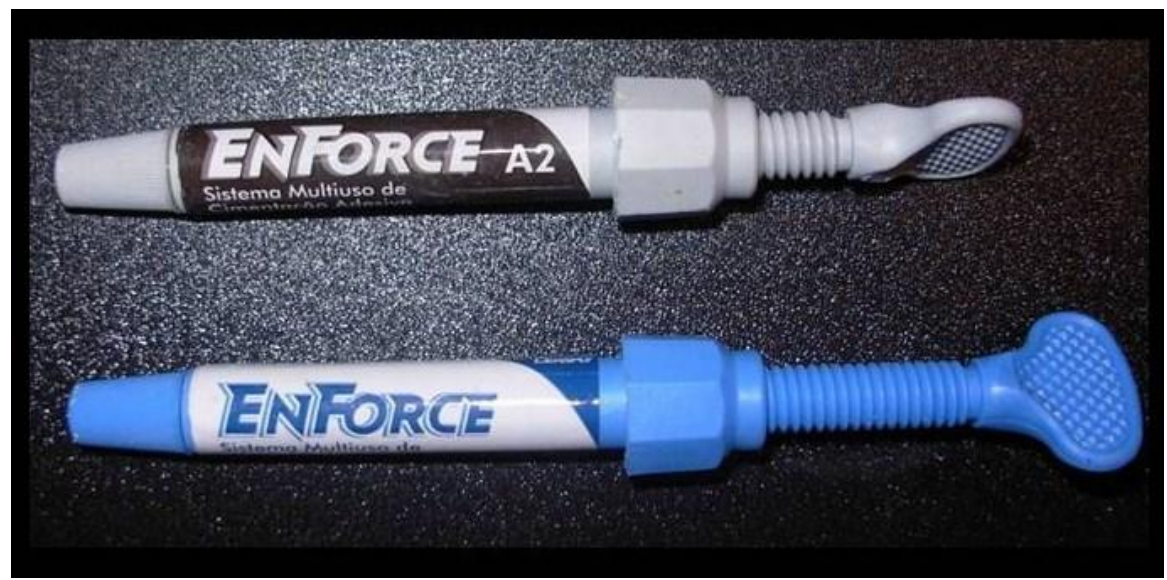

Fig. 34 Cemento a base de resina de curado dual Enforce Dentsply MR

A la dentina se la impregnó con adhesivo dentinario Single bond (3M USA) con un micropincel y se fotopolimerizó por 20 segundos. Según cómo se llevó el cemento al lecho y subdividieron en:

Grupo Cl: Se llevó el cemento a base de resina de curado dual embadurnando el perno. 
Grupo CII: Se llevó el cemento a base de resina de curado dual con lentulo a baja velocidad.

Grupo CIII: Se llevó el cemento a base de resina de curado dual con lentulo a baja velocidad y en el perno.

Por último asentados los pernos se fotopolimerizó el cemento con lámpara de luz alógena durante 90 segundos.

Se utilizaron PRRF marca Exacto Angelus ${ }^{\mathrm{MR}}$ Brasil (Fig35). Dichos pernos Presentan en porcentaje en peso, un $80 \%$ de fibras de vidrio y un $20 \%$ de resina epoxi. Muestran una forma cilíndrico - cónica y son buenos conductores de la luz de fotopilimarización.

Los PRRF se limpiaron con ácido fosfórico al $37 \%$ durante 30 segundos, luego se los lavó para retirar el ácido y se los mojó con alcohol y por último se los secó con aire limpio y seco.

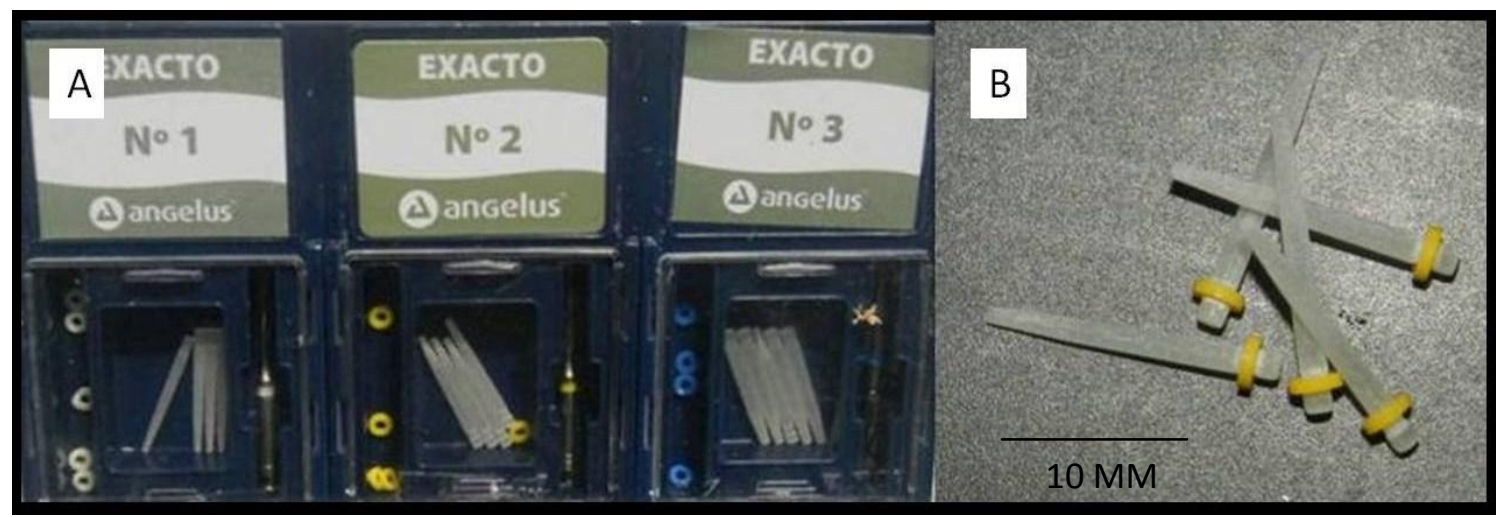

Fig. 35 A: Presentación comercial del PRRF EXACTO Angelus ${ }^{\mathrm{MR}}$ en tres medidas $\mathrm{N}^{\circ} 1,2$ Y 3 .B: Vista en detalle de los pernos translucidos con forma cónica.

Se cortaron los pernos al ras del remanente coronario en todas las muestras con piedra troncocónica y se pulieron con discos de grano medio y fino. 
Los ápices de las muestras de los tres grupos se sellaron con ionómero vítreo de obturación y todas las muestras fueron sometidas de acuerdo a las normas ISO 11405 al total de 300 termociclajes en temperaturas de $5^{\circ} \mathrm{C}$ y $60^{\circ} \mathrm{C}$ manteniendo las muestras en cada baño durante 30 segundos con tiempo de un pasaje a otro de 10 segundos. Dicho procedimiento se realizó para simular lo mejor posible lo que sucede en la cavidad bucal con respecto a los cambios de temperatura que ocurren al ingerir alimentos ${ }^{132-18-81}$.

Las piezas dentarias se cortaron con un disco de diamante a baja velocidad, con refrigeración acuosa, en sentido longitudinal, una vez seccionados se procedió a grabar con acido fosfórico las interfaces a analizar durante 5 segundos y se las limpió con ultrasonido durante 10 minutos con el fin de eliminar todo resto de los granos del disco de corte y obtener una mejor visualización.

Mediante la observación microscópica se detectaron los espacios vacíos presentes en las interfases del cemento, entre el poste y el conducto radicular. Para la enumeración se dividió en tercio superior, medio e inferior del conducto y se marcaron en un gráfico los espacios vacios en cada sección del diente.

\subsubsection{Estudio de la filtración marginal (Penetración de un colorante)}

Para este estudio fueron utilizadas 21 piezas dentarias humanas con los mismos requisitos de inclusión y exclusión que en los estudios anteriores. Se les realizó el tratamiento endodóntico y la remodelación de los conductos 
para recibir los PRRF de igual manera que en los demás experimentos realizados con anterioridad.

Se dividieron las muestras al azar en tres grupos de 7 cada uno y se los rotuló en grupos según el grado de filtración marginal (FM).

(FMA, FMB y FMC):

Grupo FMA: se cementaron los PRRF con ionómero vítreo de cementación llevado con léntulo y cargado en el perno. Muestras (FMA, FMA2, FMA3, FMA4, FMA5, FMA6 y FMA7)

Grupo FMB: se cementaron los PRRF con cemento a base de resina de autocurado llevado con léntulo y cargado en el perno. Muestras (FMB1, FMB2, FMB3, FMB4, FMB5, FMB6 y FMB7).

Grupo FMC: se cementaron los PRRF con cemento a base de resina de curado dual llevado con léntulo y cargado en el perno. Muestras (FMC1, FMC2, FMC3, FMC4, FMC5, FMC6 y FMC7).

A todas las piezas se les construyó un muñón con resina hibrida 3M z250 y se les confeccionó una corona de acrílico donde se busco cierre marginal, de esta manera se buscó imitar el periodo de provicionalización en clínica.

A todas las muestras se les selló el ápice radicular con ionómero vítreo de obturación para impedir la penetración del colorante. Todas las piezas fueron sometidas a un termociclaje como indican las normas ISO 11405. Por último se procedió a pintar toda la superficie externa de las piezas con laca en colores diferentes. 
Rosa para el grupo FMA, verde para el grupo FMB y azul para el grupo

FMC, dejando libre todo el hombro donde apoya la corono de acrílico. (Fig. 36).

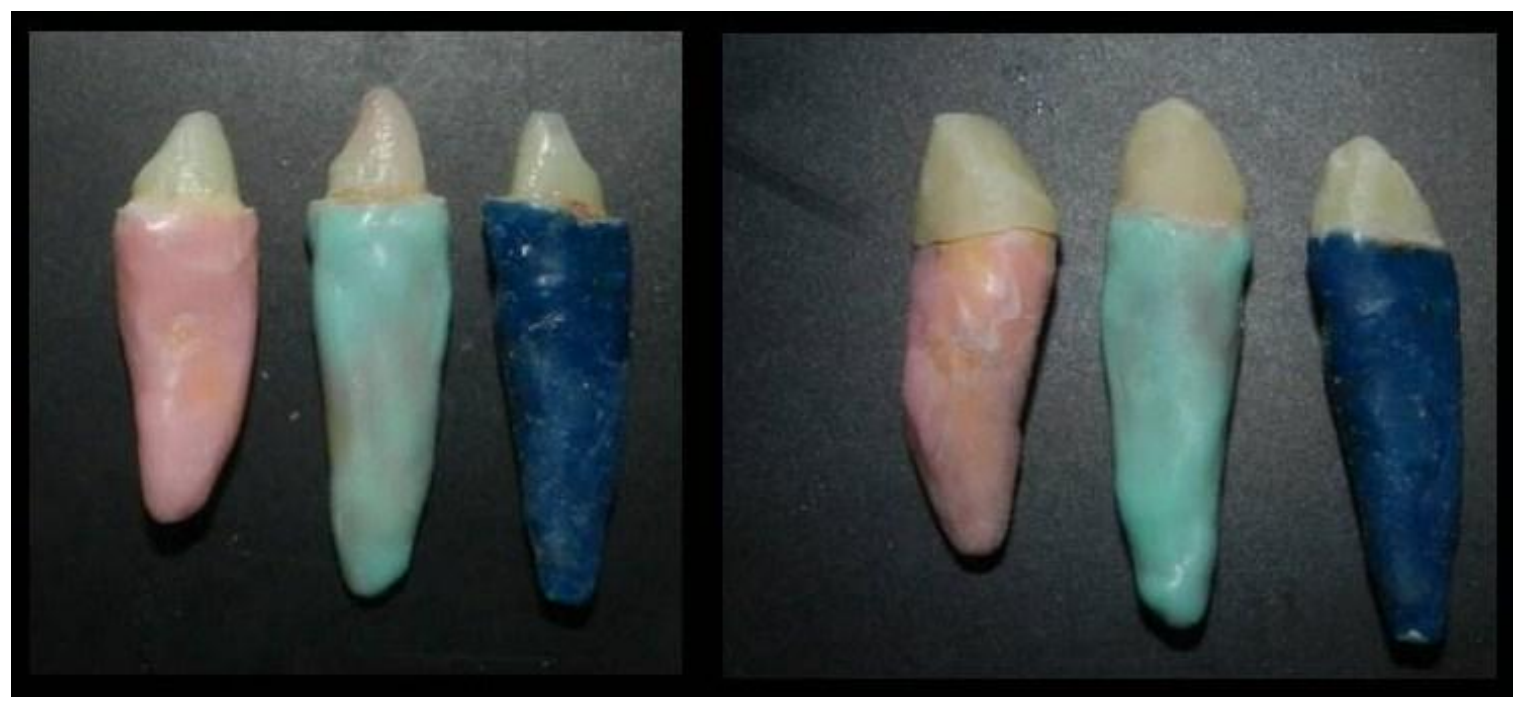

Fig.36 Derecha la confección de los muñones. Izquierda coronas de acrílico provisorias, para los tres grupos. Grupo A rosa cemento de ionómero vítreo Grupo B verde cemento a base de resina de autocurado. Grupo C azul cemento a base de resina de curado dual.

Los distintos grupos se sumergieron en azul de metileno al $2 \%$ durante 15 días para evaluar la filtración del colorante ${ }^{120}$. (Fig. 37) y luego se los mantuvo secos a temperatura ambiente. 


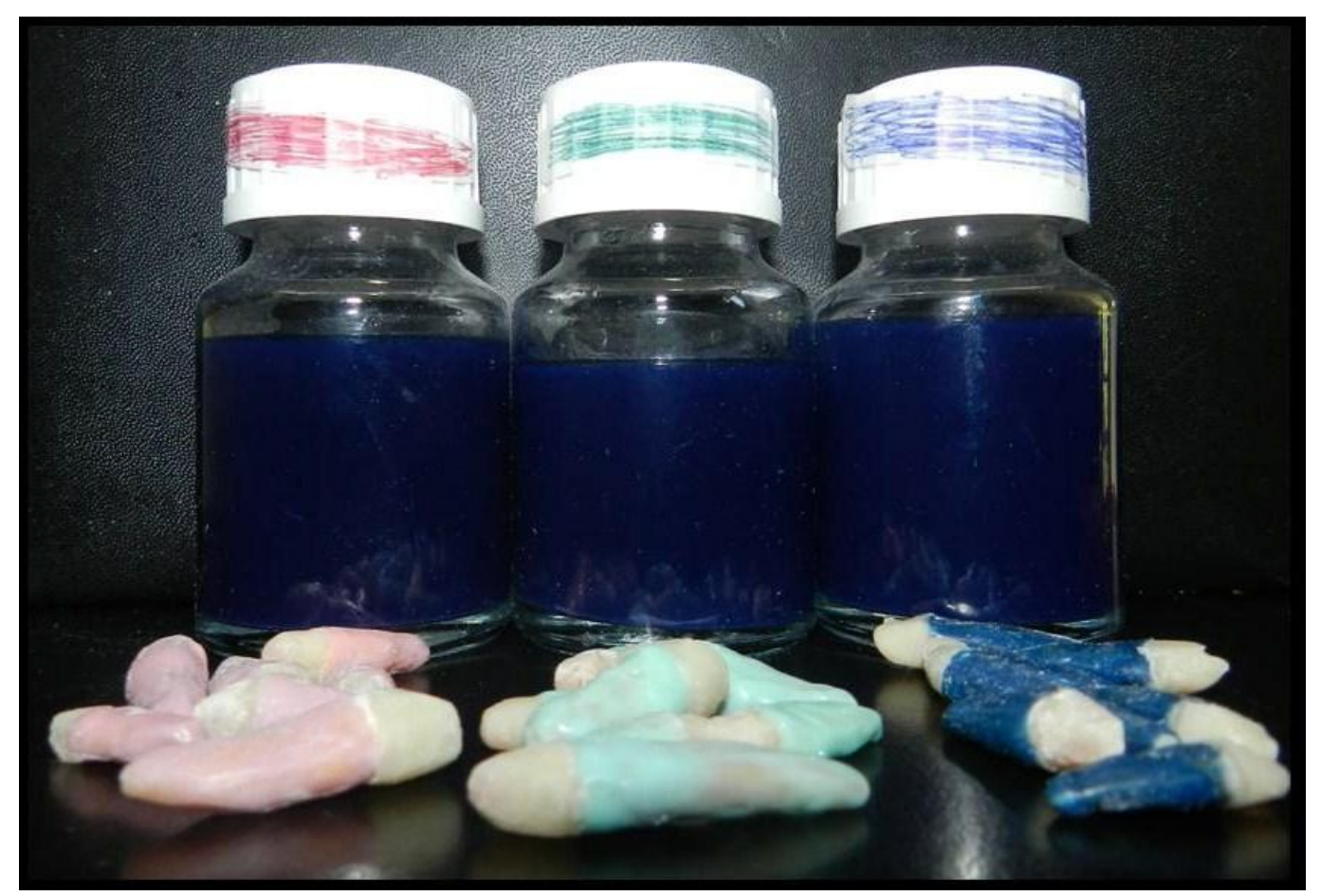

Fig. 37 las muestras de cada grupo se colocaron en recipientes separados con azul de metileno al $2 \%$ durante 7 días

24 horas antes del estudio microscópico las muestras se cortaron con discos de carburo, a baja velocidad y en forma longitudinal por el centro del PRRF.

Los cortes se colocaron bajo ultrasonido durante 10 minutos (lavadora Biosonic UC50 Coltene Suiza) para limpiar las impurezas dejadas por el disco de corte.

Las muestras se observaron y evaluaron con microscopio digital (USB ROHS China) (Fig. 38). 


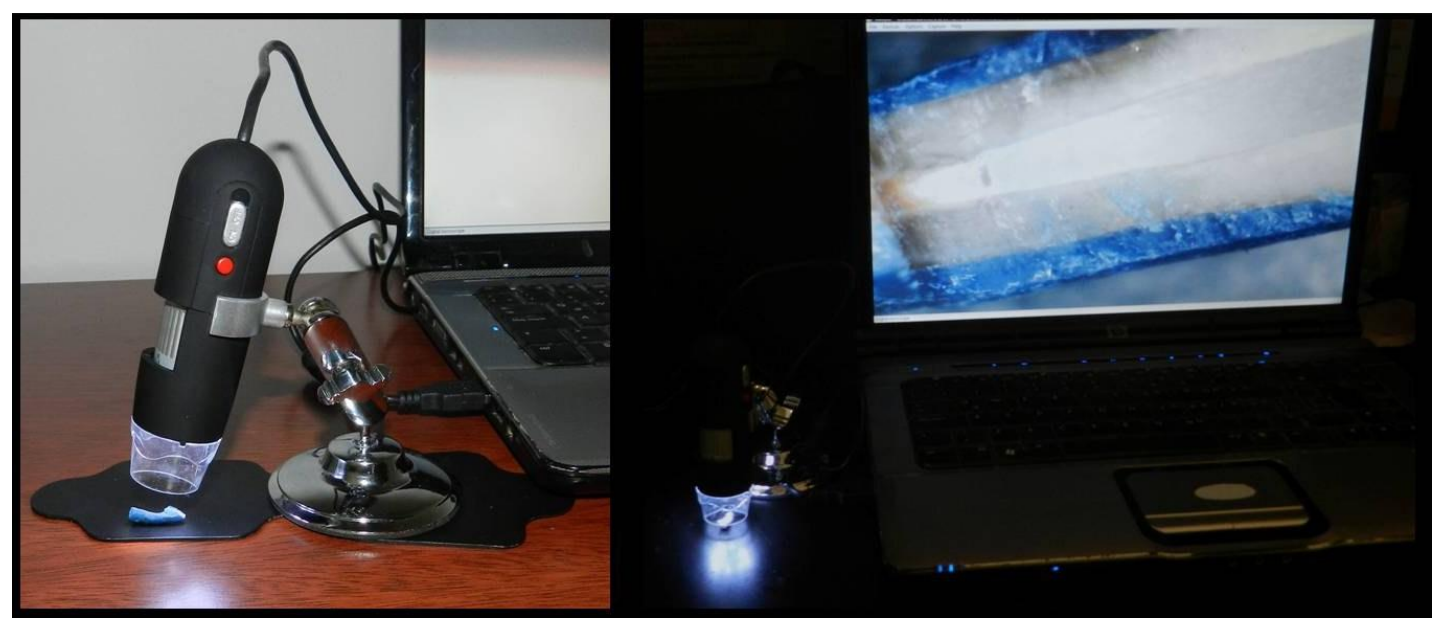

Fig.38 Microscopio digital USB ROHS (Izquierda). Imagen digital obtenida en la notebook. (Derecha).

Para la valoración de la filtración se utilizó la siguiente clasificación:

Grado 0 = no penetró el colorante.

Grado $1=$ el colorante invade hasta el tercio cervical

Grado 2 = el colorante invade hasta el tercio medio

Grado $3=$ el colorante invade hasta el tercio apical sin invadir el material de obturación endodóntico.

Grado 4= el colorante invade hasta el tercio apical invadiendo el material de obturación endodóntico.

\subsubsection{Interfases PRRF medio cementante y dentina mediante} análisis MEB.

Para la evaluación de las interfases por MEB se utilizaron 21 piezas humanas con iguales parámetros de inclusión y exclusión que en los 
experimentos anteriores. Se les realizaron los tratamientos endodónticos y la remodelación del conducto siguiendo los protocolos experimentales anteriores. Posteriormente se los dividió al azar en tres grupos (1, 2 y 3$)$ de 7 muestras cada uno $(A, B, C, D, E, F, G)$ y se les cortó la corona a $2 \mathrm{~mm}$ por arriba del límite corono radicular.

Grupo1: se cementaron los pernos con ionómero vítreo utilizando léntulo y embadurnado en el PRRF.

Los pernos se cortaron al ras en la parte cervical. Se conformaron las muestras 1A 1B 1C 1D 1E 1F $1 \mathrm{G}$.

Grupo 2: se cementaron los pernos con cemento a base de resina de autocurado con igual protocolo que en los ensayos anteriores. Se conformaron las muestras 2A 2B 2C 2D 2E $2 F 2$ G.

Grupo 3: se cementaron los pernos con cemento a base de resina de curado dual con igual protocolo que en los ensayos anteriores. Se conformaron las muestras 3A 3B 3C 3D 3E 3F 3G.

Todas las muestras se sometieron a termociclaje como en las experiencias anteriores.

El total de las muestras se cortaron con discos de carburo, a baja velocidad y en forma transversal dejando a la raíz segmentada en tres.

A continuación las muestras fueron sometidas a la acción de ácido fosfórico al $37 \%$ durante 3 segundos para limpiar las muestras luego del corte y mejorar la visualización. 
Seguidamente se las coloco en lavadora de ultrasonido Biosonic uc50 (Coltene Suiza) durante 10 minutos, con la finalidad de eliminar posibles restos pertenecientes al disco de corte.

Las muestras se guardaron secas y a temperatura ambiente. Previo al análisis microscópico las muestras se metalizaron con oro método de sputtering que dejo una capa de oro de $200 A ̈$. Esta metalización requirió de muestras libres de humedad. EI MEB utilizado fue marca Phillips 505.

\subsubsection{Formación de tags en la adhesión de PRRF. Análisis mediante MEB.}

Para este experimento se utilizaron 21 piezas dentarias humanas con los mismos parámetros de inclusión y exclusión que los anteriores experimentos.

Se conformaron tres grupos (I, II y III)

Grupo I: se cementaron los pernos con ionómero vítreo utilizando léntulo y cargado en el PRRF. Se conformaron las muestras IA, IB, IC, ID, IE, IF, IG.

Grupo II: se cementaron los pernos con cemento a base de resina de autocurado con igual protocolo que en los ensayos anteriores. Se conformaron las muestras IIA, IIB, IIC, IID, IIE, IIF, IIG.

Grupo III: se cementaron los pernos con cemento a base de resina de curado dual con igual protocolo que en los ensayos anteriores. Se conformaron las muestras IIIA, IIIB, IIIC, IIID, IIIE, IIIF, IIIG. 
Todas las muestras se sometieron a termociclaje como en las experiencias anteriores.

Cada muestra se colocó en un recipiente individual que contenía ácido clorhídrico al $30 \%$ durante 4 días, y luego en hipoclorito de sodio al $5 \%$ durante 10 minutos. (Fig. 39).

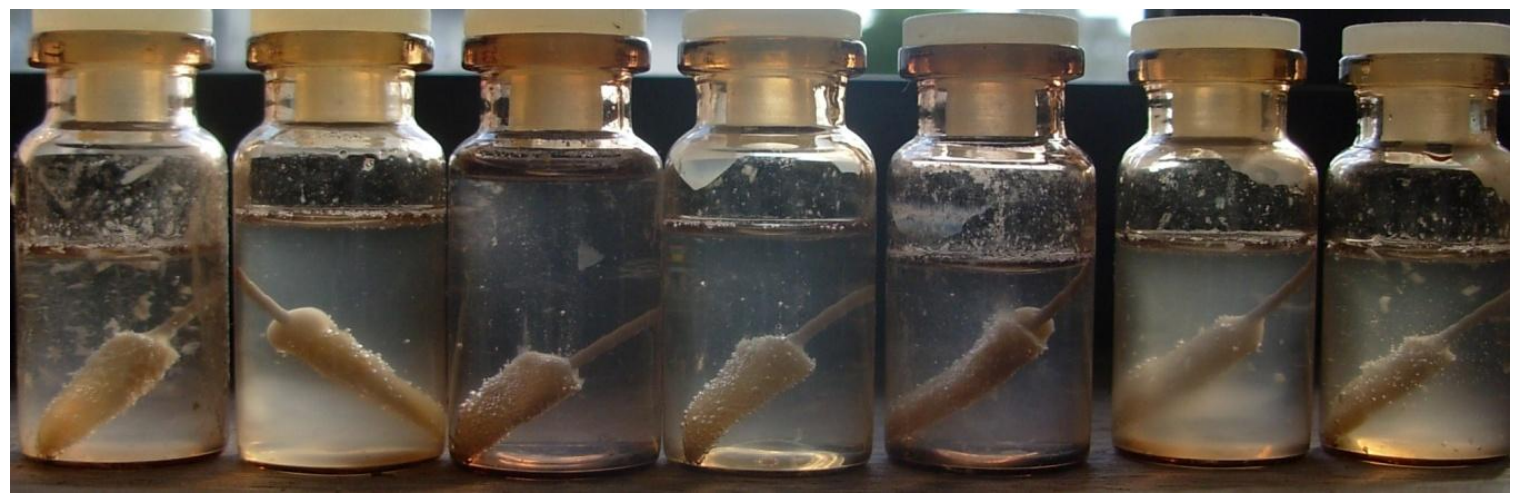

Fig.39 Muestras sumergidas en ácido clorhídrico al 30\%

Luego se siguió la secuencia siguiente: primeramente se disolvió el sustrato dental, luego se lavó las muestras con agua y se las dejó secar a temperatura ambiente. Posteriormente se las sometió a un baño de oro de 200Ä y finalmente se las observó mediante MEB (fig. 40). 


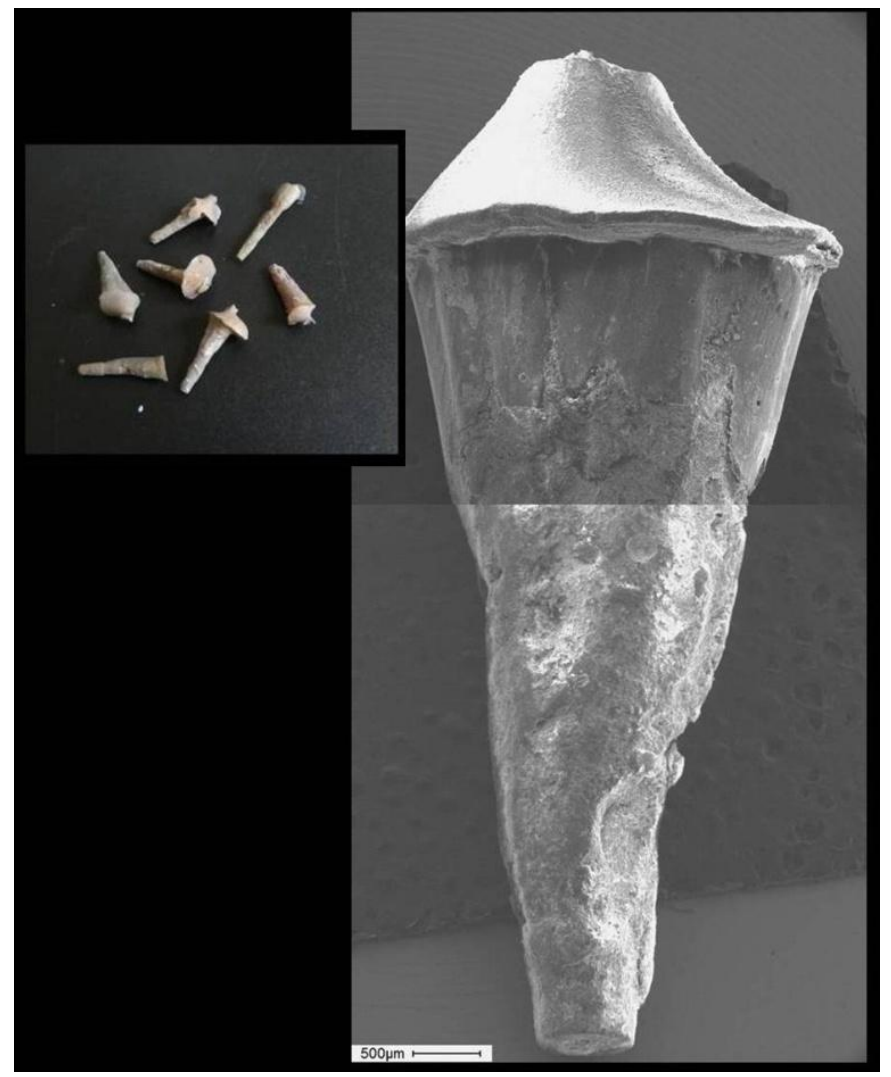

Fig.40 Microfotografía obtenida después de disolverse el sustrato dental y luego de ser metalizadas.

La valoración se realizo observando la superficie del perno y clasificándola según la presencia y ausencia de tags y el tamaño de los mismos. Se identificaron 3 grados

$0=$ no se detectan Tags.

$1=$ presencia de Tags cortos menores a 10 micrones.

$2=$ presencia de Tags largos mayores a los 10 micrones. 


\subsection{ANALISIS ESTADISTICO}

Para cada experimento se realizó el análisis estadístico sobre los resultados utilizando el análisis de varianza ANOVA. Por otra parte, se realizó la comparación de medias mediante el test Tukey determinándose el valor de $p \quad(p<0.001$ diferencia altamente significativa, $p<0.01$ muy significativa, $p<0.05$ significativa). 
4. RESULTADOS 


\subsection{Resultados de la evaluación del acondicionamiento de la dentina en el canal radicular para recibir un PRRF.}

Como ya se mencionó en materiales y métodos se contabilizaron los conductos dentinarios libres de barro dentinario, cemento y restos de gutapercha.

En la Tabla 1 se muestra la cantidad de conductos libres de residuo en cada grupo estudiado, donde se destaca la elevada contaminación producida en las paredes dentinarias al realizar la desobturación y remodelación de los conductos grupo $(\mathrm{A})$

También puede notarse que la descontaminación con alcohol yodado sólo produjo la limpieza de los restos de gutapercha y cemento pero que no modificó al barro dentinario, grupo (C), el acto seguido de utilizar ácido fosfórico provocó modificaciones superficiales, pero no sustanciales; grupo (F). En forma similar la utilización de EDTA solo que mejoró las anteriores pero no de forma suficiente, grupo (B). Por el contrario, el cambio se hace notorio al tratar la dentina con EDTA seguido de ácido fosfórico; grupo (E) o con ácido fosfórico solo; grupo (D). 


\section{TABLA 1}

\begin{tabular}{|c|c|c|c|c|c|c|}
\hline \multicolumn{7}{|c|}{$\begin{array}{l}\text { EVALUACION DEL ACONDICIONAMIENTO DE LA DENTINA EN EL CANAL RADICULAR PARA } \\
\text { RECIBIR UN PRRF (Enumeración de conductillos libres de residuo en los grupos estudiados) }\end{array}$} \\
\hline \multicolumn{7}{|c|}{ DENTINA SIN ACONDICIONAMIENTO ( GRUPO A) } \\
\hline MUESTRA A 1 & MUESTRA A2 & MUESTRA A3 & MUESTRA A4 & MUESTRA A5 & MUESTRA A6 & MUESTRA A7 \\
\hline 3 & 5 & 1 & 2 & 6 & 0 & 0 \\
\hline \multicolumn{7}{|c|}{ ACONDICIONAMIENTO DE LA DENTINA CON ACIDO FOSFORICO (GRUPO D) } \\
\hline MUESTRA D1 & MUESTRA D2 & MUESTRA D3 & MUESTRA D4 & MUESTRA D5 & MUESTRA D6 & MUESTRA D7 \\
\hline 424 & 399 & 385 & 524 & 652 & 607 & 491 \\
\hline \multicolumn{7}{|c|}{ ACONDICIONAMIENTO DE LA DENTINA CON EDTA (GRUPO B) } \\
\hline MUESTRA B1 & MUESTRA B2 & MUESTRA B3 & MUESTRA B4 & MUESTRA B5 & MUESTRA B6 & MUESTRA B7 \\
\hline 105 & 80 & 96 & 121 & 92 & 110 & 103 \\
\hline \multicolumn{7}{|c|}{ ACONDICIONAMIENTO CON EDTA MÁS ACIDO FOSFORICO (GRUPO E) } \\
\hline MUESTRA E1 & MUESTRA E2 & MUESTRA E3 & MUESTRA E4 & MUESTRA E5 & MUESTRA E6 & MUESTRA E7 \\
\hline 290 & 396 & 368 & 551 & 297 & 376 & 359 \\
\hline \multicolumn{7}{|c|}{ ACONDICIONAMIENTO DE LA DENTINA CON ALCOHOL YODADO (GRUPO C) } \\
\hline MUESTRA C1 & MUESTRA C2 & MUESTRA C3 & MUESTRA C4 & MUESTRA C5 & MUESTRA C6 & MUESTRA C7 \\
\hline 1 & 14 & 2 & 5 & 5 & 5 & 4 \\
\hline \multicolumn{7}{|c|}{ ACONDICIONAMIENTO DE LA DENTINA CON ALCOHOL YODADO MÁS ACIDO FOSFORICO (GRUPOF) } \\
\hline MUESTRA F1 & MUESTRA F2 & MUESTRA F3 & MUESTRA F4 & MUESTRA F5 & MUESTRA F6 & MUESTRA F7 \\
\hline 190 & 231 & 89 & 120 & 200 & 231 & 214 \\
\hline
\end{tabular}


En la Tabla 2 se muestran los resultados de la evaluación del acondicionamiento de la dentina en el canal radicular para recibir un PRRF.

\section{TABLA 2}

\begin{tabular}{|llc|c|c|}
\hline \multicolumn{5}{|c|}{ RESULTADOS DEL ACONDICIONAMIENTO } \\
DENTINARIO
\end{tabular}

$\mathrm{P}<0.001$

Cuando se comparan los números de conductillos abiertos para los distintos acondicionamientos dentinarios los mismos se pueden ordenar en forma creciente como: $A \cong C<B<F<E<D$.

Es decir que existe una diferencia significativa entre todos los grupos, menos en el caso del grupo A (que no recibió tratamiento) y el grupo $\mathrm{C}$ (que se trato con alcohol yodado), que se comportaron de igual forma. El que produjo el mejor acondicionamiento fue el grupo donde se usó sólo ácido fosfórico colocado y frotado con las puntas NaviTip durante 10 segundos (D), este tratamiento superó al de EDTA + acido fosfórico (E), y éste fue mejor que el del alcohol yodado más ácido fosfórico $(F)$, que aventajó a su vez al resultado obtenido con EDTA solo (B). (Gráfico 1). 


\section{GRÁFICO 1}

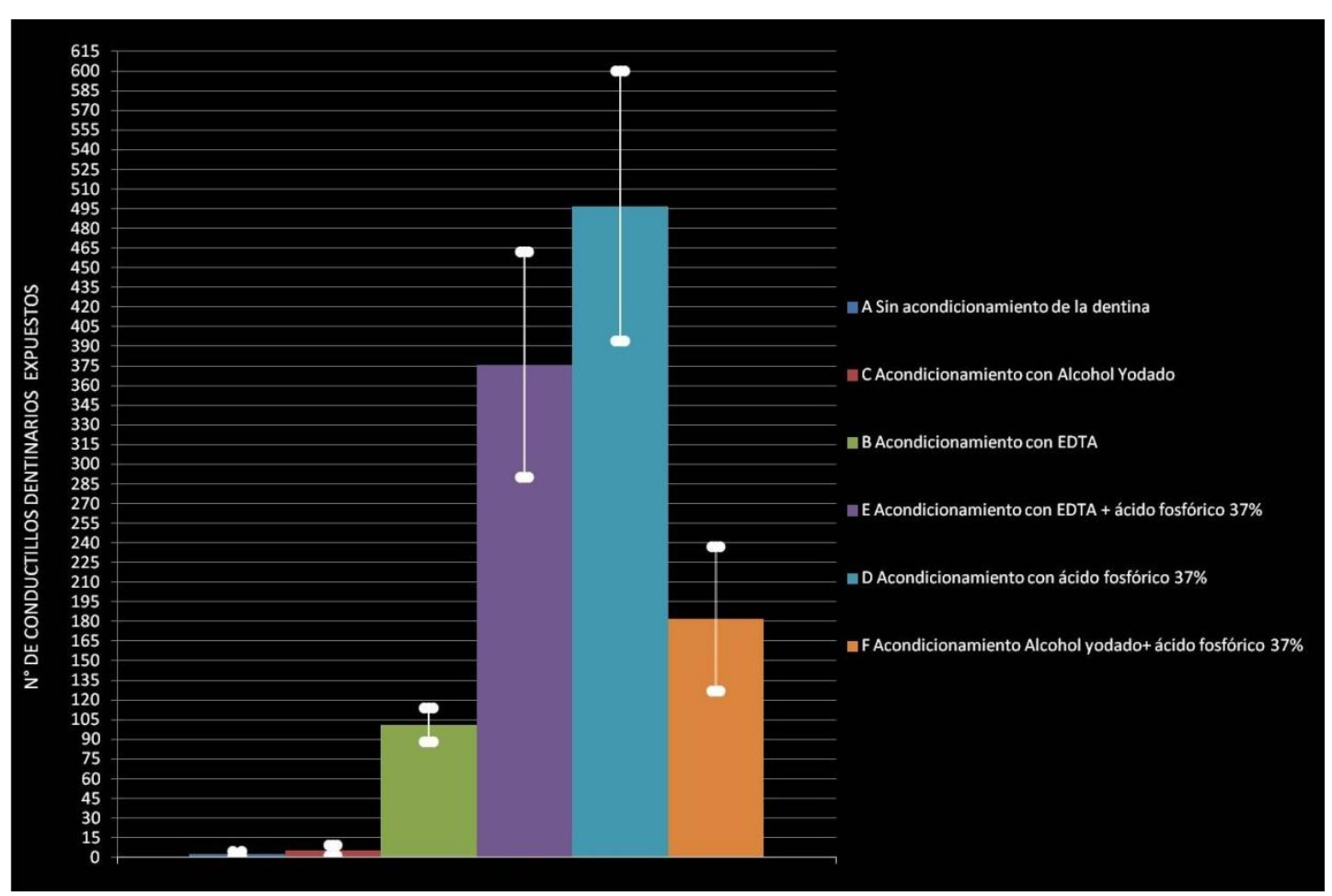

Gráfico 1. Número de conductillos dentinarios libres de contaminación para cada uno de los acondicionamientos utilizados.

La Figura 41 nos muestra microfotografias de cuatro muestras de conductos desobturados y remodelados sin recibir ningun tipo de acondicionamiento en la dentina. Se puede observar en las microfotografías el barro dentinario, restos de cemento y gutapercha que obliteran los conductillos dentinarios 


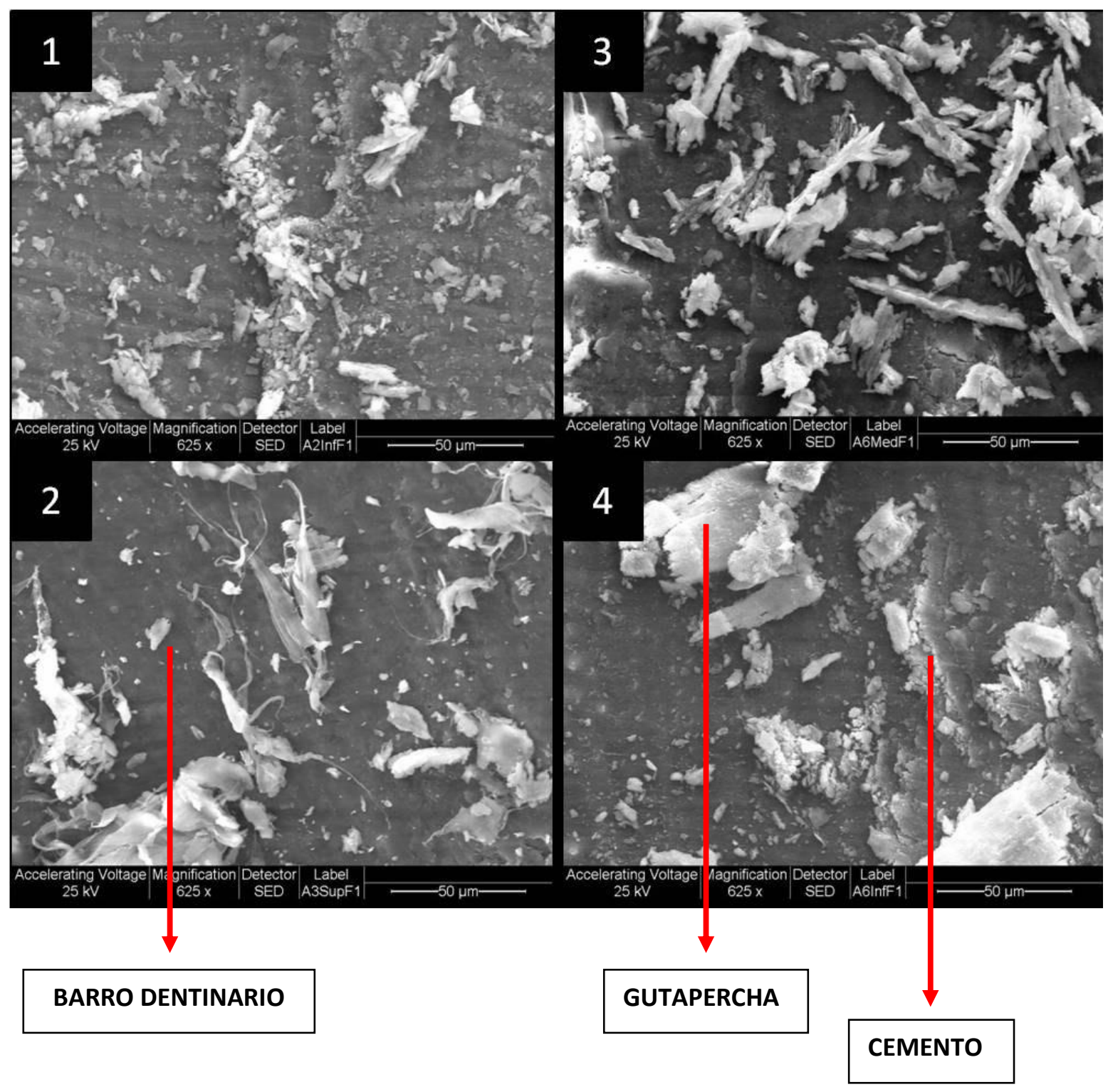

Fig.41 Microfotografías MEB 123 y 4 que representan cuatro probetas. Se muestran cómo quedan las paredes del conducto después de la desobturación y remodelación para recibir el perno. Los conductillos dentinarios se encuentran totalmente obstruidos por barro dentinario cemento y gutapercha.

En la Fig.42 se observan las microfotografías de muestras acondicionadas con alcohol yodado (C). Se hace evidente que los restos de cemento y gutapercha son eliminados, no así el barro dentinario que continua obliterando los conductillos dentinarios. Se puede notar que esta técnica no cumple con los requisitos buscados para la adhesión. En la Tabla 2 se observa que hay una diferencia altamente significativa con los otros 
grupos y que es igual al grupo que no recibió ningún tipo de tratamiento en la superficie dentinaria.

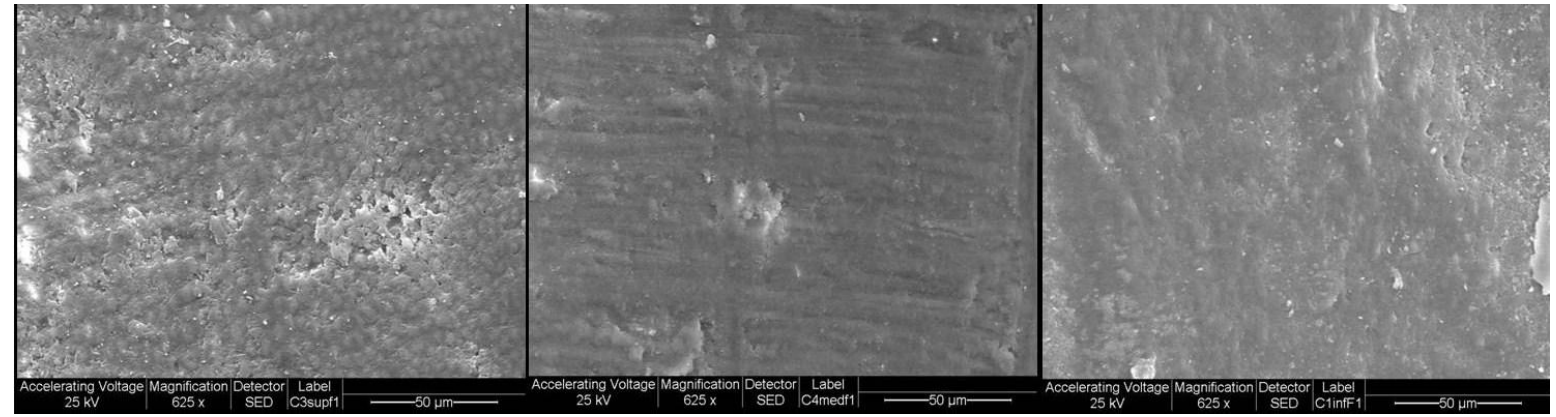

Fig.42 Microfotografías de muestras luego del acondicionamiento con alcohol yodo que posibilitó la eliminación de los restos de cemento y gutapercha pero no del barro dentinario.

La Fig.43 muestra el acondicionamiento logrado con EDTA (B) donde se observa la ausencia de restos de cemento y gutapercha y la presencia parcial de barro dentinario en algunas zonas, dejando libres de contaminación algunos conductillos dentinarios.

Estadísticamente se demostró una diferencia altamente significativa con los demás grupos mejorando los resultados del grupo que utilizó alcohol yodado (C). 


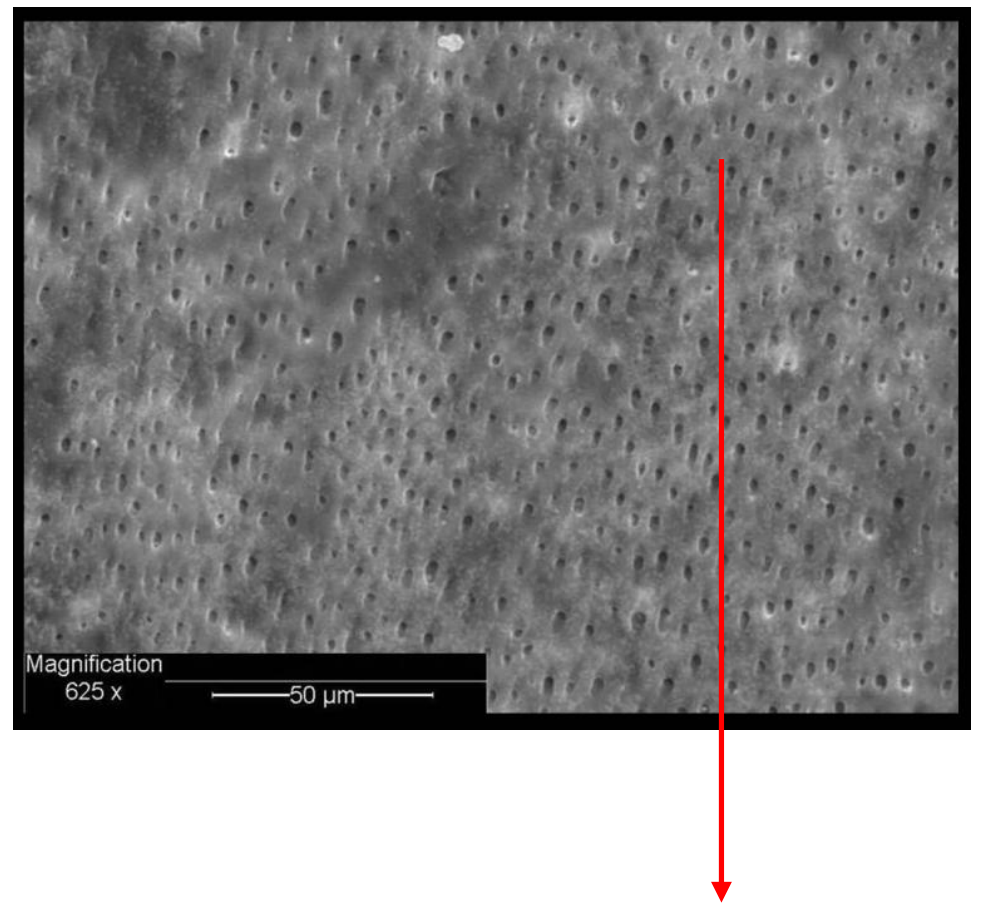

CONDUCTILLO DENTINARIO SIN TAPON DE BARRO

Fig.43 Microfotografía de una muestra luego del acondicionamiento con EDTA. Se logro limpiar la superficie de restos de cemento, gutapercha y parcialmente de barro dentinario.

En la Fig. 44 se observa una muestra luego de acondicionamiento con alcohol yodado más ácido fosfórico al 37 \% (F). Se puede apreciar una mejora respecto a las anteriores donde se hace evidente una mayor cantidad de conductillos abiertos.

Estadísticamente mostró un resultado comparativo altamente significativo con los demás grupos, mejorando el tratamiento en relación a los anteriores. 


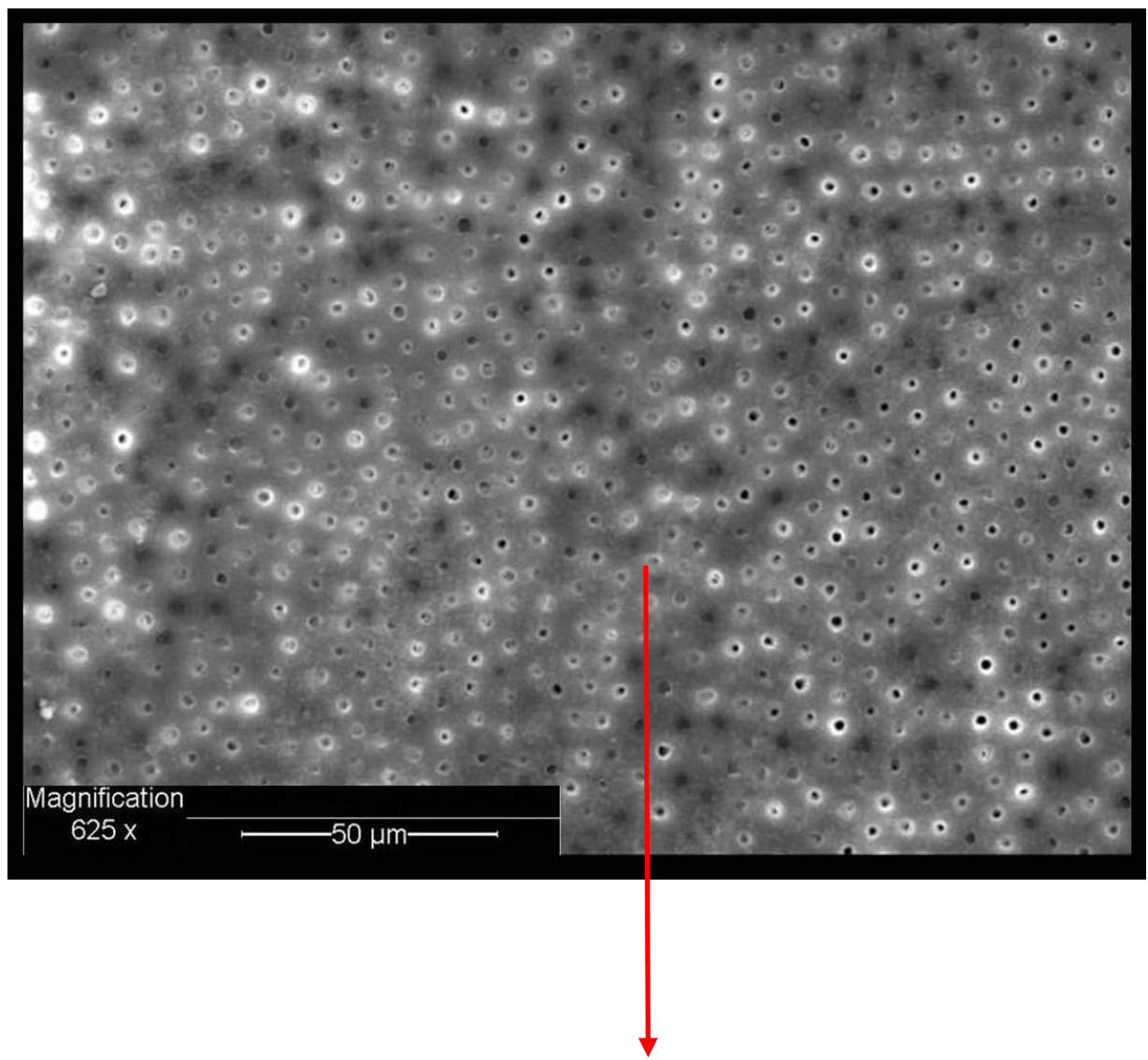

CONDUCTILLO DENTINARIO SIN TAPON DE BARRO

Fig. 44 Microfotografía obtenida luego del acondicionamiento con alcohol yodado más ácido fosfórico se nota una mejora en el acondicionamiento dentinario comparándola con las figuras anteriores.

La Fig.45 muestra el acondicionamiento realizado con EDTA más ácido fosfórico al $37 \%$ (E) ya la dentina se observa libre de contaminación y barro dentinario con una gran cantidad de conductillos abiertos mostrando ser mejor que los anteriores acondicionamientos. Estadísticamente demostró una diferencia altamente significativa con los otros tipos de acondicionamiento superando a los anteriores mostrados. 


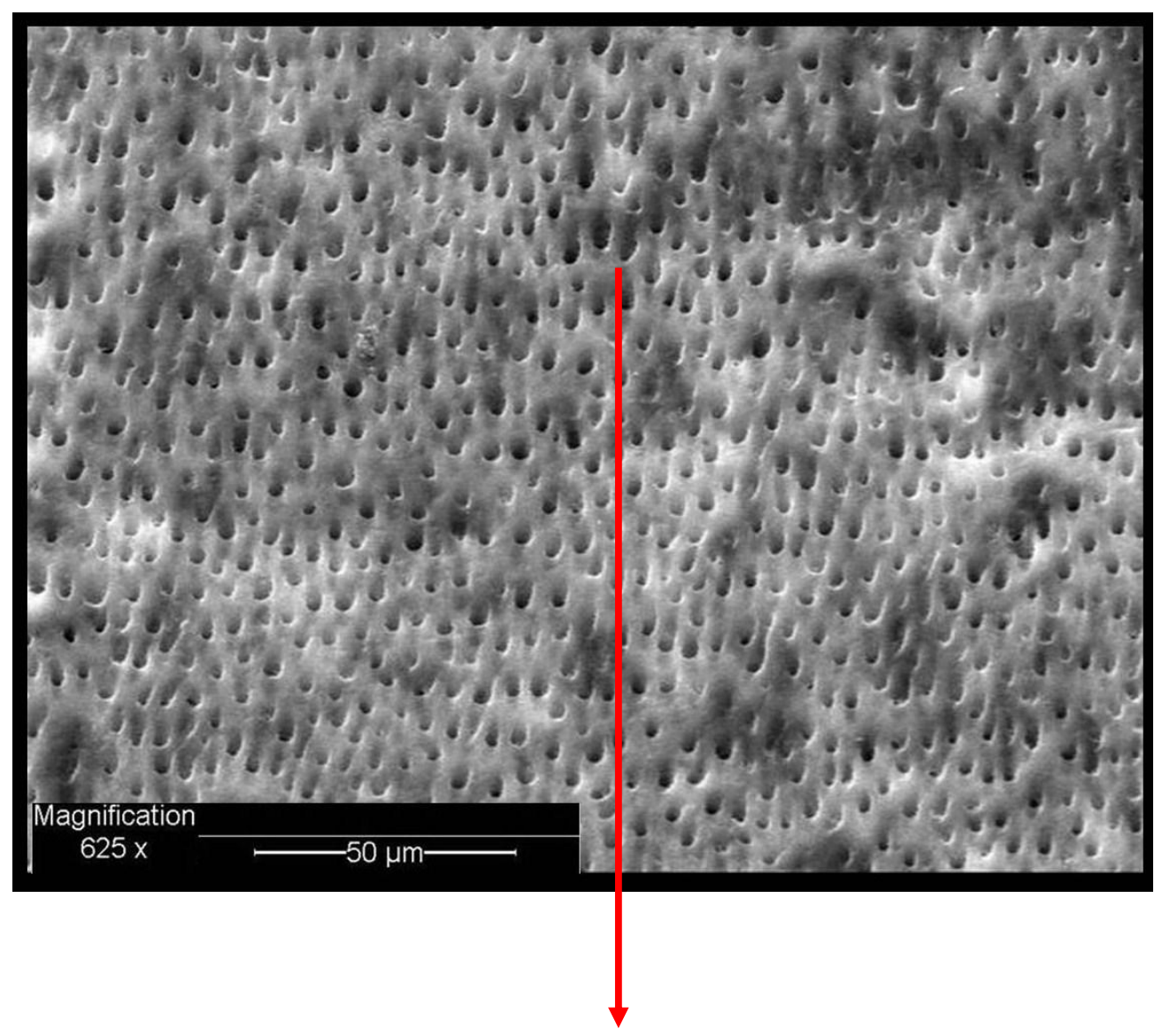

CONDUCTILLO DENTINARIO SIN TAPON DE BARRO

Fig.45 Microfotografia de una muestra luego del acondicionamiento con EDTA y ácido fosfórico se nota una marcada mejora superando los tratmientos anteriores.

La Fig 46 deja en evidencia que el acondicionamiento con ácido fosfórico al $37 \%$ colocado y frotado sobre la superficie dentinaria con puntas NaviTip durante 10 segundos deja a la dentina en las mejores condiciones para recibir el sistema adhesivo. Puede notarse en la microfotografia la gran cantidad de conductillos dentinarios abiertos y una ligera rugosidad superficial que favorecen la microretencion. 


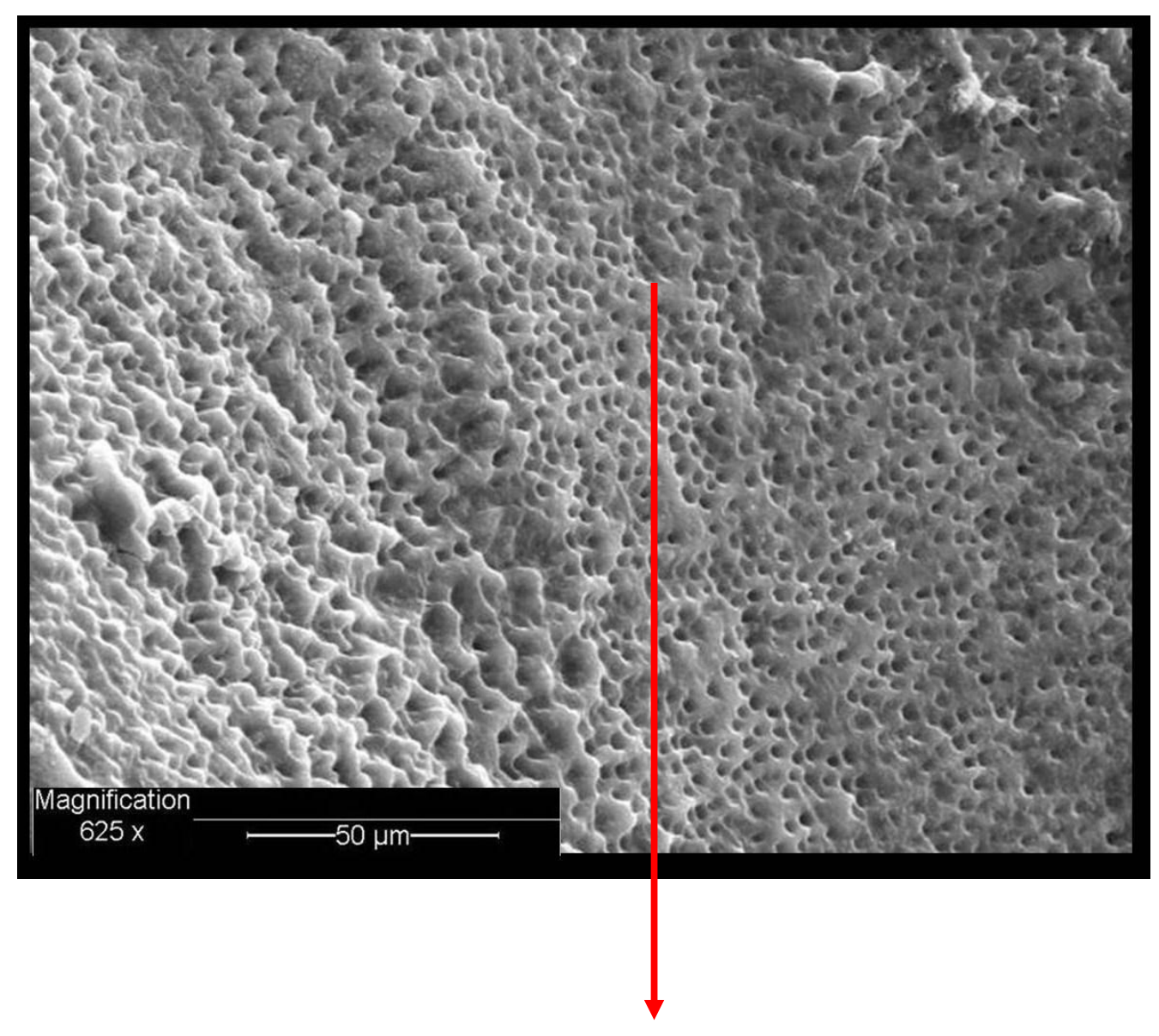

CONDUCTILLO DENTINARIO SIN TAPON DE BARRO

Fig.46 Microfotografía MEB de muestras tratadas con acido fosfórico al 37\% colocado y refregado con las puntas NaviTip se notan los mejores resultados en la limpieza del conducto para recibir un perno.

\subsection{Resultados de la evaluación de los espacios vacios de}

\section{cemento entre PRRF y dentina según la técnica clínica de cementación utilizada.}

La Fig.47 muestra esquemáticamente los resultados de la enumeración de espacios según la región, que es luego reflejada en las Tablas 3,4 y 5 . Puede observarse la distinta distribución y frecuencia del número de espacios en las regiones superior, media e inferior según la forma en que se colocó el cemento de ionómero vítreo. Se evidencia una 
mayor cantidad de espacios vacíos cuando se aplico el cemento sobre el perno, una disminución importante al llevarlo con lentulo y más aún cuando se los llevó con lentulo y sobre el perno.

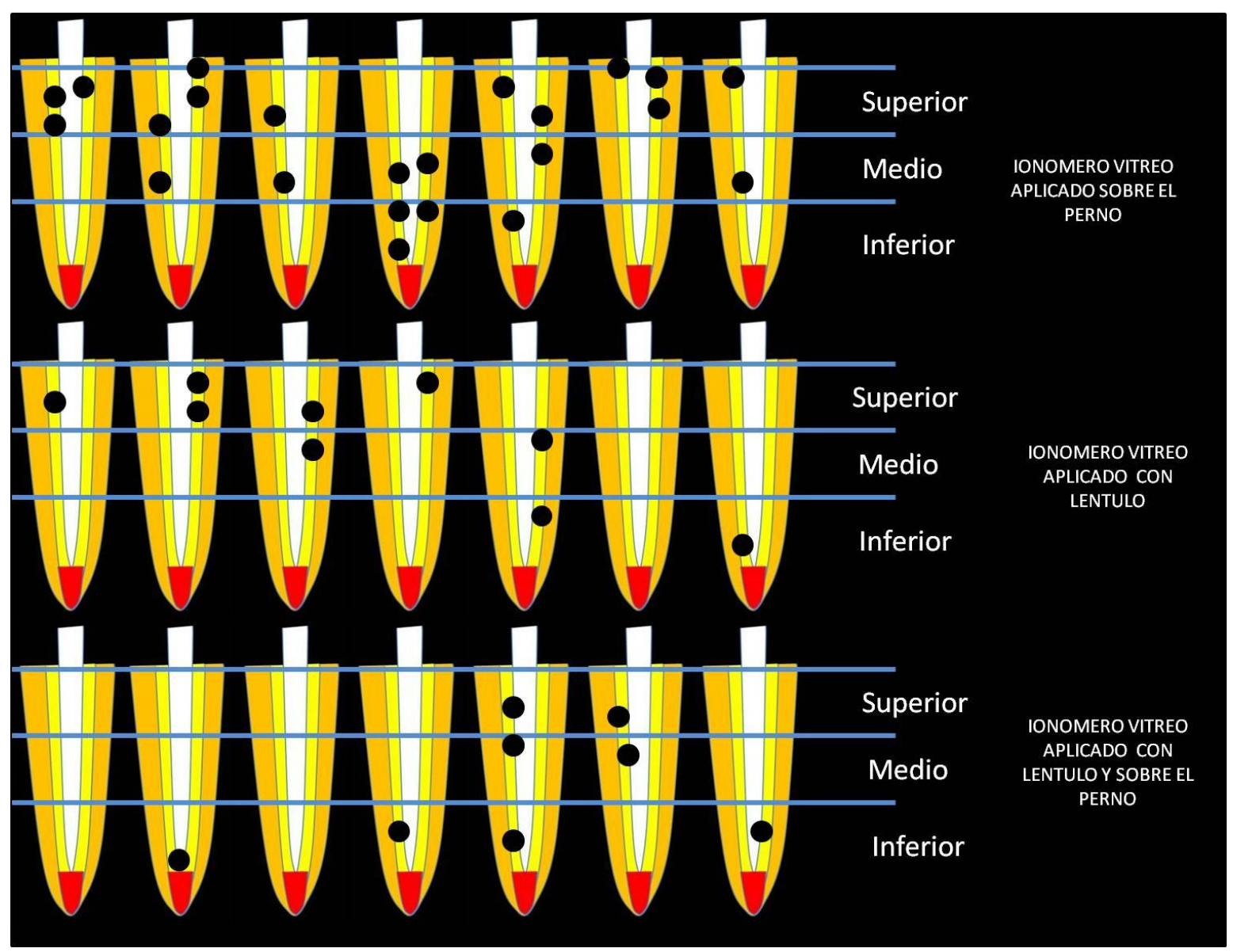

FIG.47 Esquema comparativo de las localizaciones de los espacios vacios de cemento de ionómero vítreo de todas las muestras realizado a partir de la observación microscópica. 
El Grafico 2 muestra el número promedio de espacios vacíos según la técnica y la región donde se presentaron para el cemento de ionómero vítreo.

\section{GRAFICO 2}

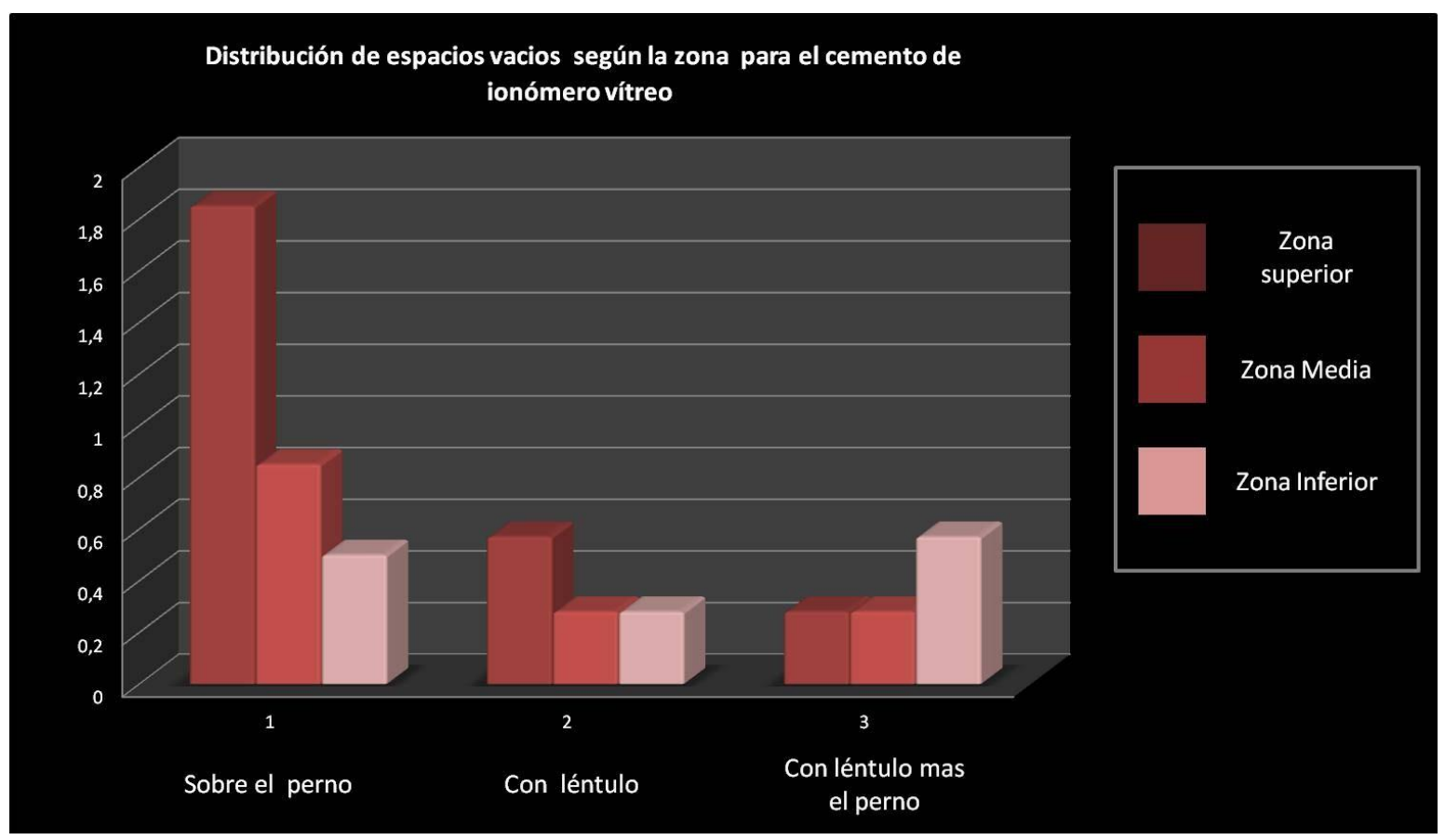

Grafico 2: Número promedio de espacios vacíos según la técnica y región para el cemento de ionómero vítreo.

Las Tablas 3,4 y 5 muestran los resultados que arrojaron las mediciones de las cantidades de espacios obtenidos con las tres técnicas estudiadas para el cemento de ionómero vítreo.

En la Tabla 3 se evidencia una gran cantidad de espacios vacios revelando en una muestra un máximo de 5 espacios y un mínimo de 2 en otras dos muestras. En el total de las muestras alcanzó 23 espacios. 
TABLA 3

\begin{tabular}{|c|c|c|c|c|c|c|c|c|}
\hline & \multicolumn{8}{|c|}{$\begin{array}{l}\text { ESPACIOS VACIOS DEJADOS POR EL CEMENTO DE } \\
\text { IONOMERO VITREO APLICADO SOBRE EL PERNO }\end{array}$} \\
\hline & $\begin{array}{l}\text { MUESTRA } \\
\text { Al1 }\end{array}$ & $\begin{array}{l}\text { MUESTRA } \\
\text { Al2 }\end{array}$ & $\begin{array}{l}\text { MUESTRA } \\
\text { Al3 }\end{array}$ & $\begin{array}{l}\text { MUESTRA } \\
\text { Al4 }\end{array}$ & $\begin{array}{l}\text { MUESTRA } \\
\text { AI5 }\end{array}$ & $\begin{array}{l}\text { MUESTRA } \\
\text { AI6 }\end{array}$ & $\begin{array}{l}\text { MUESTRA } \\
\text { A17 }\end{array}$ & TOTAL \\
\hline $\begin{array}{c}\text { NUMERO } \\
\text { TOTAL } \\
\text { DE } \\
\text { ESPACIOS }\end{array}$ & 3 & 4 & 2 & 5 & 4 & 3 & 2 & 23 \\
\hline
\end{tabular}

En la Tabla 4 observamos una disminución de espacios respecto a la técnica anterior. El total para las 7 muestras fue de 9 , con un máximo de 2 en tres muestras y una sin presentar ningún espacio.

TABLA 4

\begin{tabular}{|c|c|c|c|c|c|c|c|c|}
\hline \multicolumn{7}{|c|}{$\begin{array}{c}\text { ESPACIOS VACIOS DEJADOS POR EL CEMENTO DE } \\
\text { IONOMERO VITREO APLICADO CON LENTULO }\end{array}$} \\
\hline & $\begin{array}{c}\text { MUESTRA } \\
\text { All1 }\end{array}$ & $\begin{array}{c}\text { MUESTRA } \\
\text { All }\end{array}$ & $\begin{array}{c}\text { MUESTRA } \\
\text { All }\end{array}$ & $\begin{array}{c}\text { MUESTRA } \\
\text { Al1 }\end{array}$ & $\begin{array}{c}\text { MUESTRA } \\
\text { All }\end{array}$ & $\begin{array}{c}\text { MUESTRA } \\
\text { All6 }\end{array}$ & $\begin{array}{c}\text { MUESTRA } \\
\text { Al17 }\end{array}$ & TOTAL \\
\hline $\begin{array}{c}\text { NUMERO } \\
\text { TOTAL } \\
\text { DE } \\
\text { ESPACIOS }\end{array}$ & 1 & 2 & 2 & 1 & 2 & 0 & 1 & 9 \\
\hline
\end{tabular}


En la Tabla 5 se puede notar que una muestra presenta un máximo de 3 espacios en una muestra pero en dos muestras no se observó ningún espacio. Llegaron, a detectarse 8 espacios en el total de las 7 muestras.

TABLA 5

\begin{tabular}{|c|c|c|c|c|c|c|c|c|}
\hline & \multicolumn{8}{|c|}{$\begin{array}{l}\text { ESPACIOS VACIOS DEJADOS POR EL CEMENTO DE } \\
\text { IONOMERO VITREO APLICADO CON LENTULO Y } \\
\text { SOBRE EL PERNO }\end{array}$} \\
\hline & $\begin{array}{l}\text { MUESTRA } \\
\text { All } 1\end{array}$ & $\begin{array}{l}\text { MUESTRA } \\
\text { All } 2\end{array}$ & $\begin{array}{l}\text { MUESTRA } \\
\text { All } 3\end{array}$ & $\begin{array}{c}\text { MUESTRA } \\
\text { Alll } 4\end{array}$ & $\begin{array}{l}\text { MUESTRA } \\
\text { Alll } 5\end{array}$ & $\begin{array}{l}\text { MUESTRA } \\
\text { All } 6\end{array}$ & $\begin{array}{l}\text { MUESTRA } \\
\text { All } 7\end{array}$ & TOTAL \\
\hline $\begin{array}{c}\text { NUMERO } \\
\text { TOTAL } \\
\text { DE } \\
\text { ESPACIOS }\end{array}$ & 0 & 1 & 0 & 1 & 3 & 2 & 1 & 8 \\
\hline
\end{tabular}

La Tabla 6 nos muestra que no hay diferencia estadísticamente significativa entre llevar el cemento de ionómero vítreo con lentulo y con la combinación de llevarlo con lentulo y en el perno. En cambio, sí la hay entre estas dos técnicas y la opción de llevarlo solo embadurnado en el perno que es más deficiente. 
TABLA 6

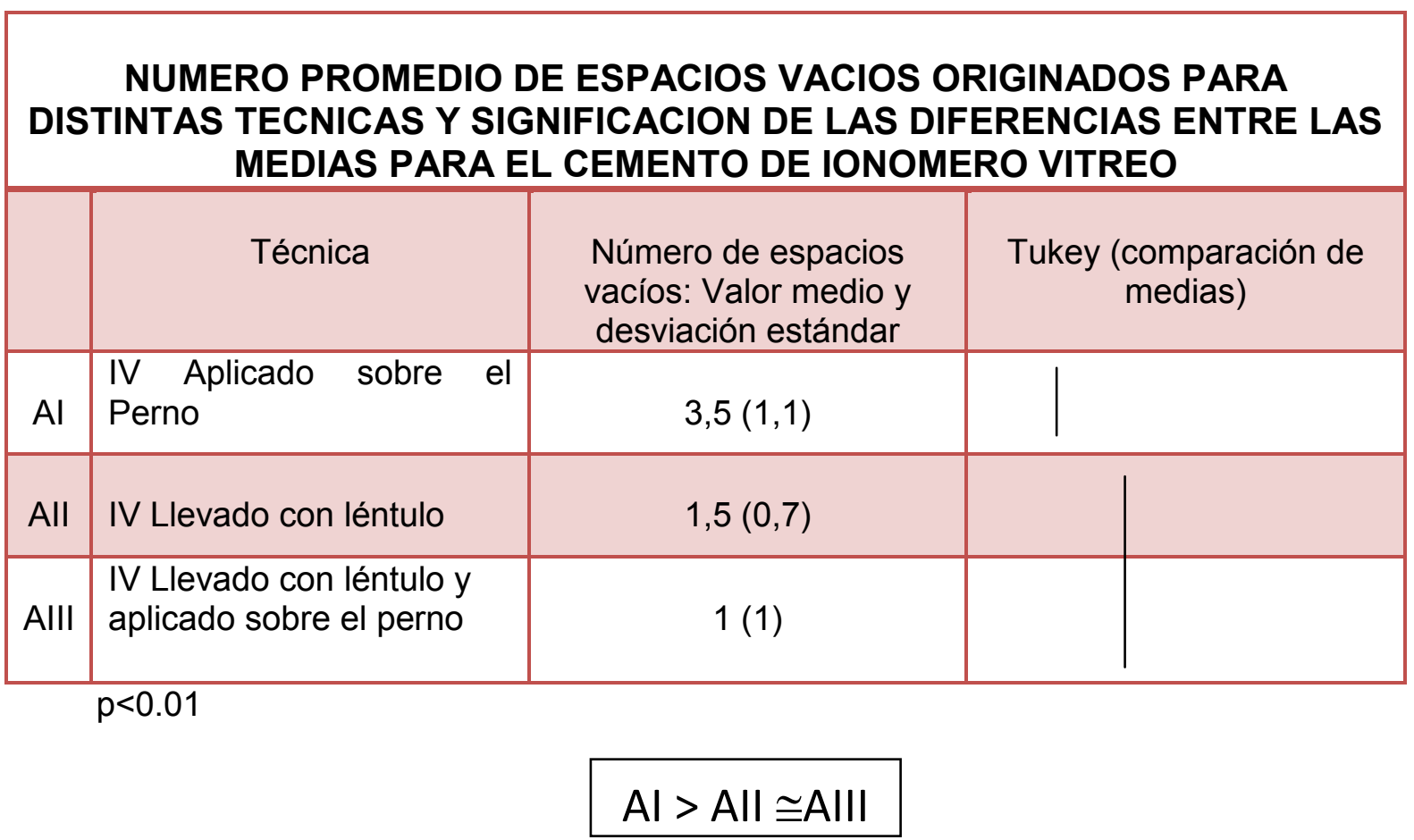

\section{GRAFICO 3}

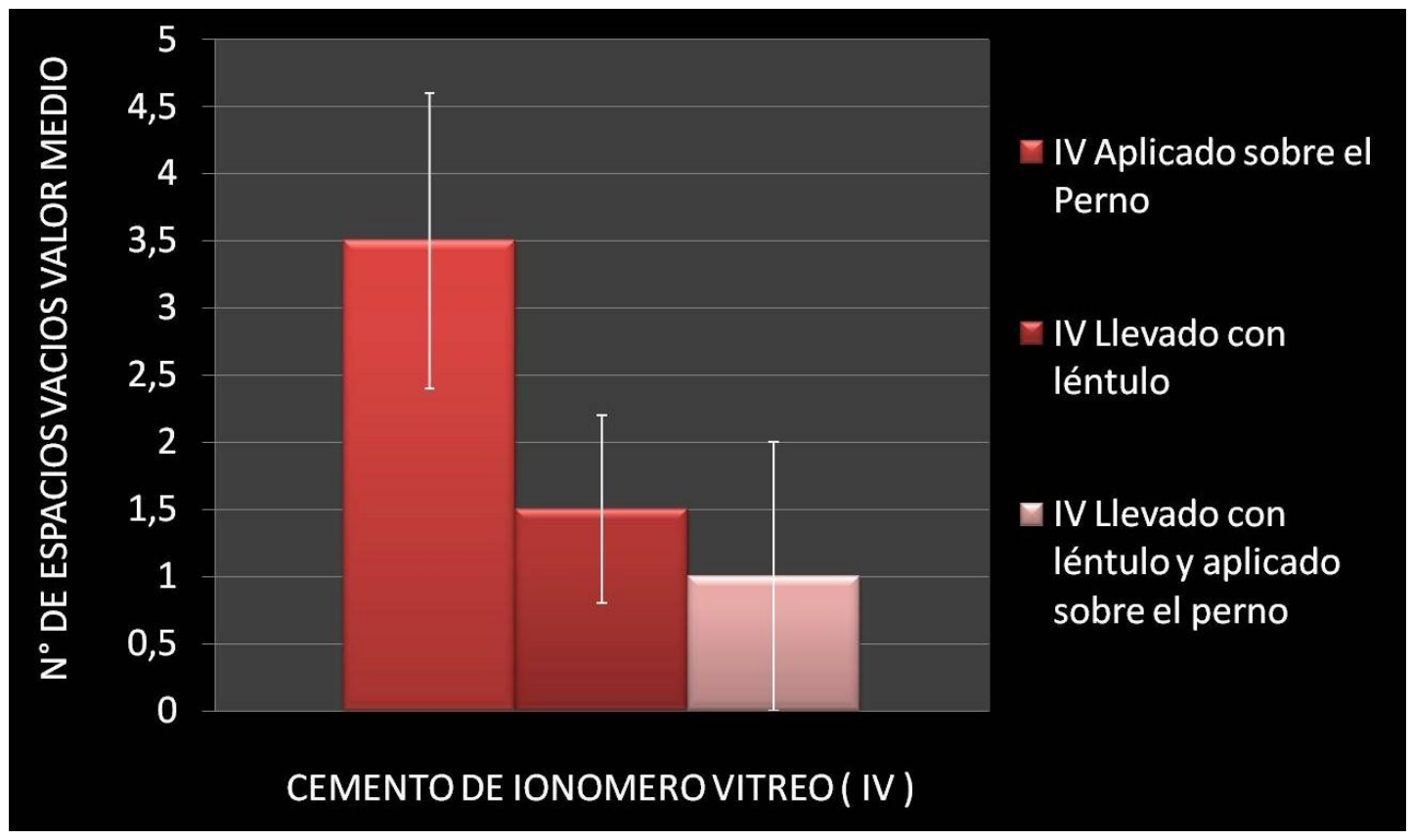

Grafico 3 .Número de espacios vacios valor media para el cemento de ionómero vítreo llevado con las tres técnicas. 
La Fig.48 muestra esquemáticamente la enumeración de los espacios según las regiones superior, media e inferior que luego es reflejada en las Tablas 7,8 y 9 . Puede observarse la distinta distribución y frecuencia del número de espacios en las regiones superior media e inferior según la forma en que se colocó el cemento a base de resina de autocurado. Se evidencia una mayor cantidad de espacios vacios cuando se aplico el cemento sobre el perno, una disminución importante al llevarlo con léntulo y más aún cuando se los llevo con lentulo y sobre el perno.

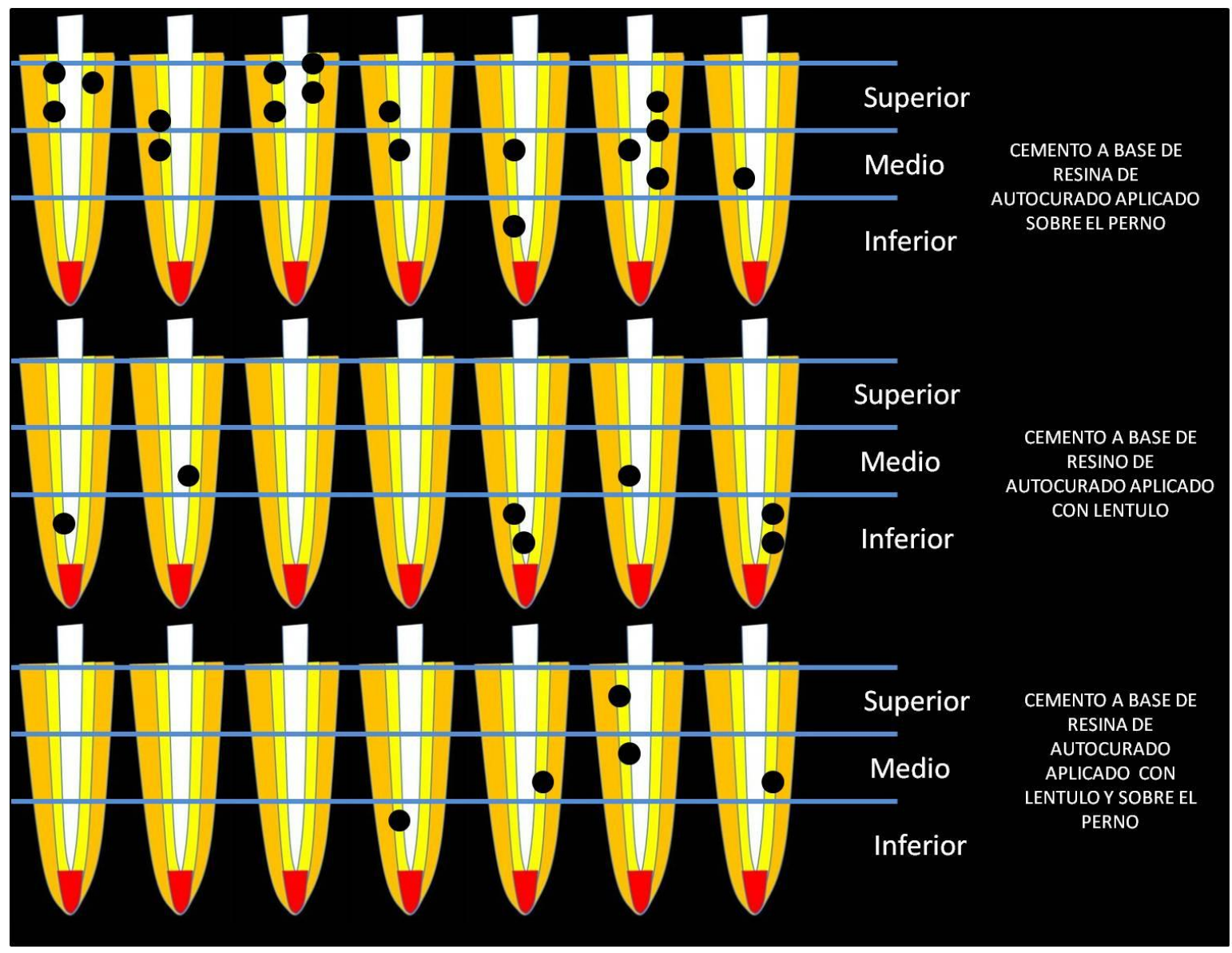

Fig.48 Esquema comparativo de las localizaciones de los espacios vacios de cemento a base de resina de autocurado de todas las muestras realizado a partir de la observación microscópica. 
El Grafico 4 muestra el número promedio de espacios vacíos según la técnica y la región donde se presentaron para el cemento a base de resina de autocurado.

\section{GRAFICO 4}

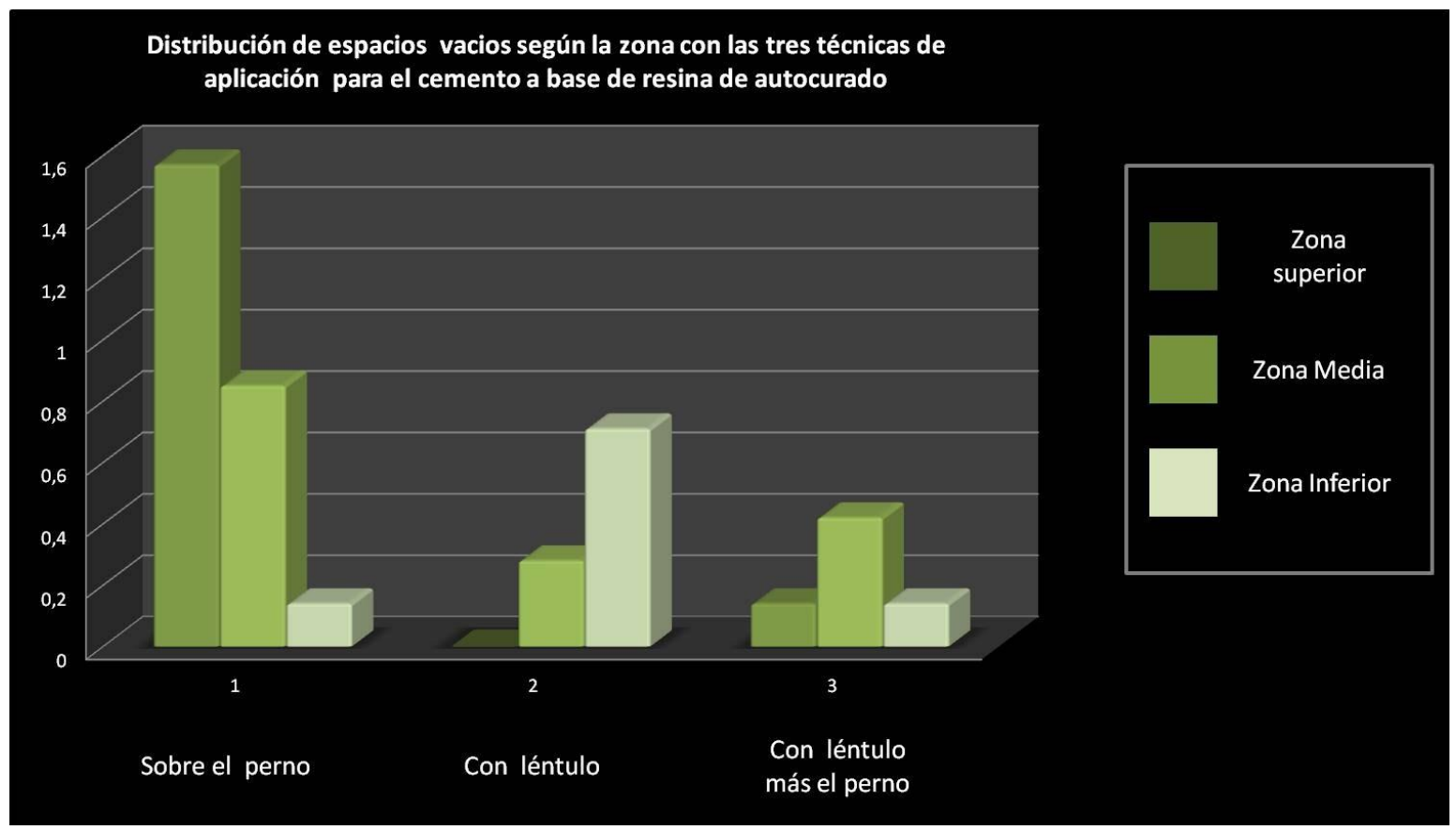

GRAFICO 3 Número promedio de espacios vacíos según la técnica y región para el cemento a base de resina de autocurado

Las Tablas 7, 8 y 9 muestran los resultados que arrojaron las mediciones de las cantidades de espacios obtenidos con las tres técnicas para el cemento de resina de autocurado.

La Tabla 7 muestra un máximo de 4 espacios en dos muestras y un mínimo de 1 espacio en una muestra. Se llego a un total de 18 espacios en el total de las muestras. 
TABLA 7

\begin{tabular}{|c|c|c|c|c|c|c|c|c|}
\hline & \multicolumn{8}{|c|}{$\begin{array}{c}\text { ESPACIOS VACIOS DEJADOS POR EL CEMENTO A } \\
\text { BASE DE RESINA DE AUTOCURADO APLICADO CON } \\
\text { EL PERNO }\end{array}$} \\
\hline & $\begin{array}{c}\text { MUESTRA } \\
\text { BI } 1\end{array}$ & $\begin{array}{c}\text { MUESTRA } \\
\text { Bl } 2\end{array}$ & $\begin{array}{c}\text { MUESTRA } \\
\text { B। } 3\end{array}$ & $\begin{array}{c}\text { MUESTRA } \\
\text { BI } 4\end{array}$ & $\begin{array}{c}\text { MUESTRA } \\
\text { BI } 5\end{array}$ & $\begin{array}{c}\text { MUESTRA } \\
\text { BI } 6\end{array}$ & $\begin{array}{c}\text { MUESTRA } \\
\text { B17 }\end{array}$ & TOTAL \\
\hline $\begin{array}{l}\text { NUMERO } \\
\text { TOTAL } \\
\text { DE } \\
\text { ESPACIOS }\end{array}$ & 3 & 2 & 4 & 2 & 2 & 4 & 1 & 18 \\
\hline
\end{tabular}

La Tabla 8 muestra una marcada disminución en la cantidad de espacios con un total de 7 para las 7 muestras. La mayor cantidad de espacios fue de 2 en dos de las muestras y se detectó la ausencia (0) espacios en dos muestras,

TABLA 8

\begin{tabular}{|c|c|c|c|c|c|c|c|c|}
\hline & \multicolumn{8}{|c|}{$\begin{array}{l}\text { ESPACIOS VACIOS DEJADOS POR EL CEMENTO A } \\
\text { BASE DE RESINA DE AUTOCURADO APLICADO CON } \\
\text { LENTULO }\end{array}$} \\
\hline & $\begin{array}{c}\text { MUESTRA } \\
\text { Bll } 1\end{array}$ & $\begin{array}{c}\text { MUESTRA } \\
\text { BIII } 2\end{array}$ & $\begin{array}{c}\text { MUESTRA } \\
\text { BII } 3\end{array}$ & $\begin{array}{c}\text { MUESTRA } \\
\text { BII } 4\end{array}$ & $\begin{array}{c}\text { MUESTRA } \\
\text { BIII } 5\end{array}$ & $\begin{array}{c}\text { MUESTRA } \\
\text { Bll } 6\end{array}$ & $\begin{array}{c}\text { MUESTRA } \\
\text { BII } 7\end{array}$ & TOTAL \\
\hline $\begin{array}{l}\text { NUMERO } \\
\text { TOAL } \\
\text { DE } \\
\text { ESPACIOS }\end{array}$ & 1 & 1 & 0 & 0 & 2 & 1 & 2 & 7 \\
\hline
\end{tabular}


En la Tabla 9 se registra una disminución en el número total de espacios respecto a los casos anteriores (5 en el total). Una muestra evidenció el máximo de 2 y tres muestras 0 .

TABLA 9

\begin{tabular}{|c|c|c|c|c|c|c|c|c|}
\hline & \multicolumn{8}{|c|}{ ESPACIOS VACIOS DEJADOS POR EL CEMENTO A } \\
BASE DE RESINA DE AUTOCURADO APLICADO CON \\
LENTULO Y SOBRE EL PERNO \\
\hline $\begin{array}{c}\text { MUESTRA } \\
\text { BIII 1 }\end{array}$ \\
$\begin{array}{c}\text { MUESTRA } \\
\text { TOTAL } \\
\text { DE } \\
\text { ESPACIOS }\end{array}$
\end{tabular}

En la Tabla 10 se comparan los resultados del cemento de resina de autocurado según los distintos procedimientos. Se nota que no hay diferencia estadísticamente significativas entre el llevado del cemento a base de resina de autocurado con lentulo y la combinación de llevarlo con léntulo y aplicar sobre el perno. En cambio, hay diferencia significativa de las medias entre estas dos técnicas y la que lo lleva sólo, aplicado al perno. 
TABLA 10

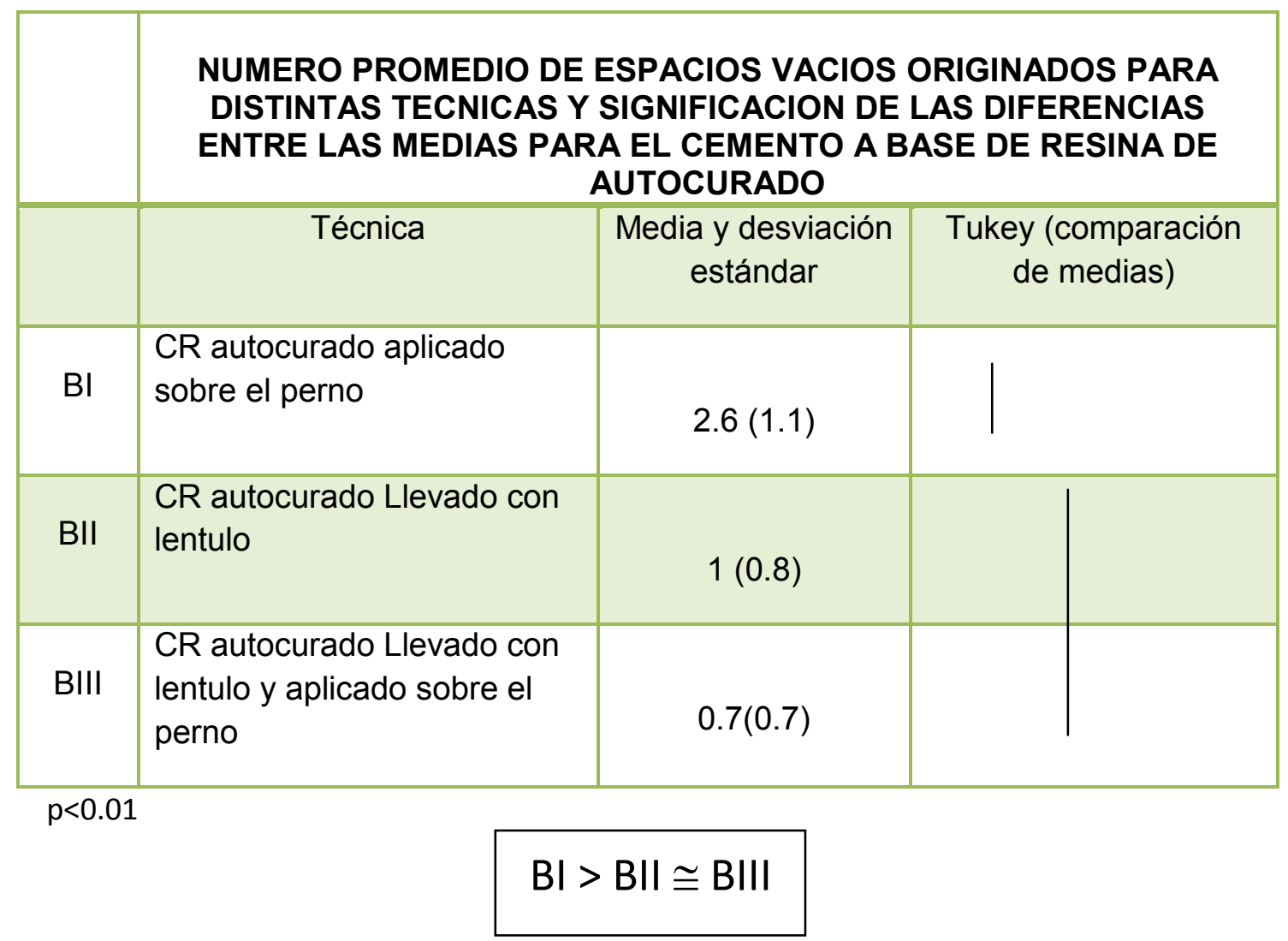

\section{GRAFICO 5}

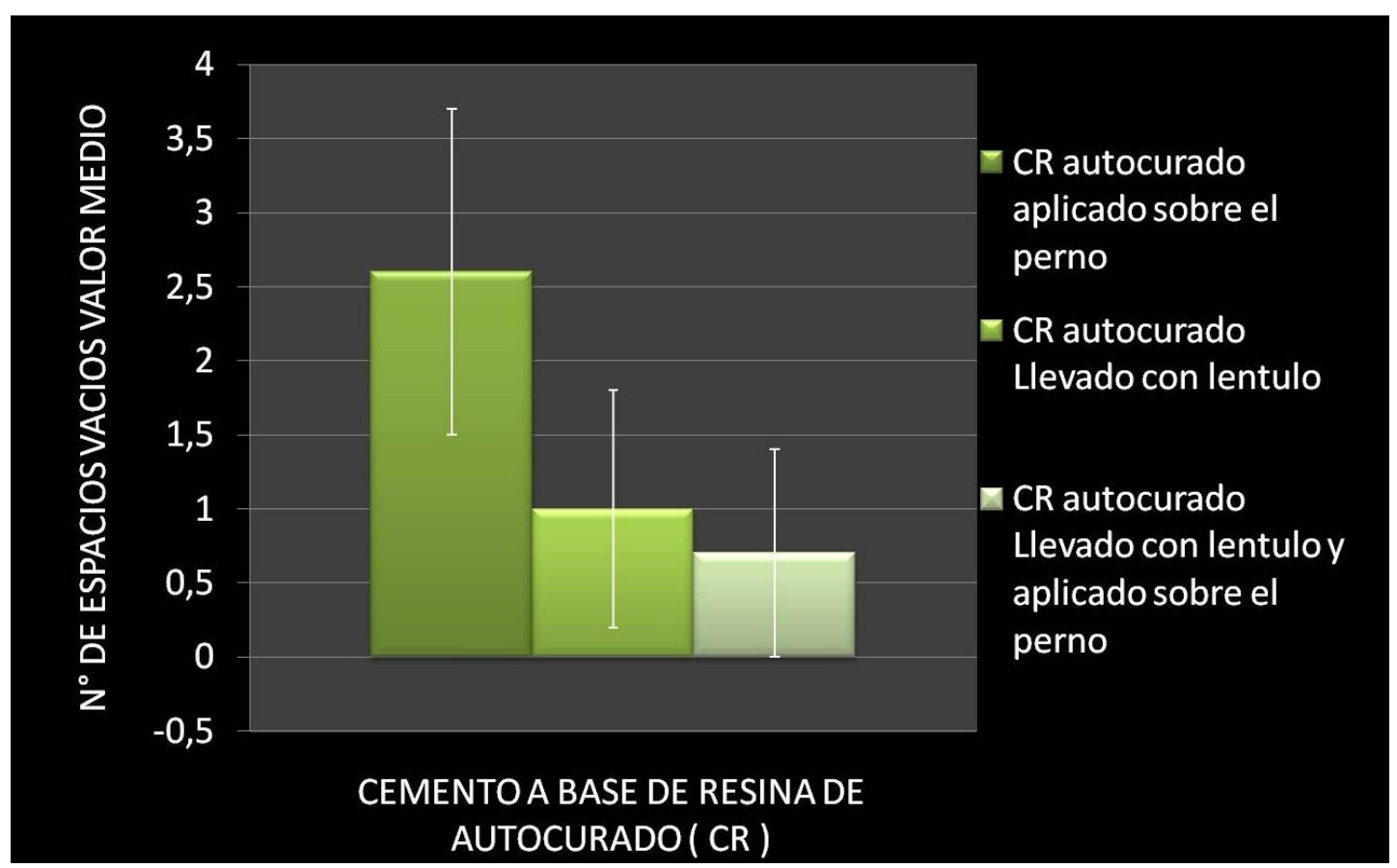

Gráfico 5. Número de espacios vacios valor media para el cemento a base de resina de autocurado. Llevado con las tres técnicas. 
En la Fig. 49 se comparan esquemáticamente los resultados de la enumeración de espacios en las distintas regiones para las distintas técnicas. En las Tablas 11, 12 y 13 se muestran los resultados totales para cada una de ellas.

Puede observarse la distinta distribución y frecuencia del número de espacios en las regiones superior media e inferior según la forma en que se colocó el cemento a base de resina de curado dual. Se evidencia una mayor cantidad de espacios vacíos cuando se aplicó el cemento sobre el perno, una disminución importante al llevarlo con lentulo y más cuando se los llevo con lentulo y sobre el perno.

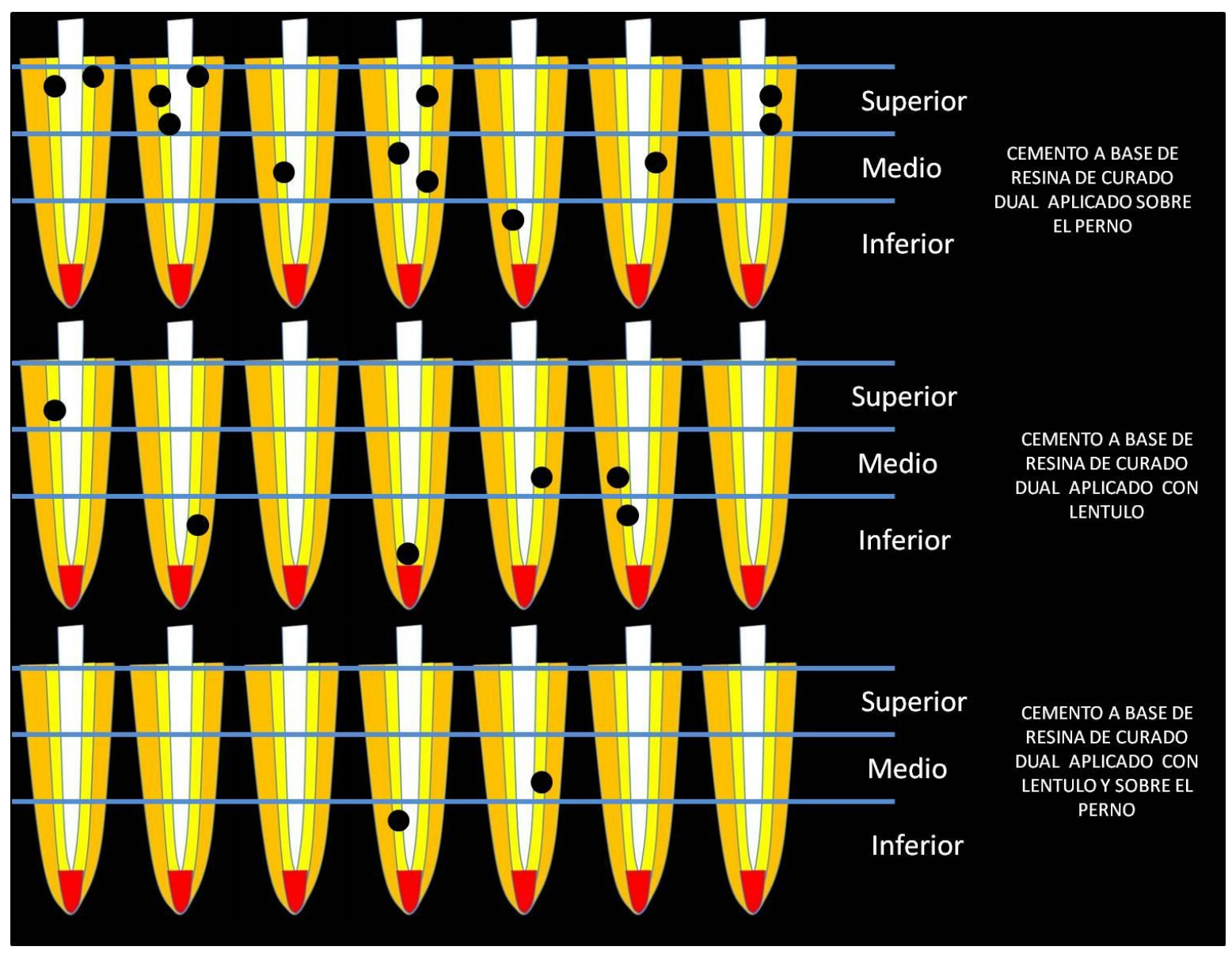

Fig.49 Esquema comparativo de las localizaciones de los espacios vacios de cemento a base de resina de curado dual de todas las muestras realizado a partir de la observación microscópica. 
El Grafico 6 muestra el número promedio de espacios vacíos según la técnica y la región donde se presentaron para el cemento a base de resina de curado dual.

\section{GRAFICO 6}

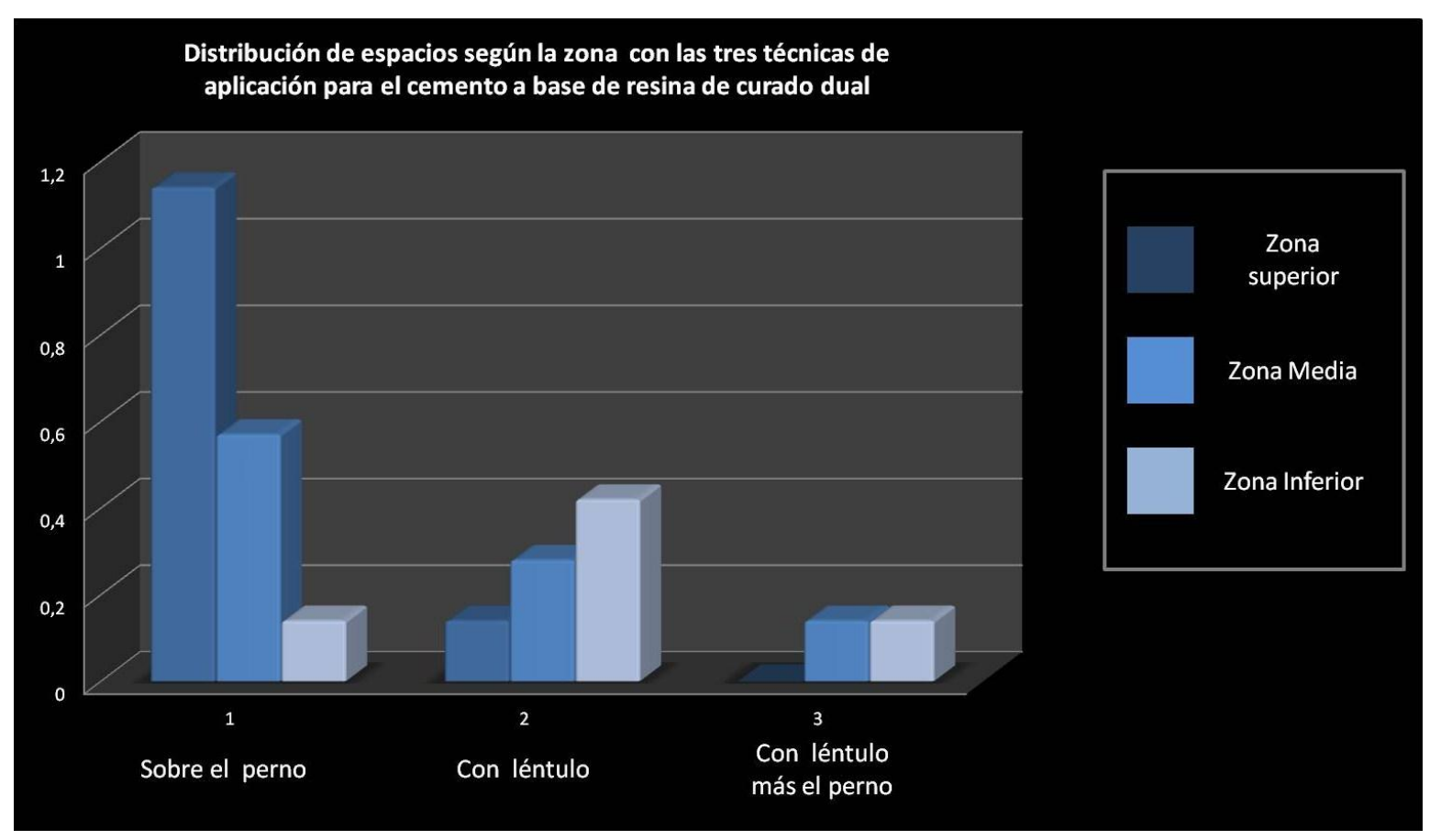

GRAFICO 4 Número promedio de espacios vacíos según la técnica y región para el cemento a base de resina de curado dual.

Las Tablas 11, 12 y 13 muestran los resultados que arrojaron las mediciones de las cantidades de espacios obtenidos con las tres técnicas para el cemento de resina de curado dual.

En la Tabla 11 se reporta un número total de 13 espacios para la técnica de cementado donde se embadurna el PRRF, con un máximo de 3 espacios en dos muestras y un mínimo de 1 en tres muestras. 
TABLA 11

\begin{tabular}{|c|c|c|c|c|c|c|c|c|}
\hline & \multicolumn{8}{|c|}{$\begin{array}{c}\text { ESPACIOS VACIOS DEJADOS POR EL CEMENTO A } \\
\text { BASE DE RESINA DE CURADO DUAL APLICADO } \\
\text { SOBRE EL PERNO }\end{array}$} \\
\hline & $\begin{array}{c}\text { MUESTRA } \\
\text { Cl1 }\end{array}$ & $\begin{array}{c}\text { MUESTRA } \\
\mathrm{Cl} 2\end{array}$ & $\begin{array}{c}\text { MUESTRA } \\
\mathrm{CI} 3\end{array}$ & $\begin{array}{c}\text { MUESTRA } \\
\text { CI4 }\end{array}$ & $\begin{array}{c}\text { MUESTRA } \\
\text { CI5 }\end{array}$ & $\begin{array}{c}\text { MUESTRA } \\
\text { CI6 }\end{array}$ & $\begin{array}{c}\text { MUESTRA } \\
\text { CI7 }\end{array}$ & TOTAL \\
\hline $\begin{array}{l}\text { NUMERO } \\
\text { TOTAL } \\
\text { DE } \\
\text { ESPACIOS }\end{array}$ & 2 & 3 & 1 & 3 & 1 & 1 & 2 & 13 \\
\hline
\end{tabular}

En la Tabla 12 se informa un máximo de 6 espacios en el total de las muestras. La mayor cantidad fue de 2 espacios en una muestra y el mínimo 0 en una muestra

TABLA 12

\begin{tabular}{|c|c|c|c|c|c|c|c|c|}
\hline \multicolumn{7}{|c|}{} & \multicolumn{7}{|c|}{ ESPACIOS VACIOS DEJADOS POR EL CEMENTO A } \\
BASE DE RESINA DE CURADO DUAL APLICADO \\
CON LENTULO \\
\hline \\
\hline $\begin{array}{c}\text { MUESTRA } \\
\text { CII1 }\end{array}$ & $\begin{array}{c}\text { MUESTRA } \\
\text { CII2 }\end{array}$ & $\begin{array}{l}\text { MUESTRA } \\
\text { CII3 }\end{array}$ & $\begin{array}{c}\text { MUESTRA } \\
\text { CII } 4\end{array}$ & $\begin{array}{c}\text { MUESTRA } \\
\text { CII } 5\end{array}$ & $\begin{array}{c}\text { MUESTRA } \\
\text { CII6 }\end{array}$ & $\begin{array}{c}\text { MUESTRA } \\
\text { CII7 }\end{array}$ & TOTAL \\
\hline $\begin{array}{c}\text { NUMERO } \\
\text { TOTAL } \\
\text { DEPACIOS }\end{array}$ & 1 & 1 & 0 & 1 & 1 & 2 & 0 & 6 \\
\hline
\end{tabular}


La tabla 13 muestra una disminución en la aplicación del cemento con esta técnica el máximo de la sumatoria de las muestras es de 2. Obteniendo 1 espacio en dos muestras y 0 en cinco muestras.

TABLA13

\begin{tabular}{|c|c|c|c|c|c|c|c|c|}
\hline & \multicolumn{8}{|c|}{$\begin{array}{c}\text { ESPACIOS VACIOS DEJADOS POR EL CEMENTO A } \\
\text { BASE DE RESINA DE CURADO DUAL APLICADO } \\
\text { CON LENTULO Y SOBRE EL PERNO }\end{array}$} \\
\hline & $\begin{array}{c}\text { MUESTRA } \\
\text { CIIII } 1\end{array}$ & $\begin{array}{c}\text { MUESTRA } \\
\text { CIII } 2\end{array}$ & $\begin{array}{c}\text { MUESTRA } \\
\text { CIII } 3\end{array}$ & $\begin{array}{c}\text { MUESTRA } \\
\text { CIII } 4\end{array}$ & $\begin{array}{c}\text { MUESTRA } \\
\text { CIII } 5\end{array}$ & $\begin{array}{c}\text { MUESTRA } \\
\text { CIII } 6\end{array}$ & $\begin{array}{c}\text { MUESTRA } \\
\text { CIII } 7\end{array}$ & TOTAL \\
\hline $\begin{array}{l}\text { NUMERO } \\
\text { TOTAL } \\
\text { DE } \\
\text { ESPACIOS }\end{array}$ & 0 & 0 & 0 & 1 & 1 & 0 & 0 & 2 \\
\hline
\end{tabular}

La Tabla 14 y Gráfico 7 nos muestra que hay una diferencia estadísticamente entre las tres técnicas. La que menos espacios dejó es la técnica que utiliza, para llevar el cemento de curado dual, el lentulo conjuntamente con el embadurnado del perno $(0,25+-0,4)$ y la que más espacios dejó es llevándolo solo con el perno $(1,85+-0,9)$. 
TABLA 14

\begin{tabular}{|c|c|c|c|}
\hline & \multicolumn{3}{|c|}{$\begin{array}{c}\text { NUMERO PROMEDIO DE ESPACIOS VACIOS ORIGINADOS } \\
\text { PARA DISTINTAS TECNICAS Y SIGNIFICACION DE LAS } \\
\text { DIFERENCIAS ENTRE LAS MEDIAS PARA EL CEMENTO A } \\
\text { BASE DE RESINA DE CURADO DUAL }\end{array}$} \\
\hline & Técnica & $\begin{array}{l}\text { Medidas y } \\
\text { desviación estándar }\end{array}$ & $\begin{array}{l}\text { Tukey (comparación } \\
\text { de medidas }\end{array}$ \\
\hline $\mathrm{Cl}$ & $\begin{array}{l}\text { Cemento a base de resina } \\
\text { de curado dual aplicado } \\
\text { sobre el Perno }\end{array}$ & $1.85(0.9)$ & \\
\hline CII & $\begin{array}{l}\text { Cemento a base de resina } \\
\text { de curado dual llevado } \\
\text { con lentulo }\end{array}$ & $0.85(0.7)$ & \\
\hline CII & $\begin{array}{l}\text { Cemento a base de resina } \\
\text { de curado dual llevado } \\
\text { con lentulo y aplicado } \\
\text { sobre el perno }\end{array}$ & $0.25(0.4)$ & \\
\hline \multicolumn{4}{|c|}{$P<0.01$} \\
\hline & \multicolumn{3}{|c|}{$\mathrm{Cl}>\mathrm{Cll}>\mathrm{ClII}$} \\
\hline
\end{tabular}

\section{GRAFICO 7}

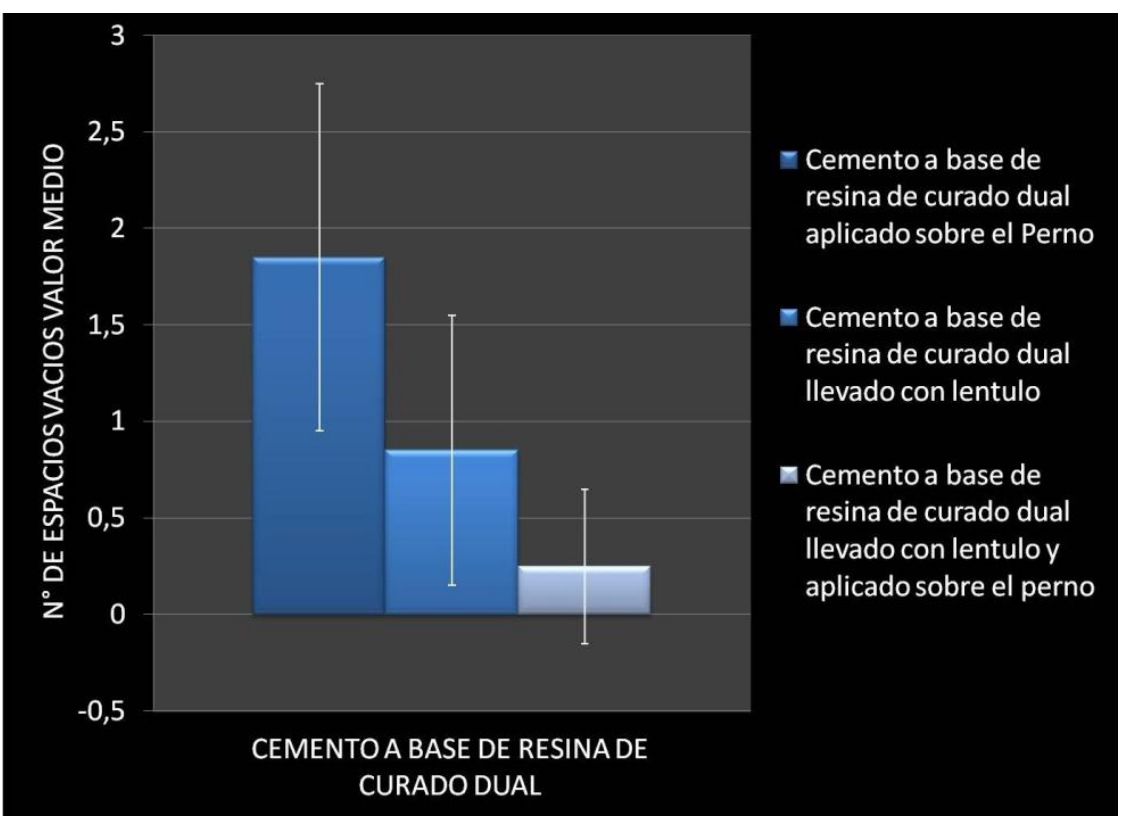


En las Tablas 1516 y 17 se comparan los resultados de las tres técnicas para llevar los cementos.

En la tabla 15 y Gráfico 8 se evidencia que con esta técnica el cemento a base de resina de curado dual fue el que menos espacios dejó. $(1,85+-0,9)$. Este número se duplica en el caso del cemento de ionómero vítreo. $(3,5+-1.1)$.

TABLA 15

\begin{tabular}{|c|c|c|c|}
\hline \multicolumn{4}{|c|}{$\begin{array}{l}\text { COMPARACIÓN DE LAS MEDIAS DE ESPACIOS VACIOS DE LOS TRES } \\
\text { CEMENTOS LLEVADOS CON EL PERNO (EMBADURNADO DEL PERNO) }\end{array}$} \\
\hline & Técnica & $\begin{array}{l}\text { Media y desviación } \\
\text { estándar }\end{array}$ & $\begin{array}{l}\text { Tukey (comparación } \\
\text { de medias) }\end{array}$ \\
\hline $\mathrm{Al}$ & $\begin{array}{l}\text { Cemento de ionómero vítreo } \\
\text { Aplicado sobre el Perno }\end{array}$ & $3,5(1.1)$ & \\
\hline $\mathrm{BI}$ & $\begin{array}{l}\text { Cemento de resina de } \\
\text { autocurado aplicado sobre el } \\
\text { Perno }\end{array}$ & $2.6(1.1)$ & \\
\hline $\mathrm{Cl}$ & $\begin{array}{l}\text { Cemento de resina de } \\
\text { curado dual aplicado sobre } \\
\text { el Perno }\end{array}$ & $1.85(0.9)$ & \\
\hline
\end{tabular}

$$
\mathrm{Al}>\mathrm{BI}>\mathrm{Cl}
$$




\section{GRAFICO 8}

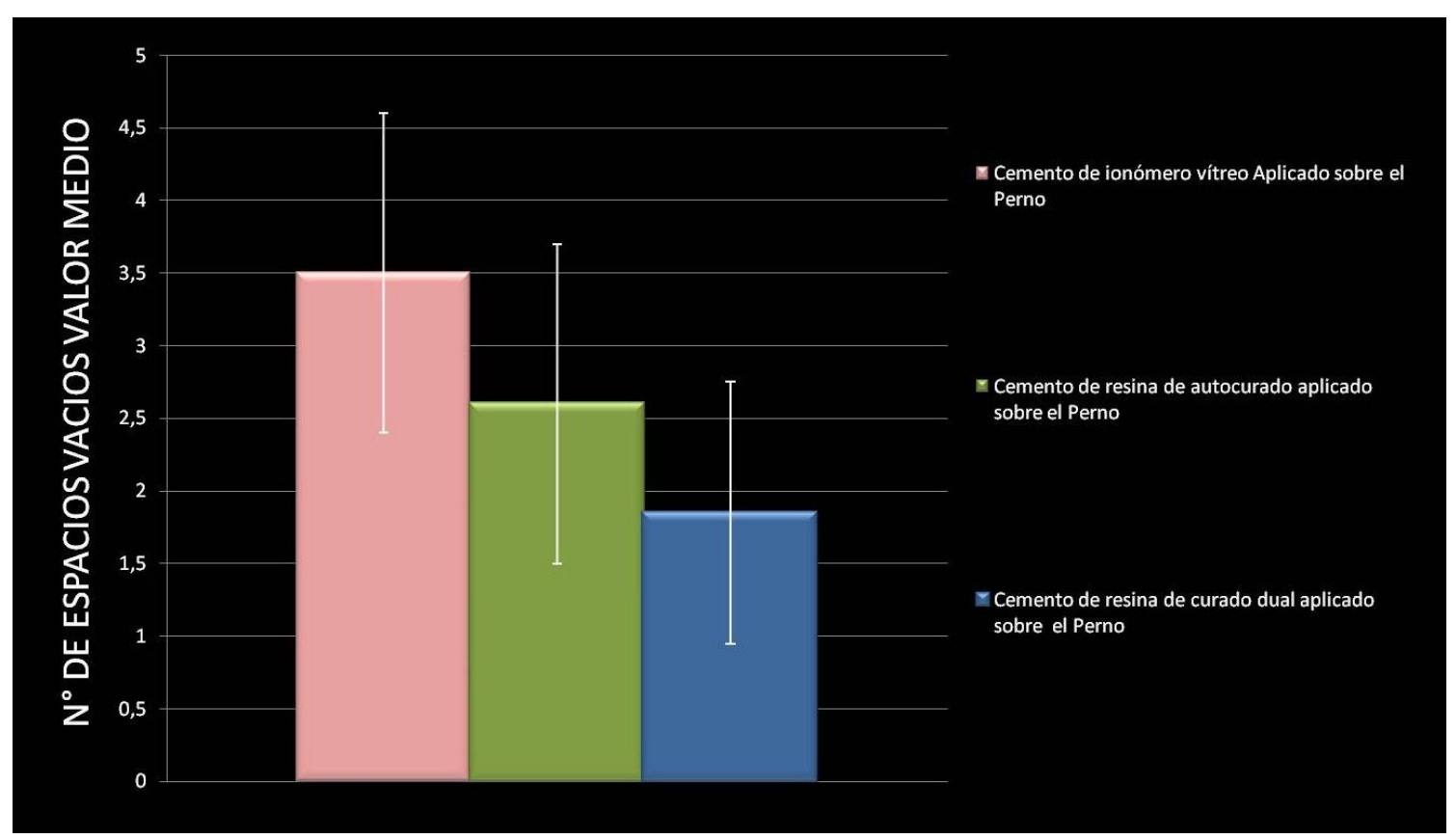

En la Tabla 16 y gráfico 9 se observa que los dos tipos de cementos a base de resina se comportan en forma similar al ser llevados con léntulo y que dejan menos espacios que el cemento de ionómero vítreo. 
TABLA 16

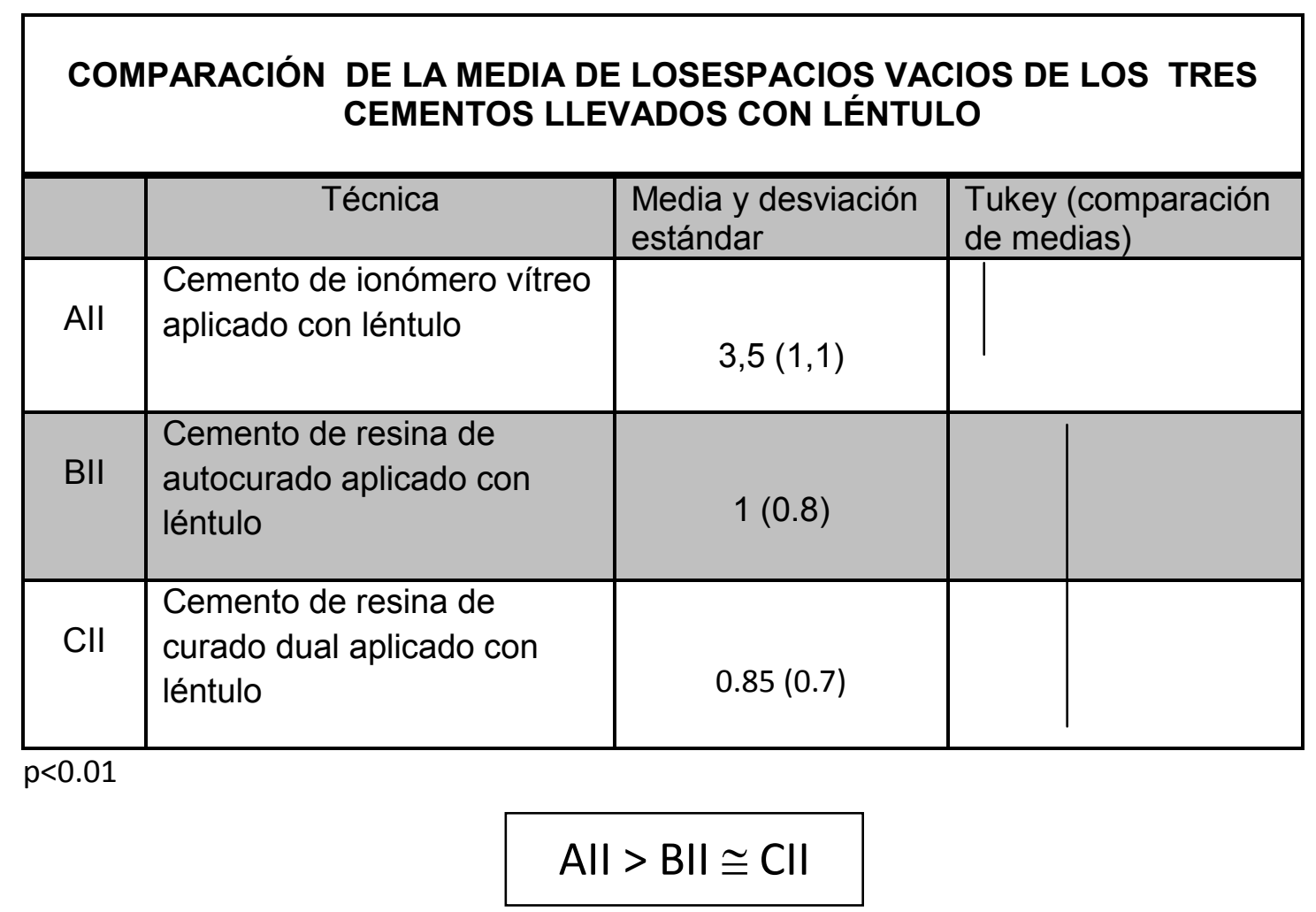

\section{GRAFICO 9}

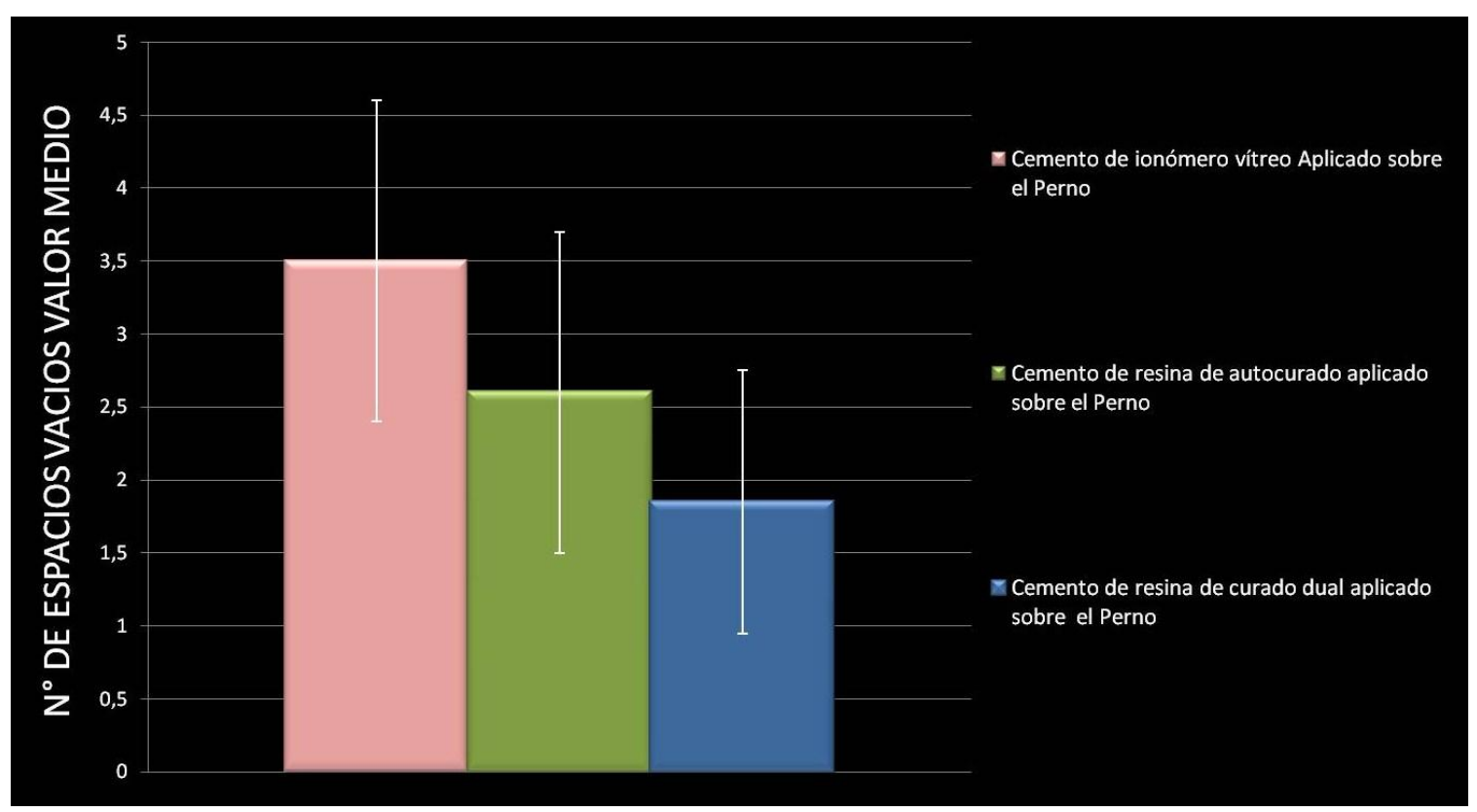


En la tabla 17 y Gráfico 10 se muestra que la aplicación con léntulo y aplicado sobre el perno (embadurnado) deja menos espacios llevando el cemento a base de resina de curado dual que con en el ionómero vítreo $p<$ 0,01 y en la colocación del cemento de resina de autocurado.

TABLA 17

\section{COMPARACIÓN DE LA MEDIA DE LOS ESPACIOS VACIOS DE LOS TRES CEMENTOS LLEVADOS CON LÉNTULO MÁS APLICADO EN EL PERNO}

\begin{tabular}{|c|l|c|l|}
\hline AIII & $\begin{array}{l}\text { Cemento de ionómero vítreo } \\
\text { aplicado con lentulo y } \\
\text { aplicado sobre el PRRF } \\
\text { desviación } \\
\text { estándar }\end{array}$ & $\begin{array}{l}\text { Tukey } \\
\text { (comparación de } \\
\text { medias) }\end{array}$ \\
\hline BIII & $\begin{array}{l}\text { Cemento a base de resina de } \\
\text { autocurado aplicado con } \\
\text { lentulo y aplicado sobre el } \\
\text { PRRF }\end{array}$ & $0.7(0.7)$ & $\mid$ \\
\hline CIII & $\begin{array}{l}\text { Cemento a base de resina de } \\
\text { curado dual aplicado con } \\
\text { lentulo y Aplicado Perno }\end{array}$ & $0.25(0.4)$ & $\mid$ \\
\hline
\end{tabular}

$\mathrm{P}<0.01$

$$
\mathrm{AlII} \cong \mathrm{BIII}>\mathrm{CIII}
$$




\section{GRAFICO 10}

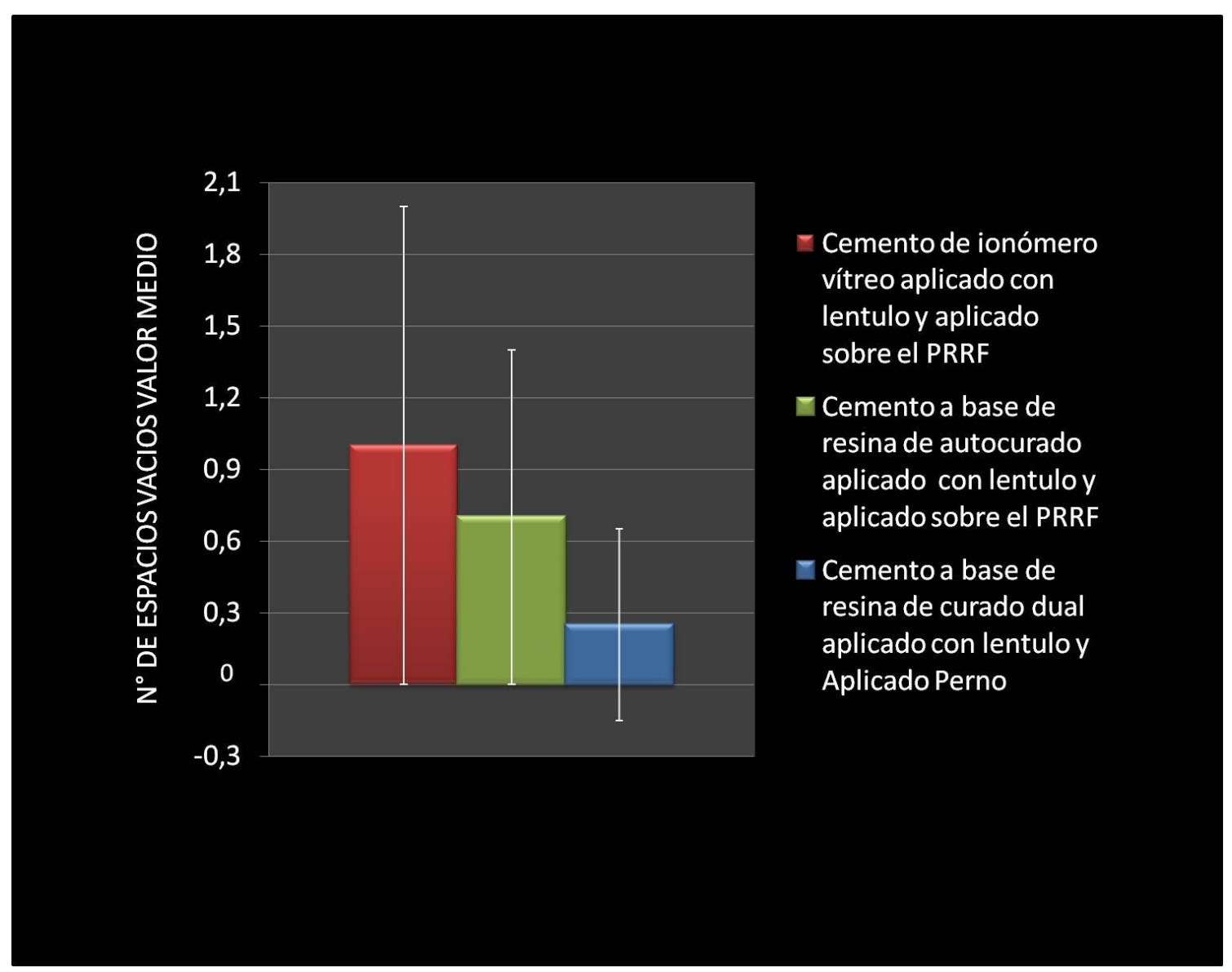

En las fotografías Fig. 50, 51 y 52 se observan algunos ejemplos de los espacios observados microscópicamente donde se pueden apreciar diferencias en ubicación, cantidad y tamaño en que se pueden llegar a presentar. 
La Fig.50 muestra la presencia de un espacio sin cemento de tamaño considerable en la zona lateral inferior.

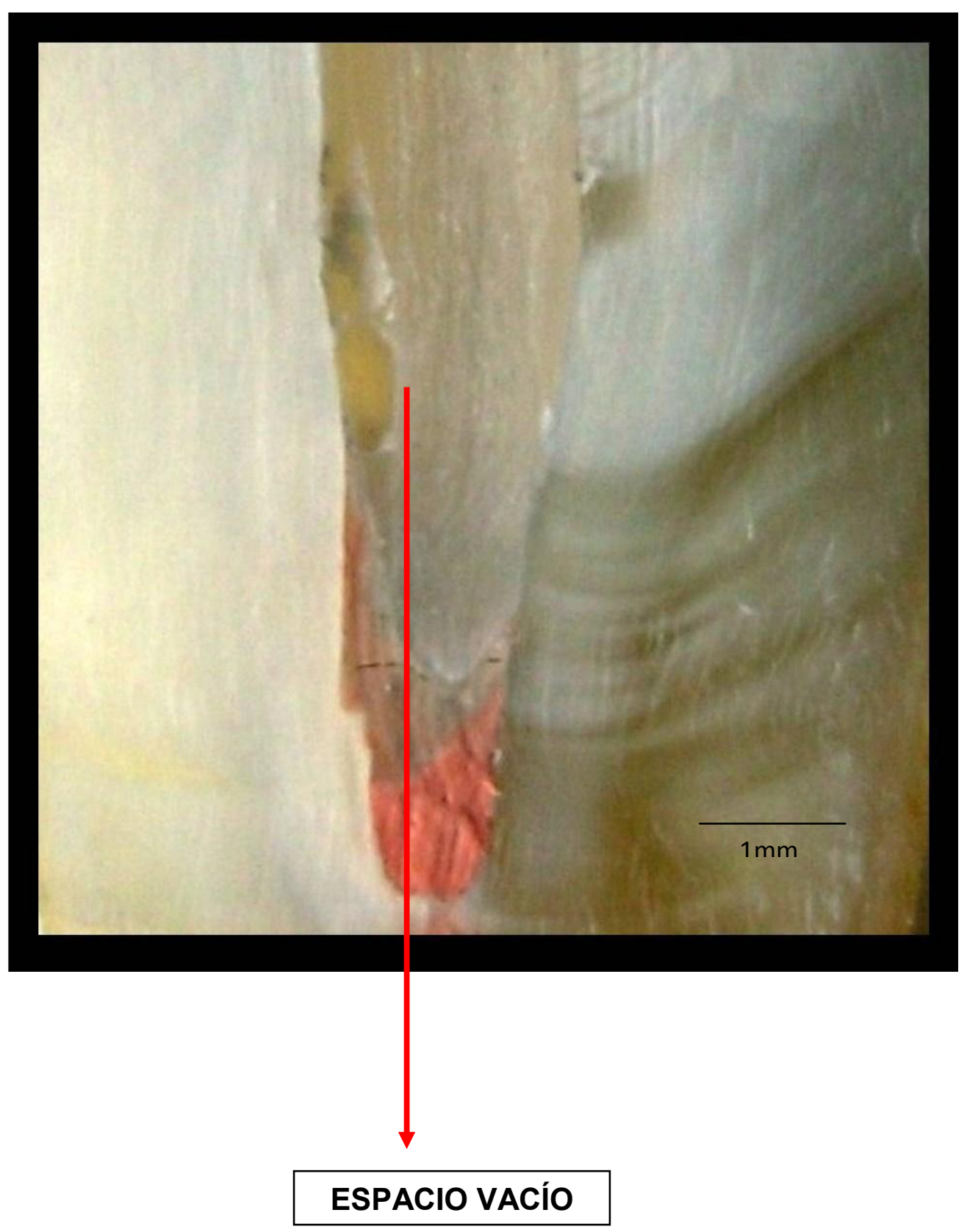

Fig.50 La microfotografía muestra un espacio vacío en la zona lateral apical. 
La Fig.51 muestra un espacio producido en la zona apical donde el perno se debe juntar con el cemento y gutapercha que sellan el conducto.

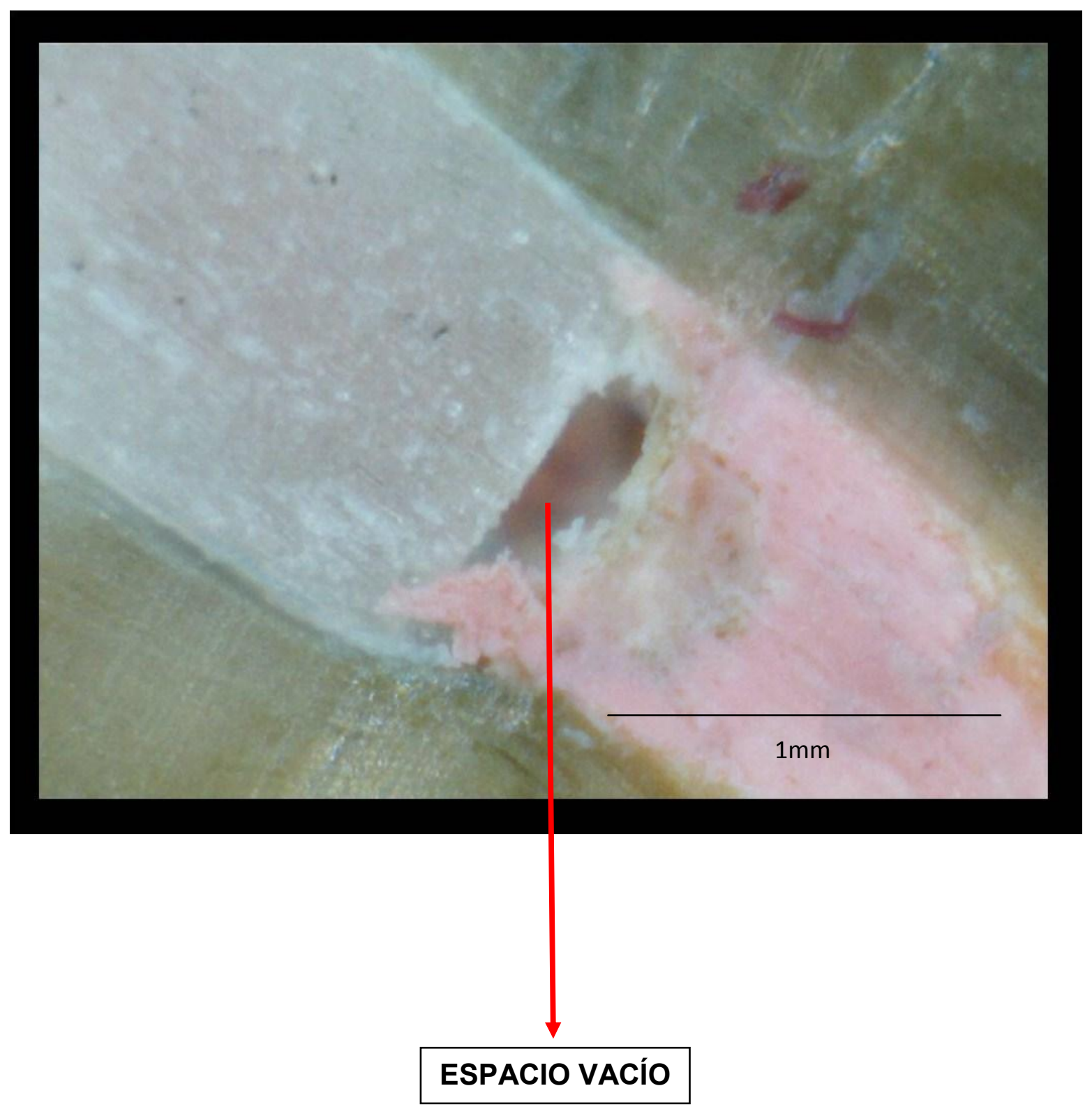

Fig. 51 La microfotografía muestra un espacio sin cemento en la zona apical limitando con la gutapercha y el cemento que cierran el ápice. 
En la Fig.52 se observan cinco espacios sin cemento de pequeño tamaño a lo largo de la muestra.

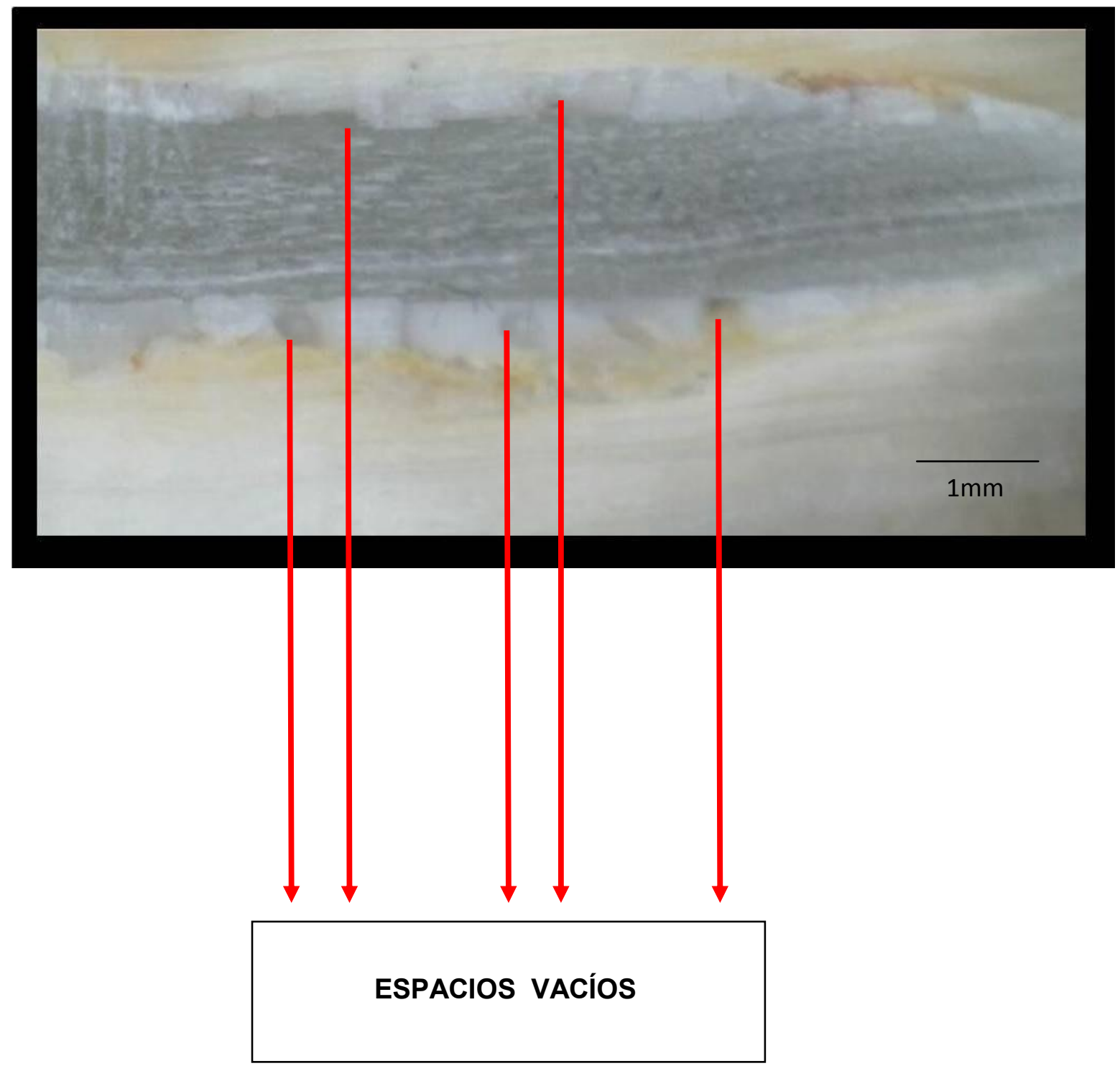

Fig.52 La microfotografía muestra 5 espacios vacíos de pequeño tamaño. 


\subsection{Resultados del estudio de la filtración marginal}

\section{(Penetración de un colorante).}

La Tabla 18 muestra la mediciones de las filtraciones de un colorante utilizando las técnicas de cementado con ionómero vítreo, cemento a base de resina de autocurado y cemento a base de resina de curado dual. Se identificaron los grados en:

0, 1, 2, 3 y 4 según el grado creciente de penetración.

En el grupo donde se utilizó al cemento de ionómero vítreo se observa que en todas las muestras hay filtración del colorante. En dos muestras el colorante llega hasta el tercio apical invadiendo el material de obturación endodóntico ( grado 4). En otras tres invade hasta el tercio apical (grado 3), y en 2 llega al tercio medio (grado 2).

En el grupo de cemento a base de resina de autocurado, en cuatro muestras invade el tercio cervical (grado 1) y en dos el tercio medio (grado 2). Solo en una muestra no se registra filtración (grado 0).

En el último grupo donde se utilizó cemento a base de resina de curado dual se registra un total de cuatro muestras sin filtración (grado 0) y tres muestras que presentan una invasión hasta el tercio cervical (grado 1). 
TABLA18

GRADOS DE FILTRACIÓN MARGINAL (PENETRACIÓN DE UN

COLORANTE)

UTILIZACIÓN DE CEMENTO DE IONÓMERO VÍTREO

\begin{tabular}{|l|l|l|l|l|l|l|}
\hline 2 & 3 & 4 & 2 & 3 & 4 & 3 \\
\hline
\end{tabular}

UTILIZACIÓN DE CEMENTO A BASE DE RESINA DE AUTOCURADO

\begin{tabular}{|l|l|l|l|l|l|l|}
\hline 0 & 1 & 1 & 2 & 2 & 1 & 1 \\
\hline
\end{tabular}

UTILIZACIÓN DE CEMENTO DE RESINA DE CURADO DUAL

\begin{tabular}{|l|l|l|l|l|l|l|}
\hline 0 & 0 & 1 & 1 & 0 & 1 & 0 \\
\hline
\end{tabular}

En la Tabla 19 y gráfico 11 vemos los resultados obtenidos en la penetración de un colorante donde se observa una diferencia mayor del (57\%) de grado 0 en el cemento a base de resina de curado dual, sobre el cemento a base de resina de autocurado (14\%) y en el cemento de ionómero vítreo no se logro que no exista la penetración del colorante. 
TABLA 19

PORCENTAJE DE LOS GRADOS DE PENETRACION DE UN COLORANTE EN LOS TRES CEMENTO

\begin{tabular}{|l|c|c|c|c|c}
\hline \multicolumn{1}{|c|}{ CEMENTOS } & GRADO & GRADO & GRADO & GRADO & GRADO \\
\hline $\begin{array}{l}\text { Cemento de } \\
\text { ionómero vítreo }\end{array}$ & 0 & 1 & 2 & 3 & 4 \\
\hline $\begin{array}{l}\text { cemento a base } \\
\text { de resina de }\end{array}$ & $14 \%$ & $57 \%$ & $29 \%$ & $-29 \%$ & \\
autocurado & & & & & \\
\hline $\begin{array}{l}\text { cemento a base } \\
\text { de resina de }\end{array}$ & $57 \%$ & $43 \%$ & - & & \\
\hline curado dual & & & & & \\
\hline
\end{tabular}

En el grafico 11 se observa los porcentajes obtenidos para cada grado en los distintos cementos utilizados. 


\section{GRAFIC011}

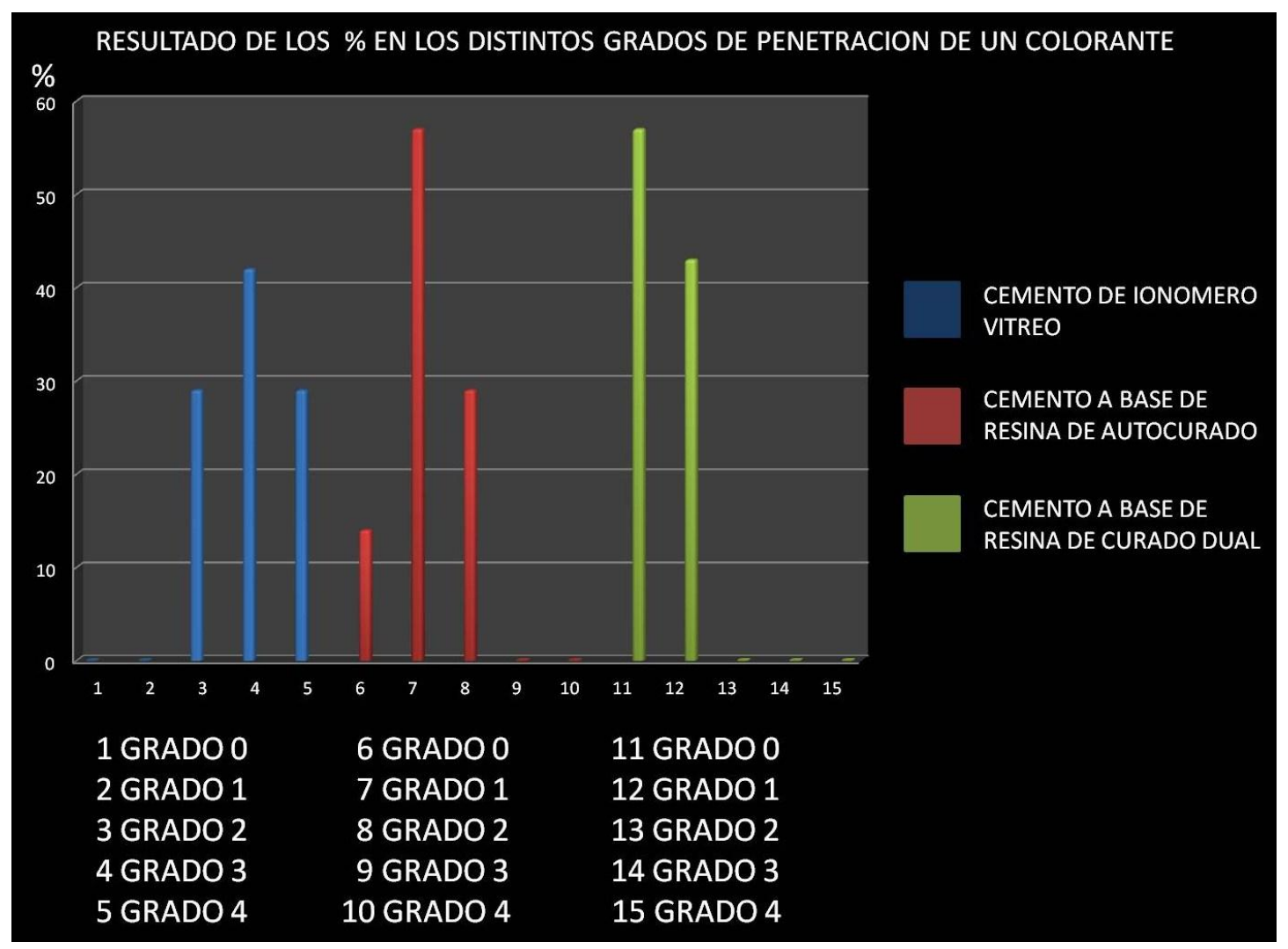

Grafico 11 se observa los porcentajes obtenidos para cada grado en los distintos cementos utilizados.

En las Fig. 53, 54 y 55 observamos ejemplos fotográficos de las observaciones realizadas a las muestras con microscopio donde se aprecian la ausencia de filtración del colorante, penetración a la zona media y la invasión del colorante al material de sellado endodóntico. 


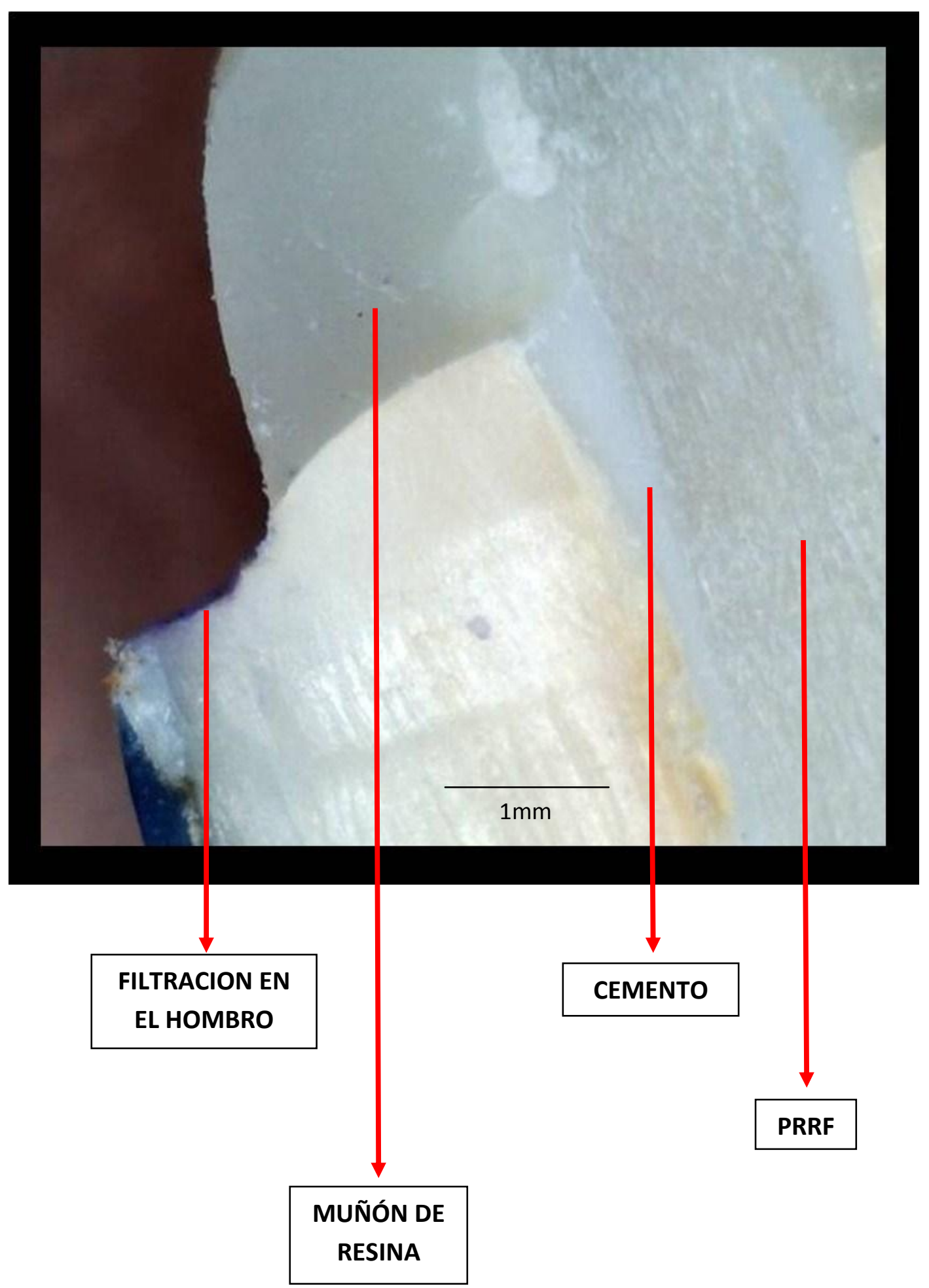

Fig. 53 La microfotografía óptica nos muestra la ausencia de filtración del colorante en la zona cervical, se observa en detalle en un corte longitudinal el perno cementado y la reconstrucción del muñón. 


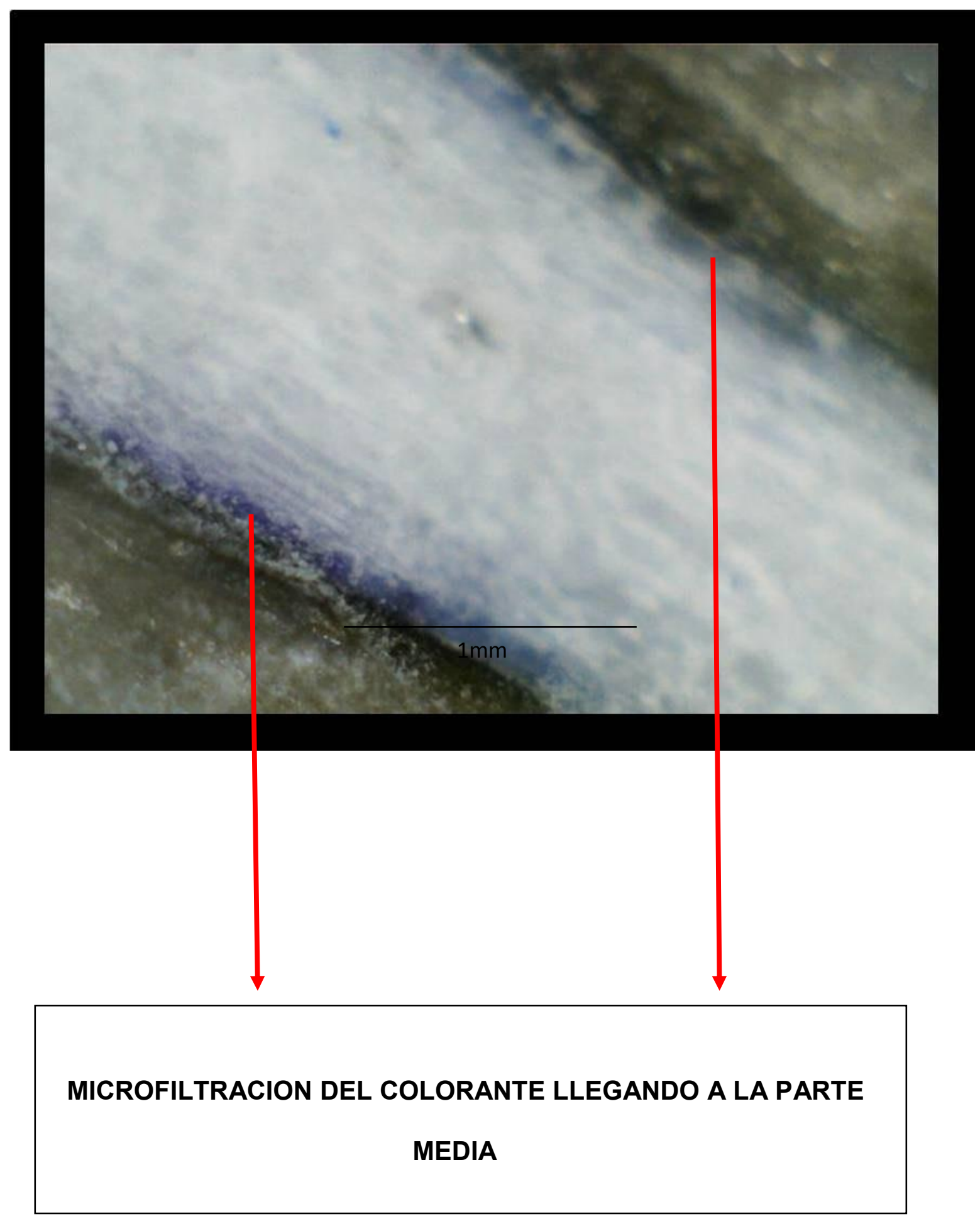

Fig. 54 La microfotografía óptica muestra la filtración a un colorante que penetró hasta el tercio medio. 


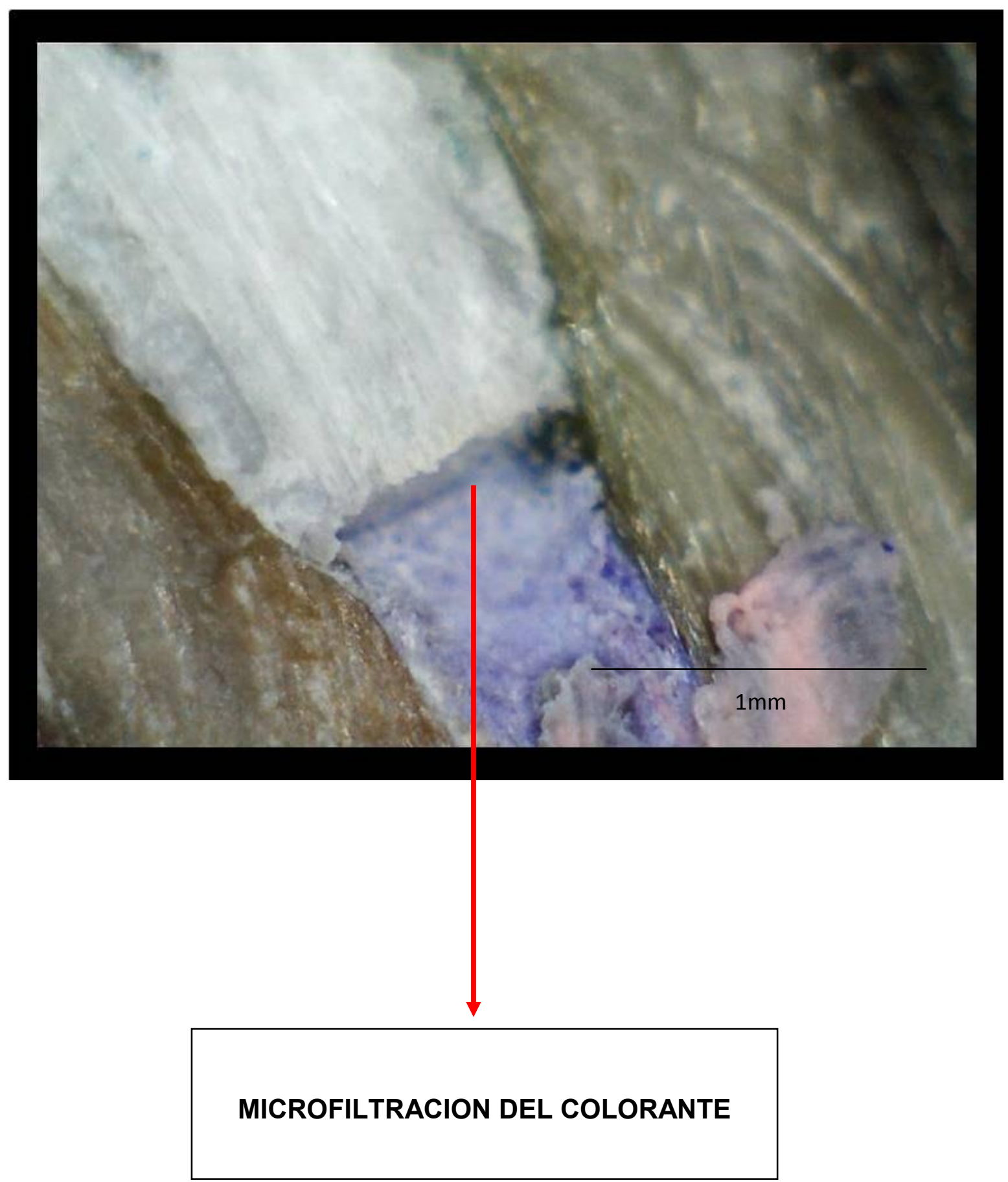

Fig.55 La microfotografía óptica muestra la filtración del colorante que llegó hasta el tercio apical invadiendo el material de obturación endodóntica 


\subsection{Análisis de las interfases PRRF medio cementante y dentina con MEB.}

Los resultados obtenidos en el análisis de los espacios de las interfases cementos - dentina como se muestran en la Tabla 20 y Gráfico 12. Se puede notar una diferencia altamente significativa, $(p<0,001)$ entre los distintos materiales. El cemento de ionómero vítreo es el que mayor interfase presento $(13,5 \pm 2,8 \mu \mathrm{m})$, seguido por el cemento de resina de autocurado, $(4.6 \pm 1,2 \mu \mathrm{m})$ y el que menos interfase dejo fue el cemento a base de resina de curado dual $(1,5 \pm 0,49 \mu \mathrm{m})$.

TABLA 20

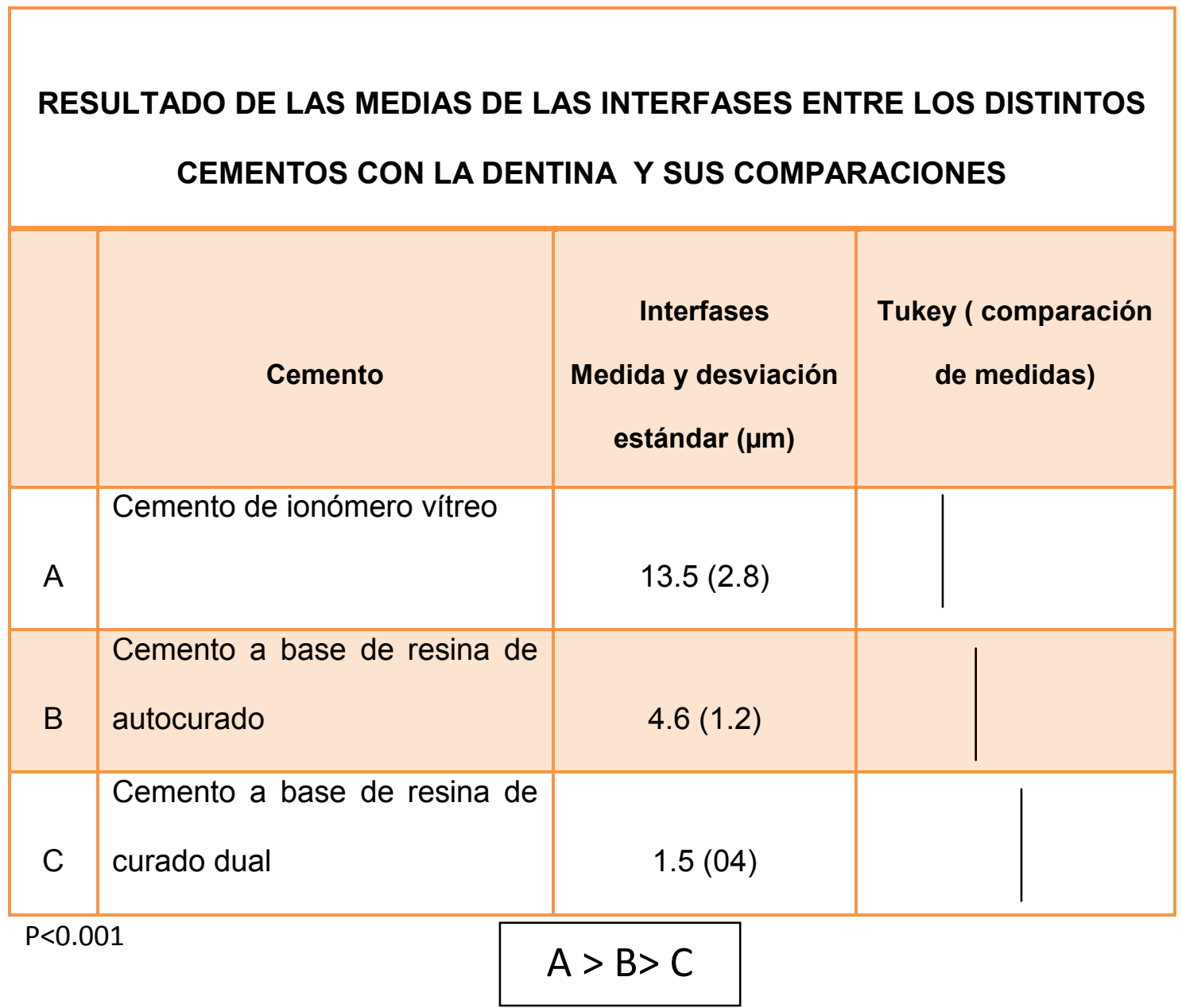




\section{GRAFICO 12}

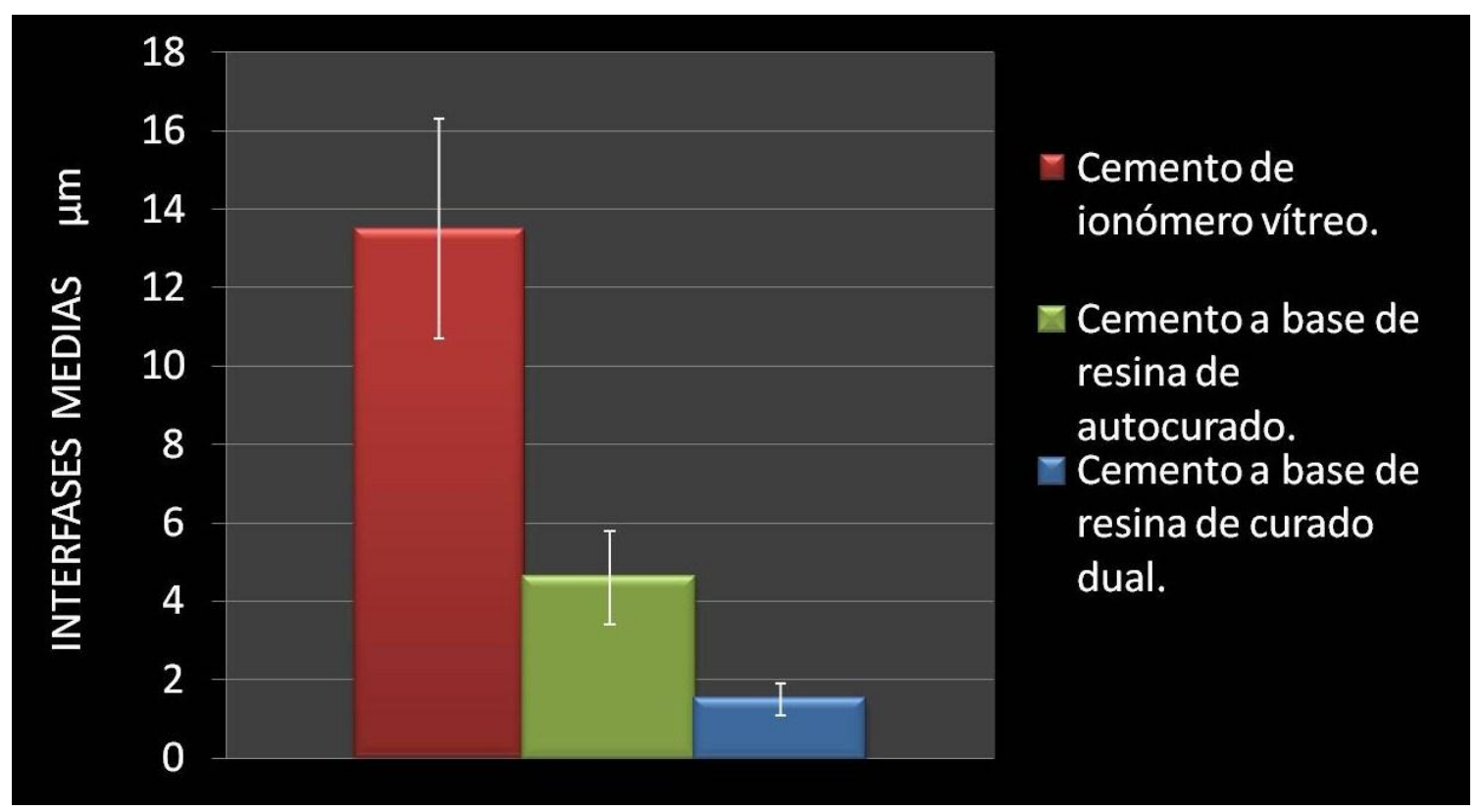

Al realizar el estudio estadístico sobre las interfases cementos PRRF se encontraron diferencias significativas $(p<0,01)$. La mayor interfase se encontró entre el ionómero vítreo y el PRRF $(8.5 \pm 7 \mu \mathrm{m})$, seguido por el cemento a base de resina de autocurado que disminuyó las interfases (6 $\pm 1,5 \mu \mathrm{m})$ y el que mejor se comportó fue el cemento a base de resina de curado dual $(2 \pm 0,5 \mu \mathrm{m})$. La Tabla 21 y el Gráfico 13 muestran las diferencias establecidas. 
TABLA 21

\begin{tabular}{|c|c|c|c|}
\hline & \multicolumn{3}{|c|}{$\begin{array}{l}\text { RESULTADO DE LAS MEDIAS DE LAS INTERFASES ENTRE LOS } \\
\text { DISTINTOS CEMENTOS CON PRRF Y SUS COMPARACIONES }\end{array}$} \\
\hline & Cemento & $\begin{array}{c}\text { Interfases } \\
\text { Medida y desviación } \\
\text { Estándar }(\mu \mathrm{m})\end{array}$ & $\begin{array}{l}\text { Tukey ( comparación } \\
\text { de medidas) }\end{array}$ \\
\hline A & $\begin{array}{l}\text { Cemento de ionómero } \\
\text { vítreo }\end{array}$ & $8.5(7)$ & \\
\hline B & $\begin{array}{l}\text { Cemento a base de } \\
\text { resina de autocurado }\end{array}$ & $6(1.5)$ & \\
\hline C & $\begin{array}{l}\text { Cemento a base de } \\
\text { resina de curado dual }\end{array}$ & $2(0.5)$ & \\
\hline$P<$ & & $A>B>C$ & \\
\hline
\end{tabular}

GRAFICO 13

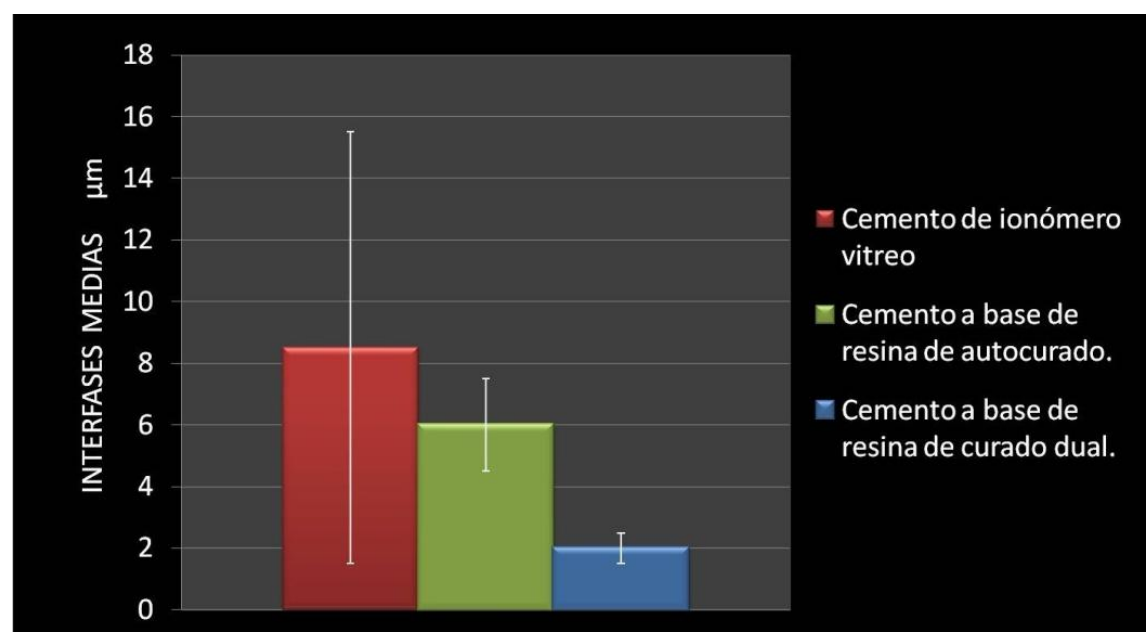


En la Fig. 56 se muestra una microfotografía MEB donde se puede observar en su totalidad una de las muestras, evidenciando todos sus componentes, diferentes tejidos, cemento y PRRF.

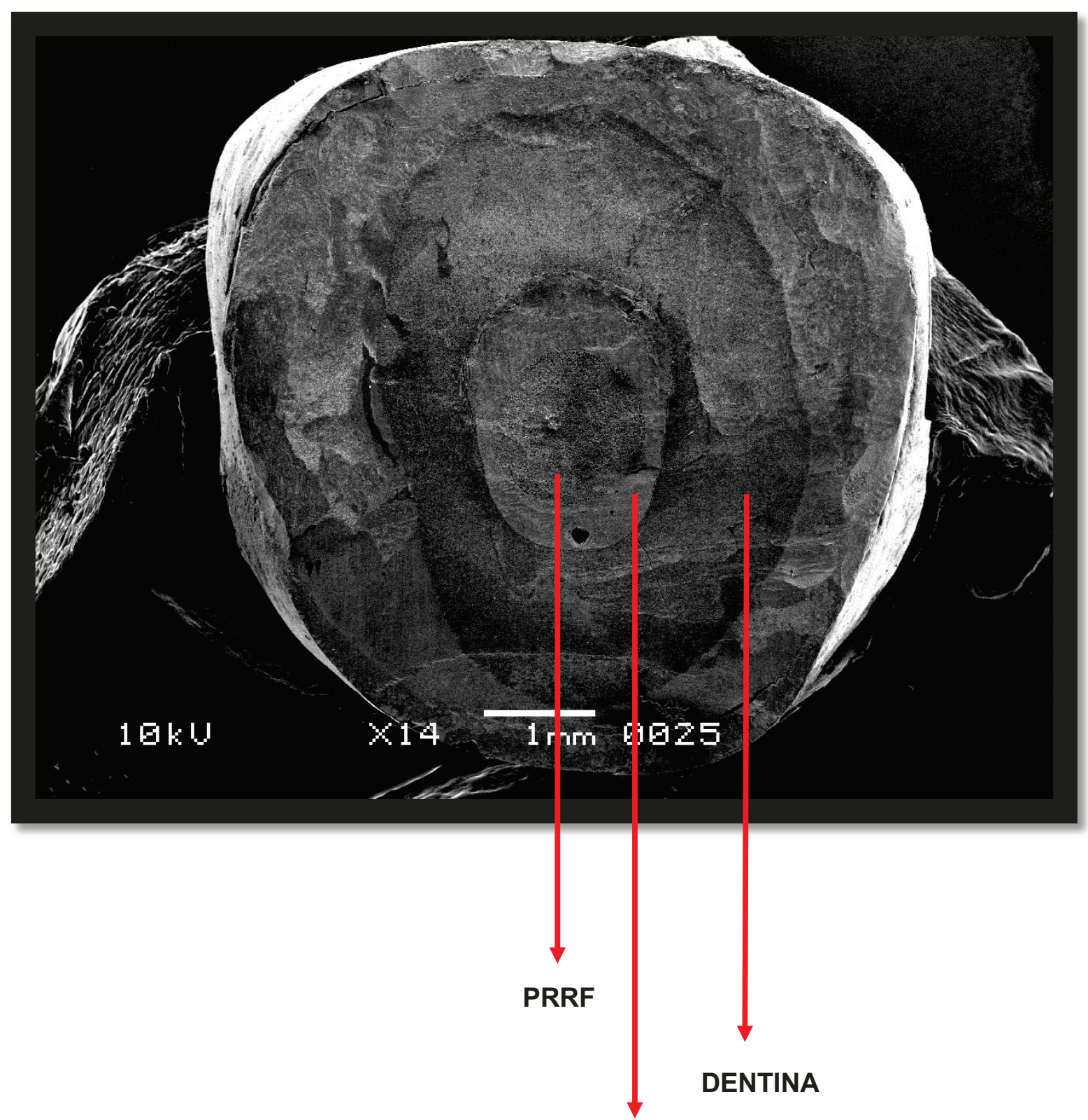

CEMENTO

Fig. 56 La microfotografía MEB muestra una imagen total de la muestra donde se observan todos los sustratos. 
En la Fig.57 se observa una ampliación de la microfotografía anterior donde ya se aprecia una interfase entre cemento y dentina.

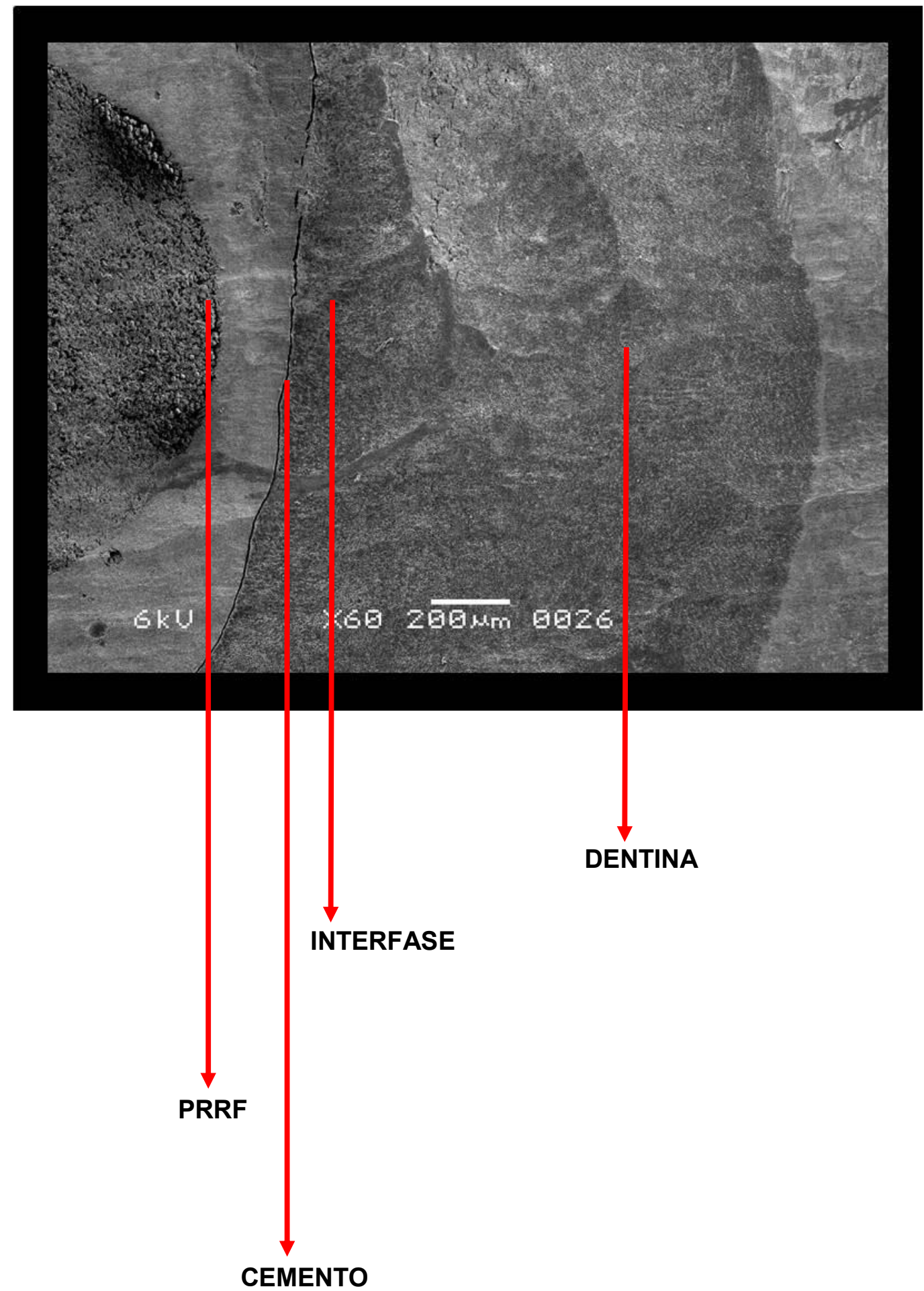

Fig.57 La microfotografía MEB deja en evidencia una interfase cemento dentina 
En la microfotografía de la Fig. 58 se observa la magnificación de la muestra a X650 la brecha entre el cemento y la dentina es de $8 \mu \mathrm{m}$.

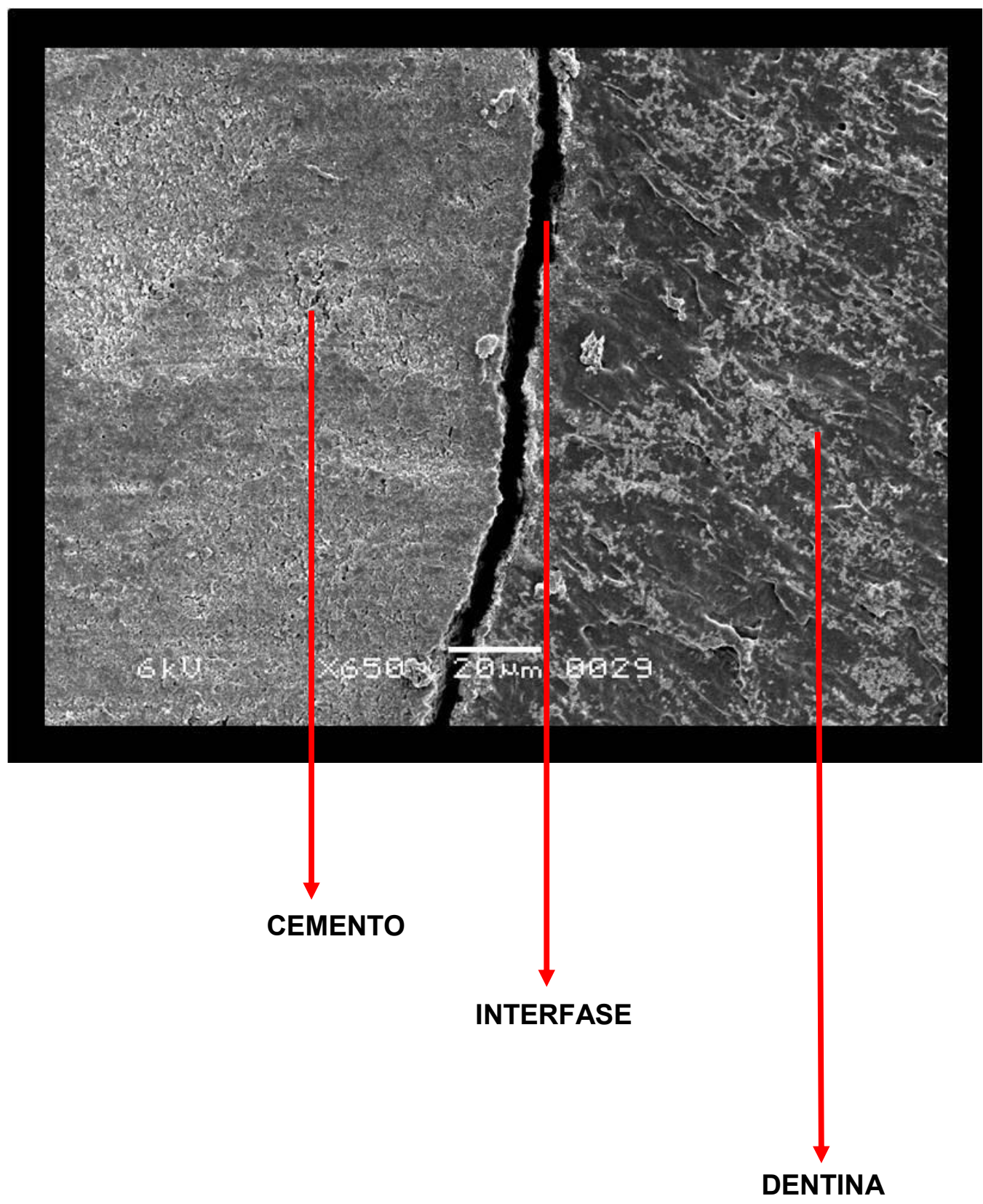

Fig. 58 La microfotografía MEB nos muestra una brecha entre el cemento y la dentina de $8 \mu \mathrm{m}$. 
En la magnificación de la muestra de la Fig.59 se observa la brecha formada entre el complejo cemento - dentina y la formada entre el cemento y el perno.

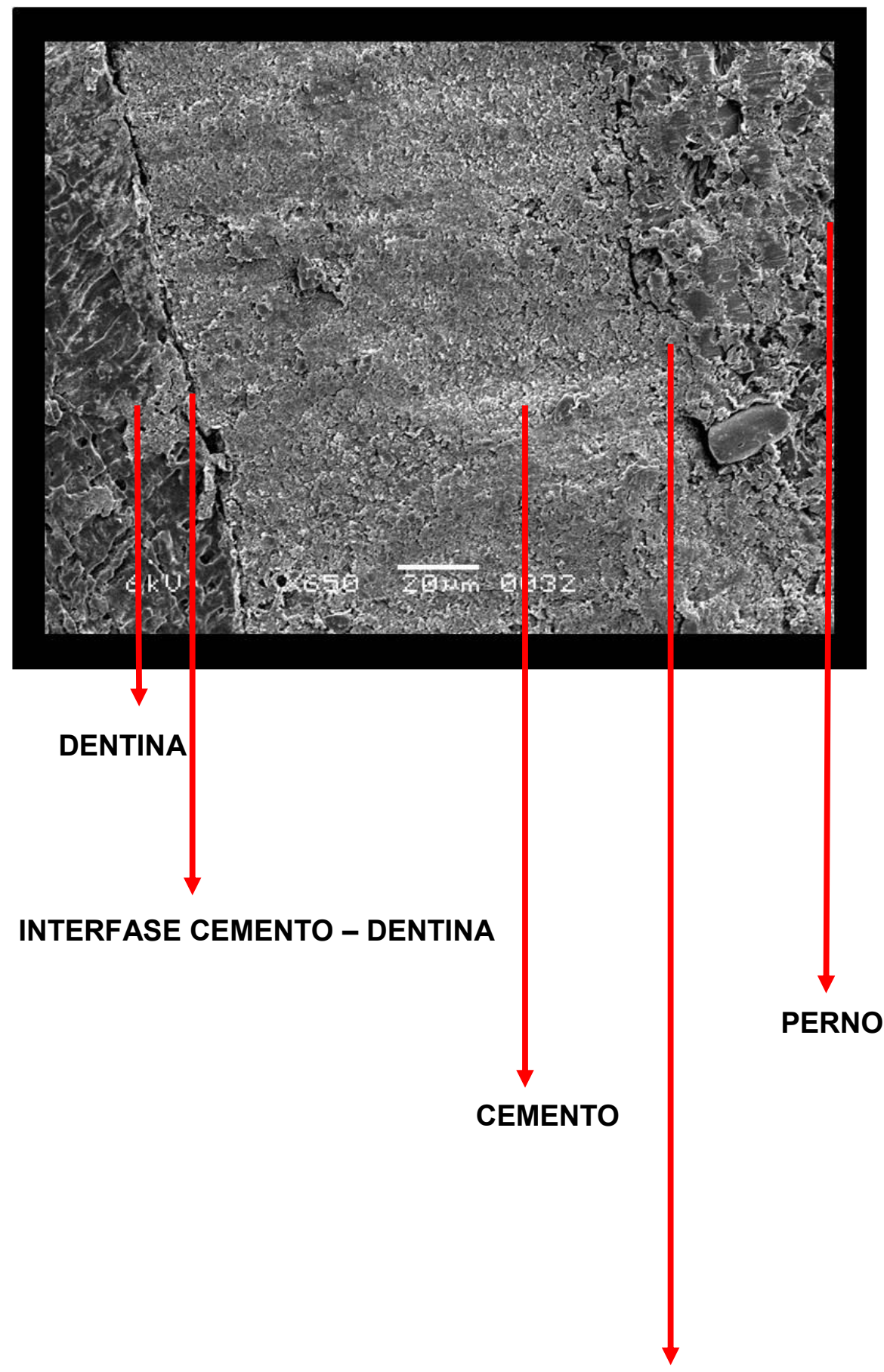

INTERFASE CEMENTO - PERNO

Fig.59 La microfotografia nos mestra las interfases entre los dos complejos cemento - dentina y cemento perno. 
Se puede observar en la Fig.60 que no se produjo ninguna brecha entre el complejo cemento - perno hay una continuidad entre los dos.

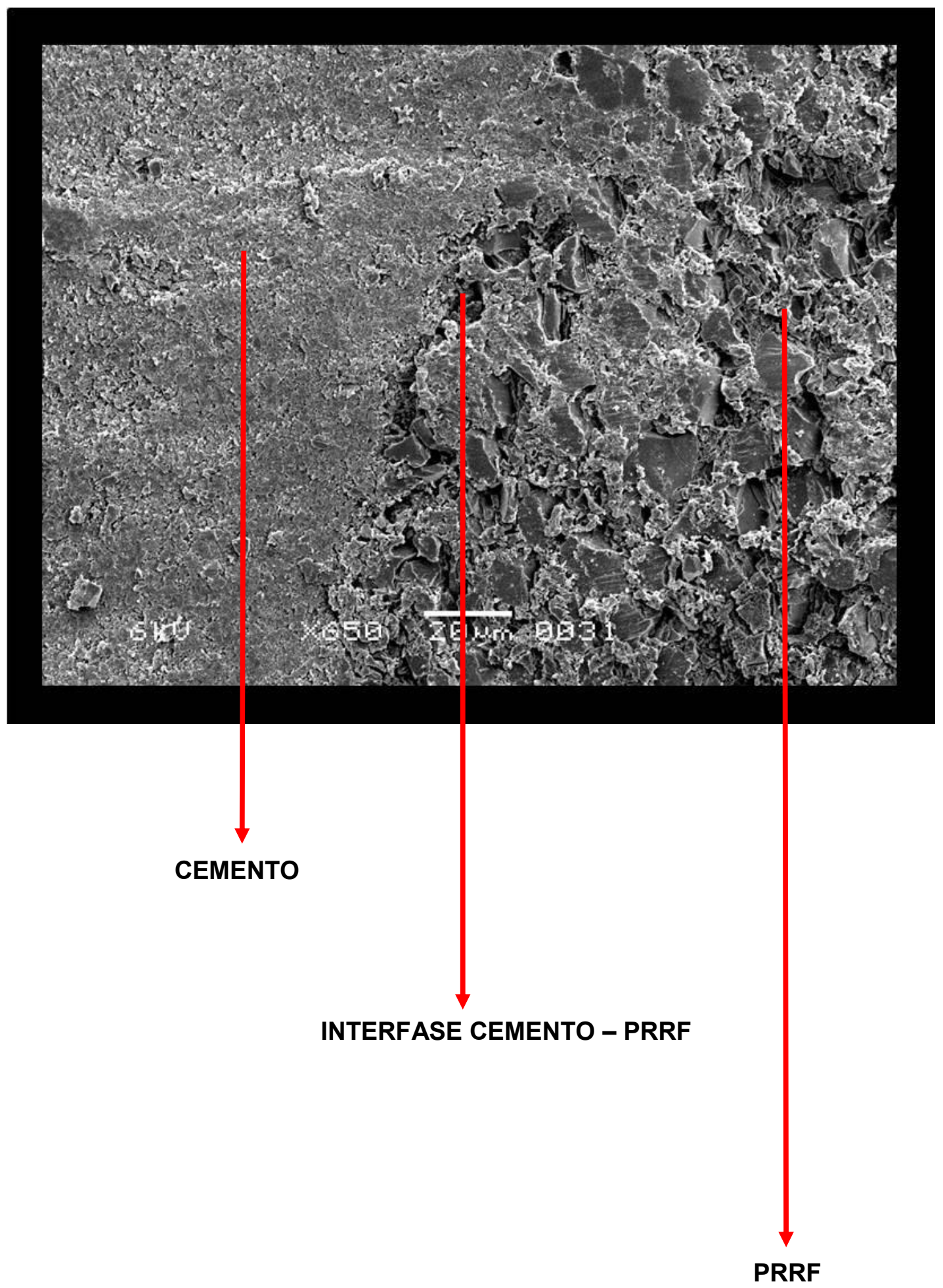

Fig.60 La microfotografía muestra en un aumento de 650x la ausencia en la interfase de brecha. 
En la Fig. 61 se puede ver la interfase PRRF y el cemento donde se presenta una brecha de $6 \mu \mathrm{m}$.

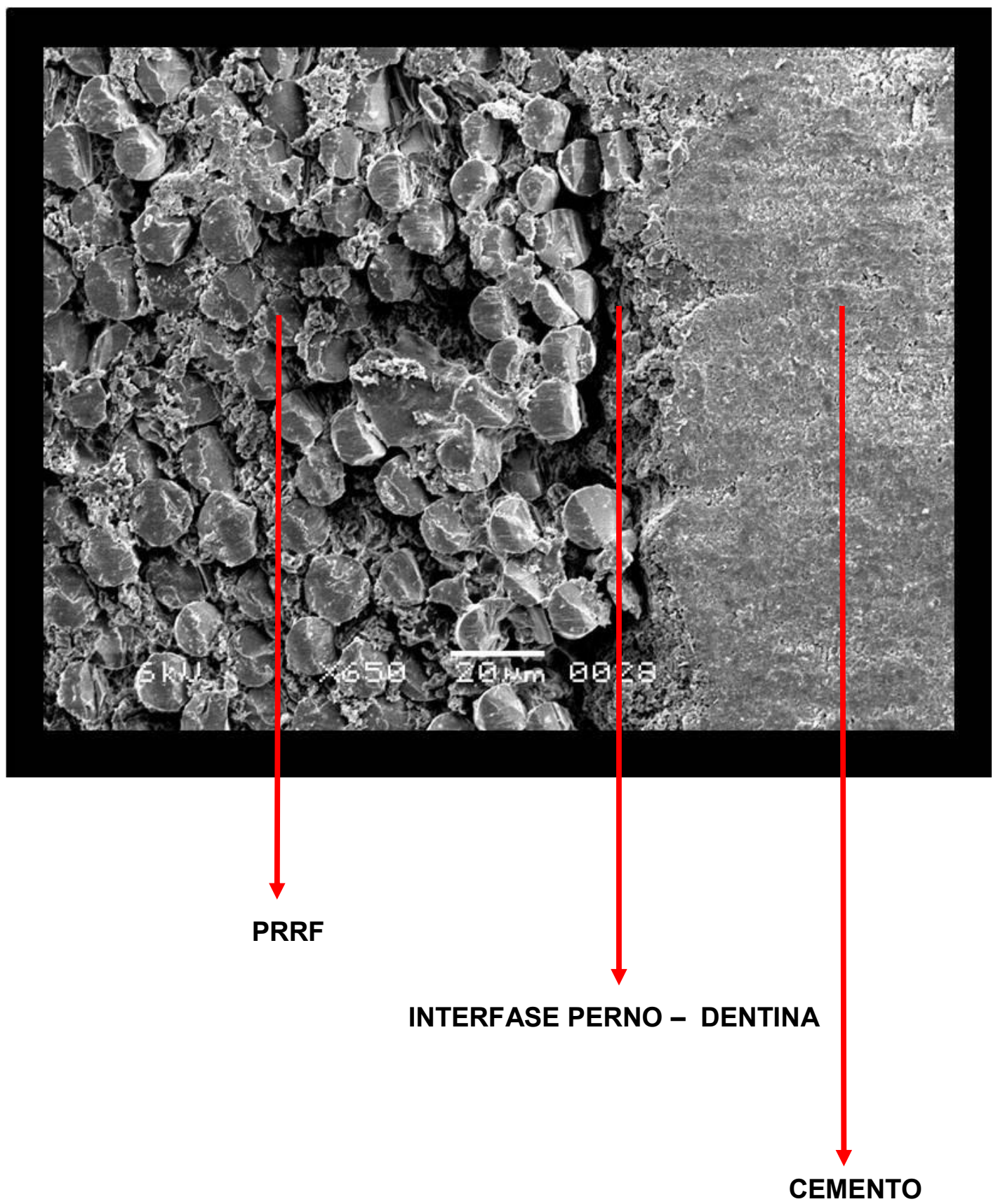

Fig.61 La microfotografía muestra una interfase con una brecha de $6 \mu \mathrm{m}$. 


\subsection{Evaluación con MEB de la formación de tags utilizando los protocolos de los experimentos anteriores para cementar un PRRF.}

En la Fig. 62 se muestra las microfotografías realizadas que dieron lugar a la clasificación que se tomo como modelo para realizar las mediciones de formación de tags en la utilización del cemento de ionómero vítreo, cemento a base de resina de autocurado y cemento a base de resina de curado dual.

La foto 1 (Fig. 62) muestra la ausencia de tags (grado 0 ), la foto 2 muestra la presencia de tags menores a los $10 \mu \mathrm{m}$ y en la foto 3 se observa la presencia de tags mayores a los $10 \mu \mathrm{m}$.

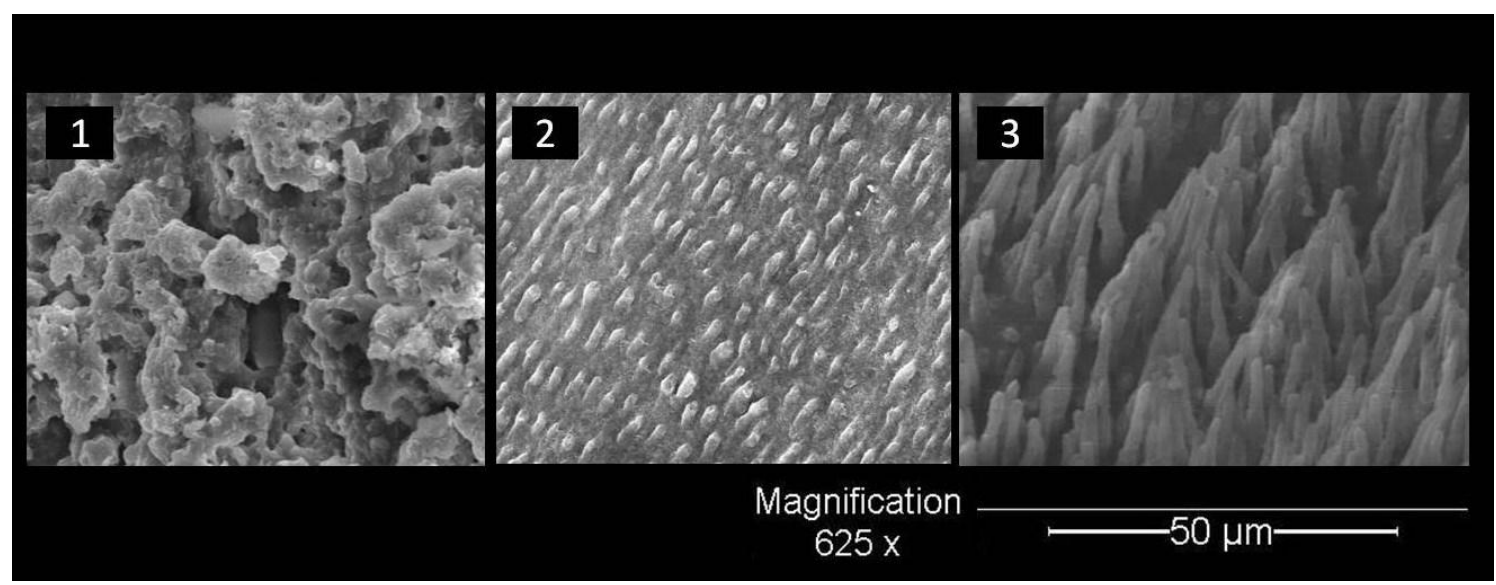

Fig.62 Las microfotografías muestran los tres parámetros utilizados para la visualización de los tags. foto1 no se forman tags, foto 2 formación de tags menores a $10 \mu \mathrm{m}$ y foto 3 formación de tags mayores a los 10 micrones.

Los resultados de las observaciones son los que se pueden detallan en la Tabla 22. Se evidencia que con la utilización de cemento de ionómero 
vítreo no se produjo la formación de tags. Con la utilización de cemento a base de resina de autocurado se obtuvo una mayor cantidad de tags menores a los $10 \mu m$ (grado1) y con la utilización de cemento a base de resina se obtuvieron en mayoría tags de más de $10 \mu \mathrm{m}$ de largo.

\section{TABLA 22}

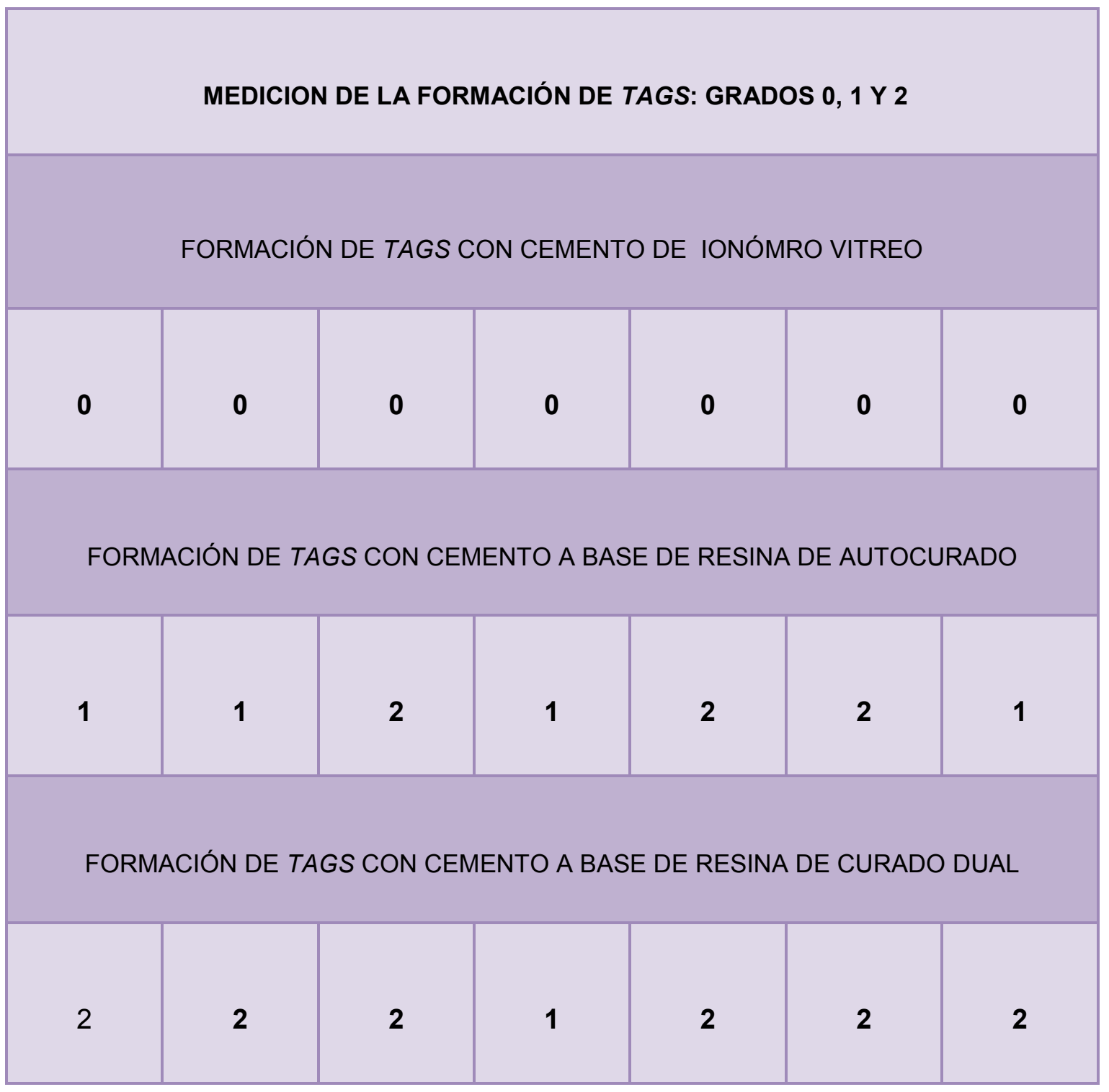

En la Tabla 23 y Gráfico14 se muestran los resultados obtenidos en el grado de formación de tags en los tres tipos de cementación. En el caso 
del cemento a base de resina de curado dual se observa un $85 \%$ de formación de tags grado dos, superior al del cemento a base de resina de autocurado que llegó a un 43\%. Por el contrario, en el cementado convencional con ionómero vítreo no se constató la formación de tags (grado $0=100 \%)$

TABLA 23

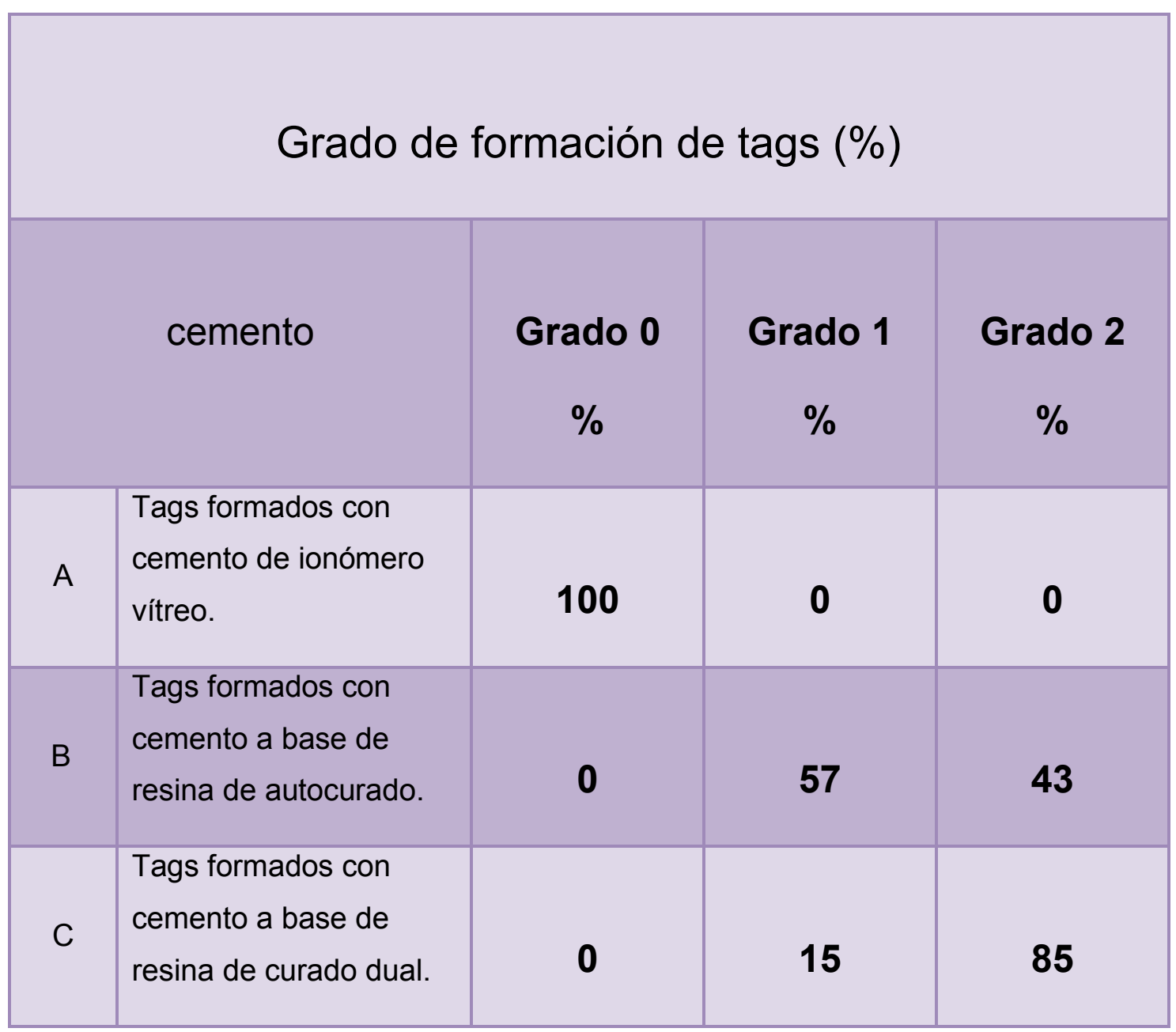




\section{Gráfico 14}

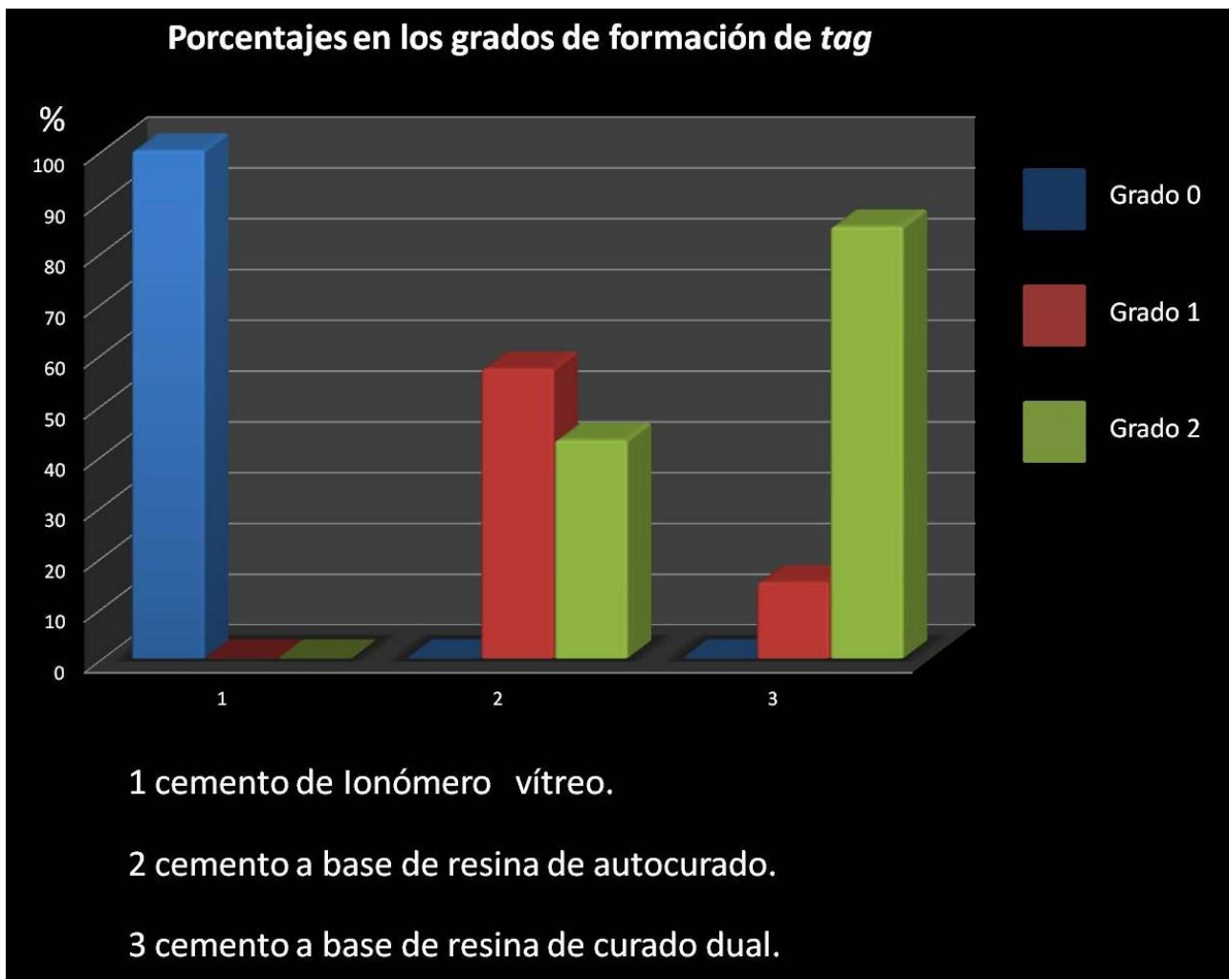


5. DISCUSION 


\section{DISCUSION}

Los PRRF presentan verdaderas ventajas clínicas a la hora de rehabilitar una pieza tratada endodónticamente ${ }^{37-124}$, pero éstas se encuentran supeditadas a varios factores que incluyen un correcto diagnóstico, la perfecta preparación del campo operatorio, la mejor técnica de fijación que pueda aportar traba mecánica y adhesiva en el lecho radicular y la destreza del operador ${ }^{87}$.

En el presente trabajo de tesis se han realizado estudios para encontrar la mejor forma de limpiar a la dentina del lecho que recibirá al PRRF y dejar a los conductillos dentinarios libres así como hallar la técnica ideal para incorporar los cementos al conducto y generar la mínima cantidad de espacios vacios. Con ese propósito, se evaluaron las interfases producidas con los tres cementos elegidos en su relación con la dentina y el PRRF, la filtración a un colorante que estos medios de cementación pueden mostrar y por último la formación de tags que estos presentan.

Factores que influyen en el proceso de adhesión en la dentina del conducto $\underline{\text { radicular }}$

En la dentina coronaria el proceso de adhesión se logra con la formación de la capa hibrida ${ }^{91-109}$, donde la desmineralización del tejido expone la trama de colágeno a la que se le infiltrará in situ un adhesivo. Por ese motivo, los resultados dependerán del colágeno que se encuentra en la 
dentina intertubular para conseguir que esta capa híbrida se forme. En principio podría esperarse que a mayor cantidad de dentina intertubular, mayor cantidad de colágeno, mayor hibridación y mayores valores de adhesión. Si esto fuera así, en el conducto radicular la adhesión debería ser mayor en el área apical ya que tenemos más dentina intertubular y menos túbulos. Sin embargo la realidad es totalmente diferente ya que existen otras variables como la menor posibilidad de visualización, menor control de maniobras clínicas, menor grado de polimerización de los adhesivos y cementos y una mayor influencia del factor de configuración, entre otras.

Para una correcta adhesión dentro del canal radicular son fundamentales la descontaminación del lecho; la apertura de los túbulos dentinarios, exponiendo el colágeno de la dentina intertubular de forma de permitir la penetración y polimerización de los adhesivos dentro de los túbulos dentinarios y la formación de los resin tags que, en el caso de la dentina coronal es considerada secundaria.

\section{Importancia del acondicionamiento dentinario}

Uno de los primeros escollos que se le presenta al clínico luego de diagnosticar el caso indicando la rehabilitación con un PRRF y realizada la desobturación parcial del conducto y remodelación del mismo, es que para evaluar la contaminación del lecho sólo se puede valer de radiografías que muestran, a nivel macroscópico, restos de cemento y gutapercha y para la limpieza microscópica debe confiar en la eficacia de diferentes sustancias irrigantes. 
Terminada la desobturación parcial del conducto y el remodelado de este para recibir el PRRF, nos encontramos con una dentina altamente contaminada con materia orgánica, cemento sellador radicular y gutapercha ${ }^{46}$. Es sabido que los conductos de forma oval o irregular son más problemáticos, ya que la remodelación del conducto para los PRRF es circular y complica la eliminación total de residuos.

Además, de la presencia física de los restos de materiales mencionados se ha reportado que la acción de compuestos fenolicos actuaría en forma negativa sobre la adhesión en el canal radicular ${ }^{72}$. Estudios como los de Hagge $\mathrm{MS}^{54}$ señalan que este efecto es más evidente cuanto más viejo es el tratamiento endodóntico. Sin embargo, otros autores sostienen que dichos efectos son irrelevantes en la adhesión siempre y cuando se limpien de la superficie dentinaria. Se ha reportado que los fenoles pueden extenderse hasta $50 \mu \mathrm{m}$ dentro de los túbulos dentinarios por lo que, en la remodelación del conducto para recibir al perno, se debe eliminar este espesor ${ }^{13-76}$.

La mayoría de los investigadores concuerdan en que la limpieza del lecho es una de las principales claves para la adhesión de los medios cementantes y la resultante integración del tejido dentinario con el $\mathrm{PRRF}^{34}$. Van Meerbeck $\mathrm{B}^{127}$ y colaboradores recomiendan que, para mantener el ambiente libre de contaminación, se realice la irrigación con alcohol durante la preparación del lecho. También Tjan $\mathrm{AH}^{123}$ demuestra que el alcohol puede contrarrestar los efectos negativos sobre la eficacia adhesiva de los fenoles en los selladores endodónticos. 
En el presente trabajo, se evaluó el acondicionamiento de la dentina del canal radicular remodelado para recibir a un PRRF con diferentes sustancias, y el empleo de puntas Navitip que permiten la colocación de estas en el fondo del conducto y limpiar en forma mecánica con sus cerdas cuando se las frota sobre la superficie dentinaria.

Se utilizó, en primera instancia, alcohol yodado al $2 \%$ por ser uno de los antisépticos de mayor uso, por su amplio espectro antibacteriano y por ser activo frente a la materia orgánica. Se realizó una exposición por 30s frotando con puntas NaviTip. Como resultado del mismo se pudo constatar mediante MEB que fue posible eliminar los contaminantes macroscópicos tales como cementos y gutapercha. Sin embargo, pudo demostrarse a través de la misma técnica que el barro dentinario estaba adherido a la superficie de la dentina radicular manteniendo cerrados los conductillos dentinarios. Se pudo constatar la liberación de parte de los conductillos dentinarios cuando se colocó seguido al alcohol yodado ácido fosfórico al $37 \%$ durante 10 s con puntas NaviTip. Como efecto adverso en esta técnica se encontró que es difícil retirar la pigmentación color marrón que deja el alcohol yodado en la dentina y, por otra parte, se logró exponer los conductillos dentinarios sólo cuando se combinó el alcohol yodado con el ácido fosfórico al $37 \%$ durante 10s aumentando los tiempos de trabajo, materiales a utilizar y costos.

Se han propuesto distintos métodos alternativos para la limpieza dentinaria. Gomez y Kina ${ }^{50}$ recomiendan limpiar con EDTA durante dos minutos y posteriormente lavar con hipoclorito de sodio al $2 \%$. Berruti y colaboradores en el libro de Scotti y Ferrari ${ }^{112}$ proponen emplear EDTA al 
$10 \%$ combinado con hipoclorito de sodio al 5\%. Otros autores ${ }^{15-} 29$ demostraron que el EDTA al 17\% combinado con el hipoclorito de sodio es eficaz para eliminar el barro dentinario.

En el presente trabajo se decidió no utilizar hipoclorito de sodio en ninguna de las técnicas ya que no tiene capacidad para remover el barro dentinario $^{73-28}$ y, si bien combinado con otras sustancias lo hace y deja túbulos abiertos, se ha reportado que genera destrucción de la dentina intertubular y reducción de su microdureza ${ }^{108-95}$. Otro motivo por el que no se utilizó el hipoclorito de sodio fue su carácter oxidante que puede alterar la polimerización de adhesivos y cementos resinosos y posteriormente disminuir la adhesión final ${ }^{110}$.

Cabe destacar que en los ensayos del presente trabajo, al utilizar EDTA al $19 \%$ aplicado y frotado contra las paredes con puntas NaviTip durante 30s se consiguió eliminar los residuos macroscópicos de cementos y gutapercha, pero el número de túbulos dentinarios abiertos fue menor al que se obtuvo con la combinación alcohol yodado y ácido fosfórico. Esta metodología se vio superada cuando se siguió a la limpieza del EDTA con el tratamiento de ácido fosfórico al $37 \%$ durante 10 s colocado y frotado con puntas NaviTip, pero se incurrió también en mayores tiempos clínicos y costos. En la observación de las microfotografías de MEB se puede notar una degradación superficial de la dentina. Lostaunau y colaboradores ${ }^{68}$ reportaron que obtuvieron resultados aceptables con EDTA al 17\% para tratar la superficie dentinaria que recibirá sistemas adhesivos, pero los valores informados corresponden a estudios realizados sobre dientes 
bovinos donde los conductillos dentinarios difieren en un mayor tamaño anatómico comparado con el de los humanos.

Nuestros resultados con ácidos fuertes como el ácido fosfórico al 37\% concuerdan con los obtenidos por Ferrari ${ }^{34}$ y Uribe Etchevarria ${ }^{126}$. Ellos observaron que dichos ácidos disuelven el barro dentinario y diversas sustancias contaminantes al tiempo que abren los túbulos dentinarios y exponen el colágeno de la dentina intertubular mejorando así los resultados adhesivos y posibilitando la formación de los tags de resina. La diferencia que propone el presente trabajo es que dichos resultados se consiguieron con un tiempo de aplicación del ácido fosfórico menor (10s) pero aplicado en forma activa (frotando el ácido contra las paredes del conducto con puntas NaviTip). Esto implica una importante ventaja operatoria en tiempos clínicos. Es decir, la utilización de esta técnica combinada química mecánica nos lleva a una mayor cantidad de túbulos dentinarios abiertos en una menor cantidad de tiempo y pasos operatorios.

Es de destacar que esta técnica mixta sigue siendo delicada, lo que hace primordial la correcta realización del aislamiento del campo operatorio. La utilización de la punta NaviTip asegura la llegada del ácido fosfórico a la profundidad del lecho. Por otra parte sus cerdas ayudan a barrer el barro dentinario al frotar el ácido sobre la dentina. Es importante señalar que posteriormente es necesario asegurarse de la total eliminación del ácido con abundante agua impulsada por una jeringa tipo Luer y que su aguja llegue a tocar el fondo del conducto radicular tratado y asegurando el éxito en dicha tarea de desacidificación. Por lo antes expuesto, esta es la mejor técnica de 
limpieza entre las evaluadas, lo que la hace recomendable para el uso clínico.

Medios y sistemas cementantes y PRRF. Sus propiedades

Los medios cementantes deben reunir ciertos requisitos para ser considerados como aptos para el cementado de restauraciones dentales entre ellos kuraray $\mathrm{J}^{63}$ : biocompatibilidad, bajo espesor de película, alta resistencia compresiva, radiopacidad, unión adhesiva a todos los sustratos, insoluble en medios bucales, fácil aplicación, liberación de flúor, disponibilidad de colores. Lo dicho nos lleva a reflexionar que es improbable que un medio cementante reúna todas las cualidades mencionadas.

Por los conceptos expuestos se observa la importancia en la determinación del medio cementante adecuado para utilizar con los PRRF y conferir la protección de la pieza dentaria ante fuerzas funcionales, parafuncionales y ante la invasión bacteriana.

En este trabajo se utilizó un cemento convencional como el cemento de ionómero vítreo y dos sistemas de cementado adhesivo, cemento a base de resina de autocurado y el otro de curado dual, utilizándose para los dos un adhesivo de $5^{\circ}$ generación.

Vale aclarar que variables como la mezcla manual o mecánica del medio cementante pueden influir directamente sobre las propiedades de material. Cabe mencionar que en este trabajo toda la selección de presentaciones de los medios cementantes utilizados correspondió a los de mezcla manual ${ }^{31}$. 
En relación al ionómero vítreo es importante mencionar que estos materiales, mediante su adhesión química a la estructura dentinaria, alcanzan valores muy bajos de adhesión a los sustratos dentarios ${ }^{12-}$ ${ }^{131}$.Desde el desarrollo de estos materiales muchos investigadores ${ }^{86}$ hicieron hincapié en la adhesión química, mediante el ácido poliacrilico a varias estructuras, especialmente a la sustancia inorgánica del esmalte y la dentina. Sin embargo, debemos tener en cuenta que la fuerza de unión que presentó no fue la deseable.

Debe considerarse que el cemento de ionómero vítreo que se empleó en este trabajo no se utiliza en conjunto con ningún sistema adhesivo como puede suceder con otras marcas comerciales. No obstante se ha aumentado la adhesión con sustancias capaces de eliminar el barro dentinario $^{42}$, como el ácido poliacrílico. De esta forma fue posible dejar expuesto el elemento inorgánico para ser atrapado por los grupos carboxilos específicos del material. Sin embargo, aun respetando este principio, los resultados no fueron satisfactorios.

Cuando se comparan los procesos de solidificación del ionómero vítreo con los de cementos a base de resina se puede constatar que existen diferencias muy importantes, Tema desarrollado en el apartado (1.10.1.1) y en el (1.10.2.1), estos procesos están relacionados con la formación de interfases, tal como se discutirá más adelante.

Un factor para destacar en este experimento, fue la necesidad de repetir varias veces la confección de probetas para los grupos donde se utilizó cemento de ionómero vítreo, pues durante el corte de las piezas 
dentarias hubo numerosos desprendimientos del material que daban cuenta de su baja adhesión.

El adhesivo y el medio cementante deben ser activados adecuadamente por las siguientes razones: a) deben poder establecer la correcta adhesión entre el poste y la dentina radicular; b) deben lograr adecuadas propiedades físicas (al mejorar el grado de conversión se mejora la dureza superficial y la resistencia la fractura ${ }^{59}$ ); c) deben poder asegurar una fijación durable en el tiempo ${ }^{33}$; d) deben reducir el fenómeno de pasaje de agua a través de la capa adhesiva.

Al emplear cementos a base de resina de curado dual deben considerarse las siguientes variables: a) la activación química de los adhesivos y el cemento a base de resina de curado dual determinan en general un bajo grado de polimerización. Esta situación sería la más habitual en un conducto radicular ${ }^{3}$; b) el grado de conversión de adhesivos y cemento a base de resina de curado dual cuando son activados únicamente por una reacción química es variable entre las marcas comerciales y en algunos casos muy baja ${ }^{3}$; c) el grado de conversión del adhesivo y el cemento a base de resina de curado dual aumenta con el tiempo después de la fijación, (es considerable la diferencia al pasar las $24 \mathrm{hs}{ }^{39}$ ); d) el grado de conversión aumenta siempre que la activación química se asocie a la activación física con luz azul ${ }^{65}$.

El empleo de adhesivos y cementos a base de resina de autocurado fue planteado por Gomez $\mathrm{JC}^{50}$ como una solución dejando de lado los cementos a base de resina de curado dual, especialmente cuando no se 
pueden fotoactivar. Sjogren y $\operatorname{col}^{116}$. concluyen en que los cementos a base de resina de autocurado alcanzan rendimientos adhesivos adecuados y se evitan los problemas técnicos de la activación por luz dentro del conducto.

Los componentes de los PRRF, en particular la matriz empleada en su confección, tienen una importancia fundamental en el proceso de adhesión. La resina epóxica empleada como matriz en gran parte de los PRRF tiene un alto grado de cadenas cruzadas y pocos grupos funcionales para reaccionar con los metacrilatos de la resina de los cementos a base de resina y con el composite de reconstrucción del muñón. En este sentido, los PRRF con matrices de resina a base de dimetracrilato como el Bis GMA o UDMA por su menor grado de conversión y persistencia de radicales libres podrían tener más probabilidad de conseguir adhesión química ${ }^{35}$. Como se discutirá más adelante una propiedad importante es la traslucidez del mismo, en particular cuando se lo emplea con una resina de curado dual.

Se coincide con lo propuesto por Sadek $\mathrm{FT}^{107}$ y colaboradores que es probable clínicamente que la adhesión entre el PRRF y el cemento a base de resinas y los cementos de ionómero vítreo dependa mayormente de las uniones micromecánicas generadas por la rugosidad de la superficie del PRRF al ser infiltradas por el material cementante y o su adhesivo.

Técnicas de transporte del cemento al lecho remodelado para el PRRF. Relación con los espacios vacíos generados.

Los estudios realizados sobre la utilización de los pernos de resina se focalizan en su diseño, particularmente cuál es el más retentivo o cómo distribuyen el estrés de cargas a las que se somete el diente. Las técnicas 
con que éste es cementado difieren según los distintos investigadores y, en algunos casos, no se les asigna la importancia debida, aún cuando son fundamentales para poder lograr que todo el sistema diente- cemento -

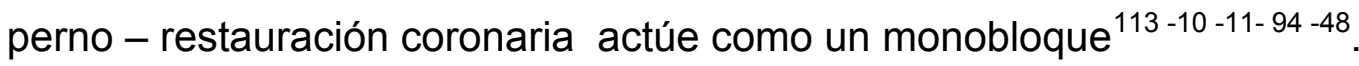

La utilización de cementos de ionómero vítreo y los cementos a base de resina son en principio técnicas muy sensibles. La mala manipulación de los mismos puede conferir defectos graves en la adhesión y traer aparejada la formación de burbujas en la interface que se pueden evidenciar en la reducción de la rigidez estructural al quedar espacios sin unión entre el perno y la dentina. Por otra parte esta baja adhesión puede conducir al desalojo del perno ${ }^{136}$.

En la clínica la forma de llevar los cementos al interior del lecho es un tema de controversias, donde profesionales eligen técnicas muy rápidas y simples como llevar el cemento sobre el perno (embadurnado), este modus operandi consiste en colocar el cemento en el perno con espátula o con pinceles y conducirlo al lecho del canal. En ese caso no debe procurarse una inserción inmediata ya que la presión hidrostática de 19,8 psi tiende a desalojarlo o asentarlo de forma incorrecta. Existen otros protocolos que son seguidos para la inyección del cemento, estos suelen ser eficaces y en ellos se recomienda colocar al cemento desde el fondo del conducto y luego de llenado introducir el perno. Sin embargo se requieren elementos muy costosos y difíciles de conseguir en nuestro país y no siempre logran llegar al fondo del canal remodelado. 
En este trabajo se compararon tres técnicas de llevar el cemento: con el perno (embadurnado), llevarlo con lentulo y llevarlo con lentulo más el agregado de cemento en el PPRF. Dichas técnicas se emplearon con tres tipos de cemento, cementado convencional con cemento de ionómero vítreo, cementado adhesivo con dos tipos de cemento: a base de resina de autocurado y a base de resina de curado dual.

Es de destacar que se tuvo en cuenta el riesgo de poder acelerar la polimerización por anaerobiosis al desplazar los cementos con instrumental rotatorio como el lentulo y posteriormente colocar el PRRF.

El análisis estadístico de los resultados de la comparación de técnicas en las condiciones que fue realizado este estudio, permitieron demostrar, que la técnica del lentulo más la aplicación en el perno, (embadurnado) es la que presento mayor eficacia demostrado por una menor cantidad de espacios vacios en la interfase entre el poste y el canal radicular.

Los resultados fueron similares a los estudios de Golstein et. al. ${ }^{49}$, quienes en base a observaciones microscópicas de los espacios vacios de cemento concluyeron que la técnica del lentulo es la más eficiente, la diferencia radicó en que cementó postes metálicos al conducto con cemento de fosfato.

Asimismo Shillingburg ${ }^{114}$ en un estudio de cementación de pernos al canal radicular, encontró que la retención del poste puede ser incrementada hasta el $90 \%$ si se utiliza el lentulo y demostró que embadurnar el PRRF con cemento resulta en la generación de una capa incompleta del mismo. Esta 
situación se repitió en el presente estudio al embadurnar los tres tipos de cementos sobre los PRRF.

Al respecto es interesante señalar que al colocar los tres tipos de cemento sobre el PRRF se lo embadurna sobre la parte superior del cuerpo en posición horizontal, cuando se lo posiciona en forma vertical para insertarlo en el lecho es probable que, al hacer presión para obtener su asentamiento, no se logre esparcir uniformemente sobre toda el área de la superficie que se dispone para la adhesión. En esta técnica los tres tipos de cemento mostraron la mayor cantidad de espacios en la zona cervical asociándose esta situación a la presión manual ejercida sobre el PRRF para alcanzar el mayor esparcimiento del cemento, también se relaciona al hecho de que en esta zona, por la forma anatómica del canal radicular, el cemento tiene su máximo espesor.

El análisis estadístico de los resultados obtenidos ha mostrado que el cemento de ionómero vítreo fue el que más espacios dejó, debido a que durante su manipulación (polvo- líquido) requiere de un espatulado y porque entre sus partículas de polvo siempre queda lugar ocupado por aire que se asocia a la aparición de espacios vacíos.

En el estudio de comparación de medias (Tukey) utilizando las tres técnicas para introducir el cemento de ionómero vítreo no se encontró diferencia significativa al momento de colocarlo con lentulo y con lentulo más el embadurnado del perno. Sin embargo, estas técnicas fueron mejores que la aplicación con el embadurnado solo. Cabe mencionar que al utilizar la técnica de colocación del cemento con lentulo el cemento es esparcido tanto 
en el fondo como en las paredes y no depende de la presión para lograr llegar a toda la superficie disponible para la adhesión.

En el caso del cemento a base de resina de autocurado mediante el método estadístico de Tukey de comparaciones múltiples se demostró que existe diferencia significativa entre llevarlo con el perno y las otras dos técnicas, pero no se encontró al igual que en el caso del ionómero vítreo, una diferencia significativa entre llevarlo con lentulo y llevarlo con lentulo más el embadurnado del PRRF.

Con respecto al cemento a base de resina de curado dual al comparar las tres técnicas se obtuvieron diferencias significativas entre ellas. La de mayor formación de espacios vacios fue la del embadurnado del PRRF y la que menos espacios mostró y, por lo tanto la mejor, es la que lo lleva con lentulo más el embadurnado del PRRF.

Haciendo las comparaciones múltiples entre la misma técnica con los diferentes tipos de cemento encontramos que al llevar los cementos con el PRRF (embadurnado) hubo diferencia significativa entre los tres grupos. Entre ellos el que menos cantidad de espacios dejo fue el cemento a base de resina de curado dual.

Cuando se los aplico con lentulo no se encontró diferencia entre los dos tipos de cementos a base de resina pero sí fue significativa entre estos y el cemento de ionómero vítreo, que resultó ser el peor material para introducirlo en el lecho con esta técnica

Al aplicarlos con lentulo más la aplicación en el perno (embadurnado) los resultados comparativos muestran que el cemento de ionómero vítreo y 
el cemento a base de resina de autocurado no mostraron diferencias. Sin embargo, fue significativa la diferencia para el cemento a base de resina de curado dual sobre estos dos últimos, por lo que esta combinación resulto ser la más eficaz.

Las variaciones observadas en el comportamiento de los distintos materiales ensayados se las puede atribuir a las diferencias en la consistencia que toman dichos materiales al ser preparados. La mayor fluidez del cemento a base de resina de curado dual resultó ser la más ventajosa.

Se ha mostrado en este trabajo que la utilización del lentulo es muy ventajosa para distribuir de la mejor manera la capa de cemento en el canal radicular. El lentulo demostró ser un instrumento rotatorio que, además de esparcir los cementos, ayuda a eliminar las burbujas que puedan encontrarse contenidas en los cementos fluidos, sobre todo las que puedan situarse en el fondo de la preparación debido al ángulo cerrado que se forma durante la conformación del lecho.

$\underline{\text { Relación entre los medios cementantes con la generación de brechas en las }}$ interfases dentina-cemento-PRRF

El efecto marginal es una de las fallas que ocurren frecuentemente en las técnicas de fijación. Estas fallas o fracturas, pueden ocurrir por un manejo inadecuado del material o por la utilización de materiales inapropiados como son los que no tienen ningún tipo de adhesión a la superficie de la estructura dentaria. Las cementaciones se comportan de 
manera diferente si se realizan con medios cementantes adhesivos o no adhesivos y por esto parte de este trabajo se abocó a analizar sistemas de adhesión de diferente estructura. Es necesario recordar algunos principios que establecen que un adhesivo debe ser fluido, y presentar baja tensión superficial, la misma tiene una relación con las uniones químicas que se encuentran en el material $^{67}$.

Se evaluó asimismo, como otro factor preponderante, la variación cíclica de la temperatura ya que los termociclajes influyen significativamente en el resultado final. Estos efectos térmicos se dan cuando varía la temperatura en la cavidad oral por ingestas de alimentos. La temperatura puede afectar a la estructura del material separando o uniendo sus átomos y ser la causal de las microfiltraciones. Las mismas pueden originarse por la diferencia entre los coeficientes de variación dimensional térmicos del diente y del material que pueden producir interfases entre el cemento y el complejo dentinario o bien entre el cemento y el PRRF.

El coeficiente de variación dimensional térmica es la variación de longitud que experimenta la unidad respectiva de un material por cada grado centígrado de variación de $\mathrm{T}^{\circ}$.

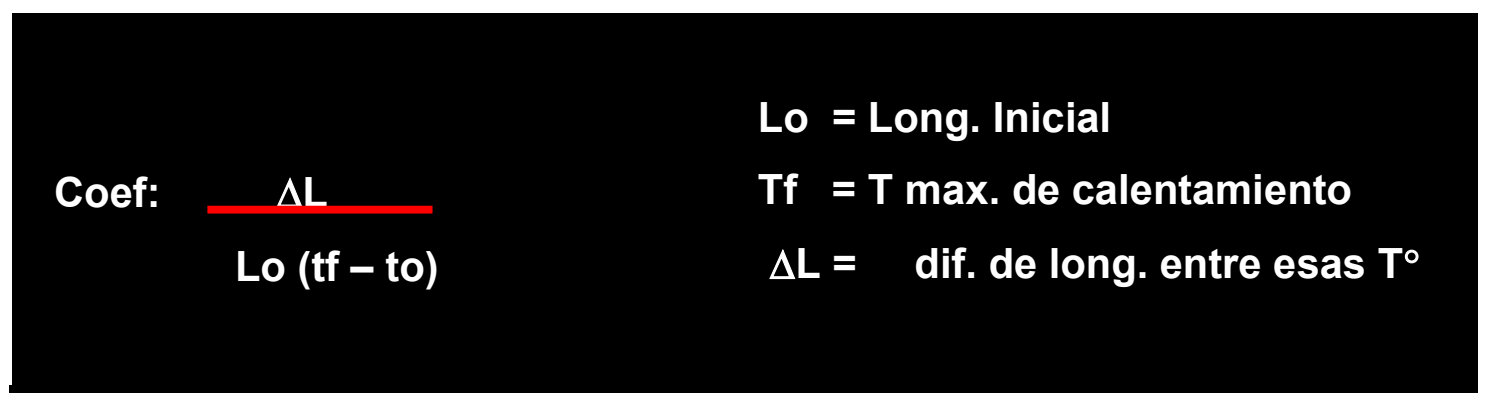


Es importante que el valor del coeficiente debe ser próximo al correspondiente a la estructura dentinaria. A mayor coeficiente, mayor percolación, siendo la percolación la entrada y salida de líquidos en la brecha diente - restauración.

Algunos autores wagnil ${ }^{131}$ demostraron con claridad que existe una relación entre las interfeses visualizadas y la filtración marginal. Este concepto validó la importancia de determinar microscópicamente la existencia o no de los espacios existentes entre los diversos sustratos. Tal como se hizo en el presente trabajo.

El método con que se preparó a las muestras para la observación en el MEB difiere de otros autores como Macari $^{71}$ ya que no se produjeron excesivas descalcificaciones en los sitios a analizar. El autor antes citado utilizó ácido clorhídrico al 5\%, con una aplicación de 45s, con el fin de poder eliminar el barrillo dentinario producido durante el corte de las muestras. En este trabajo se lo eliminó en forma superficial al barrillo dentinario y restos del instrumental de corte con ácido fosfórico al 37\% durante 3 segundos. Otros autores ${ }^{44}$ aconsejan limpiar la superficie a estudiar con agua por un término de 2 minutos. Algunos investigadores han advertido que sin el tratamiento descrito el sistema de cementos se vería como un depósito de partículas similares a cristales ${ }^{5}$. Para mejorar la limpieza y para poder retirar todos los restos del agente grabador en este trabajo se realizó el lavado en una lavadora de ultrasonido durante cinco minutos, obteniéndose un muy buen resultado.

Al observar por MEB al ionómero vítreo como elemento cementante de un PRRF se constató que se formaban brechas en sus interfases con los 
sustratos estudiados. Por lo tanto, si bien es cierto que el coeficiente de variación dimensional térmico del ionómero vítreo es similar al de la estructura dentaria $^{86}$, esta importante propiedad demuestra no ser la única causal de que se formen espacios en las interfases en un sistema de adhesión.

En los estudios desarrollados en este trabajo se demostró, mediante la comparación de los tres materiales cementantes, que el cemento de ionómero vítreo no se comporta aceptablemente al analizar las interfases con la estructura dentaria y con el PRRF. Contrariamente, otros autores aún lo consideran aceptable para rehabilitaciones similares ${ }^{57}$.

El comportamiento del ionómero vítreo podría estar asociado a la reacción de fraguado por la unión de un ácido y una base, que trae aparejada una contracción y por lo tanto puede inducir la formación de brechas en las interfases.

Los cementos a base de resina, en cambio, se caracterizan por pasar al estado sólido mediante una polimerización. Este proceso es de suma importancia ya que las diferencias en los resultados de los tres materiales ensayados son, en gran parte, causadas por los distintos tipos de endurecimiento, en conjunto con el método de adhesión. Por este motivo los cementos a base de resina mostraron interfases significativamente menores en relación al cemento de ionómero vítreo tanto en relación a la interfase con la dentina como con el PRRF. Las menores interfases también pueden ser atribuidas a las bajas viscosidades que presentan estos cementos. 
También debemos tener en cuenta que todos los materiales analizados tienen en común que, al endurecer por reacciones químicas, producirán movimientos del sustrato hasta finalizar dicha reacción, este es un factor importante en la formación de interfases ${ }^{111}$.

Clínicamente es importante mantener al PRRF en posición y bajo presión durante el tiempo necesario para su fraguado. Se constató que, tanto el cemento de ionómero vítreo como el cemento a base de resina de autocurado, requieren mucho más tiempo para su fraguado que el cemento a base de resina de curado dual. Esta reducción es muy significativa en relación con los tiempos clínicos de atención al paciente por lo que este último cemento presenta muchas ventajas en relación a los otros dos ya que se puede controlar y reducir los tiempos de fraguado.

En la clínica es fundamental que las interfases no presenten brechas ya que ellas son la entrada de los microorganismos bucales. Cabe preguntarse dónde se encontraría la diferencia más apreciable y cuáles cementos forman o no brechas en sus interfases. La experiencia demuestra que aquéllos que endurecen mediante un activador físico cerraron los espacios analizados mejor que aquéllos que presentan una reacción química. Al analizar comparativamente los resultados se pudo comprobar que, utilizando cemento de ionómero vítreo como medio de fijación, la brecha resultante fue significativamente mayor a las obtenidas con los cementos a base de resina tanto en la relación con la dentina como con el PRRF logrando un cierre inapropiado. Por otra parte, comparando los dos cementos a base de resina el de autocurado y el de curado dual encontraron 
brechas menores para este último tanto en su relación con el tejido dentinario como con el PRRF.

En las interfases relacionadas con el PRRF debemos destacar que un aspecto importante a analizar es la estructura y composición del PRRF. Con respecto a la adhesión a la matriz de la resina del PRRF las opiniones son controvertidas. Varias investigaciones refieren la existencia de radicales libres en la superficie de los PRRF con las cuales la matriz resinosa, Bis GMA u otros dimetacrilatos de los cementos a base de resina, podría reaccionar $^{112-98}$. Por el contrario, otros trabajos señalan la total ausencia de radicales libres. Esta ausencia estaría asociada al mayor grado de polimerización que posee la matriz de resina del PRRF, al tiempo transcurrido desde la fabricación del hasta el momento de su fijación y a la contaminación superficial que se genera antes de la cementación $\operatorname{adhesiva}^{107}$.

$\underline{\text { Relación entre la generación de brechas en las interfases y la microfiltración }}$ $\underline{\text { marginal }}$

Las interfases observadas por MEB mostraron una relación directa con el análisis colorimétrico de la filtración. Las muestras donde los PRRF se cementaron con ionómero vítreo resultaron ser las de mayor penetración del colorante. Esto indicaría una relación directa con el tamaño de la brecha ya que las cementadas con los cementos a base de resina, que presentan brechas más finas o inexistentes, resultaron ser las de menor penetración. Como consecuencia, en los grupos estudiados en este trabajo se mostró, 
que cuanto mayor era la brecha producida en la interfase, mayor era la penetración del colorante.

Al analizar la filtración marginal los resultados de este trabajo coinciden con los de White ${ }^{134}$ y Roig ${ }^{106}$ que reportan una intima relación entre la filtración y las interfases producidas. Otros autores utilizaron colorantes como la fucsina básica ateyah ${ }^{4}$ para determinar filtraciones marginales sin variar considerablemente los resultados.

La graduación de 0 a 4 que se utilizó en este trabajo para ponderar la filtración es probablemente más representativa y exacta que la de 0 a 3 utilizada por kloke ${ }^{62}$. Con un mayor número de grados fue posible diferenciar si se llegó a invadir el cemento de obturación endodóntica y advertir las complicaciones clínicas que esto trae aparejadas. Por otra parte, el realizar el corte de la muestra a la mitad en forma longitudinal permite tener mayor precisión y facilidad para evaluar que la lograda usando protocolos reportados en otros trabajos ${ }^{2}$ donde las muestras eran cortadas en tres rodajas, coronal, media y apical.

Fue posible constatar que la penetración del colorante en el cemento de ionómero vítreo se produjo en todos los casos presentando un máximo de $42 \%$ para la filtración grado 3 , un $29 \%$ para el grado 2 y un $29 \%$ para el grado 4. Por otra parte, al analizar la penetración del colorante en el sistema adhesivo cemento a base de resina de autocurado y adhesivo de $5^{\circ}$ generación se determina que un $14 \%$ no presentó filtración (grado 0) mientras que la mayor proporción (57\%) presentaba grado 1 y el $29 \%$ restante grado 2. En este caso se advirtió una menor filtración en 
profundidad. El sistema adhesivo cemento a base de resina de curado dual y adhesivo de $5^{\circ}$ generación mostró los mejores resultados ya que un $57 \%$ de las muestras no presentó filtración y el 43\% restante exhibió una filtración de grado 1. Este resultado permite inferir que es el cemento ideal en las condiciones de trabajo ensayadas.

Es importante destacar que el sistema adhesivo tuvo como principal función impedir o disminuir la filtración esto, en la cavidad oral, se traduce como una barrera que impide el infiltrado bacteriano entre la estructura dentaria y PRRF reduciendo la posibilidad de procesos infecciosos.

Se coincide con otro trabajos $^{88}$ en que las técnicas de adhesión que acondicionen la dentina en forma independiente, vale decir con la aplicación del acondicionador ácido, seguido de lavado y secado, tienen ventajas. Los valores de adhesión intraconducto mejoran cuando se emplean adhesivos de grabado independiente. En cambio, las técnicas adhesivas o autograbantes de acción ácida, son más suaves y no alcanzan a disolver el barro dentinario y despejar la entrada de los túbulos para su infiltración ${ }^{88}$. Esta situación suele resultar favorable en dientes vitales por cuestiones biológicas ya que no se aumenta en forma considerable la permeabilidad de la dentina. Al conservar el smear plug o tapón de barro dentinario los monómeros no tienen capacidad de ingresar y entrar en contacto con los tejidos pulpares por lo que la técnica adhesiva es menos irritante. En el caso de un diente endodónticamente tratado la irritación pulpar no existe y, por lo analizado hasta ahora, la fuerza de adhesión es decisiva para el éxito del tratamiento y, consecuentemente, estos adhesivos no se deben emplear. 
Otro aspecto a tener en cuenta es el comportamiento de los adhesivos en ambientes húmedos que, en algunos casos, pueden afectar en forma negativa su rendimiento. La presencia de agua lleva en lapsos variables a la degradación de la capa adhesiva acortando el tiempo de duración del proceso adhesivo ${ }^{125-23-74}$. Este fenómeno afecta el rendimiento adhesivo en lo inmediato y a distancia y es más evidente al emplear algunas marcas de adhesivos. Cabe recordar que en el caso del diente tratado endodónticamente la presión pulpar positiva está ausente y el adelgazamiento de las paredes radiculares lleva a un aumento de la humedad en la superficie del lecho para el PRRF. El agua puede penetrar en el interior del conducto desde el periodonto, este suceso se hace más evidente cuanto más instrumentado esté el conducto y sus paredes queden más delgadas. Aún así, en el proceso de adhesión sobre el diente tratado endodónticamente es más importante tener en cuenta la influencia del agua que puede quedar en la dentina después del grabado con ácido.

Los adhesivos funcionan como membranas semipermeables ya que dejan pasar el agua ${ }^{38}$. Una vez aplicado el adhesivo, la presencia de ácidos en la superficie estimula por un gradiente osmótico la salida del agua ${ }^{74}$. Si el adhesivo posee bajo grado de conversión (grado de polimerización) existirá mayor concentración de monómeros hidrófilos ácidos sin polimerizar, que facilitan aún más el pasaje del agua a través de la capa adhesiva. La presencia de agua en la superficie de la capa adhesiva aumenta con los minutos posteriores a la aplicación de los adhesivos haciendo que los valores de la adhesión con el medio cementante resinoso (cementos a base de resina) disminuyan proporcionalmente. Este problema es mayor cuando 
la polimerización del cemento es lenta, y ello ocurre cuando la activación del cemento es únicamente producto de una reacción química (cementos a base de resina de autocurado).

\section{Ventajas del uso de cemento de curado dual y PRRF traslúcidos.}

Los resultados del presente trabajo han mostrado ventajas del uso de cementos de resina de curado dual. En general aceptamos, como hacen referencia los autores anteriores que los adhesivos y cementos a base de resina de autocurado desarrollan un grado de conversión más alto que aquellos de activación dual cuando polimerizan en ausencia de la luz. Sin embargo, el desarrollo comercial en la actualidad llevó a que los cementos a base de resina de curado dual igualen o mejoren a los de autocurado a través de la activación física con luz visible (fotoactivación), se puede asegurar una polimerización de adhesivos y cementos a base de resina de curado dual más completa y superar los problemas antes mencionados. Se impone entonces conseguir fotoactivación (se emplea luz de 400 a 500 nm de longitud de onda (luz azul) como activador físico de la reacción de polimerización) de adhesivos y cementos a base de resina de curado dual en el proceso de la fijación de los PRRF. . Para cumplir dicho cometido es necesario que llegue luz al adhesivo y al cemento en cantidad y calidad adecuada. En el promedio de los conductos fotoactivados al cemento y al adhesivo la luz que les llega solo alcanza en cantidad adecuada el tercio coronario dejando en la parte media y apical materiales con bajo grado de polimerización ${ }^{35}$. Fue necesario entonces otro recurso técnico para hacer llegar la energía requerida dentro del lecho, esto se logró con la conducción de la luz a través del PRRF, pudiéndose solucionar los problemas 
expuestos, dando más seguridad al proceso de cementación adhesiva dentro del canal radicular. La profundidad de polimerización depende de varios factores relativos al material (el tono y el grado de translucidez), y relativos a la luz (la intensidad y longitud de onda y el tiempo de incidencia sobre los materiales). En promedio en los postes de efectiva conducción de luz, la intensidad lumínica que llega a la porción apical es un cuarto de la emitida desde el extremo coronal ${ }^{112}$.

Por esto se sugiere que el operador debe tener siempre en cuenta los siguientes puntos: a) seleccionar el poste con comprobada capacidad de transmisión de luz. b) Cortar el perno a la medida requerida antes de cementarlo. c) Aumentar los tiempos de exposición de la luz. d) utilizar lámparas con un flujo radiante no menor a los $800 \mathrm{~mW} / \mathrm{cm} 2$.

\section{Influencia de la formación de tags sobre el proceso de adhesión}

A lo largo de este trabajo se discutió la necesidad de limpiar todo material que obstruye a los canalículos dentinarios y de conseguir mecanismos alternativos a la hibridación de la dentina que aporten más seguridad al proceso adhesivo. Se fundamentó la necesidad de formar tags de resina en los túbulos dentinarios y generar la adhesión en la dentina tan particular de un diente tratado endodónticamente.

Los tags de resina compensan en parte la falta de adhesión por deficiente formación de la capa hibrida con el colágeno. Las zonas coronales y medias del conducto son más favorables en este aspecto porque presentan mayor densidad de túbulos ${ }^{36}$. Se explicó que acondicionar la dentina con ácidos fuertes como el fosfórico al $37 \%$ permite limpiar dentina 
y al mismo tiempo abrir los túbulos para la penetración de monómeros y formación de tags.

Al analizar los resultados de los ensayos de formación de tags de este trabajo se demostró que, como era de esperar, el cemento de ionómero vítreo, que produce una cementación del tipo convencional, no generó tags en los conductillos dentinarios. Por otra parte los tags obtenidos para los dos tipos de cementación adhesiva, cementos a base de resina de auto y fotocurado más adhesivo de $5^{\circ}$ generación, presentaron formas cónicas igual a los estudios de Chappel $\mathrm{RP}^{17}$. De acuerdo a su longitud los tags se clasificaron como de grado 0,1 y 2. La evaluación porcentual reveló un $85 \%$ de tags de grado $2(10 \mu \mathrm{m})$ para la combinación cemento a base de resina de curado dual y adhesivo de $5^{\circ}$ generación versus un $57 \%$ en los de cemento a base de resina de autocurado. En cuanto a su distribución pudo constatarse que se encontraron tags de menor tamaño y cantidad en la parte apical y de mayor longitud en la parte media y coronal del lecho que recibirá al PRRF.

La mayor formación de tags de resina, estrechamente ligada a la mayor conversión de adhesivos y cementos a base de resina de autocurado y curado dual, se logró satisfactoriamente con la técnica clínica utilizada. Este dato es de relevancia, sobre todo teniendo en cuenta que a las muestras se las sometió a un termociclado antes de su observación, ausente en otros estudios ${ }^{121}$. Por otra parte, se puede resaltar que el PRRF utilizado en los ensayos demostró tener una alta capacidad de transmitir la luz y provocar la activación del cemento y adhesivos correspondientes, 
permitiendo la formación de tags. La mayor formación de tags asegura una correcta adhesión y sellado.

Cabe destacar que este ensayo complementa los resultados de los estudios realizados en los experimentos de interfases y filtración a un colorante. Es decir, permite inferir que la técnica que menos interfases generó presentó la mayor formación de tags y mostró la menor filtración del colorante.

\section{Selección de la mejor combinación de materiales y técnicas.}

El análisis de los resultados del presente trabajo ha permitido concluir que la mejor combinación de materiales y técnicas correspondiente a la limpieza del conducto es mediante la utilización de ácido fosfórico al $37 \%$ durante 10 s colocado y frotado con puntas NaviTip.

El mejor método para llevar el cemento al lecho del canal radicular remodelado para un PRRF es con el léntulo más el colocado en el PRRF (embadurnado) y el mejor cemento fue el cemento a base de resina de curado dual ya que produjo la menor cantidad de espacios vacíos y el mayor número de tags y redujo la formación de brechas en las interfases. A partir de dicha selección y de la experiencia recabada durante los ensayos se generó un protocolo con el fin de establecer un conjunto de procedimientos destinados a estandarizar la práctica odontológica en lo referente a lograr la mejor técnica de fijación que pueda aportar traba mecánica y adhesiva en el lecho radicular a un PRRF. 
6. CONCLUSION 


\section{CONCLUSION}

La odontología ha logrado avances importantes en los últimos años, los más significativos quizás llegan relacionados a modificaciones en los materiales o técnicas ya aplicadas. En este contexto los PRRF representan la última solución para la reconstrucción del diente endodónticamente tratado.

La posibilidad de encontrar una opción donde se conjuguen varios factores como: condiciones optimas de los materiales, la técnica sencilla, rápida y costos accesibles le brindan a esta técnica una nueva perspectiva y un desafío al clínico general.

En este trabajo pudimos cumplimentar los objetivos planteados ya que analizamos y valoramos microscópicamente cuáles son las técnicas que mejor cumplen la función de descontaminar la superficie dentinaria para recibir un sistema adhesivo. Para realizar una correcta selección de materiales y técnicas fue necesario realizar observaciones microscópicas para determinar cuál es la técnica que genera menor cantidad de espacios vacíos en el momento de introducir el cemento para fijar el PRRF. También se pudo determinar la existencia de brechas en las interfases producidas entre cemento y PRRF que podrían inducir infiltraciones y cuantificarlas. Asimismo, se logró medir microscópicamente la formación de tags en los conductillos dentinarios del lecho modificado para recibir un PRRF y, por último se pudieron relacionar los resultados de la generación de interfases 
con los obtenidos en la penetración de un colorante y en la formación de tags.

Como conclusión podemos afirmar que nuestras hipótesis fueron claramente convalidadas. Se demostró que existen técnicas de limpieza de dentina que producen mejores resultados en la descontaminación y liberación de los tapones de barro que obstruyen los conductillos dentinarios. Se constata también que existen técnicas para llevar el cemento al lecho preparado para el PRRF que disminuyen la generación de espacios vacíos mejorando el campo de adhesión y, por último, que algunos medios cementantes causan un cierre defectuoso durante la fijación del PRRF.

Las técnicas de descontaminación de la dentina del canal radicular que se compararon fueron las siguientes:

- Sin acondicionamiento.

- Acondicionamiento con alcohol yodado al $2 \%$ colocado y frotado con puntas NaviTip por 20s.

- Acondicionamiento con alcohol yodado al $2 \%$ colocado y frotado con puntas NaviTip por 20s, más acido fosfórico al $37 \%$ colocado y frotado con puntas NaviTip por 20s.

- Acondicionamiento con EDTA colocado y frotado con puntas NaviTip por 20s.

- Acondicionamiento de EDTA colocado y frotado con puntas NaviTip por 20s, más acido fosfórico al $37 \%$ colocado y frotado con puntas NaviTIP por 20s. 
- Acido fosfórico al $37 \%$ (colocado y frotado 10 s con puntas NaviTip.

Las técnicas para llevar al cemento al interior del lecho que recibirá el PRRF que se compararon fueron las siguientes:

- Llevado sobre el PRRF (embadurnado).

- Llevado con lentulo.

- Llevado con lentulo y sobre el PRRF (embadurnado)

Los materiales utilizados en la cementación fueron los siguientes:

- Cemento de ionómero vítreo (cementación convencional)

- Cemento a base de resina de autocurado ( cementación adhesivo)

- Cemento a base de resina de curado dual (cementación adhesiva)

Para completar los sistemas de adhesión se utilizo adhesivo de $5^{\circ}$ generación.

En las condiciones en que estos ensayos fueron ejecutados fue posible concluir que:

La técnica que pudo descontaminar mejor la dentina del canal radicular eliminando los restos de cemento y gutapercha más el barro dentinario y dejando libre el acceso de los conductillos dentinarios fue la utilización de acido fosfórico al $37 \%$ aplicado y frotado con puntas NaviTIP durante 10s. Cabe mencionar que la utilización de EDTA al 19\% rindió buenos resultados cuando se la combinó con el ácido fosfórico al 37\% y los 
peores resultados se obtuvieron con el uso del alcohol yodado, que solo removió los restos de cementos y gutapercha.

A la hora de evaluar qué técnica introduce mejor al cemento en el conducto radicular pudo constatarse que la mejor es la que utiliza el lentulo más el embadurnado del PRR, ya que fue la más eficaz. Esta técnica permitió alcanzar una mejor distribución del cemento dentro del conducto radicular y menor generación de espacios vacíos comparada con las obtenidas mediante las otras técnicas ensayadas (cemento colocado sobre el perno y cemento llevado con el léntulo).

De los cementos utilizados en los ensayos el que peor comportamiento presento (mayor formación de espacios vacios) fue el cemento de ionómero vítreo mientras que el cemento que demostró formar la menor cantidad de espacios vacios fue el cemento a base de resina de curado dual.

Al evaluar la penetración de un colorante la técnica de cementación adhesiva con la utilización del adhesivo de $5^{\circ}$ generación y el cemento a base de resina de curado dual mostraron menor filtración en comparación con el adhesivo de $5^{\circ}$ generación y el cemento a base de resina de autocurado. En tanto la utilización de una técnica de cementado convencional como el uso de cemento de ionómero vítreo evidenciaron mayor filtración con una diferencia altamente significativa respecto a los otros métodos.

La conclusión que se obtiene analizando las observaciones de las interfases dentina/PRRF de los tres tipos de cemento es que el cemento de 
ionómero vítreo no se ha comportado de forma apropiada dejando amplias interfases que clínicamente llevarían a una rápida filtración microbiana. La cementación adhesiva, en cambio, arrojó los mejores resultados con diferencias significativas respecto a otros procedimientos, siendo el cemento a base de resina de curado dual como el que permitió los mejores cierres marginales hacia la dentina y al PRRF. Pudo demostrarse también que existe una estrecha relación entre la generación de interfases y la filtración.

La valoración de los tags formados en las técnicas de cementación adhesiva utilizadas en este trabajo confirmó que para los dos tipos de cemento, a base de resina auto y fotocurado, se logró la activación de los mismos. El que dejó un mayor porcentaje de tags grado 2 (mayores a 10 $\mu \mathrm{m})$ fue el cemento a base de resina de curado dual. Como era de esperar, el ionómero vítreo (cementado convencional) no penetró en los conductillos dentinario.

Por lo antes dicho la evaluación de distintas combinaciones de técnicas de limpieza, materiales y técnicas de cementación dejó en evidencia que la combinación limpieza con ácido fosfórico al 37\% utilizando la punta NaviTip, colocación del cemento con lentulo y embadurnado más la técnica de adhesión con cementos a base de resina de curado dual fue la que generó menos brechas en las interfases, presentó la menor filtración y obtuvo el mayor porcentaje de formación de tags. Por lo tanto es de esperar que su aplicación lleve a los mejores resultados clínicos.

En base a un análisis estadístico de los resultados de las distintas combinaciones fue posible entonces seleccionar a las técnicas y materiales 
idóneos que permitirían un cierre periférico y en profundidad, disminuyendo la filtración marginal y los problemas que esto trae aparejado especialmente en lo que se refiere a la vulnerabilidad de la pieza tratada endodónticamente. La técnica de limpieza de la dentina, la técnica de aplicación para el cemento y el uso del cemento que resultó exitoso en este trabajo son recomendables y deberían ser aplicados por el clínico general confiando en un pronóstico satisfactorio.

\subsection{Recomendaciones.}

Luego del análisis de los resultados del presente trabajo es posible recomendar para la rehabilitación de piezas tratadas endodónticamente que requieren de la colocación de un PRRF el siguiente protocolo:

- Realizar un correcto diagnostico clínico de la pieza a tratar evaluando el remanente dentario, tejidos de soporte, ubicación en el arco, relación con las piezas vecinas y su antagonista y chequear la oclusión.

- Realizar un correcto estudio radiográfico, para evaluar el correcto estado del tratamiento endodóntico, que se encuentre libre de fracturas radiculares, procesos periapicales y enfermedades periodontales. También con dicha radiografía se puede realizar la elección del perno comparándola con el ancho del conducto y determinar la profundidad de trabajo. 
- Realizar el aislamiento absoluto del campo operatorio. Remover todo el tejido deficiente y llegar a observar con comodidad la entrada al conducto radicular.

- Con fresas de Gate-Gliden realizar la desobturación a la profundidad pre establecida y continuar con las fresas de largo, para terminar con la fresa que entrega el fabricante para su perno, que dará forma y ajuste al conducto para el mejor asentamiento del PRRF.

Tomar una radiografía para observar si quedan residuos macros de cemento y gutapercha. Si quedan, eliminarlos con limas o pasando nuevamente la fresa sobre la pared que los contiene.

- Realizar la prueba del PRRF para detectar si llega en profundidad al final del lecho labrado. seguidamente proceder a cortarlo en su parte coronal a la medida del tratamiento coronario que recibirá y limpiarlo con alcohol

- Grabar la superficie dentinaria con acido fosfórico al $37 \%$ durante 10 s aplicándolo y frotándolo contra las paredes dentinarias con puntas NaviTip. Lavar con agua en forma abundante asegurándose que llegue al fondo del conducto remodelado y proseguir con el secado utilizando conos de papel.

- Llevar con micropincel adhesivo monocomponente de $5^{\circ}$ generación e impregnar todas las paredes realizando presión contra las mismas. Posteriormente fotopolimerizar por 20s.

- Preparar el cemento a base de resina de curado dual hasta formar un color homogéneo y llevar al interior del conducto con lentulo, con el cemento sobrante embadurnar el PRRF y posicionarlo en el interior 
de conducto y luego manteniéndolo bajo presión, retirar el excedente y fotopolimerizarlo por 90 s.

A partir de este momento se prosigue con los pasos de la restauración coronaria como lo dicte el caso, ya sea con una restauración directa o indirecta 
7. BIBLIOGRAFIA 


\section{BIBLIOGRAFIA}

1. Andreasi Bassi M. La diffusione de lla luce attraverso i perni in fibra di quarzo epossido a doppia conicitá. Atti Simposio Intern. Odontoiatria Adesiva eRiconstructtiva, 2001; 5: 21-26.

2. Arias C, Azzarri M, ET.AL. Analisis de las posibles interfases producidas en la fijación de postes de fibra de vidrio a la estructura dentaria. Rev. Soc. Odontol. La Plata, 2010; XXIII, (41): 28-35.

3. Arrais CA, Giannini M, et. al. Microtensile bond strength of dualpolimerizing cementing systems to dentin usingdifferent polymerizing modes. J Prosthet Dent, 1997; (2): 99-106.

4. Ateyah E, Elhejazi A. shear bond streng and microleakage of four tipes of dentin adhesive materials. J Contemp. Dent. Pract. 2004 Feb; 5 (1): 67-73.

5. Bagly M. Adhesion a dentina. Análisis de las interfases. Condiciones experimentales. J Clinical Odont. 1998; 3, (1):45.

6. Baraban B.: The restoration of endodontically treated teeth. An up date. J Prosthet Dent. 1989; 61: 10-15.

7. Beacciani R.La biomeccanica del dente trattato endodónticamente. Implicazioni cliniche. Dental Cadmos, 2002; 1: 15-35.

8. Bergman B, Lundquist P. Restaurative and endodontic results after treatment with cast post and cores. J Prosthet Dent 1989; 61: 1015.

9. Bertoldi HA. Incrustaciones de resina compuesta. Consideraciones generales. Rev. Asoc. Odont. Arg. 2004; 92, (3): 253-264. 
10. Bertoldi HA. Nuevos enfoques en la rehabilitación coronaria del diente endodónticamente tratado. Rev. Asoc. Odont. Arg. 2002; 90, (4): 266-275.

11. Bertoldi HA. Odontologia Adhesiva y protesis. LA carta odontológica sociedad Peruana de prótesis dental y maxilo facial; 2000; 5, (16): 19-25.

12. Birtcil R. A 30 month clinical evaluation of the influence of finishing and size of restoration on the marginal performance of fiver amalgam alloys. J Dent Res. 1981, 60, (12): 1949-56-

13. Boone K, Murchinson DF, et. al. Post restoration: theth effect of secuence of post-space preparation, cementation time, anddifferent sealers. J Endod. 2001; 27, (12): 768-771.

14. Buonocure MG. A simple method of increasing the adhesion of acrylic filling materials to enamel. J Dent. Res. 1955; 34: 849-853.

15. Calt S, Serper A. Time - dependent effects of EDTA on dentine structures. J Endod. 2002; 28: 17-19.

16. Casanellas Bassols JB, GIL Mur F. Aplicación de los plásticos reforzados con fibras para la aplicación de dientes endodonciados. Rev. Odont. Estomatol. Esp. 1995; 7: 37

17. Chapel RP, Cobb Ch M, et, al. Dentinal tubule anastomosis: A potential factor in adhesive bonding. J Prost. Dent. 1994; 72, (2) $183-188$

18. Cristensen GJ. A promossing new category dental cement, JADA. 1995; $126: 781$. 
19. Cristensen GJ. Update in resin cements. Newsletter. CRA. 1993; 1: $1-3$

20. Chistensen GJ. Wento use fillers, buil ups or post an cares. J am. Dent. Assoc. 1996; 127: 1397-1398.

21.Dallari A, Rovatti L. IL sistemacomposipost perni endocanalari di terza generazione. Matina, Bologna, 1994.

22. Deustsch AL, Musikant EL. Torque placed by dentist on prefabricated threaded post. J Prost. Dent. 1985; 53: 323-25.

23. De Munk J, Carvalho RM, et.al. A critical review of the durability of adhesion to tooth tissue: Methods and result. J Dent Res. 2005; 84 (2): 118-132.

24. Diestchi B, Ronelli M, et. al. adaptation of adhesive post and cores to dentin after fatigue testing int. J Prost, 1997; 10: 498-507.

25. Duret B . Composipost: filosofia tecnica e prospettive cliniche. Odontoiatria adhesiva e ricostrutiva. 1997; 1: 11-17-

26. Duret B, Reynaud M, et. al. Interet des materiaux a structure unidirectionnelle dans les reconstitutions corono-radiculaires. J Biomat Dent, 1992; 542: 69-77.

27. Duret B, Reynaud M, et. al. Un nouveau concelt de reconstitution corono- rediculaire: le composipost . Le Chir Dent de France 1990; 542: 69-77.

28. Ensinas $P$. Estudio de MEB de diferentes volúmenes de irrigación con hipoclorito de sodio al 2,55 sobre el deposito de barro dentinario en la sparedesd del conducto radicular. Rev. Soc. Arg. Endod.2009, 35: 9 
29. Ensinas $P$. evaluacion de los efectos del EDTE sobre el barro dentinario, en la dentina radicular en distintosperiodos de tiempo. Un estudio con microscopia electrónica de barrido. RAOA, 2010 ; 48: 73-37.

30. Eriksson JH. Sundstron F: Temperature riseduring root canal preparation a possible cause of damage to tooth and periodontal tissue. Swdsh Dental J 1984; 8: 217-23.

31. Fabianelli A, Kugel G. Efficacy of self-etching primer on sealing margins of clas II restorarions: Am J Dent. 2003 Feb; 16 (1): 3741.

32. Fauchard $P$. Le chirugien dentiste ou traite des dents. 2 eme ed. Rev. Corr.et.augm. Paris. Pierre Jean Maritte 1746. Paris J Prelat 1961.

33. Ferracane JL, Grrener M, et al.: the effect of resin formulation on the negree of conversion and mechanical properties of dental restorative. J Biomed Mat Res, 1986; 20: 121 -1 31.

34. Ferrari M. Fiber posts an endodontically treated teeth: A compendium if scientific and clinical perspectives. 2008 Modern Dentistry Medi Sud Africa.

35. Ferrari M, Vichi A, et.al. restrospective study of the clinical performance of fiber posts. Am J Dent, 2000; 13: 9 -13.

36. Ferrari M, Vichi A, et.al. Efficacy of different adhesive techniques on bonding to root canal walls: An SEM investigation, 2001; Dental Material 17: $422-429$. 
37. Fraga $R$, Chaves $B$, Mello $G$, et. al. fracture resistence of endodontically treatd roots after restoration. J Oral Rehab. 1998; 25: $809-813$

38. Frankenberger R, Tay FR. Self - etch vs etch - and - rinse adhesives: effect of thermo - mechanical fatigue loading on marginal quality of bonded resin composite restorations. Dental Material; 21: $397-412$.

39. Fonseca RG, Artusi TP, et.al. diametral tensile strength of dualcuring resin cements submitted exclusively to autopolymerization. Quintessence Inti. 2007; 527 -531.

40. Fredrikson M, Astback J, et. al. Restrospective study of 236 patients with restored by carbon fiber reinforced epoxy resin posts . J Prosthet, 1998; 8: 151-157.

41. Fusayama T. Non-presure adhesion of a new adhesives resins. J Dent. Res. 1979; 54 (4): 1364 - 1370.

42. Garcia Barbero E, et.al. La adhesión a la amalgama en el momento actual: nuevas perpectivas AV Odontologia 1994; 10: 37 $-51$.

43. Glants PO, Nilner K. Root canal posts- sone prosthodontic aspects. Endod Dent Traumatol. 1990; 49: 243 - 253.

44. Godder B, Zhukovsky L, et al. Microleakage reduction using glas ceramic inserts. Am. J Dent 1994; APR, 7 (2): 74-76.

45. Goldberg F. evolution of the incidence of transportation after placement an removal of calcium hydroxide. J Eendod 2004; 30: $646-648$ 
46. Goldberg F. Estudio comparative de las limpiezas de las preparaciones para anclaje intraradicular inmediatos y mediatas. Rev. Asoc. Odont. Arg. 2004; 92 (1) 36 -39.

47. Golman M, De Vitre R, et. al. SEM estudi of posts cemented with an unifell cement. J Dent Rest. 1984, 63: 1003 - 1005.

48. Goldstein G, Hudis S et. al. Comparison of four techniques for the cementation of posts. J Prosthet Dent 1986; 55: 209 - 211.

49. Golstein R. Odontologia estética Vol, II, Restauraciones en dientes endodonciados., Ars. Medica segunda edición, 2002; 364 - 371.

50. Gomez JC, Kina S. La adhesión en prostodoncia fija. Cap. XIV. En: Gilberto H. Haro (ed). Adhesion en odontología restauradora. Curitiba, Parana (Brasil): Editora Maio.

51. Gomez JC. La adhesion es prostodoncia fija. Adhesion en odontología restauradora. Curitiba Brasil. Ed Maio.

52. Goracci C, Tay F, et. al. The contribution on friction to the dislocation resistance of bonded fiber posts. JOE 31 (8): $608-$ 612.

53. Goss $\mathrm{MJ}$, Tuner $\mathrm{CH}$. Intraradicular hydrostatic pressure changes during the cementation of posts retained crows. J Oral Rehabil 1983; 10: 237.

54. Hagee MS. Retention of posts luted with phosphate monomerbased composite cement in canals obturated using a eugenol sealer. AM J Dent. 2002; 15, (6): 378 - 372. 
55. Helfer AL, Melnick S, Shilder H. Determinations of the misture content of vital and pulpless teeth. J Oral Surg. 1972; 34: 661 669.

56. Henrry PJ. Photoelastic analysis of post core restorations. J Aust. Dent.1977; 22: 157 - 159.

57.108-Hitakker D, Kneale M. The dentina-predentina interfase in huan thee. Br Dent J. 1979; 146: 43-46.

58. Hood JA: Methos to improve fracture resistance pf teeth. In posterior composite resin dental restaurative material. Ed Vanherle\&Smith, Utrecht, 1985. $443-450$.

59. Howard T. the effect of a translucent post on resin composite depth oj ccure. Dent Master. 2004: 20: 617-622.

60. Howe CA, Mc Kendry DJ. Effect of endodontic acces preparation on resistance to crow root fracture. J Am Dent ass, 1990; 121: 712715.

61. Kern JC, Pleimes AW, et. al. Stability of restorations with alporcelain or metal post an cores. J Dent. Res. 1992; 71: 122.

62. Kloke A. Invitro investigation of indirect bonding with a hydrofi+hilic primer. Angle Orthod. 2003 Aug; 73 (4) : 445 - 450.

63. Kuraray j. Simposium .2000; pp: 131 - 148

64. Leavy JM. An evaluation of post length within the elastic limit of dentin .J Prosthet Dent 1987; $57: 277$ - 81

65. Leevailoj C. Shear bond strength of dual-cured and self-cured resin composites to denting using different bonding agents an techniques. Oper. Dent. 2007; 32 (2): 149 - 159 
66. Lewistein I, Grajower R: Root dentin hardness of endodontically treated tech. J Endodon. 1981; 7: 421 - 422.

67. Loguercia A. In vitro microleakaje of packable composites in clase II restorations. Quint. Int. 2004 Jan; 35 (1): 29 - 34.

68. Lostaunau C, Volpe S. Adaptacion e integridad del cementado de endopostes de fibra de cuarzo con la técnica de inyectado en conductos radiculares amplios. Actas Odont. 2011; Vol VIII, (2) 5 14.

69. Lovadahl PE, Nicholls JI. Pin-retained amalgam cores vs cast-gal dowel-cores. J Prosthet Dent 1977; 38: 507514.

70. Loweistein WR, Rathkamp RA. Study on pressoreceptive sensibility of the tooth. J Dent. Res. 1955; 34: $287-294$.

71. Macari S: Scaning electron microscopy evaluation of interfase of three adhesives systems. Bras Dent. J 2002; 13 (1): 33 -38.

72. Macchi RL. Influence of endodontic materials on the bonding of composite resin to dentin. ENdod. Dent. Traumatol 1992; 8 (1): 26 -29 .

73. Mader C, Baumgartner J, Peters D. Scanning electron microscope investigation of the smeared layer on root canal walls. J Endod. 2009; 10: $477-483$.

74. Malacarne J, Crvalho RM, et. al. Water sorption/solubility of dental adhesive resins. Dent. Mat. 2006; 22: $973-980$.

75. Malferrari S, Monaco C, et. al. clinical evaluation of teeth restored with quartz fiber reinforced epoxy resin posts in . J Prosthodont 2003, 16: $39-44$. 
76. M anocci F, Ferrari M, et. al. Microleakage of endodontically treatd teeth restored with fiber post an composite cores after cyclic looding: A confocal microscopic study. J Prosthet Dent 2001, 85: $284-291$

77. Mannocci F, Sherriff M, et. al. Trhee point bending test of fiber post. J Endodon.2001; $27: 758-761$

78. Mathis R, Ferracore J. Propertiers of a glass ionómero/resin composite hybrid material. Dent Mater 1989; 5: 335 - 358

79. Mattison CD. Photoelastic stress analysis of cast gold endodontic post, J Prosthet Dent 1882; 48: 407.

80. Mc Comb D, Smith DC. A preliminary study of root canal after endodontic procedures. J Endodon. 1973; 1: 238 - 241.

81. Mc Lean J. A criteria for the predictably restorable endodontically treated tooth J Can. Dent, Assoc. 1998; 91: 652.

82. Mc Lean J. Cementos de ionómero de vidrio. Quintessence Ed. Esp. 1991; 4 (5) : $273-279$.

83. Lean J. Evolución de los cementos de ionómero de vidrio una visión personal, J Esth Dent. Edit. Esp 1995; 5 (1): 6 - 20.

84. Meister F, Lommel TJ. Diagnosis an possible causes of vertical root fractures. Oral Surg. 1980; 49: $243-253$.

85. Milot $\mathrm{P}, \mathrm{S}$ tein RS. Root fracture in endodontically treated teeth relatd to post selection an crown design. J Prosthet Dent 1992; 68: $428-355$.

86. Mjor I, Fejerskov O. Histology of the human tooth. 2 da Edic. Copenhague, Munksguard 1979. 
87. Muñiz L.Rehabilitación estética en dientes tratados endodónticamente. Postes de fibra y posibilidades clínicas conservadoras. San Pablo (Brasil) Livraria Santos E ditora 2010.

88. Muñiz L, Mathias $P$. The influence of sodium hypochorite and root canal sealers on post retention in different regions. Oper. Dent. 2005; 30: $533-539$.

89. Myenberg $\mathrm{KH}$, Luthy $\mathrm{H}$; et. al. Zirconia post: a new all-ceramic concept fornon vital teeth. J Esthet. Dent. 1995; 7: 73 - 80.

90. Nakabayashi D. Biocompatibility an promotion of adhesion to tooth subtrated. C.R.C critical reviews in biocompatibility 1984; 1: 25 52.

91. Nakabayashi N, Pashely DH. Hibridization of dental hard tissues. 1999; Quintessence Berlin.

92. Nathanson D, Moin K. Metal-reinforced anterior tooth replacement using acid-etch composite resin technique. J Prosthet Dent 1980; 43: $408-412$

93. Nathanson D. Resin retained post: retention mechanisms. J Den. Res. 1989; 9: 11 - 34 .

94. Nissan J, Dimitry $Y$, Asiff D. The use of reinforced composite resin cement as compensation reduced length. J Prosthet Dent.2001; 86: $304-308$.

95. Niu W. A scanning electron microscopic study of dentinal erosion by final irrigation with EDTA an Na OCL solutions. Int. End. 2002; $35: 934-939$. 
96. Nyman S, Lindhe J.Longitudinal study of combined periodontal an prothetic treatmen with advanced periodontaldisease. J Periodontal 1979; 50: $163-1669$.

97. Obermay G, Walton RE. Vertical root fracture an relative deformation during obturation post cementation. J Prosthet Dent 1997; 66: $181-1877$.

98. Perdigao J, Gomez G, et. Al: The effect of silane on the bond streg this of fober posts Dental.Material 2006; 22: 752 - 758.

99. Postell FR, Bernier WE, et. al. The effect of inmediative versus delayed dowel spae preparation on the intepity of the apical seal. $\mathrm{J}$ Endodon.1982; 8: 154 - 160.

100. Radovic I. The effect of sandblasting on adhesion of dural cared resin composite to meth acrylic fiber post: microtensile bond strength an SEM evaluation. J Dent. 2007; 35: 496 - 502.

101. Randow K, Glatz P. On cantilever loading of vital an non-vital teeth. Acta Odontol. Scond. 1986; 44: $271-277$.

102. 18-Rauschemberg CR. Permeabilidad dentinaria. Ramificaciones clínicas. Fundamentos biológicos. Clínicas odontalgias de Norte America 1992; 2: 239 - 255.

103. Reeh ES. Reduction in tooth stiffnes as a result of endodontic an restaurative procedures . J Endodon. 1989; 15: $512-516$.

104. Riedling W, Kappet HF. Veranderung einer gingivaver farbung nach. austausch eines wurzlstiftes und versorgung mitles glaskeramik ein fallbericht . Quintessenz 1998; 39: 1959. 
105. Rivera E, Yamauchi G et. al. Dentin colagen cross-link of root filled and normal teeth. J Endodon. 1988; 14: 195.

106. Roig Cayon M, Brau AE, et. al. Consideraciones generales sobre el uso clínico de los adhesivos dentinarios. Oper. Dent. Endodon. 1997; 1(1): 10.

107. Sadek FT, Monticelli F, et. al- Bond strength performance of different resin composites used as core materials around fiber posts . Dental Materials 2007; 23: 95 - 99.

108. Saleh A, Ettman W. Effect of endodontic irrigation solution on microhordness of root canal dentine. J Dent. 1999; 27: 43 - 46 .

109. Sano H: Leakage with-in the hybrid layer. Oper. Dent 1995; 20 (1): $131-148$.

110. Santos JN. Effect of clinical irrigants on the bond strength of a self-etching adhesive to pulp chamber dentin. J endod; 32 (11): 1088- 1090

111. Saygili G, Sahmali S. Effect of ceramic surface treatment on the shear bond strengths of two luting agents to all-ceramic materials. J Oral Rehabil.2003 Jul; 30 (7): 758 - 756.

112. Scotti R, Ferrari M. Pernos de fibra bases teoricas $y$ aplicaciones clínicas Barcelona. España: Masson 2004.

113. Schwartz R, Robbins JW. Post placement an restoration of endodontically treated teeth J Endodontiics 2005; 30 (5): 289 -301.

114. Shillingburg H. fundamentals of fixed prosthodontics. Restoration of endodontically treated teeth. Quintassence Books. Third Edition Canada 1997; 198 - 206. 
115. Shillingburg HT, Kessler JC. Restauration of endodontically treated tooth. Quintassence Pub. Co, Chicago. 1982; 12- 44.

116. Sjogren G, Molin M, et. al. Ceramic inlays (cerec) cemented resing luting agent. A 2-year clinical study. Acta Odontol.Scand 1995, 53 (5): $325-330$.

117. Sorensen JA, Engelman MJ. Effect of post adaptation on fracture resistance of endodontically treated teeth J Prosthet Dent 1990; 64: $419-424$.

118. Sorensen JA, Mrtinoff JF. Clinically significant factors in dowel desing. J Prosthet Dent. 1984; 54: 28 - 34.

119. Sorensen JA, Mrtinoff JF. Intracoronal reinforcement an coronal coverage: A study of endodontically treated teech. J Prosthet Dent $1984 ; 51: 780-784$.

120. Standlee G, Capoto A. Edodontic dowel retention with resinous cements. J Prosth Dent 1992; 68: 913.

121. Suh BI, Feng L, et. al. Factors contributing to the incompatibility between simplified-step adhesives an chemically-cured or dualcured composites. Part III. E effect of acidic resin monomers. J Adhes Dent. 2003; 5: 267 - 268.

122. Texeira EC, Texeira FB, et. al. An invitro assessment of prefabricated fiber post systems JADA 2006; 137: 1006 - 1012.

123. Tjan $\mathrm{AH}$, Nemets $\mathrm{H}$. Effect of eugenol containing endodontic sealers on retention of prefabricated posts luted with adhesive composite resin cement. Quintessence Int. 23 (12): 839 - 844. 
124. Toksavul $\mathrm{O}$, Tomas $\mathrm{M}$, et. al. effect of luting agents and reconstruction techniques fracture resistance of pre-fabricated post systems. J Oral. Rehabilitation 2005; 32: 433 - 440.

125. Trushkowsky R. Fiber post selection and placement criteria: a review. Inside Dentistry 2008; 4: 2 - 5 .

126. Uribe Echavarria J, Prioto EG, Spadillero de Lutri M. Adhesion a esmalte y dentina con adhesivos poliméricos. En adhesión Odontologica Restauradora de ALODYB cap 4, 471 - 711. Ed Maio Curitiba Parana Brasil.

127. Van Meerbeek B, De Munck J, Yoshida Y, et. al. Buonocuore memorial lectura. Adhesion to enamel and dentin: current status an future challenges. Oper. Dent 2003; 28: $215-235$.

128. Vichi A, Simoni G, et. al. Comparison betweentwi clinical procedures for bonding fiber post into root canal: A microscopic investigation. J Endodontics Vol 8 (5). 355 - 360.

129. Vieira D, Muench A. An "in vitro" microleakage research of composite indirect onlays. Rev Paul. Odontol.1998 Jan - Feb; 20 (1): $17-18,20-22$.

130. Wagner WC, Chu TM. Biaxial flexural strergth and indentation fracture toughness of three new dental core ceramic. J Prosthet Dent 1996; 76: $140-144$

131. Wagnild G. Restoration of endodontically treated teeth. The path ways of the pulp 19987 th: $45-46$. 
132. Wagnild G, Mueller K. Chapter twenty. Restoration of endodontically treateth teeth. En Cohen S, Burns R, The Path ways of the pulp. 7 th 1998.

133. Wataha JC. Biocompatibilityof dental casting all oys : a review .J Prosthet Dent 2000; 83 (2) : 223 -234.

134. White $\mathrm{S}$, Ingles $\mathrm{S}$, et. al. Influence of marginal opening on microkeakage of cemented artificial crows. J Prosthet Dent 1994 71 (3). $257-264$.

135. Yaznadie N, Maood M. Carbon fiber acrylic resin composite: an investigation on transverse strength. J Prosthet Dent, 1985; 54: $543-547$

136. Yu WJ, KWAN I, et. al. An evaluation of localized debonding betwing fibre post an root canal wall by finite element simulation, int J Endodontic 2006; 10: 1111 -1115.

137. Zailkind $\mathrm{M}$, Hochman N. Esthetic conside rations in restoring endodontically treated teeth with post an cores. J Prosthet Dent 1998; 79: $702-705$.

Od. Pablo Fernando Bianchi

Doctorando
Prf. Dr. Pedro Salazar

Director 